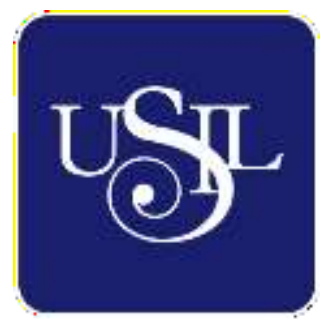

UNIVERSIDAD

SAN IGNACIO

DE LOYOLA

ESCUELA DE POSTGRADO

\title{
PLAN DE NEGOCIOS PARA LA CREACIÓN DE UNA INSTITUCIÓN EDUCATIVA DEL NIVEL INICIAL
}

Trabajo de Investigación para optar el grado de:

KARINA DEL ROSARIO ARICOCHE RAMIREZ

Maestro en Ciencias Empresariales con Mención en Gestión

Financiera

MAYURY JACKELINE ESPINO CARRASCO

Maestro en Ciencias Empresariales con Mención en Gestión del

Capital Humano

JOSE EDUARDO PONCE VERA

Maestro en Ciencias Empresariales con Mención en Gestión

Financiera

ROYER VASQUEZ CACHAY

Maestro en Ciencias Empresariales con Mención en Gestión

Financiera

Asesor:

Dr. Edmundo Rafael Casavilca Maldonado

Lima - Perú 


\section{DEDICATORIA}

Dedicamos esta investigación principalmente a Dios, por habernos dado la vida y permitido haber llegado hasta estos momentos tan importantes en nuestra formación profesional. A nuestras familias que siempre han estado con nosotros y todo aquel que nos ha brindado su apoyo sobre todo esas personas que no pueden acompañarnos en estos momentos. 


\section{RESUMEN EJECUTIVO}

El plan de negocios para la creación de una institución educativa del nivel inicial en la ciudad de Chiclayo tiene como propósito desarrollar el estudio de mercado, el perfil técnico y la evaluación financiera para dicho proyecto.

Los resultados encontrados en el estudio de mercado permiten señalar que el proyecto cuenta con un mercado potencial de padres de familia del sector socio económico A/B que busca este servicio. Es decir, existe un mercado interesado en un colegio de educación inicial reconocidos por su calidad educativa y que permita la formación adecuada de los niños entre tres a cinco años. Asimismo, los padres de familia mostraron interés en participar en el proceso de aprendizaje de sus hijos en interacción con los docentes.

En este contexto, se plantea una estrategia para el nuevo colegio orientada a la diferenciación en la calidad educativa y el servicio a los padres de familia. Esta estrategia estará basada en un modelo educativo de vanguardia que permitirá posicionar al colegio como entidad educativa innovadora orientada a satisfacer la demanda latente en el mercado de educación inicial.

En relación con el perfil técnico se han determinado los principales procesos del colegio. Este mapeo de los principales procesos como el de matrícula y captación permite que el nuevo colegio cuente con un conjunto de actividades diseñadas al apoyo del proceso educativo. Asimismo, se ha establecido la viabilidad técnica para iniciar el colegio de educación inicial con una infraestructura adecuada y que cumple los estándares señalados para este tipo de colegio.

Finalmente, la evaluación económico - financiera muestra que el proyecto de creación de un colegio de educación inicial es viable al obtener un valor presente neto 
mayor que cero y una tasa interna de retorno superior al costo capital de los inversionistas. Estos resultados se obtuvieron comparando el monto de la inversión inicial en terreno, construcción y equipamiento con los flujos proyectados para los próximos diez años del proyecto. 


\begin{abstract}
The business plan for creation of an educational institution of initial level in the city of Chiclayo aims to develop market study, technical profile and financial evaluation for this project.

The results found in the market study indicate that this project has a potential market of parents from the socio-economic sector A / B seeking this service. It means, there is a market interested in a school of initial education recognized for its educational quality and that allows the adequate formation of the children between three to five years. Likewise, parents showed an interest in participating in the process of learning their children in interaction with teachers.

In this context, one strategy is proposed for this new school, which aimed at differentiating the quality of education and service to parents. This strategy will be based on a state-of-the-art educational model that will allow the school to position itself as an innovative educational institution aimed at satisfying the latent demand in initial education market.

In relation to the technical profile, the main processes of the school have been determined. This mapping of the main processes such as enrollment and enrollment allows the new school to have a set of activities designed to support the educational process. Likewise, the technical feasibility has been established for starting the initial education school with adequate infrastructure and meeting the standards set for this type of school.
\end{abstract}

Finally, the economic - financial evaluation shows that the project in order to create an initial education college is viable by obtaining a net present value greater than zero and an internal rate of return higher than the capital cost of the investors. These results were 
obtained by comparing the amount of the initial investment in land, construction and equipment with the projected flows for the next ten years of the project. 
INDICE

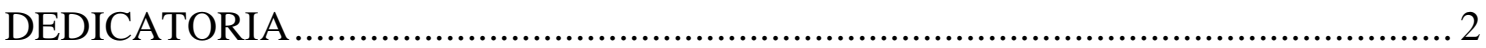

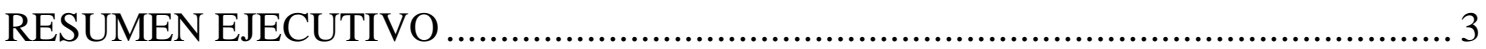

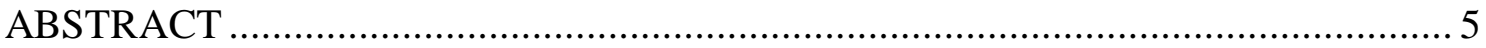

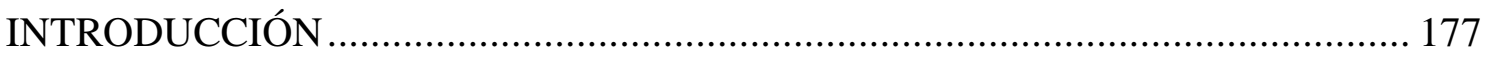

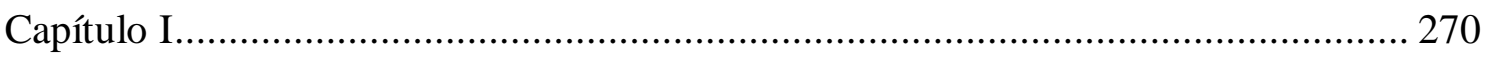

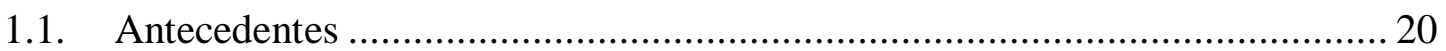

1.2. Determinación del Problema u Oportunidad................................................ 22

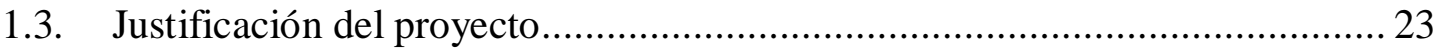

1.4. Objetivos Generales y Específicos ........................................................ 23

1.5. Alcances y Limitaciones de la Investigación ........................................... 266

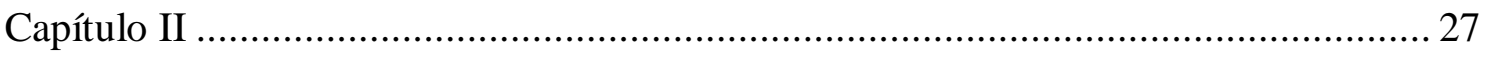

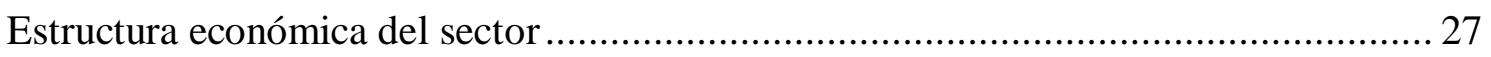

2.1. Descripción del estado actual de la industria................................................. 27

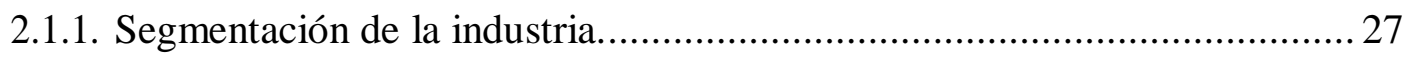

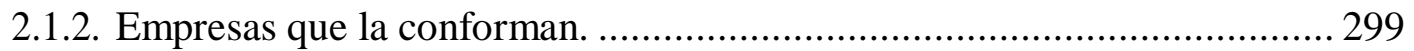

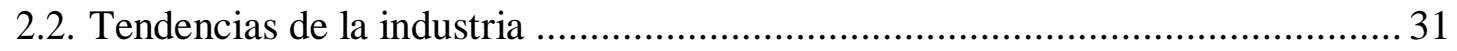

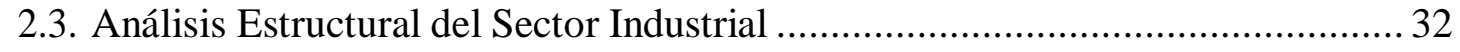

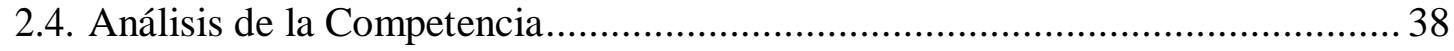

2.4.1. Empresas que ofrecen el mismo producto o servicio, indicando las semejanzas y diferencias que tienen con el proyecto de empresa......................... 38

2.4.2. Participación de mercado de cada uno de ellos....................................... 44

2.4.3. Matriz de perfil competitivo................................................................. 45

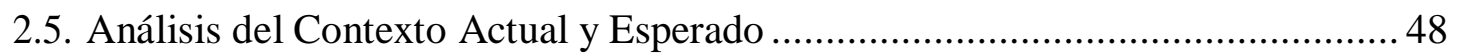

2.5.1. Análisis Político-Gubernamental......................................................... 48

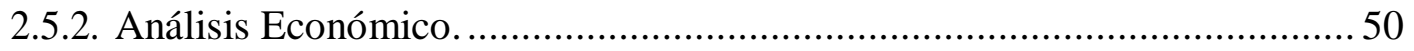

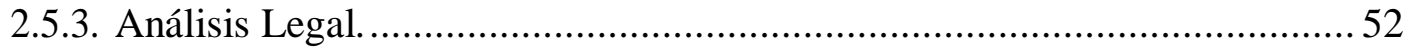

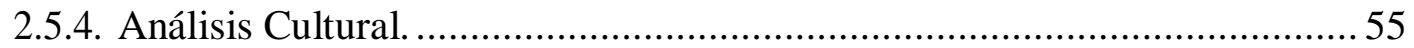

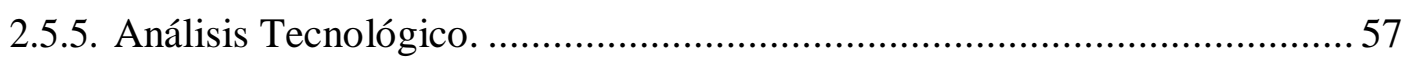

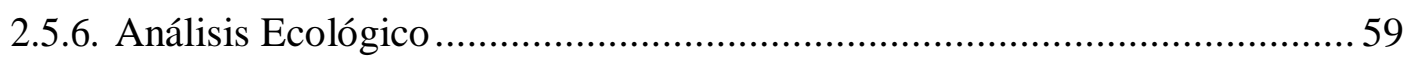

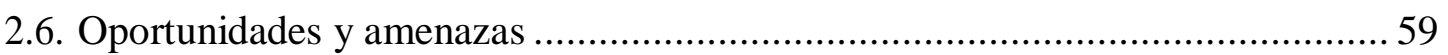

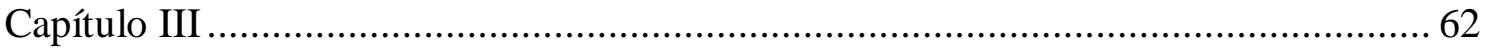

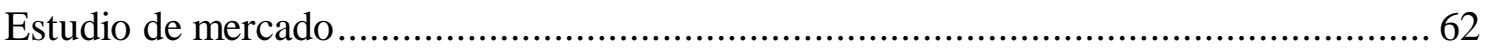

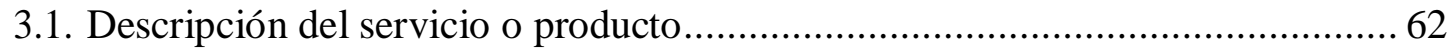

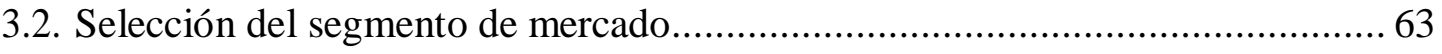

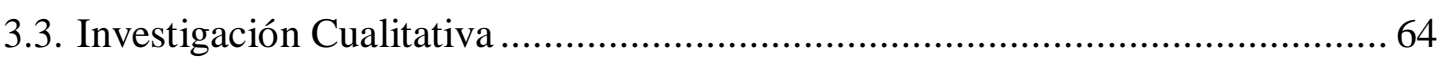

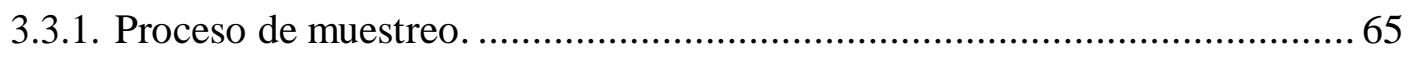




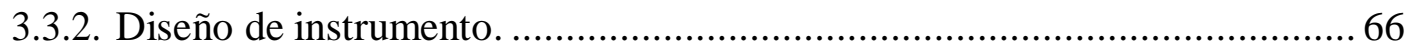

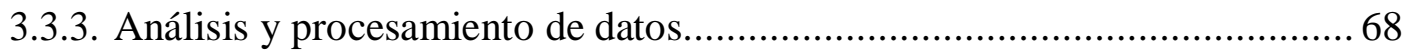

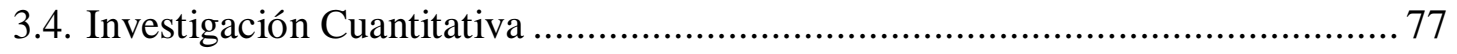

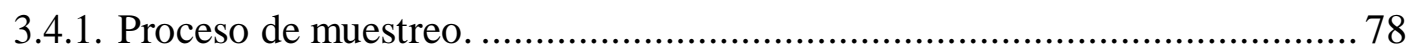

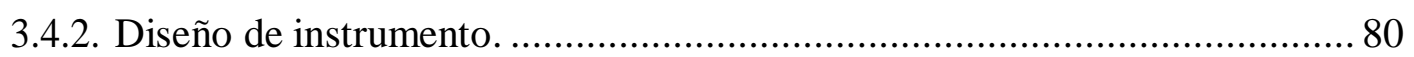

3.4.3. Análisis y procesamiento de datos........................................................ 81

3.5. Conclusiones y recomendaciones del estudio cualitativo y cuantitativo ......... 93

3.6. Perfil del consumidor tipo y sus variantes................................................ 96

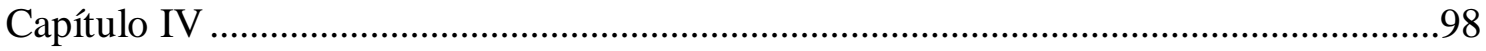

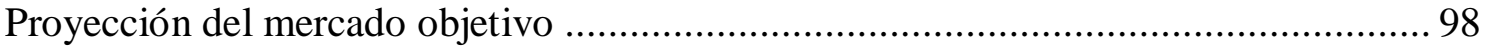

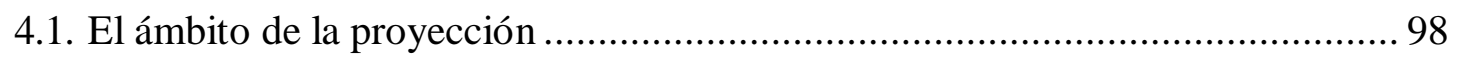

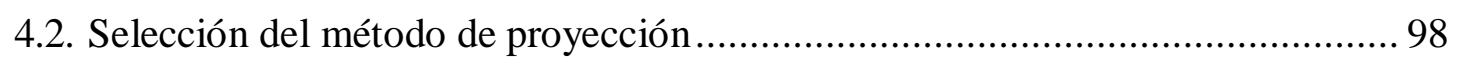

4.2.1. Mercado Potencial ............................................................................ 98

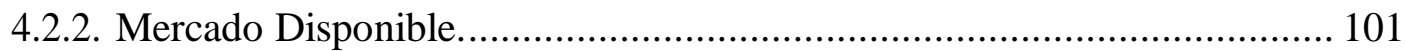

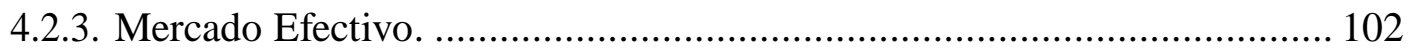

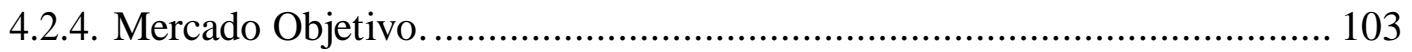

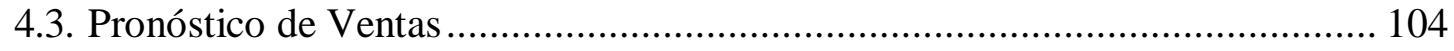

4.4. Aspectos críticos que impactan el pronóstico de ventas ................................. 106

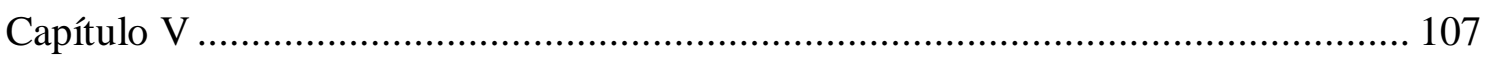

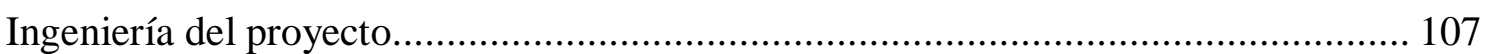

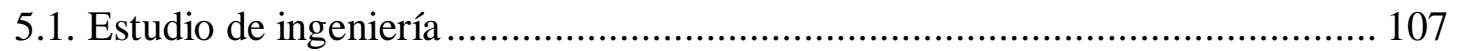

5.1.1. Modelamiento y selección de procesos productivos. .............................. 107

5.1.2. Selección del equipamiento................................................................. 116

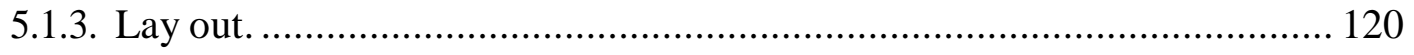

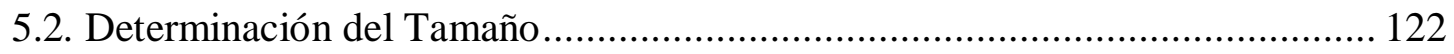

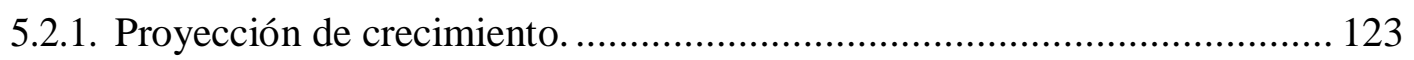

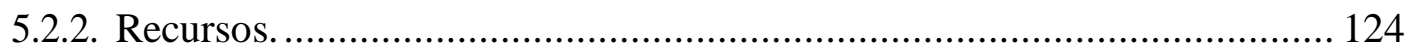

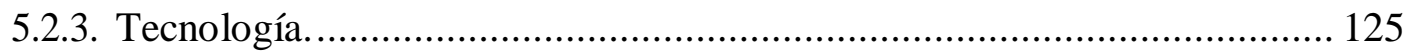

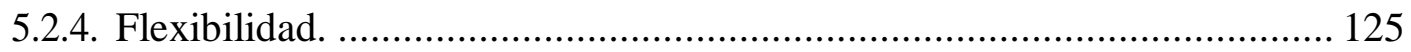

5.2.5. Selección del tamaño ideal.............................................................. 126

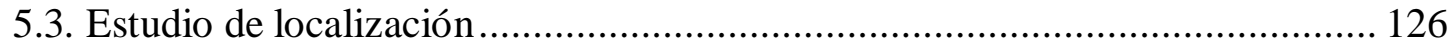

5.3.1. Definición de factores locacionales................................................. 126

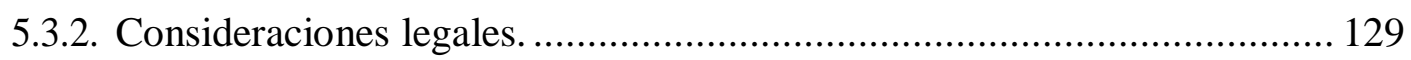

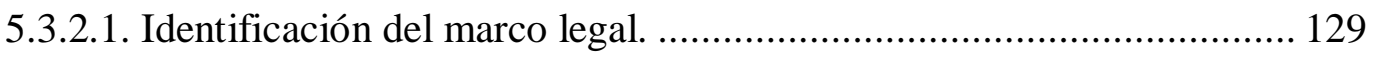

5.3.2.2. Ordenamiento jurídico de la empresa ............................................. 132

5.4. Determinación de la localización óptima ................................................. 132 


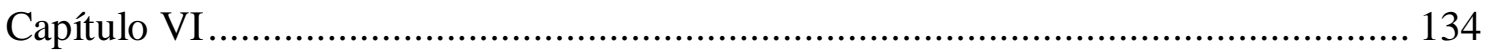

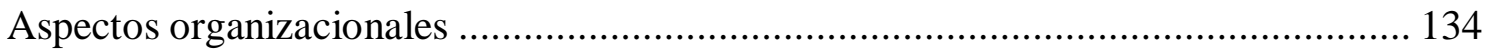

6.1. Caracterización de la cultura organizacional deseada..................................... 134

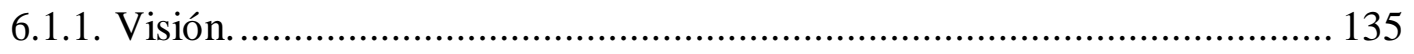

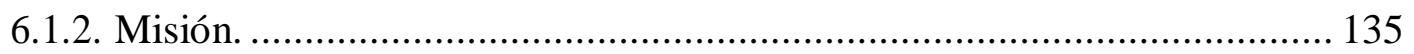

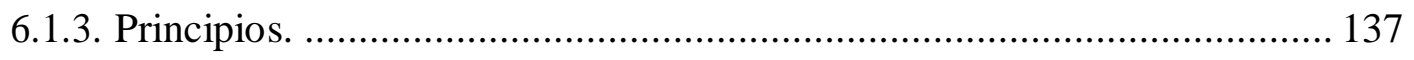

6.2. Formulación de Estrategias del Negocio ..................................................... 138

6.2.1 Estrategia de Negocios............................................................... 138

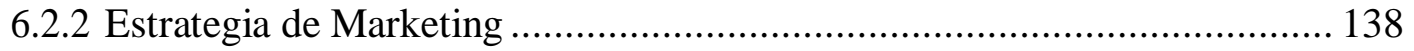

6.2.3 Estrategia de Recursos Humanos. ......................................................... 139

6.3. Determinación de las ventajas competitivas críticas....................................... 139

6.4. Diseño de la estructura organizacional deseada............................................ 140

6.5. Diseño de los perfiles de puestos clave ......................................................... 142

6.6. Remuneraciones, compensaciones e incentivos .......................................... 148

6.7. Política de recursos humanos................................................................. 150

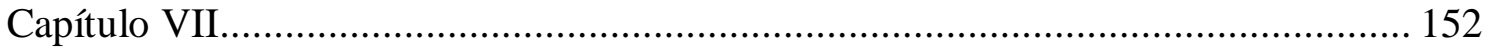

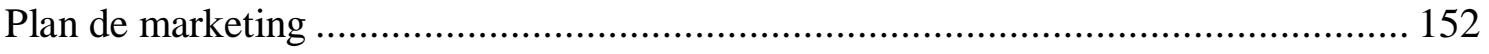

7.1. Estrategias de marketing ..................................................................... 152

7.1.1. Estrategia de Producto. .................................................................... 153

7.1.2. Estrategia de Presencia Física ............................................................. 155

7.1.3. Estrategia de Personal. ....................................................................... 156

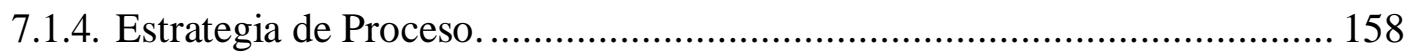

7.1.5. Estrategia de Precio. ...................................................................... 160

7.1.6. Estrategia de distribución.................................................................. 162

7.1.7. Estrategia de promoción y publicidad..................................................... 163

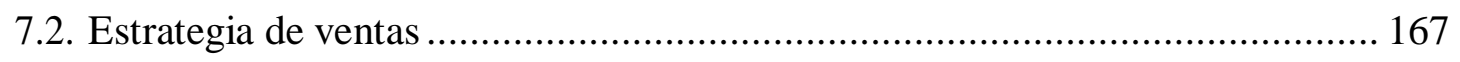

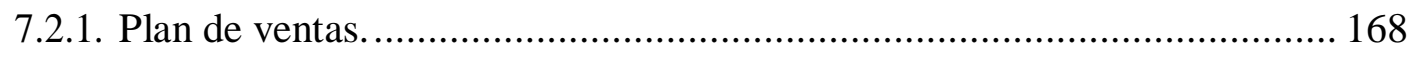

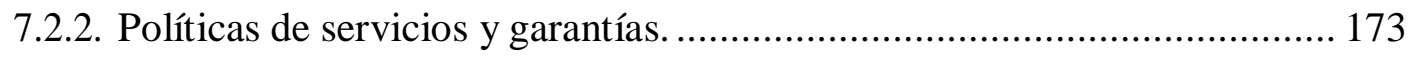

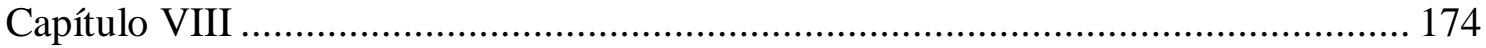

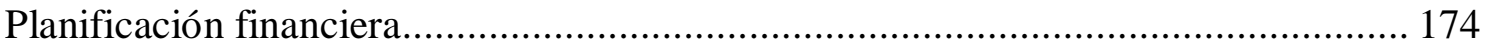

8.1. La inversión 174

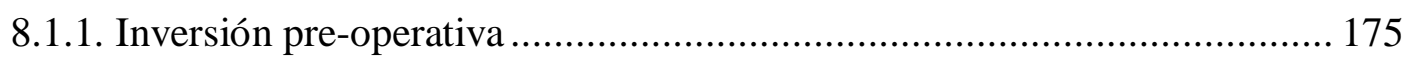

8.1.2. Inversión en capital de trabajo. .......................................................... 176

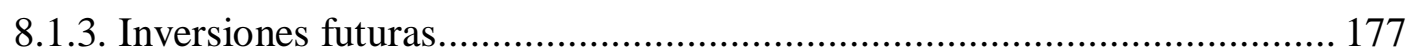

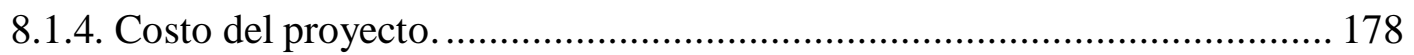

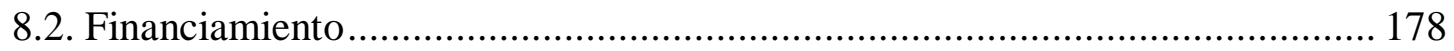


8.2.1. Capital y costo de oportunidad........................................................... 179

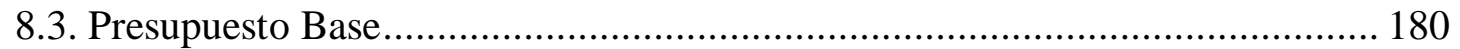

8.3.1. Presupuesto de ventas. ................................................................ 180

8.3.2. Presupuesto de costos de producción. .............................................. 18383

8.3.3. Presupuesto de compras..................................................................... 18484

8.3.4. Presupuesto de Gasto de Ventas...................................................... 18484

8.3.5. Presupuesto de gastos administrativos............................................... 18585

8.3.6. Presupuesto de marketing y ventas................................................. 18686

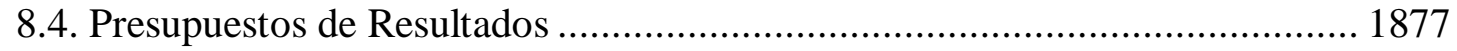

8.4.1. Estado de ganancias y pérdidas proyectado....................................... 1877

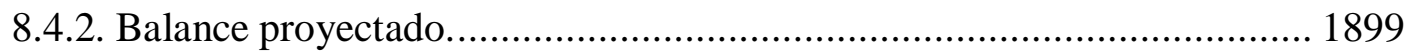

8.4.3. Flujo de caja proyectado................................................................. 19191

8.4.4. Recuperación de Capital de Trabajo e Inversiones. ............................. 19393

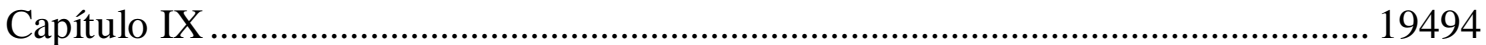

Evaluación económico financiera ................................................................. 19494

9.1. Evaluación Financiera ….................................................................... 19494

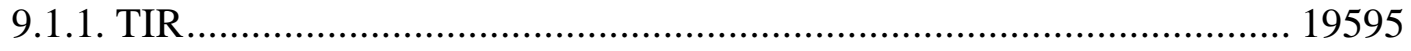

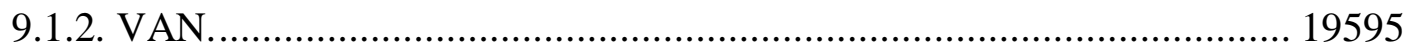

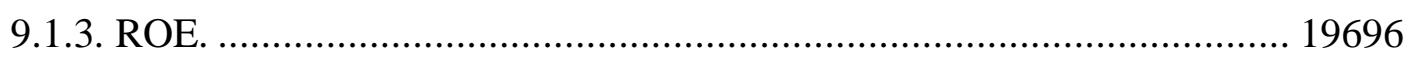

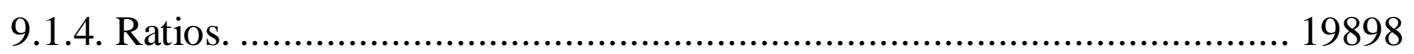

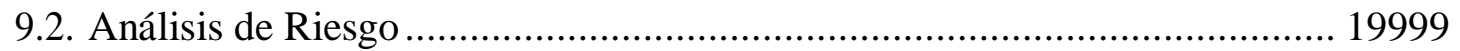

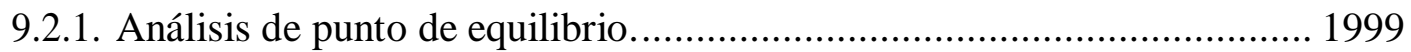

9.2.2. Análisis de sensibilidad................................................................. 200

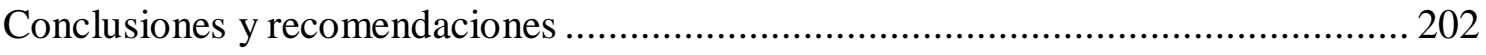

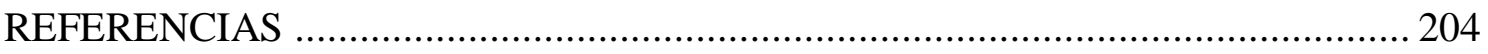

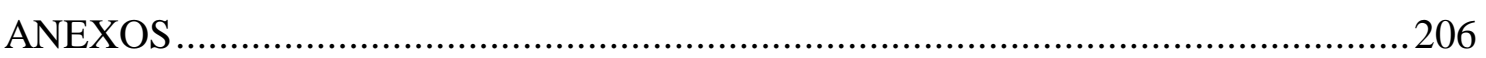

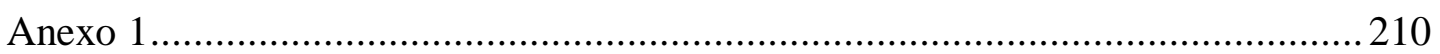

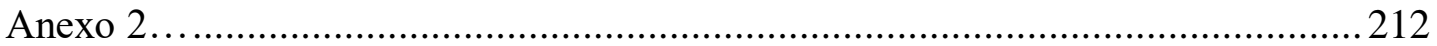

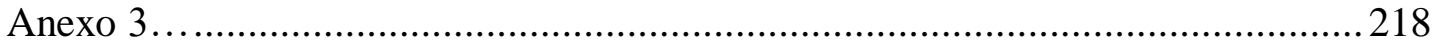

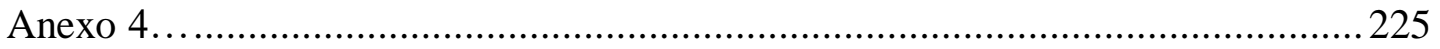

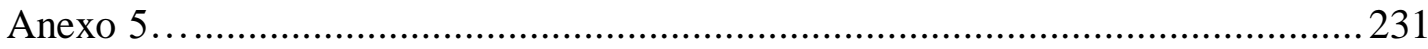

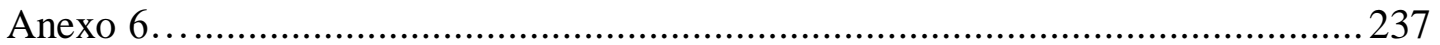

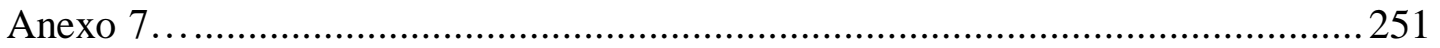

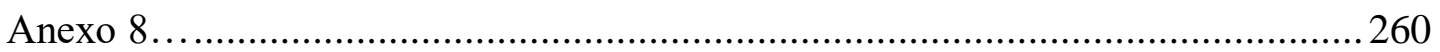

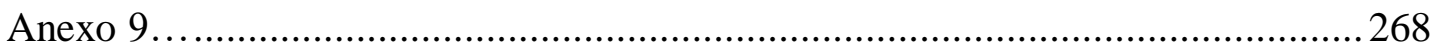

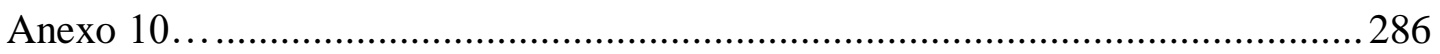

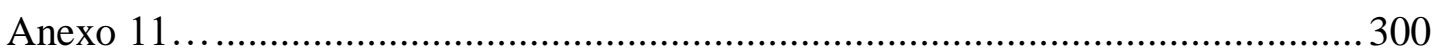

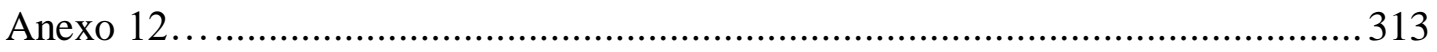

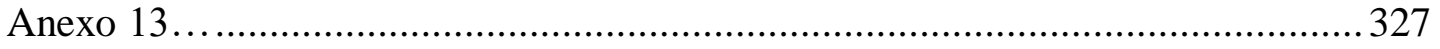

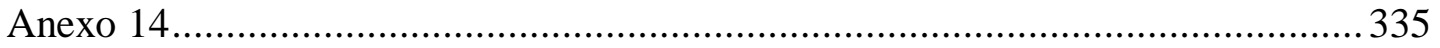


Anexo 15 .

336

Anexo 16.

.378 


\section{Lista de Tablas}

Tabla 1 Centros Educativos del Nivel Inicial del Censo Escolar 2012 ........................30

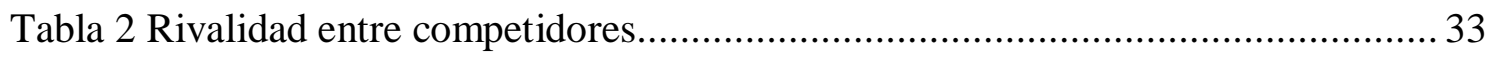

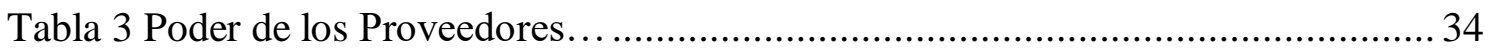

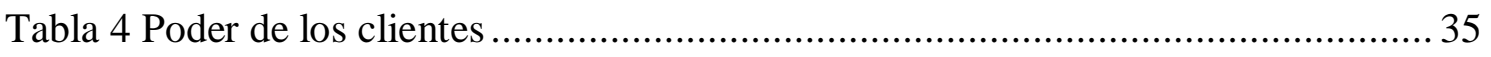

Tabla 5 Amenaza de Productos Sustitutos .................................................................... 35

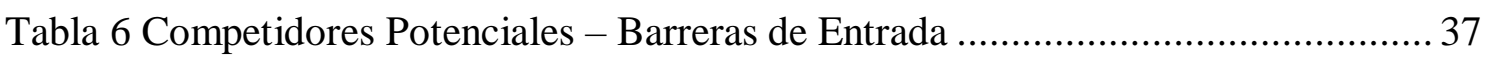

Tabla 7 Competidores Potenciales - Barreras de Salida............................................. 37

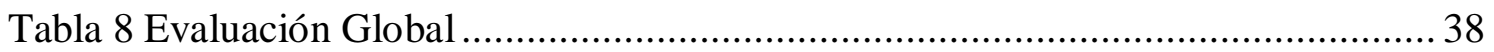

Tabla 9 Colegios iniciales de la ciudad de Chiclayo .............................................. 45

Tabla 10 Matriz de Perfil Competitivo ............................................................... 47

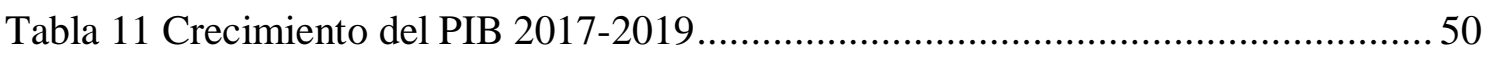

Tabla 12 Tipo de Cambio 2016-2019 ..................................................................... 51

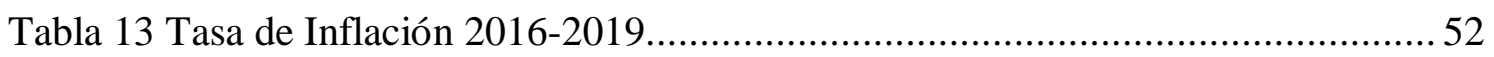

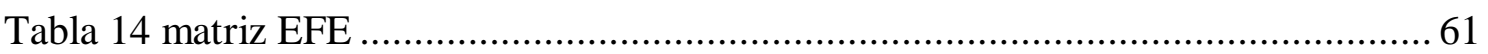

Tabla 15 Respuestas individuales en el focus group de un participante con hijos en un colegio .....

Tabla 16 Respuestas individuales en el focus group de los participantes sin hijos en un colegio

Tabla 17 Resumen respuestas de padres de familia con hijos en colegio de educación

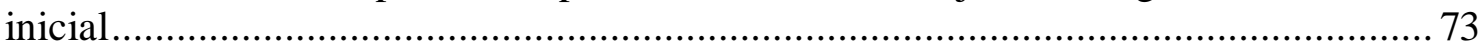

Tabla 18 Resumen (Padres de Familia sin hijos en Colegio de Educación Inicial) ....... 75

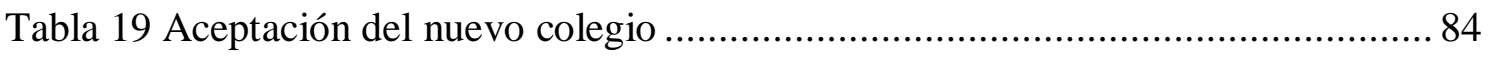

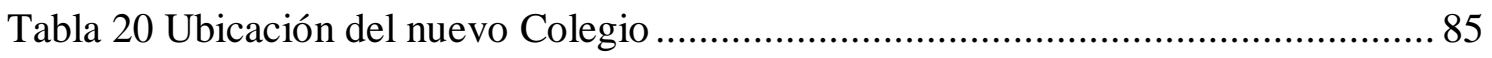

Tabla 21 Entrega del reporte de desempeño y comportamiento................................... 85

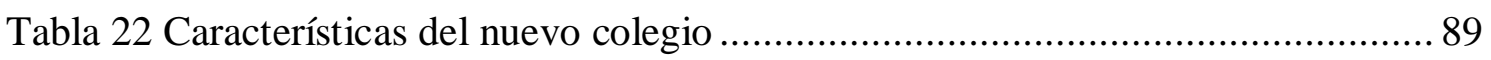

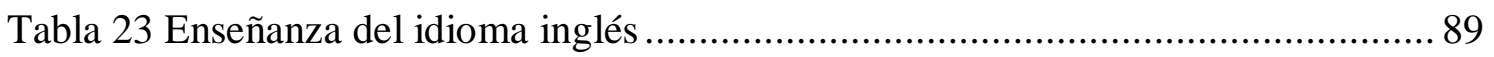

Tabla 24 Población de los distritos de Chiclayo, José Leonardo Ortiz y la Victoria de la Provincia de Chiclayo 2000 - 2015 ........................................................................... 100

Tabla 25 Población Proyecta de la Provincia de Chiclayo 2016 - 2027 .................... 101

Tabla 26 Cálculo del Mercado Potencial ............................................................. 101

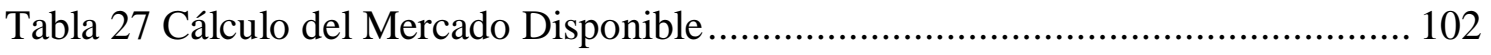

Tabla 28 Ponderación de pruebas de concepto........................................................ 103

Tabla 29 Cálculo del Mercado Efectivo................................................................. 103

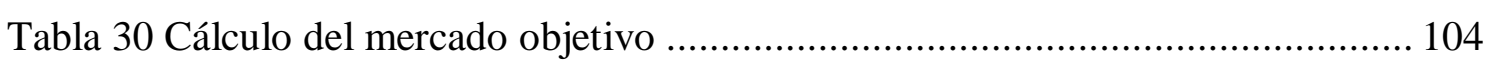

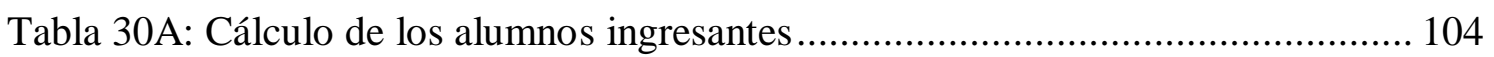

Tabla 31 Cálculo de ventas para el colegio de educación inicial .............................. 105

Tabla 32 Muebles y Equipos de la Oficina de Admisión.......................................... 117 
Tabla 33 Muebles y Equipos de la Dirección..... 117

Tabla 34 Muebles y Equipos de la Oficina Administrativa / Docentes ...................... 118

Tabla 35 Muebles y Equipos de la Oficina de Registros ......................................... 118

Tabla 36 Muebles y Equipos de las Aulas ............................................................. 118

Tabla 37 Muebles y Equipos de la Sala de Juegos .................................................... 119

Tabla 38 Muebles y Equipos del Área de Refrigerio................................................. 119

Tabla 39 Muebles y Equipos de la Biblioteca ............................................................ 119

Tabla 40 Inversión Total en Muebles y Equipos para el Colegio.............................. 120

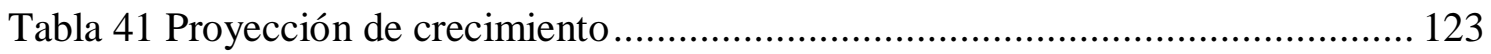

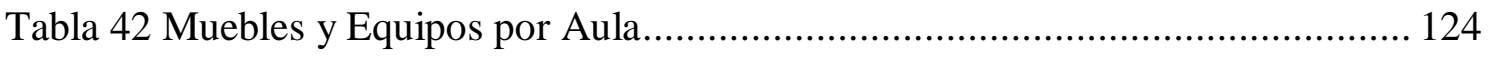

Tabla 43 Muebles y Equipos para el Área de Registros .......................................... 125

Tabla 44 Muebles y Equipos del Área de Refrigerio.................................................. 125

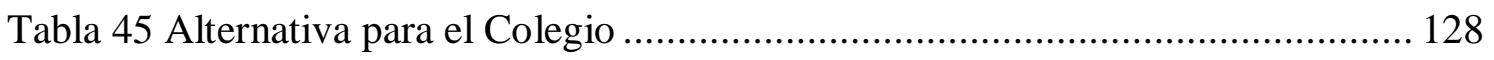

Tabla 46 Cálculo de ubicación del colegio ............................................................. 129

Tabla 47 Sueldos y salarios del personal del Colegio........................................... 149

Tabla 48 Personal docente del Colegio ................................................................... 149

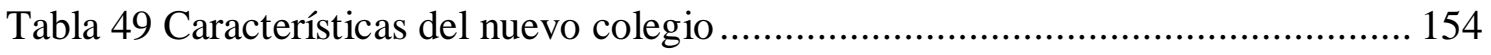

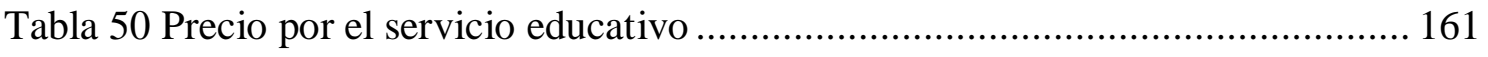

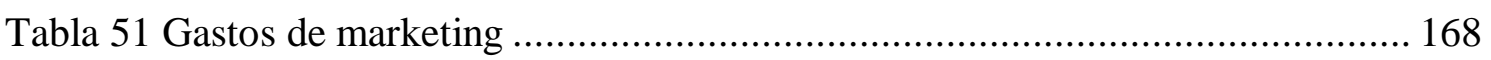

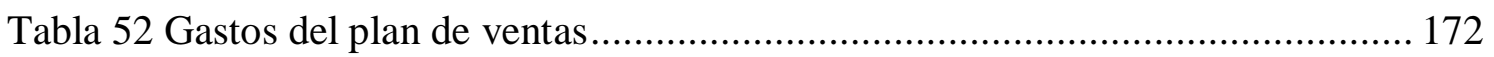

Tabla 53 Captación de alumnos del plan de ventas ................................................. 172

Tabla 54 Inversión Terreno y Construcción............................................................. 174

Tabla 55 Inversión Mobiliario y equipo: Oficinas y Aulas ....................................... 175

Tabla 56 Inversión en intangibles y pre operativos ................................................. 176

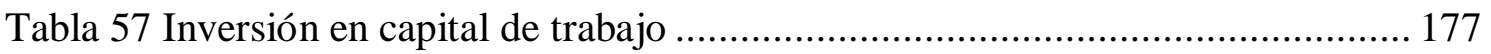

Tabla 58 Inversión Construcción Aulas, Mobiliario y Equipo................................... 177

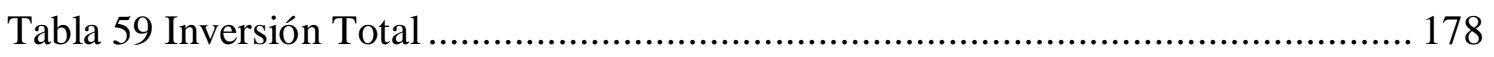

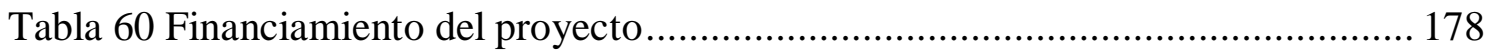

Tabla 61 Beta del sector educación ...................................................................... 179

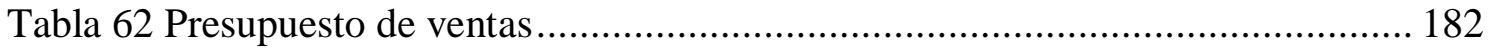

Tabla 63 Costos de producción............................................................................ 183

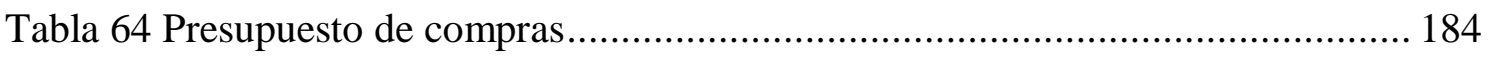

Tabla 65 Presupuesto de gasto de ventas ............................................................ 185

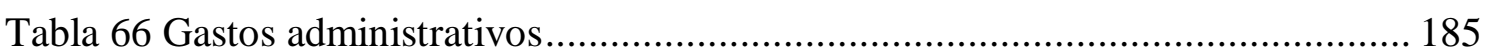

Tabla 67 Presupuesto de marketing y ventas .......................................................... 186

Tabla 68 Estado de Ganancias y Pérdidas ............................................................... 188 
Tabla 69 Balance General .

190

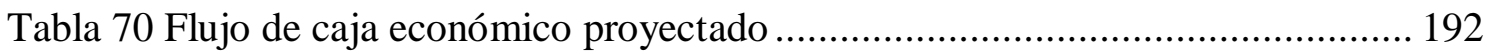

Tabla 71 Recuperación de Capital de Trabajo e Inversiones .................................... 193

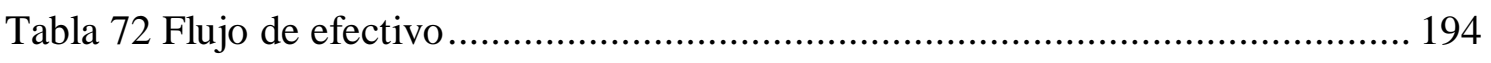

Tabla 73 Punto de equilibrio del proyecto ........................................................... 200 


\section{Lista de Figuras}

Figura 1 Colegio Victoria Barcia Boniffatti.............................................................. 40

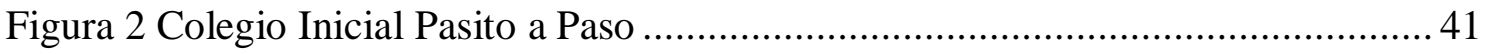

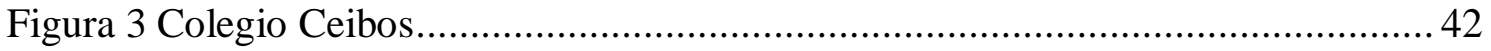

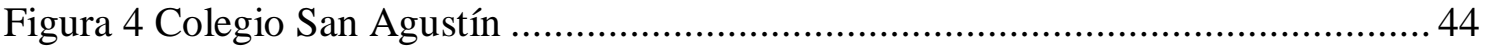

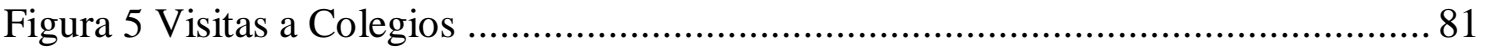

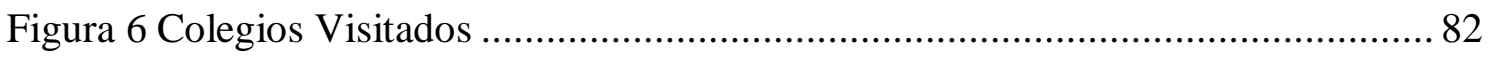

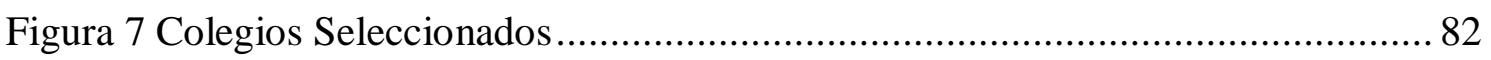

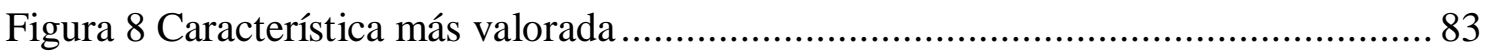

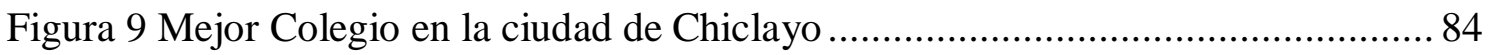

Figura 10 Característica más valorada del mejor Colegio ........................................ 85

Figura 11 Medio de información que permitió dar a conocer el colegio ........................ 85

Figura 12 Persona que decide sobre la matrícula .................................................... 86

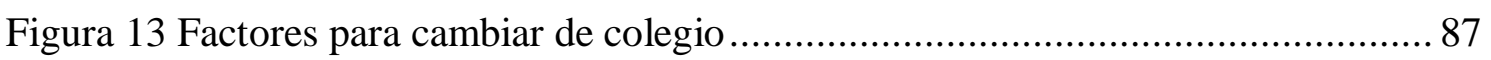

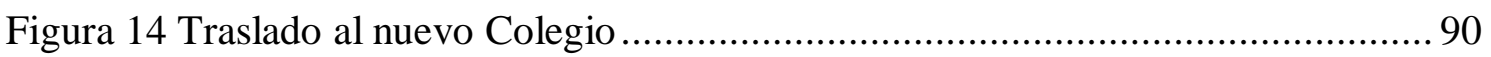

Figura 15 Medios para recibir información del colegio........................................... 91

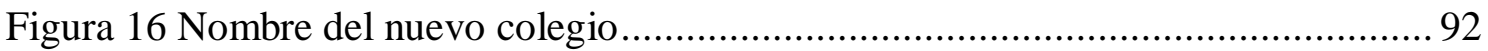

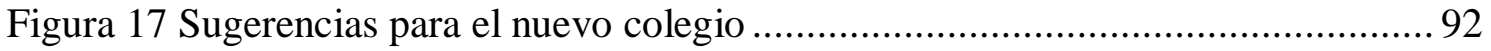

Figura 18 Aceptación del colegio versus sugerencias para el nuevo servicio.................94

Figura 19 Aceptación del colegio versus sistema de entrega de información................ 94

Figura 20 Aceptación del colegio versus ubicación del colegio ...................................95

Figura 21 Aceptación del colegio versus nombre del colegio......................................96

Figura 22 Aceptación del colegio versus rango de edad de los interesados....................96

Figura 23 Aceptación del colegio versus rango de ingreso de los interesados ..............97

Figura 24 Proceso General del Colegio .............................................................. 107

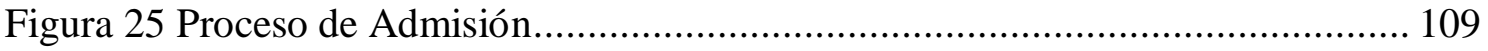

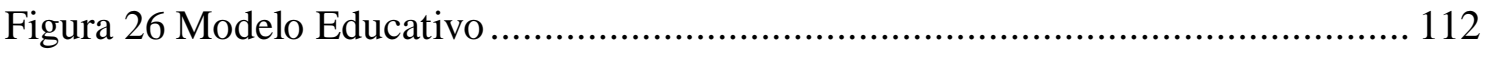

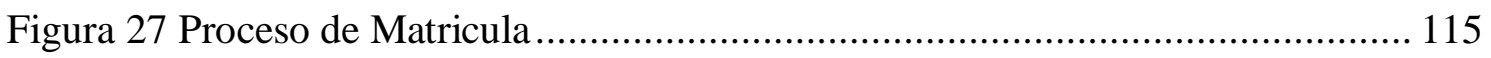

Figura 28 Distribución de las Oficinas y Aulas primer nivel................................... 121

Figura 29 Distribución de las Oficinas y Aulas segundo nivel .................................. 122

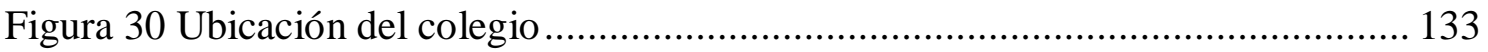

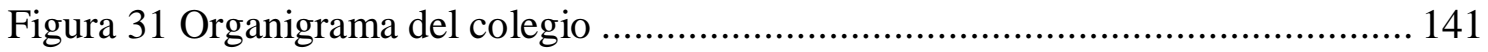

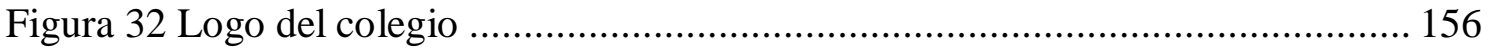

Figura 33 Servicio de Atención al Padre de Familia ............................................... 159

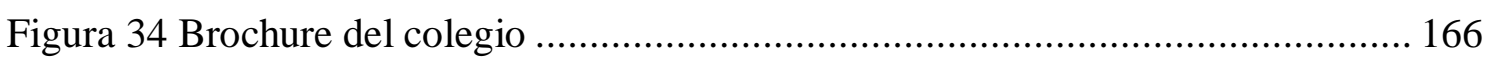

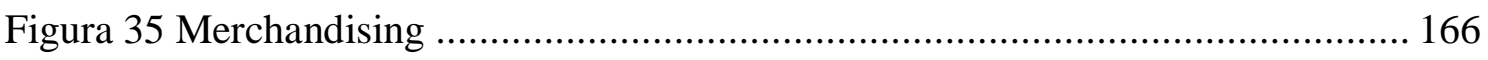




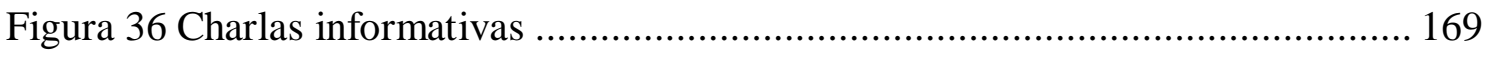

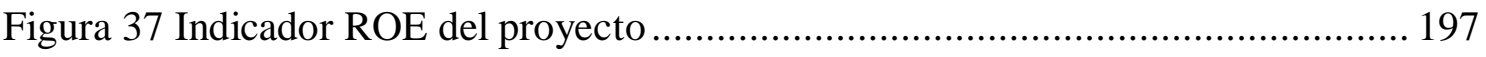

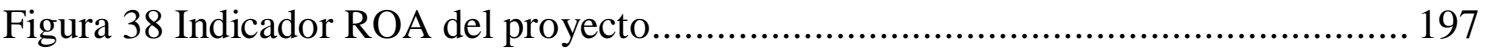

Figura 39 Indicador rentabilidad antes de intereses e impuestos .............................. 198

Figura 40 Indicador rentabilidad sobre ventas ..................................................... 199 


\section{INTRODUCCIÓN}

El presente proyecto presenta el plan de negocios para la creación de una institución educativa del nivel inicial en la ciudad de Chiclayo. El estudio se inició en agosto del año 2016 y concluyó en diciembre del mismo año.

La metodología usada comprende cinco etapas: la primera consiste el análisis de la industria para establecer los elementos competitivos en este negocio, la segunda se enfoca en la investigación de mercado para determinar la factibilidad del proyecto, la tercera se orienta al estudio de ingeniería para conocer los procesos que se usan en ésta actividad educativa, la cuarta es para diseñar el plan de marketing a fin de determinar cómo dar a conocer el colegio a las personas interesadas, la quinta es para realizar el estudio económico con el propósito de fijar nivel de inversión, así como la evaluación financiera con la finalidad de conocer la rentabilidad del proyecto.

En este marco el proyecto desarrollado comprende los siguientes capítulos: Capítulo I: a fin de presentar los antecedentes, la justificación, determinar la oportunidad que se desea aprovechar, los objetivos generales y específicos, así como los alcances y limitaciones del proyecto.

Capitulo II: permite dar a conocer el análisis estructural de la industria y las tendencias del entorno. Así, se realiza el estudio de la propuesta educativa de los colegios de educación inicial en la ciudad de Chiclayo y sus elementos competitivos, que se muestran en la matriz de perfil competitivo; las tendencias de las principales variables del entorno y como podrían afectar al negocio detectando las oportunidades y amenazas que se podría generar con los cambios que se pronostican. 
Capitulo III: muestras los resultados del estudio de mercado a nivel cualitativo y cuantitativo. En el primer caso se presenta los aspectos relevantes detectados a través del focus group y las entrevistas a profundidad. En el segundo caso se da a conocer los resultados de las encuestas que fueron aplicadas al mercado potencial a fin de conocer sus preferencias sobre el nuevo colegio propuesto.

Capítulo IV: presenta la proyección del mercado a fin de determinar el mercado objetivo. Para ello se analizar las tendencias del crecimiento de los padres de familia que tienen hijos entre tres a cinco años que se encuentra en el nivel socio económico seleccionado. Este mercado objetivo proyectado nos permite fijar las ventas del servicio educativo de colegio para los próximos años.

Capítulo V: analiza los procesos del servicio educativo del colegio, la inversión requerida en infraestructura para implementar el colegio, la distribución de los ambientes del colegio, el marco normativo y jurídico que lo regula, y finalmente la ubicación óptima del colegio considerando los factores locacionales.

Capítulo VI: se diseña la estrategia de negocio a desarrollar por el nuevo colegio, luego las estrategias a nivel funcional, las estructura organizacional del colegio, el perfil del personal que deberá laboral en la institución educativa, y las políticas a seguir por el área de recursos humanos con los colaboradores a contratar.

Capítulo VII: desarrolla el plan de marketing para dar a conocer el nuevo colegio a los padres de familia interesados y a la comunidad en general. Con esta finalidad se ha diseñado un plan de lanzamiento del colegio y se han establecido las estrategias y actividades a llevar a cabo para continuar con el proceso de comunicación del nuevo colegio al mercado objetivo.

Capitulo VIII: presenta el monto de la inversión total en infraestructura para iniciar las actividades del colegio, las proyecciones de venta; los presupuestos de operaciones, 
administrativos, de marketing y ventas, y gastos financieros; y los estados de resultados como el estado de pérdidas y ganancias, el balance general y el flujo de efectivo.

Capitulo IX: muestra los resultados de la evaluación financiera del proyecto y el análisis de ratios de las proyecciones del estado de resultados. A fin de conocer la sensibilidad del proyecto se realiza un análisis de los flujos esperados con variaciones en las variables más importantes que podrían afectar el proyecto.

Conclusiones y Recomendaciones: a fin de presentar los aspectos más relevantes de la investigación y algunos elementos a tomar en cuenta durante el proceso de implementación del proyecto.

Finalmente, debemos agradecer al profesor del curso por sus valiosas enseñanzas y a las personas expertas que a través de sus conocimientos y experiencia nos permitieron comprender de mejor manera el sector educativo inicial y de este modo preparar mejor el presente proyecto. 


\section{Capítulo I \\ Generalidades}

\subsection{Antecedentes}

La educación inicial constituye el primer nivel del sistema de educación básica regular en el país y se orienta a los niños menores de seis años. Según la Ley General de Educación No. 28044 (2003), en su artículo 36 establece que este nivel "atiende a niños de 0 a 2 años en forma no escolarizada y de tres a cinco años en forma escolarizada". Así, las modalidades que presenta son: cunas, guarderías, nidos, jardines, kindergarten (se usa para referirse a jardines de infancia) y centros no escolarizados. La educación escolarizada es aquella que está institucionalizada por la Ley General del Educación y se imparte en instituciones autorizadas, mientras que la educación no escolarizada no está regulada por la ley mencionada.

El propósito de la educación inicial, según la Oficina de Estudios Iberoamericanos (OEI) de los Sistemas Educativos Nacionales - Perú (2012) es "brindar atención integral al niño menor de 6 años, y orientación a los padres de familia y a la comunidad para lograr desarrollar en el niño, sus emociones, su dinamismo, su lenguaje, su sensibilidad social, su desarrollo afectivo, etc.”. Es decir, la educación inicial busca llevar a cabo prácticas de crianza, a fin de promover el desarrollo integral de los niños.

Por consiguiente, el nivel de educación inicial es una etapa fundamental en la formación y desarrollo de los niños entre tres a cinco años, al enfocarse al desarrollo de sus potencialidades. De ahí, que las instituciones educativas de este nivel deben 
orientarse no solamente al niño sino a la familia y a la comunidad, a fin de brindar los elementos necesarios para el desarrollo del niño de una manera integral.

Respecto a la situación actual de la educación inicial se tiene que, según un artículo de Mariella Sausa (2015), la mayoría de profesores que enseña en este nivel no cuenta con la preparación específica para llevar a cabo su labor. Si bien los docentes cuentan con una formación pedagógica, su preparación no se ha enfocado a la formación de niños en educación inicial. Esta situación se ve reflejada posteriormente en el nivel de educación primaria, cuando los niños de los primeros grados no cuentan con las habilidades que se deben desarrollar a nivel inicial.

Otro aspecto es la infraestructura no adecuada de los colegios de educación inicial, dado que los ambientes de aprendizaje no han sido construidos especialmente para este tipo de colegios o dichos centros educativos no han sido preparados para este tipo de actividades. Así, en la mayoría de los casos, los centros educativos de este nivel son casas que se han adaptados para que funcione como centro de educación inicial. Es decir, estos ambientes se adecuan para llevar a cabo labores de aprendizaje, según el criterio de los docentes o del dueño del centro inicial en el ámbito privado. Esta falta de infraestructura adecuada no permite que se imparta una educación inicial de calidad en el país.

En la ciudad de Chiclayo existen más de 300 colegios de este nivel, tanto en el ámbito público como en el privado. En el caso del sector privado, existen 148 colegios de educación inicial (según las modalidades indicadas), que se encuentran localizados 
en diferentes zonas de la ciudad y brindan un servicio, fundamentalmente, a las familias que residen o laboran cerca de la institución educativa. (Colegios en Perú.com,2016).

En la actualidad, los colegios existentes en la ciudad de Chiclayo se enfocan en la educación en el niño descuidando, muchas veces, los esfuerzos para lograr la participación de la familia y la comunidad, a fin que puedan participar activamente en el desarrollo de las capacidades de los niños. Asimismo, en algunos casos no cuentan con la infraestructura adecuada para el proceso de enseñanza y los docentes no han sido formados para este nivel.

\subsection{Determinación del Problema u Oportunidad}

En el ámbito de educación inicial, se ha encontrado que existe la necesidad en la ciudad de Chiclayo de una institución educativa que brinde una educación de este nivel, diferenciada tanto por su propuesta educativa innovadora como por su infraestructura adecuada, por la calidad de sus docentes y que sea reconocida por su calidad en el servicio.

Por consiguiente, se requiere una institución educativa que logre la participación de los padres de familia mediante la capacitación a fin que comprendan la importancia de colaborar de una manera efectiva en el estímulo de los niños para lograr su desarrollo integral. Además, se hace necesaria una institución educativa de nivel inicial que cuente con los ambientes para lograr el aprendizaje adecuado y con los docentes formados para realizar la enseñanza en este nivel. 
En este sentido, se propone la creación de un Colegio de Educación Inicial en la ciudad de Chiclayo para las familias de los niveles socio económico A y B que buscan una educación inicial de calidad para sus hijos, que considere las nuevas tendencias de educación en este nivel, ofreciendo una propuesta educativa diferenciada a las que ofrecen las instituciones educativas actuales, así como prestar un servicio con estándares de calidad reconocidas en el ámbito regional.

\subsection{Justificación del proyecto}

El proyecto de creación de un colegio de educación inicial se justifica en la medida que la oportunidad encontrada permitirá lo siguiente:

a) Mercado: se buscará satisfacer una necesidad existente en el mercado, mediante el desarrollo de una propuesta que permita la creación de un colegio de educación inicial en la ciudad de Chiclayo, con un nuevo modelo educativo y de servicio. Asimismo, este nuevo concepto permitirá incluir un modelo educativo orientado a desarrollar competencias en los niños de tres a cinco años, con docentes formados para ejercer la docencia en este nivel.

b) Social: se buscará crear una institución educativa de nivel inicial con prácticas orientadas a la calidad y que se oriente a lograr un compromiso social con la comunidad, a partir de alcanzar los objetivos financieros y de competitividad.

\subsection{Objetivos Generales y Específicos}

\section{Objetivo General.}

El objetivo del presente estudio es elaborar un plan de negocios para crear un colegio de educación inicial en la ciudad de Chiclayo que iniciaría actividades el año 2018. 
El plan de negocios desarrollado para un colegio de educación inicial muestra que se puede iniciar este tipo de institución educativa en la ciudad de Chiclayo. El estudio de mercado realizado muestra la posibilidad de implementar un Colegio de Educación Inicial en la Ciudad de Chiclayo para niños entre tres a cinco años.

\section{Objetivos Específicos}

a) Analizar el mercado de educación básica en la ciudad de Chiclayo mediante un estudio de mercado que permita conocer las características de la demanda.

b) Llevar a cabo un análisis de la competencia existente entre los colegios de educación básica a fin de establecer las oportunidades para mejorar el servicio.

c) Elaborar un estudio técnico a fin de conocer la infraestructura para un colegio de educación inicial.

d) Formular un plan de marketing que permita conocer los aspectos de mercado a tomar en cuenta para lanzar este servicio.

e) Evaluar la rentabilidad del proyecto de creación de un colegio de educación inicial a fin de establecer la viabilidad para su implementación.

\section{Objetivos Específicos SMART}

\section{Producto}

Diseñar el modelo educativo completo del nuevo colegio antes de iniciar la campaña de captación de estudiantes.

\section{Presencia Física}

Elaborar al 100\% una página web que permita brindar información sobre el colegio antes del inicio de operaciones del colegio

\section{Personal}


Contratar el 100\% del personal docente y administrativo según el cronograma establecido para iniciar operaciones.

Capacitar a todo el personal docentes sobre el modelo educativo adoptado por el colegio.

\section{Proceso:}

Diseñar completamente todos los procesos académicos y administrativos del colegio antes de iniciar operaciones.

\section{Precio:}

Realizar un estudio de mercado para fijar el monto de la matrícula y pago mensual del servicio educativo del colegio

\section{Distribución}

Comunicar la ubicación del colegio y los servicios que ofrece a los sectores del mercado meta del colegio

\section{Promoción y Publicidad}

Realizar una campaña publicitaria en los medio de difusión locales a fin de dar a conocer el servicio educativo del colegio tres meses antes del inicio de actividades Realizar una campaña publicitaria en las redes sociales a fin de dar a conocer el colegio a nuestro mercado meta.

\section{Ventas}

Llevar a cabo una campaña de ventas en los principales puntos que visitan los potenciales interesados en el servicio educativo

Capacitar durante 24 horas al personal de ventas sobre los aspectos diferenciales del servicio educativo del colegio

\section{Finanzas:}

Alcanzar el punto de equilibrio al tercer año de operación del negocio 
Realizar la inversión necesaria para cubrir el 100\% del capital de trabajo durante el primer año de operación de la empresa.

\subsection{Alcances y Limitaciones de la Investigación}

El presente proyecto se formula considerando los siguientes alcances:

a) El proyecto se plantea para formar una institución educativa solamente a nivel inicial.

b) El proyecto se llevará a cabo en la ciudad de Chiclayo y no se considera otras ciudades de la región.

c) El análisis de las tendencias para evaluar el entorno del proyecto se realizará para los próximos diez años 2018 - 2017.

Las limitaciones del proyecto son las siguientes:

a) La disposición para participar en las entrevistas del estudio por parte de las personas de los niveles socioeconómicos A y B a quienes se enfoca el proyecto.

b) Limitada información sectorial por parte de los directivos de los colegios iniciales que existen actualmente.

c) El acceso a la información financiera y procesos administrativos de otros colegios de la localidad será limitada, dado que se maneja de manera confidencial. 


\section{Capítulo II}

\section{Estructura económica del sector}

\subsection{Descripción del estado actual de la industria}

La demanda de educación privada en general ha experimentado un crecimiento sostenido en los últimos años, lo cual se refleja en la creación de nuevos colegios en el sector tanto en Lima como en provincias. En la zona urbana de la ciudad de Chiclayo existen más de 300 colegios (UGEL 2012) que atienden la demanda existente.

\subsubsection{Segmentación de la industria.}

La educación inicial es parte de la educación básica regular, la cual comprende los siguientes niveles según la Ley General de Educación (No. 28044, 2003).

a) Nivel de Educación Inicial: la educación inicial es el primer nivel de la educación básica regular: Este nivel se orienta a niños de cero a dos años en forma no escolarizada y de tres a cinco años en forma escolarizada.

b) Nivel de Educación Primaria: la educación primaria es el segundo nivel de la educación básica regular. Los estudios en este nivel tienen una duración de seis años.

c) Nivel de Educación Secundaria: la educación secundaria constituye el tercer nivel de la educación básica regular. La duración de los estudios en este nivel es de cinco años.

En el nivel de educación inicial se tienen dos etapas, la primera que atiende a niños a partir de los tres meses de edad hasta los tres años en forma no escolarizada y la 
segunda que atiende a los niños entre tres a seis años de forma escolarizada. Los centros de educación en este nivel son:

a) Cuna: es un tipo de institución educativa que atiende los requerimientos de la primera etapa de la educación básica regular, para niños de tres meses a menores de tres años. Brinda un servicio de educación orientado al desarrollo integral y de acuerdo a las necesidades de permanencia horaria de los niños. Este servicio también atiende necesidades de salud, alimentación y atención psicológica en jornadas diarias de uno a dos turnos (cuatro a ocho horas) según las necesidades de las familias.

b) Jardín: es una institución educativa dirigida a niños menores de tres a seis años. Son las instituciones educativas que satisfacen los requerimientos de la segunda etapa de la educación básica regular y están destinadas a ofrecer actividades pedagógicas que propicien el aprendizaje y desarrollo de todas las dimensiones de su personalidad (bio- psicomotor, cognitivo y socio afectivo). También ofrecen, servicios complementarios y compensatorios de salud y nutrición.

c) Cuna - Jardín: para niños de tres meses a menores de seis años. Son las instituciones educativas que atienden las dos etapas de educación básica regular, cuentan con una administración unitaria y por lo general la jornada diaria se prolonga a dos turnos.

La educación básica inicial es obligatoria y las instituciones de este nivel son de carácter privado y de carácter público. En el caso de la educación básica inicial que ofrece el Estado es de carácter gratuito. 
Existen dos tipos de instituciones educativas a nivel inicial: las polidocentes y las unidocentes.

a) Institución polidocente: son las instituciones en las que se tiene un docente por cada sección y la actividad pedagógica se realiza en su aula correspondiente. Las aulas de este tipo de institución son denominadas aulas por grupo de edad o grupo etario.

b) Institución unidocente: cuando en la institución educativa se tiene un docente a cargo de un aula o sección conformada por niños de diferentes edades. Este tipo de aulas son denominadas aulas integradas y las instituciones a las que corresponden se ubican en aquellos lugares donde la demanda educativa es menor.

\subsubsection{Empresas que la conforman.}

El sector de educación inicial de la ciudad de Chiclayo está conformado por 312 colegios tanto públicos como privados según el censo escolar del 2012 realizado por la UGEL - Chiclayo. Los colegios privados son 148, los cuales están integrados en general por el servicio de cuna y de jardín cubriendo de esta manera los dos primeros niveles de educación inicial. La relación total de colegios se muestra en el Anexo No. 1, mientras que los treinta primeros colegios por población estudiantil se muestran en la Tabla 1.

Con respecto a la infraestructura, la mayoría de colegios de educación inicial en la ciudad de Chiclayo son casas acondicionadas para brindar este servicio. Esta situación determina que los colegios de educación inicial generalmente no cuenten con las áreas de psicomotricidad, recreación, verdes, talleres; que se requieren para brindar el servicio educativo. 
Tabla 1

Centros Educativos del Nivel Inicial del Censo Escolar 2012

\begin{tabular}{|c|c|c|c|c|c|c|c|}
\hline \multirow{2}{*}{$\begin{array}{l}\text { Número y/o nombre de la } \\
\text { institución educativa }\end{array}$} & \multicolumn{6}{|c|}{ Matricula por edades simples y sexo } & \multirow{2}{*}{$\begin{array}{l}\text { Total } \\
\text { alumnos }\end{array}$} \\
\hline & $3 \mathrm{H}$ & $3 \mathrm{M}$ & $4 \mathrm{H}$ & $4 \mathrm{M}$ & $5 \mathrm{H}$ & $5 \mathrm{M}$ & \\
\hline LA ANUNCIATA & 30 & 24 & 35 & 33 & 39 & 36 & 197 \\
\hline SAN AGUSTIN & 28 & 25 & 31 & 33 & 45 & 30 & 192 \\
\hline 052 SANTA ANA & 38 & 22 & 35 & 24 & 41 & 29 & 189 \\
\hline CEIBOS & 20 & 22 & 33 & 42 & 32 & 38 & 187 \\
\hline SANTA MARIA REINA & 0 & 35 & 0 & 53 & 0 & 83 & 171 \\
\hline PARAISO SCHOOL & 21 & 10 & 25 & 37 & 42 & 25 & 160 \\
\hline MANUEL PARDO & 21 & 10 & 35 & 23 & 55 & 15 & 159 \\
\hline CRAYOLAS & 26 & 13 & 20 & 26 & 31 & 39 & 155 \\
\hline CONSORCIO EDUCATIVO & 14 & 23 & 29 & 27 & 30 & 28 & 151 \\
\hline \multicolumn{8}{|l|}{ TALENTOS } \\
\hline ROSA MARIA CHECA & 17 & 28 & 16 & 35 & 12 & 40 & 148 \\
\hline SANTA CECILIA & 10 & 20 & 23 & 25 & 28 & 37 & 143 \\
\hline SANTA ROSA DE LIMA & 24 & 21 & 30 & 22 & 22 & 18 & 137 \\
\hline LUISA DE LA TORRE & 22 & 22 & 33 & 19 & 18 & 22 & 136 \\
\hline PRISMA & 34 & 26 & 23 & 26 & 15 & 12 & 136 \\
\hline MARIA MONTESSORI & 14 & 13 & 34 & 25 & 22 & 20 & 128 \\
\hline SANTO TORIBIO DE & 9 & 16 & 29 & 17 & 36 & 20 & 127 \\
\hline \multicolumn{8}{|l|}{ MOGROVEJO } \\
\hline ELSA GMEINER & 30 & 5 & 28 & 20 & 26 & 13 & 122 \\
\hline SAGRADO MAESTRO & 8 & 14 & 28 & 15 & 22 & 33 & 120 \\
\hline MARIA LUCRECIA PRADO & 9 & 16 & 19 & 22 & 31 & 22 & 119 \\
\hline \multicolumn{8}{|l|}{ VARGAS } \\
\hline SANTA ANA & 19 & 20 & 17 & 29 & 13 & 19 & 117 \\
\hline BILINGÜE DISNEYLANDIA & 21 & 19 & 19 & 21 & 18 & 14 & 112 \\
\hline BETHANNIA SCHOOL & 8 & 5 & 18 & 18 & 32 & 27 & 108 \\
\hline NIÑO FELIZ & 20 & 14 & 19 & 14 & 19 & 20 & 106 \\
\hline GIRASOLES SCHOOL SAC & 18 & 14 & 24 & 17 & 19 & 12 & 104 \\
\hline SAN JUAN MARIA VIANNEY & 16 & 16 & 20 & 16 & 18 & 17 & 103 \\
\hline EL NAZARENO & 10 & 11 & 25 & 23 & 19 & 15 & 103 \\
\hline MARIA REICHE NEUMAN & 7 & 19 & 20 & 11 & 18 & 25 & 100 \\
\hline INDEPENDENCIA & 7 & 9 & 14 & 16 & 27 & 21 & 94 \\
\hline JESUS EL BUEN PASTOR & 12 & 19 & 12 & 16 & 20 & 15 & 94 \\
\hline \multicolumn{8}{|l|}{ FRANCISCO VILCHEZ } \\
\hline PAREDES & 15 & 15 & 18 & 19 & 16 & 10 & 93 \\
\hline
\end{tabular}




\subsection{Tendencias de la industria}

Existe actualmente una demanda creciente por el servicio de educación inicial, dado que los padres de familia buscan instituciones educativas que les brinden una educación de calidad para sus hijos. En este sentido, los padres de familia de los colegios de educación inicial están tomando mayor conciencia en cuanto a la inclusión de todos los niños en este nivel de educación. Así, se puede observar que los padres de familia se preocupan en mayor medida por la educación de sus hijos a nivel inicial, siendo más exigentes con los servicios que brindan estas instituciones, especialmente en la calidad de los docentes, seguridad y limpieza.

En el sector privado los colegios de educación inicial se están enfocando a la adopción de nuevos programas pedagógicos como es el caso del PEICE (Proyecto de Excelencia e Innovación en Calidad Educativa) antes llamado proyecto OPTIMIST. Este modelo educativo está orientado a brindar estimulación organizada a los niños en el nivel inicial y de manera personalizada a fin de lograr un aprendizaje eficiente mediante el uso de programas de lectura y motricidad. El programa se estructura de acuerdo a la edad de cada niño.

Por otro lado, en los colegios iniciales del sector público existe gran preocupación debido a que sus docentes no están aplicando de una manera adecuada el programa “APRENDIENDO JUGANDO” adoptado por el Ministerio de Educación para la educación de los niños en este nivel. La razón fundamental es que los docentes de este nivel no lo han implementado según las pautas que establece el modelo, dejando que los niños solo jueguen durante su aprendizaje. Esta situación genera una desventaja 
para los niños que asisten a estos colegios, ya que cuando inician la educación primaria no saben aún leer o escribir correctamente.

\subsection{Análisis Estructural del Sector Industrial}

El análisis estructural del sector de colegios de educación inicial se realizará usando el modelo de las cinco fuerzas de Porter según se presenta en David (2013). Las fuerzas que afectan al sector industrial son: el poder de negociación de proveedores, poder de negociación de los consumidores, rivalidad entre las empresas competidoras, el poder de productos sustitutos, las barreras de entrada y salida para los ingresantes potenciales al sector.

a) Competencia: en la ciudad de Chiclayo, los colegios que tienen un sistema educativo similar son: Boniffati, Caritas Felices y Kinder Smile. Otros colegios, que compiten en el mercado son: Pasito a Paso y el San Agustín.

En general los elementos de competencia son la limpieza del colegio, la plana docente calificada, y la seguridad para los niños. Asimismo, los colegios organizan talleres que no se solicitan en la currícula de estudios y que lo ofrecen como un servicio adicional para los niños. Ver Tabla 2 en donde se muestra los elementos que determinan la rivalidad entre los competidores 
Tabla 2

Rivalidad Entre Competidores

\begin{tabular}{llll}
\hline & & & \\
& & & \\
\hline Número de colegios similares & & & Pequeño \\
\hline Crecimiento relativo de la industria & Grande & & Bajo \\
\hline Limpieza del Colegio & Lento & & Especializado \\
\hline Seguridad para los niños & Alto & Bajo \\
\hline Número de competidores & Estándar & Bajo \\
\hline Docentes calificados & Alto & Atractivo \\
\hline Evaluación general & Alto & & \\
\hline
\end{tabular}

b) Proveedores: en general los colegios de educación inicial adquieren para sus actividades papelería, juegos pedagógicos y de entretenimiento, inmobiliario, equipos de tecnología, instrumentos musicales, entre otros. Las empresas que proveen los principales insumos que requieren los colegios iniciales en la ciudad de Chiclayo son:

Hans Educa: empresa que diseña y fabrica juegos educativos para desarrollar la motricidad de los niños.

Kiddy`s House: tienda especializada en materiales para desarrollar las habilidades del niño y de juegos la para estimulación temprana, y la psicomotricidad. En la Tabla 3 se presenta los aspectos que definen el poder de los proveedores. 
Tabla 3

Poder de los Proveedores

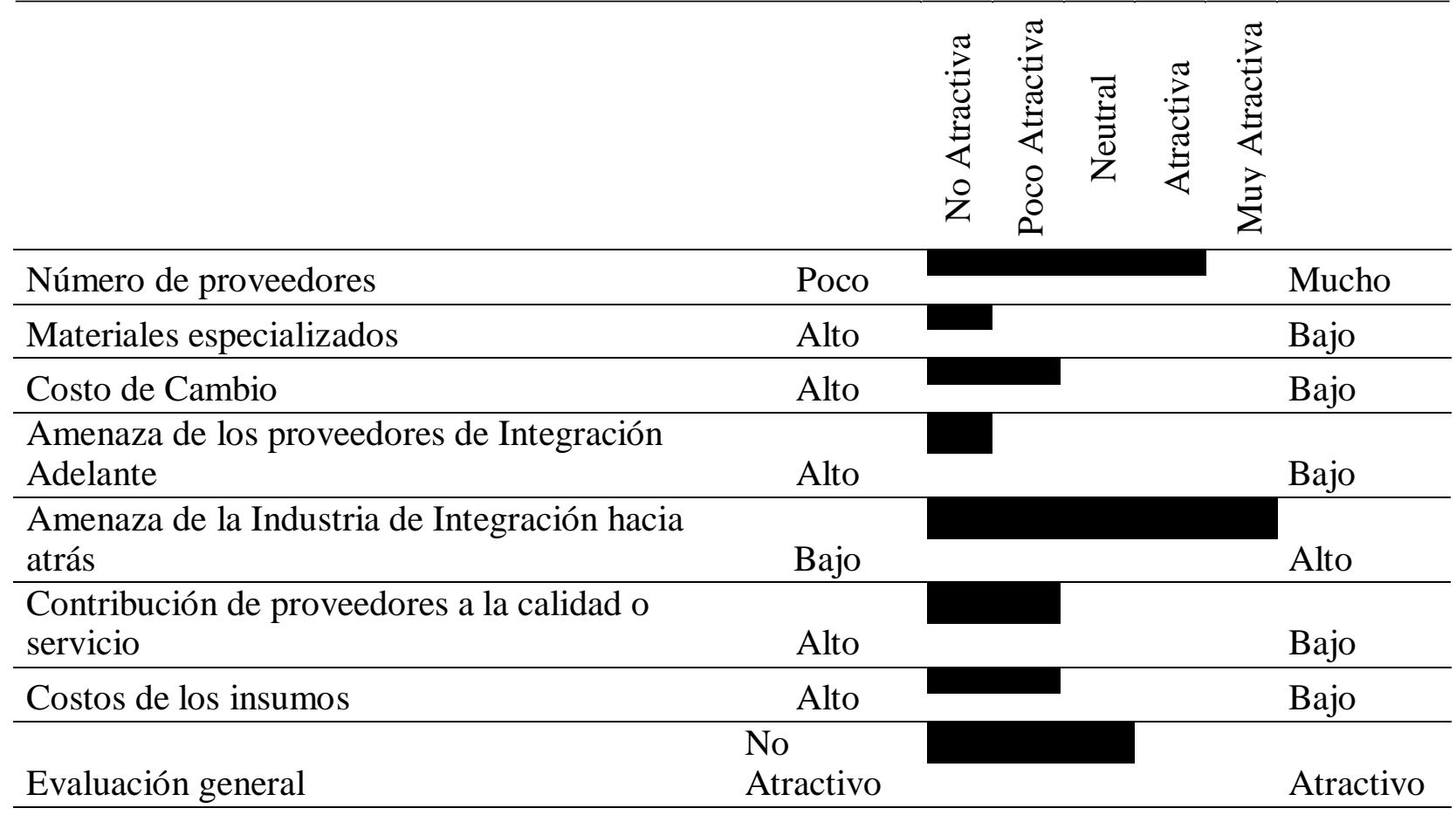

c) Clientes: las personas que requieren el servicio son los padres de familia de niños de tres meses para las cunas y de tres años para los colegios del nivel inicial. Los niveles socioeconómicos de los padres de familia que matriculan a sus hijos es una institución privada son A y B.

La persona que realiza el seguimiento de los niños en el colegio es la madre y también los realiza la abuelita. En general son los padres de familia quienes llevan al niño al colegio y se desplazan entre diez a veinte minutos para llegar al colegio desde su domicilio. En la Tabla 4 se indica los elementos que definen el poder de los clientes entre los colegios de nivel inicial 
Tabla 4

Poder de los Clientes

\begin{tabular}{lllll}
\hline & & & & \\
& & & & Mucho \\
\hline Número de clientes & & & & \\
\hline Compras en volúmenes & Poco & & & Poco \\
\hline Disponibilidad de sustitutos & Mucho & & & Alto \\
\hline Costo de cambio & Bajo & & & Bajo \\
\hline Amenaza del cliente de integrarse hacia atrás & Alto & & & Atractivo \\
\hline Contribución a la realización del cliente & Bajo & & & \\
\hline Evaluación general & No Atractivo & & & \\
\hline
\end{tabular}

d) Sustitutos: las instituciones que brindan un servicio similar son los colegios de educación inicial estatales. En la ciudad de Chiclayo existen actualmente 98 colegios iniciales públicos que están organizados generalmente como nido y jardín. En la Tabla 5 se puede apreciar los aspectos que determinan el poder de esta fuerza en el sector educativo de nivel inicial.

Tabla 5

Amenaza de Productos Sustitutos

\begin{tabular}{|c|c|c|c|c|c|c|}
\hline & & 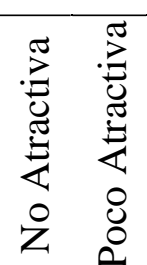 & $\begin{array}{l}\bar{\pi} \\
\stackrel{\Xi}{0} \\
z\end{array}$ & 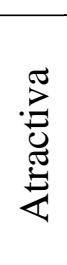 & 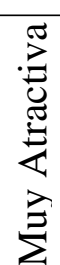 & \\
\hline Disponibilidad de sustitutos cercanos & Grande & & & & & Pequeño \\
\hline Costo de Cambio & Bajo & & & & & Alto \\
\hline Calidad del servicio sustituto & Alto & & & & & Bajo \\
\hline Valor/precio del sustituto & Alto & & & & & Bajo \\
\hline Evaluación general de la fuerza & No Atractivo & & & & & Atractivo \\
\hline
\end{tabular}


e) Potenciales Ingresantes: en el sector de educación inicial existen empresas que desean ingresar al sector de educación inicial, como es el caso del Grupo Interbank con sus colegios Innova, la Universidad San Martin de Porras, Santo Toribio de Mogrovejo, entre otros.

Una barrera de entrada para el ingreso de nuevos colegios de educación inicial es el tamaño del terreno, ya que se requiere para la autorización un área mínima de 750 metros cuadrados. Asimismo, se debe contar con la licencia para el funcionamiento que lo otorga la Municipalidad Provincial de Chiclayo; que además se encarga de inspeccionar constantemente que las instalaciones sean las adecuadas, la limpieza sea la correcta, y la licencia de funcionamiento se encuentre vigente.

En el caso de los colegios educación inicial privados que tienen un nido, estos no cuentan con el respaldo del Ministerio de Educación, ni INDECOPI para exigir que el nido de origen otorgue un certificado en el caso que los padres de familia deseen cambiar a sus hijos de institución educativa Esta situación determina que algunos padres no cumplan con los pagos correspondientes a la institución, pues no existe barreras para cambiar a los niños de un nido a otro. En la Tabla 6 se presenta los elementos que determinan las barreras de entrada en este sector. 
Tabla 6

Competidores Potenciales - Barreras de Entrada

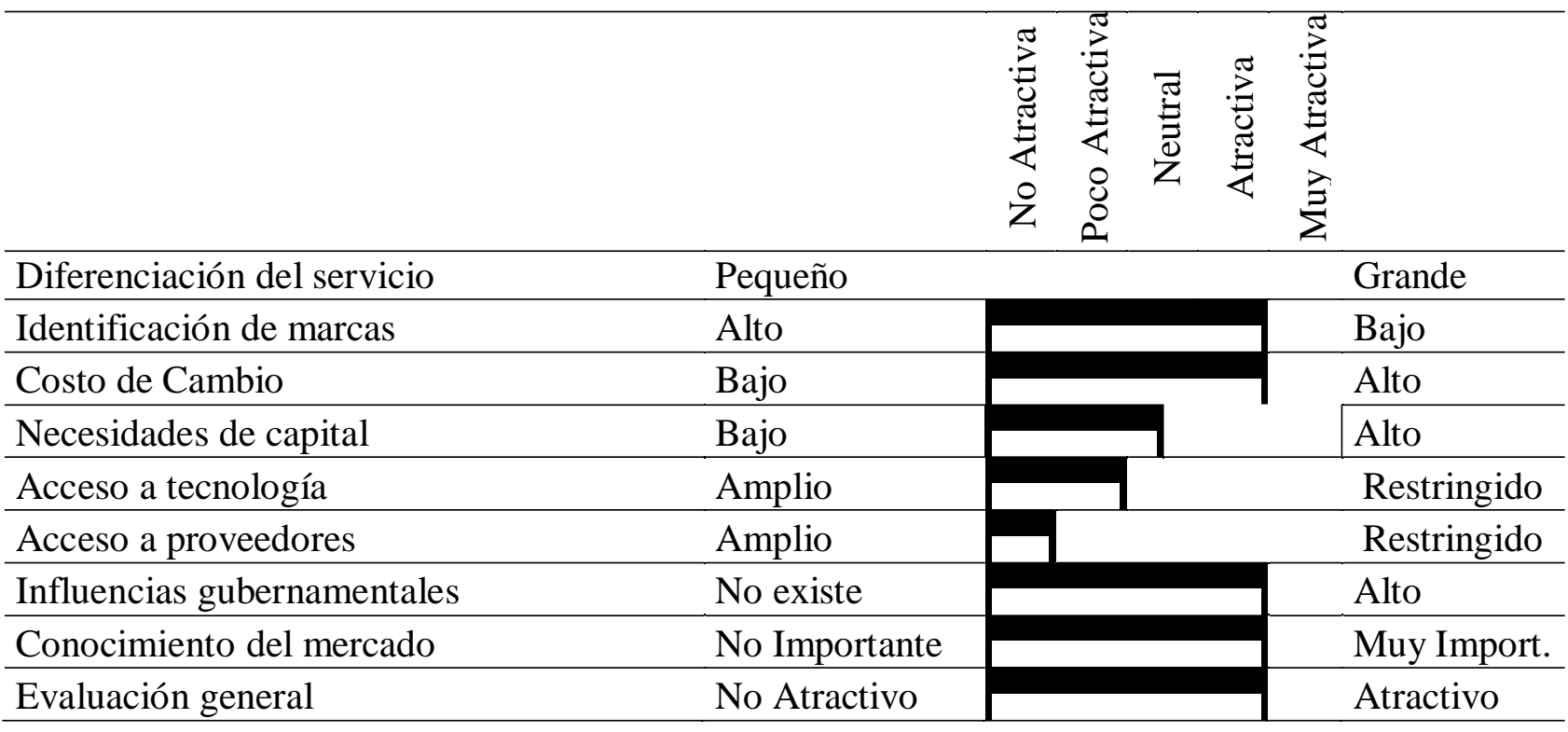

En la Tabla 7 se indican los aspectos que determinan las barreras de salida en el sector educativo a nivel inicial.

Tabla 7

Competidores Potenciales - Barreras de Salida

\begin{tabular}{lllll}
\hline & & & & \\
& & & & \\
& & & & \\
\hline Especialización de los activos & & Alto & Bajo \\
\hline Costos de salida & Alto & & Bajo \\
\hline Relaciones estratégicas & Alto & & Bajo \\
\hline Barreras emocionales & Alto & & Bajo \\
\hline Restricciones gubernamentales y sociales & Alto & & Atractivo \\
\hline Evaluación general & No Atractivo & & & \\
\hline
\end{tabular}


La evaluación global de las cinco fuerzas de Porter se muestra en la Tabla 8. El valor resultante se calcula como el promedio de las evaluaciones generales de cada fuerza.

Tabla 8

Evaluación Global

\begin{tabular}{|c|c|c|c|c|c|}
\hline & 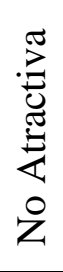 & 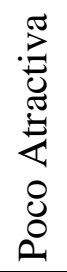 & 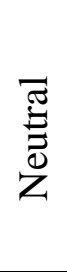 & 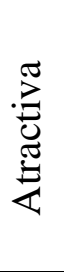 & 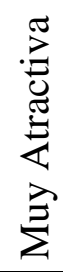 \\
\hline \multicolumn{6}{|l|}{ Barreras de entrada } \\
\hline \multicolumn{6}{|l|}{ Barreras de salida } \\
\hline \multicolumn{6}{|l|}{ Rivalidad entre competidores } \\
\hline \multicolumn{6}{|l|}{ Poder de los compradores } \\
\hline \multicolumn{6}{|l|}{ Poder de los proveedores } \\
\hline \multicolumn{6}{|l|}{ Disponibilidad de sustitutos } \\
\hline Evaluación Global & & & & & \\
\hline
\end{tabular}

\subsection{Análisis de la Competencia}

\subsubsection{Empresas que of recen el mismo producto o servicio, indicando las semejanzas y diferencias que tienen con el proyecto de empresa.}

En la ciudad de Chiclayo se cuenta con diferentes colegios que ofrecen el servicio educativo a nivel inicial. Entre estos colegios tenemos al CEIBOS, Victoria Barcia Boniffatti, Pasito a Paso, San Agustin, entre otros. A fin de conocer las características de instituciones educativas que brindan actualmente un servicio similar a la propuesta se han realizado entrevistas con las Directoras de dos de los Colegios señalados y los otros colegios se ha obtenido información de fuentes secundarias principalmente por revisión de la página web de dichas instituciones educativas. Asimismo, se ha entrevistado un experto en el sector educativo y un docente de educación inicial que tienen más de veinte años de experiencia en el sector. 
En los Anexos 2 al Anexo 7 se presenta la ficha técnica para las entrevistas y la transcripción de las entrevistas realizadas a los expertos indicados.

Las entrevistas a las Directoras se hicieron a la Sra. Pilar Llontop Directora del C.E.I.P Victoria Barcia Boniffatti (más de veinte cinco años de funcionamiento) y a la Sra. Luz Eliana Pérez Montenegro Directora del C.E.I.P. Pasito a Paso (tiene aproximadamente diez años de operaciones en el sector).

Colegio Inicial Victoria Barcia Boniffatti: Brinda el servicio de enseñanza a nivel inicial en la ciudad de Chiclayo. A nivel de educación inicial cuenta con el modelo educativo PEICE, que permite que la institución brinde una educación personalizada. Así, el uso de esta metodología permite que el Colegio pueda desarrollar en los niños la escritura y la motricidad de una manera natural. El número de niños en el salón de clase es de veinte para los grupos de tres a cuatro años, mientras que el caso de alumnos de cinco años es de veintiocho. Ver Figura 1.

La tecnología que usan en este nivel es básica (pizarra interactiva y una computadora para el docente). Los niños en general no tienen acceso a equipos de cómputo, dado que lo que se busca es que los niños de esta edad puedan socializar y no tener equipos que puedan llevarlos a un trabajo individual.

En contraste con lo que ofrece este colegio, la propuesta del nuevo colegio considera enfocarse solo al nivel inicial y el uso de la tecnología para comunicarse con los padres de familia, a fin de involucrarlos en el proceso de formación de sus hijos. Por otro lado, se está considerando brindar clases de inglés, de modo que exista un aprendizaje de otro idioma al inicio del proceso educativo del niño. 


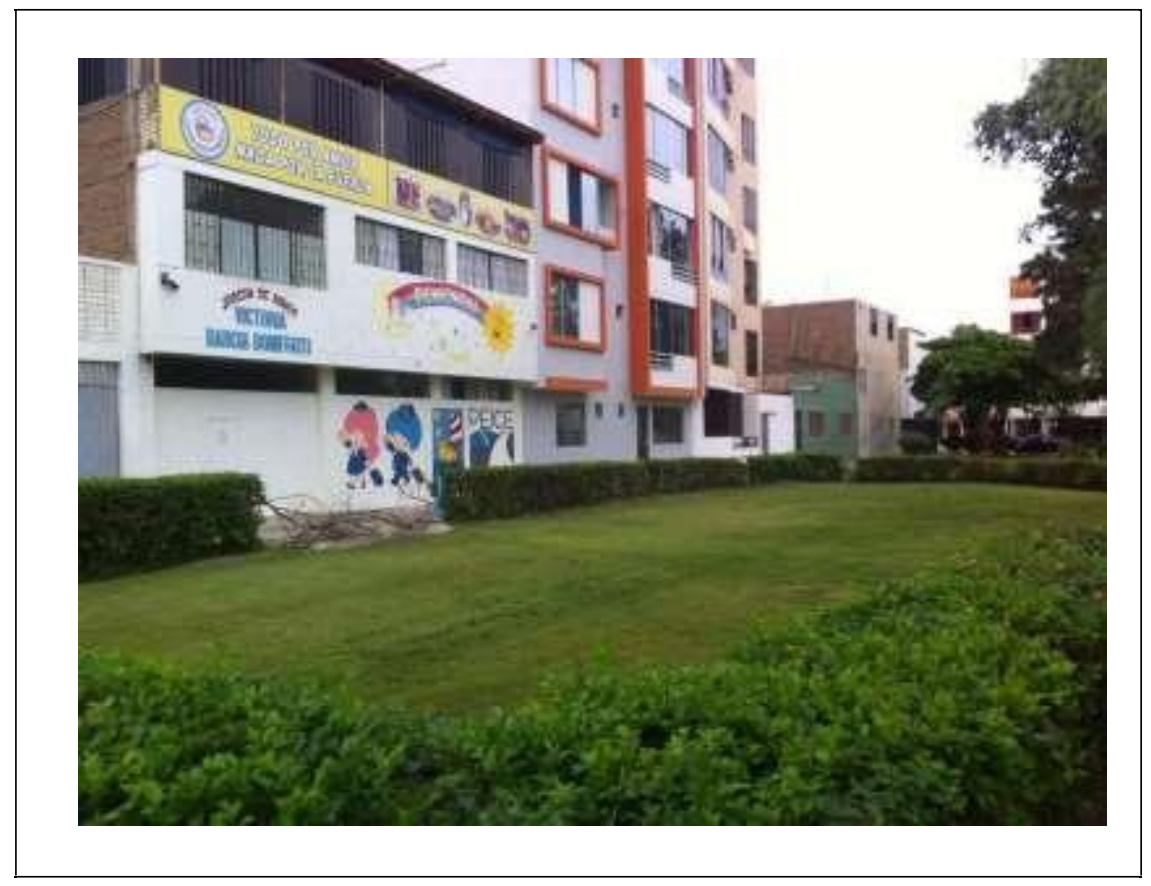

Figura 1. Colegio Victoria Barcia Boniffatti

Colegio Inicial Pasito a Paso: brinda el servicio de estimulación prenatal para las madres gestantes, estimulación temprana para niños de tres meses a dos años y educación inicial para niños de tres a cinco años. El método que utiliza para el aprendizaje de los niños es el método POINT, que propicia el aprendizaje temprano de los niños (entre cero a seis años) y el desarrollo de inteligencias múltiples mediante el uso de diferentes recursos metodológicos. El número de alumnos por salón de clase es de doce. Ver Figura 2.

En relación con la tecnología el colegio se usan computadoras y un sistema de multimedia para la proyección de videos y juegos como parte del proceso de aprendizaje. En el colegio se llevan a cabo talleres que permite la formación integral del niño, como arte, danza, karate, cuentos entre otros. 
En contraste con lo que ofrece este colegio, nuestra propuesta considera enfocarnos sólo al nivel inicial y el uso de la tecnología para comunicarnos con los padres de familia a fin de involucrarlos en el proceso de formación de sus hijos. Por otro lado, se está considerando brindar clases de inglés, de modo que exista un aprendizaje de otro idioma al inicio del proceso educativo del niño. Asimismo, estaremos organizando algunos talleres adicionales a los que se ofrece en la currícula.

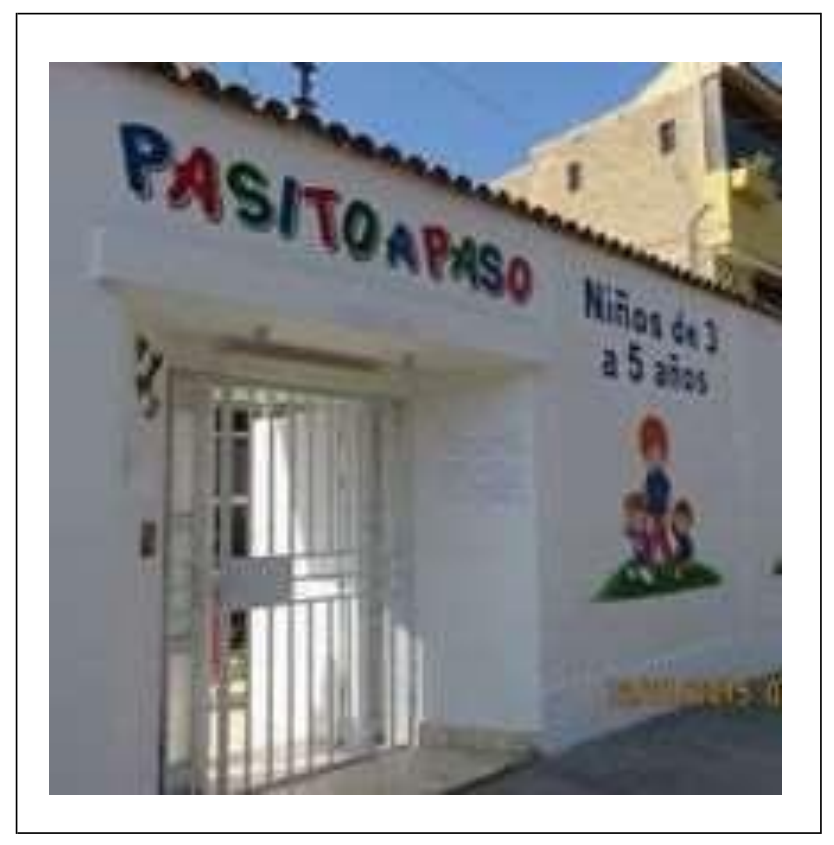

Figura 2. Colegio Inicial Pasito a Paso.

Colegio Ceibos: cuenta con los tres niveles de educación básica: inicial, primaria y secundaria. Tiene más de 25 años de operación brindado el servicio educativo en la ciudad de Chiclayo.

Aplica el Proyecto Optimist para el proceso de enseñanza aprendizaje para los niños que están en el nivel inicial. Este modelo le permite una formación integral que comprende el desarrollo cognoscitivo, actitudinal y físico de sus alumnos. Su modelo educativo ha sido acreditado por Fomento de Centros de Enseñanza de España, por la 
Escuela de Capacitación Pedagógica de Perú, según lo indica en su página web http://www.ceibos.edu.pe (2016).

Su infraestructura física consiste de 18 aulas para el nivel inicial (incluye aulas para niños del nivel de cuna) y cuenta con amplias áreas verdes. Con relación a la tecnología, el colegio tiene computadoras para uso de los profesores y alumnos, así como juegos didácticos que favorecen el aprendizaje de los niños.

Desarrolla diferentes programas como parte de su proceso educativo, como programa de desarrollo de idiomas, lógico matemático, música, valores, entre otros, que favorecen el desarrollo integral de los niños. Nuestra propuesta incluye también la realización de programas, pero además se busca la participación del padre de familia en el proceso educativo del niño.

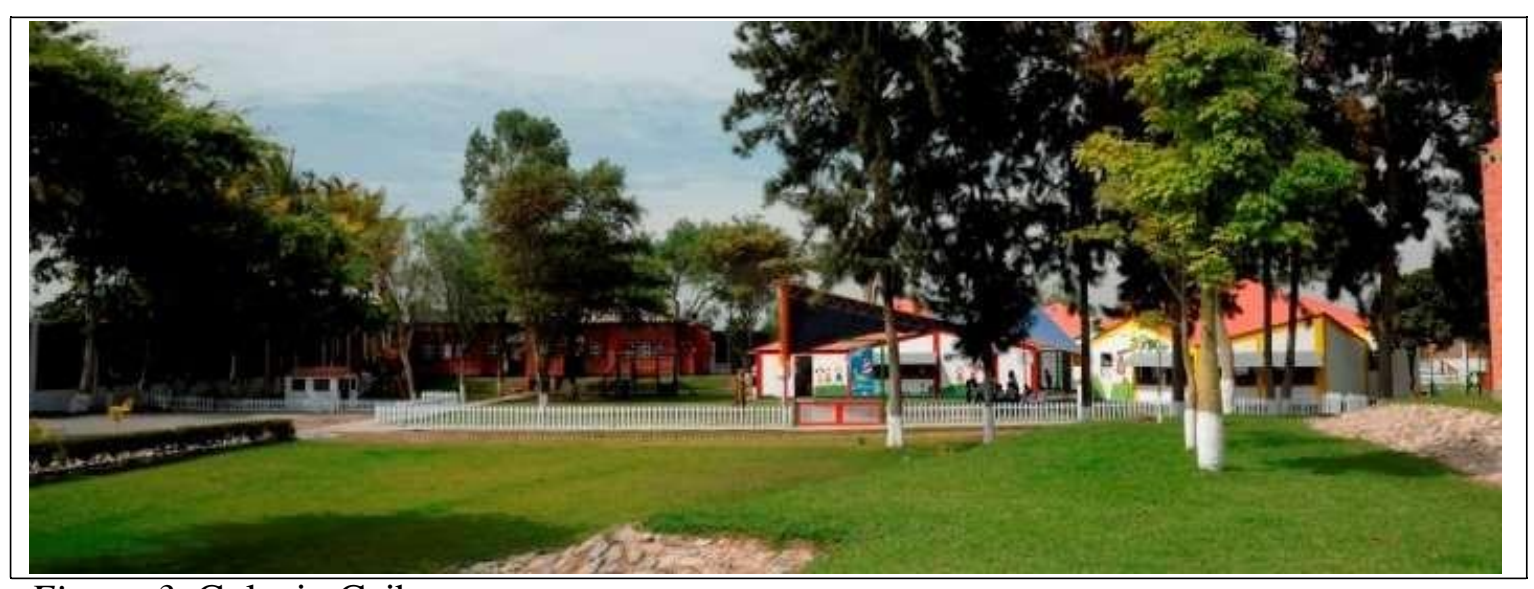

Figura 3. Colegio Ceibos

Colegio San Agustín: El colegio consta de los tres niveles de educación básica regular: inicial, primaria y secundaria. Tiene aproximadamente 50 años de presencia en el sector educativo. Empezó con el nivel de primaria y luego fue añadiendo los otros 
niveles de educación, según lo indica en su página web:

http://sanagustinchiclayo.edu.pe/ (2016).

A nivel inicial atiende a niños entre 3 a 5 años con un modelo educativo que le permite mediante un aprendizaje activo el desarrollo integral. El modelo adoptado es el PROYECTO OPTIMIST (Peice), que tiene como fundamento brindar una educación orientada a desarrollar la autonomía e independencia de los niños. Sus profesores están capacitados en educación personalizada, lo que permite implementar el modelo educativo propuesto. En la propuesta educativa del colegio propuesto se busca la formación integral del niño mediante un modelo que busca la colaboración del padre de familia y llevar a cabo programas de inglés a fin de favorecer el aprendizaje del segundo idioma en este nivel.

La infraestructura con la que cuenta es el soporte para el proceso educativo, se basa en aulas para el trabajo colaborativo de los niños, patios y áreas verdes para el recreo de los niños, biblioteca infantil especialmente diseñada para niños de tres a siete años, biohuerto y biogranja. Con relación a la tecnología, el Colegio tiene pizarras interactivas y computadoras para uso de los profesores durante su clase. 


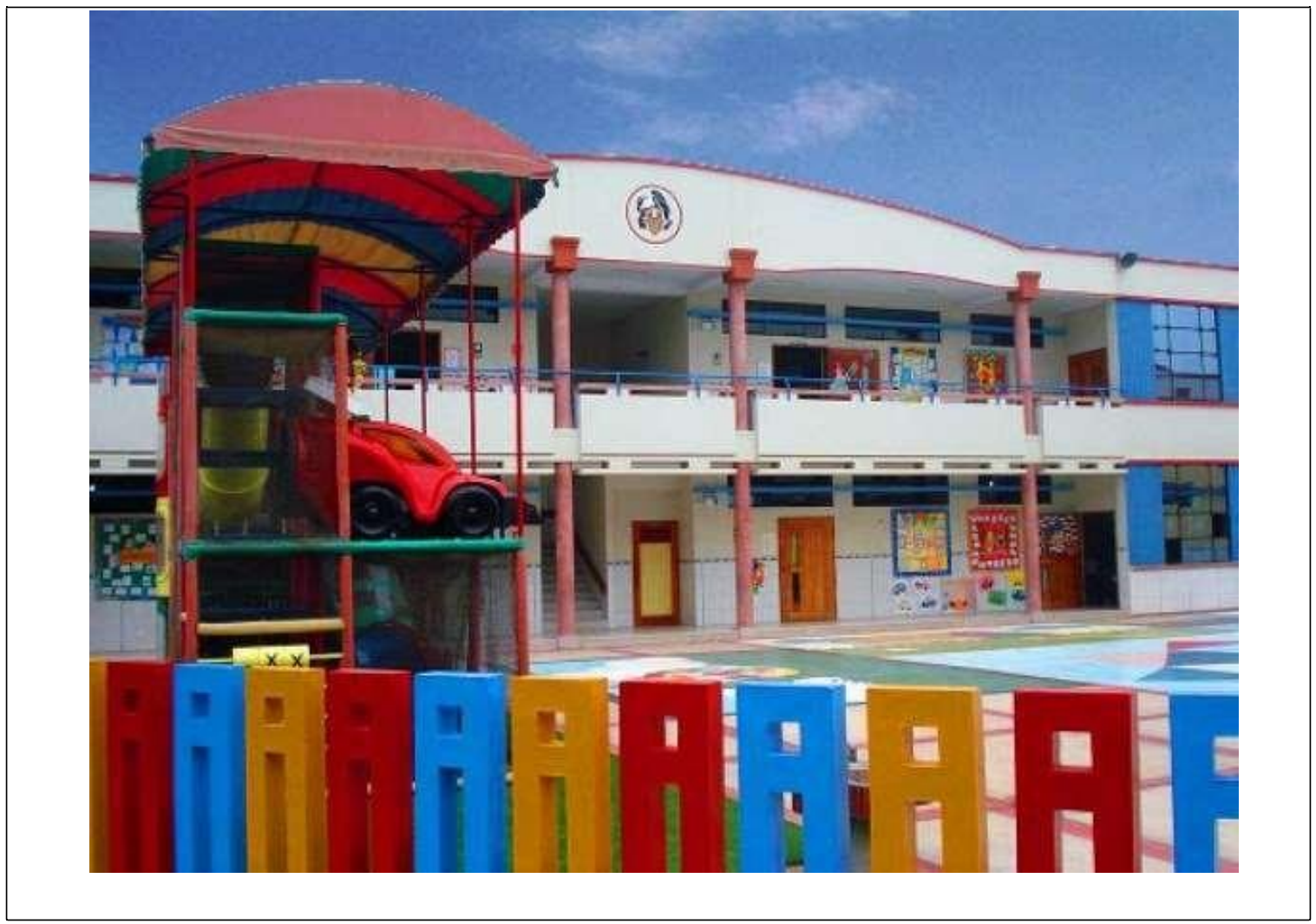

Figura 4. Colegio San Agustin

\subsubsection{Participación de mercado de cada uno de ellos.}

Si bien no existe información en detalle sobre la participación de mercado de los colegios de educación inicial, se puede estimar de manera aproximada el porcentaje de alumnos que tienen respecto al total de los 304 colegios de educación inicial de carácter privado que existen en la ciudad de Chiclayo (solamente para los distritos de Chiclayo, José Leonardo Ortiz, la Victoria y Pimentel).

Existe un número elevado de colegios privados en la localidad y la cantidad de alumnos que tienen es más de cien en solo 40 de ellos, mientras que los otros colegios tienen menos de esa cantidad de alumnos. En la tabla 9 se puede apreciar que la institución educativa a nivel inicial con el mayor número de alumnos es el Colegio 
Ceibos, que además según el estudio de mercado realizado es considerado el mejor colegio de la ciudad de Chiclayo.

Tabla 9

Colegios iniciales de la ciudad de Chiclayo

\begin{tabular}{lrr} 
Colegio & Número de alumnos & Porcentaje de alumnos \\
\hline Ceibos & 248 & $1,58 \%$ \\
Prisma & 240 & $1,53 \%$ \\
Santa María reina & 215 & $1,37 \%$ \\
Santa Cecilia & 212 & $1,35 \%$ \\
La Anunciata & 208 & $1,32 \%$ \\
Crayolas & 196 & $1,25 \%$ \\
Manuel Pardo & 179 & $1,14 \%$ \\
San Agustín & 167 & $1,06 \%$ \\
Juan Mejía Baca & 153 & $0,97 \%$ \\
Creciendo con Amor & 148 & $0,94 \%$ \\
\hline Nota.
\end{tabular}

Nota. UGEL Chiclayo, 2016

\subsubsection{Matriz de perfil competitivo.}

Para elaborar esta matriz se tomaron tres colegios de educación inicial reconocidos en el medio. Uno de ellos es el Colegio San Agustín, que tiene más de cincuenta años de operación y dos colegios Pasito a Paso y Victoria Barcia Bonoffatti, uno con veinte y cinco años en el sector educativo y el otro con aproximadamente diez años respectivamente, pero que dado su enfoque son reconocidos como colegios líderes en la región.

Los factores claves del éxito que se usaron para comparar los colegios de educación inicial son los siguientes:

a) Infraestructura: se requiere como mínimo 750 metros cuadrados de área para el colegio. Se debe contar áreas de juego a fin de trabajar con los aspectos 
vinculados con la movilidad de los niños, así como áreas verdes para uso en el recreo de los niños.

b) Número de niños por salón: se requiere que en un salón de clase el número máximo de alumnos sea de 25 .

c) Docentes especializados en educación inicial: los docentes del colegio deben estar especializados en este tipo de educación.

d) Talleres vivenciales: que permiten ofrecer un elemento adicional a los niños al no estar fijado en la normatividad del sector.

e) Modelo educativo para el desarrollo del niño: se debe elegir un modelo que permita estimular a los niños en su proceso de aprendizaje.

f) Involucramiento de los padres de familia: los padres buscan la participación en el proceso de formación de los niños.

g) Mensualidad: se busca una tarifa que esté al alcance de la economía familiar.

El porcentaje asignado a cada uno de los factores estratégicos claves fue estimado consultando a los expertos del sector educativo. Así por ejemplo se colocó un $30 \%$ a la infraestructura por el impacto que tiene este factos en lo usuarios del Colegio y la competencia con otros colegios. El número de alumnos por salón, así como los docentes especializados son otros factores estratégicos que determinan el nivel de perfil competitivo del negocio. Los resultados de la comparación entre tres colegios en la matriz de perfil competitivo se muestran en la Tabla 10. 
Tabla 10

Matriz de Perfil Competitivo

Factores Estratégicos Clave

San Agustín

Pasito a Paso

Boniffatti

Infraestructura

$30 \%$

$10 / 3$

$6 / 1.8$

$8 / 2.4$

Número de niños por salón

$20 \%$

$8 / 1.6$

$10 / 2$

$8 / 1,6$

Docentes especializados en

$10 \%$

$10 / 1$

$10 / 1$

$10 / 1$

educación inicial

Talleres vivenciales

$10 \%$

$8 / 0.8$

$8 / 0.8$

$8 / 0.8$

Modelo educativo para el

$10 \%$

$10 / 1$

$10 / 1$

$10 / 1$

desarrollo del niño

Involucramiento de los

$10 \%$

$8 / 0.80$

$8 / 0.8$

$8 / 0.8$

padres de familia

Precio

$10 \%$

$5 / 0.50$

$9 / 0.90$

$10 / 1$

Total

1

8.7

8.3

8.6

Nota. Entrevista a los Directores de los Colegios Pasito a Paso y Victoria Barcia Bonoffatti. Octubre 2016.

La evaluación mediante la matriz de perfil competitivo muestra que el Colegio San Agustín cuenta con una mejor evaluación de los factores estratégicos clave. El resultado alcanzado es coincidente con los estudios del mercado, en donde el Colegio San Agustín es considerado el segundo mejor colegio después del Colegio Ceibos. Por su parte, el Colegio Bonifatti se encuentra ubicado entre los seis mejores colegios de la ciudad de Chiclayo. 


\subsection{Análisis del Contexto Actual y Esperado}

El análisis del contexto permite reconocer los cambios en algunas de las variables que impactan en el Colegio. Las variables consideradas son política gubernamental, económica, social, legal, cultural y tecnológico.

\subsubsection{Análisis Político-Gubernamental.}

En el año 2016, luego de un proceso electoral muy disputado se eligió en el mes de junio al Presidente para los próximos cinco años, resultando electo el Sr. Pedro Pablo Kuczynski, de la agrupación política Peruanos por el Kambio (PPK).

Según el plan de gobierno de dicha agrupación política y por lo manifestado durante la presentación del Primer Ministro Fernando Zavala ante el Congreso de la República el día 18 de agosto del 2016 se espera un entorno favorable para la educación. Así, el nuevo el nuevo Primer Ministro expreso que para el año 2021 fecha del bicentenario, se ampliará el acceso a la educación inicial pasando de un $84 \%$ a un 95\% de alumnos que asisten en este nivel de educación. En el caso de la Región Lambayeque, según el INEI (2015), el nivel se asistencia de los niños en el nivel de educación primaria es del $91.6 \%$ y para educación inicial el promedio es del 85\%.

Asimismo, el Primer Ministro dio a conocer que el gobierno planea que en este nivel se impartan tres horas semanales de arte y cinco horas de inglés. También, en su discurso ante el Congreso manifestó que el nuevo gobierno plantea duplicar de $30 \%$ a $60 \%$ el número de estudiantes que reciben educación física como parte del programa de estudios. 
Otro aspecto que refirió el Primer Ministro fue el aumento de sueldo para los maestros que laboran en la educación pública señalando que para el año 2018 “ningún docente percibirá menos de 2000 soles”. En este sentido, es importante señalar el compromiso que tiene el nuevo gobierno por mejorar la educación y la calidad de vida de los docentes del sector público.

Si bien a inicios del periodo de gobierno se previa una situación política complicada para el nuevo gobierno, dado que la mayoría en el Congreso es del partido de oposición, esta situación no se ha presentado en estos tres primeros meses de gobierno y se espera que en los siguientes meses continúe la estabilidad política. Por consiguiente, para los próximos años se prevé que pueda existir una estabilidad política a partir del dialogo entre el principal partido de oposición y el gobierno. Por otro lado, los programas de gobierno que se espera impulse la nueva administración a fin de consolidar el crecimiento del país, determinará un entorno favorable para la inversión privada, así como el apoyo a la mejora en la educación.

En la región de Lambayeque, el Gobierno Regional presentó en mayo del año 2015 dos programas para mejorar la calidad de la educación en la zona: Programa Educativo de Mejora de los Aprendizajes en la Región Lambayeque (PEMAR): el propósito es mejorar el aprendizaje en matemática y la comprensión lectora de los niños de educación primaria. También se busca mejorar el aprendizaje bilingüe de los niños de este nivel. Sistema de Acompañamiento Pedagógico y Evaluación Continua: este sistema permitirá evaluar el logro de los aprendizajes de los estudiantes que asisten a las instituciones educativas del nivel primario de educación básica regular en la región. 
Dado este contexto, a nivel nacional y regional se considera que existe un entorno político gubernamental favorable para el proyecto de creación de un colegio de educación inicial en la ciudad de Chiclayo. Esta situación se presenta dado que el gobierno nacional planea incrementar la cobertura de educación inicial y el apoyo a la inversión privada, mientras que el gobierno regional está impulsando la mejora en la calidad educativa. Po consiguiente, en relación con esta variable los cambios esperados no tienen un impacto con los negocios.

\subsubsection{Análisis Económico.}

Según el Marco Macroeconómico Multianual (MMM) que publica el Ministerio de Economía y Finanzas para el periodo 2017 - 2019 (2016), el país tendrá un crecimiento sostenido los próximos años. Así, se prevé una tasa de crecimiento del $4 \%$ para el año 2016, 4,8 para el año 2017 y de un crecimiento más de 4\% para los siguientes años, tal como se muestra en el Tabla 11.

Tabla 11

Crecimiento del PIB 2017-2019

\begin{tabular}{lc}
\hline Año & PIB $(\boldsymbol{\%})$ \\
\hline $\mathbf{2 0 1 6}$ & 4,0 \\
\hline $\mathbf{2 0 1 7}$ & 4,8 \\
\hline $\mathbf{2 0 1 8}$ & 4,3 \\
\hline $\mathbf{2 0 1 9}$ & 4,1 \\
\hline
\end{tabular}

Nota. Tomado de "Marco Macroeconómico Multianual 2017 - 2019". Ministerio de Economía y Finanzas. Perú.

Por parte del Gobierno Regional de Lambayeque se están llevando a cabo proyectos para mejorar la infraestructura local, lo que determina un entorno favorable para generar nuevos empleos y aumentar el poder adquisitivo de la población. En el 
portal de Proyectos de Inversión Pública del Ministerio de Economía y Finanzas se puede conocer los proyectos que actualmente se están ejecutando.

En este contexto de crecimiento se presenta un ambiente favorable para la creación del colegio de educación inicial, dado que se estima una situación económica estable a nivel nacional y regional que estimula a que las familias puedan invertir en educación para sus hijos.

En relación con el tipo de cambio, según el Marco Macroeconómico Multianual 2017 - 2019, (2016), el tipo de cambio se estima que presenta una ligera estabilidad pasando de un valor de 3,37 para el año 2016 a un valor de 3,55 el año 2019, tal como se puede apreciar en el Tabla 12.

Según la estimación presentada, se considera que la variación en el tipo de cambio permitirá un nivel de estabilidad en la economía. Por consiguiente, se prevé que existirá un ambiente favorable para la inversión en el proyecto de creación de un colegio de educación inicial.

Tabla 12

Tipo de Cambio 2016-2019

\begin{tabular}{ll}
\hline Año & Tipo de cambio (soles por dólar) \\
\hline $\mathbf{2 0 1 6}$ & 3.37 \\
$\mathbf{2 0 1 7}$ & 3.48 \\
$\mathbf{2 0 1 8}$ & 3.55 \\
$\mathbf{2 0 1 9}$ & 3.55 \\
\hline
\end{tabular}

Nota. Tomado de "Marco Macroeconómico Multianual 2017 - 2019". Ministerio de Economía y Finanzas. Perú. 
Otra variable en la economía es la inflación, la cual según el "Marco Macroeconómico Multianual 2017 - 2019”, se mantendrá con una variación que irá disminuyendo de un 3,1\% estimado para este año 2016 a un valor aproximado del $2 \%$ para el año 2019, tal como se muestra en el Tabla 13.

Tabla 13

Tasa de Inflación 2016-2019

\begin{tabular}{ll}
\hline Año & Inflación \% \\
\hline $\mathbf{2 0 1 6}$ & $3,1 \%$ \\
$\mathbf{2 0 1 7}$ & $2,8 \%$ \\
$\mathbf{2 0 1 8}$ & $2,6 \%$ \\
$\mathbf{2 0 1 9}$ & $2,0 \%$ \\
\hline
\end{tabular}

Nota. Tomado de "Marco Macroeconómico Multianual 2017 - 2019”. Ministerio de Economía y Finanzas. Perú.

Esta situación se considera en el rango normal de variación de precios. Es decir, no se espera un nivel de inflación elevado en el país, lo que permitirá consolidar proyectos de inversión en el país y por consiguiente para el proyecto de creación del colegio.

\subsubsection{Análisis Legal.}

El marco legal vigente que norma y regula las instituciones educativas privadas está conformado por las siguientes Leyes y Reglamentos:

a) Ley N ${ }^{\circ}$. 28044, Ley General de Educación: establecer los lineamientos generales de la educación en el Perú y del sistema educativo en el país. Asimismo, se establece las funciones de las instancias de gestión del sistema educativo peruano y de las instituciones educativas privadas en el país. 
b) Ley No. 26549, Ley de los Centros Educativos Privados: dispones las regulaciones que son aplicables a las actividades de los centros educativos y programas de educación en el país.

c) El Decreto Legislativo Nº 882, Ley de Promoción de la Inversión en la Educación: fija las condiciones y garantías para la inversión privadas en el sector educativo en el país. Esta normatividad se aplica a todas las instituciones privadas en el país vinculadas con la educación.

d) El Reglamento de la Ley General de Educación: establece el proceso de regulación de los lineamientos generales de las actividades educativas según la Ley General de Educación.

e) Reglamento de las Instituciones Privadas de Educación Básica y Educación Técnico Productiva: dispone las normas que regulan la autorización para iniciar, funcionar organizar y gestionar un centro de educación básica y técnica en el país, así como los aspectos a considerar para la supervisión.

f) Normas emanadas del Ministerio de Educación: son aspectos específicos de la educación que dispone el Ministerio de Educación.

Estas normas sustentan los requerimientos a las instituciones educativas privadas por parte de las Direcciones Regionales de Educación y las Unidades de Gestión Educativa Local (UGEL).

La Ley General de Educación (No. 28044, 2003) establece el ámbito normativo para las instituciones educativas del nivel básico en el marco de libertad de enseñanza, señalando que la educación básica es de carácter obligatorio y tiene como finalidad satisfacer las necesidades básicas de aprendizaje de los niños "considerando las 
características individuales y socioculturales de los educandos”. Asimismo, se establece las denominaciones para las instituciones de nivel inicial que son: cuna, jardín y cunajardín.

La Ley General de Educación señala en el artículo $36^{\circ}$ que la “educación inicial cumple la finalidad de promover prácticas de crianza que contribuyan al desarrollo integral de los niños, tomando en cuenta su crecimiento socio afectivo y cognitivo, la expresión oral y artística y la sicomotricidad y el respeto de sus derechos”.

La mencionada ley en su artículo $72^{\circ}$ reconoce a las instituciones educativas carácter privado y señala que la autorización de funcionamiento, de dichas instituciones educativas le corresponde a las Direcciones Regionales de Educación, en coordinación con las Unidades de Gestión Educativa Local. También la UGEL, como instancia de ejecución del Gobierno Regional, tiene entre sus funciones la de encargarse de la continuidad del servicio educativo y del desarrollo del proceso pedagógico a cargo de las instituciones educativas de nivel básico.

Por su parte, en el Reglamento de la Ley General de Educación, se establece además, los sistemas de gestión para guiar a las instituciones sus decisiones técnicoadministrativas en el corto, mediano y largo plazo. Los instrumentos de gestión son:
a) Proyecto Educativo Institucional.
b) Reglamento Interno.
c) Proyecto Curricular de Centro.
d) Cuadro de distribución de horas y de secciones.
e) Plan Anual de Trabajo. 
f) Presupuesto Anual.
g) Informe de Gestión Anual.

Los instrumentos indicados sirven como marco para la formulación, ejecución y control de las actividades de la institución educativa.

Por otro lado, el Ministerio de Educación a través del Reglamento de las Instituciones Privadas de Educación Básica y Educación Técnico Productiva establece las normas que rigen la autorización de funcionamiento, organización, administración y supervisión de las instituciones privadas de Educación Básica. En este reglamento se indica los procedimientos que se deben seguir para solicitar la autorización de un centro educativo de nivel inicial.

Por consiguiente, dado que existe aspectos legales que corresponden al sector de educación y su apoyo a la inversión privada, se considera que la creación de un colegio de educación inicial de carácter privado es factible y cuenta con un respaldo legal que permite su desarrollo.

\subsubsection{Análisis Cultural.}

La demanda por una educación de calidad se debate con más frecuencia en los foros, medios de comunicación, en el gobierno y en general en la sociedad. Existe la necesidad de contar con una educación que prepare para los nuevos retos que se presentarán en el presente siglo y que además los prepare para el trabajo. En el caso de los niños se requiere una educación básica de calidad que les permita tener las bases para una mejor formación en el futuro. 
En el ámbito del hogar, la mujer se ha estado incorporando cada vez más a las actividades laborales fuera del hogar dejando el proceso de formación de sus hijos a otras personas o instituciones. Así, este nuevo contexto determina que los niños deben asistir a las instituciones educativas desde más pequeños como las cunas en donde se inicia su proceso de formación.

Los niños actualmente cuentan con un mayor acceso a juegos e información a través del internet, lo que ha permitido un mayor empoderamiento en su proceso de aprendizaje. En este nuevo escenario la educación se ha orientado hacia la formación de competencias que le permitan al niño continuar con su proceso de aprendizaje de manera continua.

El proceso de globalización ha creado la necesidad entre los padres de familia que sus hijos deben conocer otros idiomas y culturas. Esta nueva demanda ha generado que los colegios implementen programas bilingües a fin que los niños como parte de su aprendizaje logren dominar un segundo idioma.

En el país la delincuencia se ha incrementado, lo que ha causado que las instituciones tengan que tomar una serie de medidas para contrarrestar la inseguridad en las grandes ciudades. Para las instituciones educativas ha implicado aumentar la seguridad a fin de proteger la infraestructura del colegio, del personal que labora, y de los niños que estudian en el lugar. Si bien el nuevo gobierno se ha comprometido a luchar contra la inseguridad ciudadana, la tendencia es que la inseguridad se mantendrá en los siguientes meses ocasionando mayores costos por el incremento de acciones para cuidar la seguridad en las empresas y en las instituciones en general. 
Por tanto, las tendencias culturales tienen un impacto en la creación de un nuevo colegio, dado que se deberán diseñar para tener un rol más activo en la formación de los niños, para desarrollar competencias, para brindarle la preparación en otros idiomas, así como para ofrecerles un mayor nivel de seguridad.

\subsubsection{Análisis Tecnológico.}

Actualmente la tecnología ha logrado, introducir a través de nuevos equipos (computadoras, teléfonos inteligentes, televisión inteligente, tabletas) y de nuevos sistemas de comunicación (multimedia, telemática) de la era digital, cambiar algunas actividades relacionadas con la educación, a fin de que se realice de una manera más descentralizada y de forma asíncrona (el contacto se puede realizar de manera diferida dado que no se requiere que coincidan en el tiempo).

El uso de internet es más frecuente entre los niños lo que permite nuevas formas para comunicarse y relacionarse. También permite contar con una fuente de información inmensa que ofrece a los docentes el acceso a investigaciones a nivel internacional. Otro uso del internet es como soporte para el proceso de aprendizaje, dado que permite completar las actividades académicas y fortalecer el trabajo colaborativo entre los estudiantes.

Así, el uso de nuevos equipos en las actividades diarias y la velocidad del internet que se espera siga creciendo permitirán trasmitir información más rápido y desarrollar nuevos programas académicos para los estudiantes y de vincular con estudiantes de otros colegios del mismo nivel a nivel mundial y de crear redes de 
colaboración entre alumnos, así como para los docentes. Por consiguiente, la incorporación de las Tecnologías de la Información y la Comunicación (TIC) en la educación permitirá generar "una vía para mejorar la calidad de la enseñanza y un camino para dar respuesta a las nuevas exigencias que plantea la sociedad de la información”, (Martín-Laborda, 2005 p. 100).

Asimismo, la nueva tecnología permitirá crear espacios virtuales de modo que la educación no se vea limitada por el espacio y el tiempo que requiere la educación presencial y además facilita que los padres de familia puedan participar de manera activa en el proceso de enseñanza de sus hijos. También la nueva tecnología plantea nuevos retos, como el de contar con profesores que conozcan el uso de las TIC, dado que los alumnos lo usan desde pequeños, y lo apliquen en el proceso de aprendizaje. Además, se requiere que los colegios deben contar con la infraestructura adecuada a fin de aprovechar las ventajas de la comunicación digital.

Por tanto, el uso de la nueva tecnología como soporte al proceso educativo ha generado la necesidad de cambiar el proceso pedagógico y de crear nuevos entornos didácticos a partir de nuevos modelos de formación de los alumnos. En general el uso de las TIC en la educación ha generado un nuevo ambiente para la formación continua a partir de la creación de ambientes virtuales para el aprendizaje. 


\subsubsection{Análisis Ecológico.}

La sociedad actualmente está más preocupada por el cuidado y la conservación del ambiente. Este cuidado por el medio se estima crecerá en el futuro como una demanda social a las instituciones de toda índole

En este contexto, las instituciones educativas deberán enfocarse a lograr que sus estudiantes tomen conciencia sobre el cuidado del ambiente mediante la implementación de cursos en su currículo que traten temas relacionados con la preservación del ambiente.

\subsection{Oportunidades y amenazas}

El análisis del entorno ha permitido detectar algunas oportunidades que fortalecen la iniciativa de crear un colegio de educación inicial.

a) Existe un clima favorable a la inversión privada que está promoviendo el nuevo gobierno.

b) La economía en el país está creciendo lo que determina que la población goce de un mayor poder adquisitivo.

c) El país cuenta con un marco legal que regula la autorización para la creación de nuevos colegios de educación inicial.

d) La tecnología permite que se desarrollen nuevos programas orientados a plantear nuevas alternativas para la educación inicial.

e) La tecnología permite crear nuevos entornos para el aprendizaje y espacios para la participación de los padres de familia. 
f) La mejora en la calidad de la educación es considerada como prioritaria en el nuevo gobierno, facilitando de esta manera la creación de nuevas instituciones educativas iniciales que cumplen con los estándares de calidad.

g) El cuidado del medio ambiente permite crear nuevos programas en los colegios de educación inicial a fin que los niños tomen conciencia desde muy temprana edad.

h) Los costos de los factores que permiten prestar el servicio permanecerán sin cambios debido a una inflación mínima.

i) El avance en la tecnología permite la creación de nuevos programas educativos a fin de fortalecer el proceso de enseñanza.

Asimismo, este análisis ha permitido detectar algunas amenazas que podrían afectar el desarrollo del Colegio:

a) La inseguridad ciudadana que determina que los padres de familia estén al pendiente de sus hijos.

b) La situación política del país dado que el poder legislativo se encuentra en manos de la oposición.

c) La incertidumbre sobre las nuevas políticas en educación y tributaria implementar por el gobierno.

d) La falta de definición de las políticas económicas que implementara el nuevo gobierno.

e) La posibilidad que algunos colegios de Lima deseen ampliar sus operaciones en ciudades de provincia.

A partir del análisis anterior se puede señalar que existen oportunidades que se deben aprovechar a fin de iniciar un colegio de educación inicial en la ciudad de Chiclayo. 
1. Análisis externo: integración vertical de los colegios

Se incluye en la matriz EFE la posibilidad que algunos colegios de primaria y secundaria puedan integrarse hacia atrás y de esta manera ofrecer el servicio educativo, lo que podría constituir una amenaza para el nuevo colegio.

Tabla 14

Matriz EFE

Factores externos clave

Ponderación Calificación Puntuación

Ponderada

Oportunidades

Crecimiento de la economía del país

$0.20 \quad 3 \quad 0.60$

Clima favorable para la inversión

$\begin{array}{lll}0.05 & 4 & 0.20\end{array}$

Nuevas tecnologías para la educación

$0.10 \quad 4$

0.40

Nuevo gobierno impulsa programas para

0.05

3

0.15

mejorar la educación

Costo de los equipos y mobiliario tendrán

0.10

3

0.30

una ligera variación en el precio

Amenazas

Inseguridad ciudadana

0.20

2

0.40

Incertidumbre sobre la nueva política en

0.05

2

0.20

educación

Falta definir e implementar nuevas

0.05

2

0.20

políticas económicas

Integración Vertical hacia atrás de algunas

0.10

1

0.10

instituciones educativas

Colegios de otras regiones se instalen en

0.10

1

0.10

Chiclayo

\begin{tabular}{lll}
\hline Total & 1.0 & 2.65 \\
\hline
\end{tabular}

El resultado muestra que las instituciones educativas en la Ciudad de Chiclayo de nivel inicial están preparadas para enfrentar los cambios del entorno, es decir pueden aprovechas las oportunidades que se presentaran en el futuro. 


\section{Capítulo III \\ Estudio de mercado}

\subsection{Descripción del servicio o producto}

El servicio a desarrollar es un colegio de educación inicial para niños entre tres a cinco años localizado en la ciudad de Chiclayo. El colegio será una institución privada que estará enfocado a brindar un servicio educativo a los niños.

El colegio de educación inicial a formar tendrá las siguientes características:

a) Cuenta con una infraestructura adecuada de un colegio de educación inicial (apoyo de un psicólogo, salas de juego que apoyen el aprendizaje, un biohuerto, biblioteca especial para niños).

b) Los docentes estarán certificados en educación inicial con licenciatura de universidad.

c) Contará con un modelo de aprendizaje basado en el desarrollo de competencias de los niños de tres a cinco años. El modelo está basado en la participación activa de los niños durante su proceso de aprendizaje que se orienta al desarrollo de sus habilidades.

d) Los salones de clase estarán diseñados para un máximo de 25 alumnos. Esta cantidad de alumnos permitirá un mejor proceso de aprendizaje y un servicio educativo más personalizado.

e) Se aplicará tecnología de punta permitiendo a los padres de familia observar a sus hijos mediante cámaras de videos con un software instalado en sus teléfonos celulares, así mismo recibirán información a través de sus correos electrónicos sobre el comportamiento y avances de sus niños. 
f) Se realizarán reuniones con los docentes y padres de familia vía Skype.

g) Se brindará clases en idioma inglés, con docentes especialistas en aulas multimedia que cuentes con un software especializados para un mejor aprendizaje para los niños.

h) Permite la participación de los padres de familia en el desarrollo del niño en colaboración con los docentes del colegio, en actividades festivas durante el año escolar.

\subsection{Selección del segmento de mercado}

El colegio de educación inicial estará enfocado a padres de familia de los niveles socioeconómico $\mathrm{A} / \mathrm{B}$ que residan en la ciudad de Chiclayo, que tengan niños entre dos y cuatro años y que estén interesados en contar con el servicio de educación inicial para sus hijos. En general, los padres de familia a los que se planea ofrecer el servicio del colegio inicial son personas entre 26 a 35 años de edad y que valoran la calidad de la educación para sus hijos.

Según la Sociedad Peruana de Empresas de Investigación de Mercado ([APEIM],2014), la familia de este nivel socioeconómico en la zona urbana de la región Lambayeque son un $13.6 \%$ del total de la población. Las personas entre la edad de 26 a 35 años son de un $11.7 \%$ en el nivel A y de un $13.1 \%$ en el nivel B. El promedio general de ingreso mensual de la familia del nivel $\mathrm{AB}$ es de 6,266 soles, de los cuales destina al rubro de esparcimiento, diversión, servicios culturales y de enseñanza 509 soles en promedio. Casi un $50 \%$ de las personas de este nivel labora como trabajador dependiente. 
Con relación al uso de Internet, más de un $90 \%$ de las personas se comunica a través de este medio (correo electrónico, chat, entre otros) desde su hogar en primer lugar y como segunda alternativa lo hace desde su centro laboral.

\subsection{Investigación Cualitativa}

La investigación cualitativa es una metodología que está orientada a obtener datos y un conocimiento descriptivo del problema de investigación, a partir de la observación de la comunicación verbal y no verbal de las personas que están vinculadas al contexto de la investigación. La investigación cualitativa "es de naturaleza exploratoria y no estructurada, se basa en pequeñas muestras”. (Malhotra,2008, p.42) Las técnicas cualitativas más comunes son las entrevistas a profundidad y las reuniones de grupo (focus group).

En la investigación cualitativa realizada en este estudio se llevaron a cabo reuniones o "focus group" con los padres de familia relacionados o interesados en el servicio de educación inicial, y también se llevaron a cabo entrevistas a profundidad con expertos en este nivel de educación. Así, se han realizado cuatro focus group con un promedio de seis a ocho participantes. Dos de ellos fueron con padres de familia que tienen hijos en un colegio inicial a fin de conocer su experiencia con el servicio, mientras que las otras dos reuniones se llevaron a cabo con padres de familia que están planeando matricular a sus hijos en un colegio de educación inicial. También se realizaron cuatro entrevistas de profundidad, considerando a los siguientes expertos:

a) Especialista en educación inicial de la UGEL.

b) Expertos del sector (directores de colegio inicial). 
c) Docente de colegio inicial.

Los objetivos planteados para la investigación cualitativa fueron:

a) Conocer las variables que inciden en el comportamiento de compra del servicio de los padres de familia que buscan un colegio de educación inicial.

b) Identificar el perfil de los padres de familia que buscan un colegio inicial con relación a sus características personales y familiares.

c) Identificar las características de un colegio de educación inicial en relación con los requerimientos del servicio que son demandados por los padres de familia

d) Validar la demanda del servicio de un colegio de educación inicial para padres de familia de nivel socioeconómico A/B.

\subsubsection{Proceso de muestreo.}

\section{Focus group.}

A fin de seleccionar a los participantes en el focus group se consideró el perfil del cliente que se detalla en la ficha técnica para este estudio, según se muestra en el Anexo 2 y 3. A partir de la definición del perfil cliente, la invitación se realizó a un grupo de padres de familia de los niveles socioeconómicos A y B, que demandan un colegio privado de educación inicial y que cumplen con las siguientes características:

a) Grupo de padres de familia con experiencia: que tienen un hijo cursando educación inicial en un colegio de la localidad, motivo por el cual se considera que conocen por experiencia personal directa el servicio al alumno. Estos padres de familia tienen un ingreso familiar de más de seis mil soles mensuales. 
b) Grupo de padres de familia si experiencia: que no tienen actualmente niños matriculados en un colegio inicial, pero que están interesados en contar con el servicio de educación inicial para sus hijos entre dos y cuatro años en el siguiente año. Estos padres de familia tienen un ingreso familiar de más de seis mil soles mensuales.

\section{Entrevistas a profundidad.}

Se realizó las entrevistas a cuatro expertos según el perfil. (Ver anexo 2, 3 y 4). Así, se realizó la invitación a expertos en el tema de educación inicial, que cumplían con el siguiente perfil:

a) Personas que investiguen o cuenten con experiencia laboral en la enseñanza y/o gestión de colegios de educación inicial. La experiencia que se requiere para ser considerado experto debe ser como mínimo diez años y que además debía ser reconocido en el medio por sus aportes en el ámbito de la educación básica.

\subsubsection{Diseño de instrumento.}

Para el focus group se utilizó la guía de pautas la cual consta de las fases de presentación, calentamiento y listado de preguntas. En el caso de la entrevista a los expertos se usó un cuestionario la cual comienza con la fase de presentación y luego las preguntas relevantes sobre el sector, normatividad, mercado, servicio.

Los temas que se plantearon como preguntas a los padres de familia durante la sesión del focus group son las siguientes: (Ver anexo 2 y 3). 
a) Comportamiento de compra del servicio: frecuencia de compra, uso del servicio en otros colegios, beneficios percibidos de un colegio de educación inicial, comunicación que han recibido de otros colegios iniciales de la localidad, medios donde investiga sobre colegios iniciales.

b) Características del servicio: características deseadas del colegio de educación inicial (horario, monto de pago de la mensualidad de enseñanza, participación de los padres como apoyo durante la formación del niño, calidad de la enseñanza deseada, calidad de los docentes del colegio requerido).

c) Aceptación del servicio. aceptación del servicio del colegio inicial propuesto de modo que se pueda establecer una percepción de la demanda para el colegio.

Para el caso de las entrevistas a profundidad, Los temas que se plantearon como preguntas a los expertos durante las entrevistas fueron las siguientes: (Ver Anexos 1,4, $5)$.

a) Estructura del sector: colegios de educación inicial existentes y la manera en que compiten, características de los usuarios del servicio, estrategias predominantes de la empresas en el sector, requerimientos del Ministerio de Educación, requerimientos de otros sectores (como INDECI, Municipalidad, entre otros), barreras existente en el sector para nuevos ingresantes, posicionamiento de los colegios de educación inicial en la ciudad de Chiclayo, forma de publicidad que realizan, promociones que llevan a cabo los colegio del sector en Chiclayo, programa de lealtad de los colegios para los padres de familia.

b) Características del servicio: características del servicio que ofrecen los colegios de educación inicial (horarios de los colegios, medios para el pago de la mensualidad, monto promedio de la mensualidad que cobran los colegios de este nivel en 
Chiclayo, calidad de la enseñanza, modelo de enseñanza predominante, certificación de los docentes del colegio de educación inicial en Chiclayo).

c) Demanda: nivel de demanda existente para colegios de educación inicial, sectores de la población que demandan educación inicial privada, el tipo de comunicación que buscan recibir los padres por parte de los colegios, proceso de selección de un colegio inicial por parte de los padres de familia.

d) Tendencias: modelos educativos existentes, nuevos modelos educativos para la educación inicial, nuevas características de los colegios de educación inicial, uso de la tecnología en la educación inicial, nuevos requerimientos por parte de las entidades del gobierno para este tipo de colegio, nuevas demandas sociales para los colegios de este nivel.

\subsubsection{Análisis y procesamiento de datos.}

El procesamiento de los datos obtenidos de los focus group o entrevistas a profundidad se llevó a cabo considerando los siguientes pasos:

a) Se transcribió lo que expresó cada uno de los participantes durante la sesión del focus group o durante la entrevista a profundidad.

b) Luego, en las matrices individuales se colocaron los datos obtenidos por cada persona con relación a las variables de interés del estudio.

c) Finalmente, se realizó la suma de las respuestas de cada una de las variables de las matrices individuales y se presentan los resultados en la matriz resumen tal como se puede ver en las tabla 15 y 16 . 
Tabla 15

Respuestas individuales en el focus group de un participante con hijos en un colegio

\section{Respuestas}

\section{Conocimiento del servicio}

Quien toma la decisión en la familia para el colegio que asiste (ió) su hijo

Educación personalizada, con

Aspectos que valoró para seleccionar el colegio ambientes acogedores y seguros para ellos

Actividades para los padres de familia que realizan en el colegio

Motivos de satisfacción con el colegio Modalidad de pago de la mensualidad del colegio

Monto total (mensual) que pago al colegio Razones para cambiar su hijo a otro colegio
La experiencia es buena

Efectivo

No cuenta con taller de ballet $\mathrm{u}$ otros

\section{Conocimiento de la competencia}

Aspectos que le agradó de los colegios que visitó

Aspectos que no le agradó de los colegios que visitó

Razones para considerar los mejores colegios de educación inicial

Razones para no considerar a los colegios como los mejores
Lo que buscaron era una atención con un menor número de alumnos por aula

\section{Características del servicio}

Factores del servicio al alumno que son importantes para seleccionar un colegio

Factores del servicio al padre que son importantes para seleccionar un colegio

Factores determinantes considerados para seleccionar un colegio

Certificación en educación inicial de los docentes del colegio

Razones si considera que el colegio inicial debe estar integrado con uno de primaria

Modo en que lleva su hijo al colegio

El mismo o su esposa

Distancia que recorre para llevar su hijo al colegio

Zonas de recreación, que puedan practicar deportes

Seguridad y docentes capacitados 
El colegio debe ser bilingüe

\section{Características del Colegio Presentado}

Motivo para seleccionar este colegio en caso de estar funcionando

Monto de pago mensual que estaría dispuesto a pagar

Forma de pago deseada de la mensualidad del colegio

Debitado de una cuenta

Factores determinantes para cambiar a su hijo a este colegio

Lo que no le gusta del colegio

Diferencias entre el colegio actual de su hijo y el colegio presentado

La metodología de clases

Diferencias entre otros colegios y el colegio presentado

Existen colegios similares al presentado en la ciudad de Chiclayo

Los docentes capacitados en primeros auxilios

Mejoras sugeridad para el colegio presentado

Medio de comunicación de preferencia para

recibir información sobre el colegio

Interés en recibir promoción o publicad del

colegio presentado

Habría seleccionado este colegio para su hijo

Tabla 16

Respuestas individuales en el focus group de los participantes sin hijos en un colegio

Respuestas

\section{Conocimiento del Servicio}

Planea matricular a su hijo(s) en un colegio inicial

$\mathrm{Si}$

Quien tomará la decisión en la familia para el colegio que asistió su hijo

Aspectos que valora para seleccionar el colegio

Pareja

Respeto y amistad entre los niños

\section{Conocimiento de la competencia}

Aspectos que le agradó de los colegios que visitó

Infraestructura y calidad de docentes

Aspectos que no le agradó de los colegios que visitó

Sin áreas de recreación 
Razones para considerar los mejores colegios de educación inicial

Santa Ángela (infraestructura)

Razones para no considerar a los colegios como los mejores

Razones para seleccionar un colegio para su hijo

Plana docente y áreas de recreación

\section{Características del servicio}

Factores del servicio al alumno que son importantes para seleccionar un colegio

Factores del servicio al padre que son importantes para seleccionar un colegio

Factores determinantes considerados para seleccionar un colegio Certificación en educación inicial de los docentes del colegio Si todos los docentes certificados

Razones si considera que el colegio inicial debe estar integrado con uno de primaria Modo en que lleva su hijo al colegio Distancia que recorre para llevar su hijo al colegio El colegio debe ser bilingüe Si debe ser bilingüe

\section{Características del Colegio Presentado}

Motivo para seleccionar este colegio en caso de estar funcionando Inclusión de niños especiales

Monto de pago mensual que estaría dispuesto a pagar 400

Forma de pago deseada de la mensualidad del colegio

Factores determinantes para matricular a su hijo a este colegio

Infraestructura y metodología

Lo que no le gusta del colegio No se evidencia área de enfermería o tópico

Diferencias entre el colegio seleccionado

para su hijo y el colegio presentado Diferencias entre otros colegios y el colegio Espacios de recreación presentado

Existen colegios similares al presentado en la ciudad de Chiclayo Mejoras sugeridas para el colegio presentado Medio de comunicación de preferencia para recibir información sobre el colegio Virtual Interés en recibir promoción o publicad del colegio presentado 
Seleccionaría este colegio para su hijo

Los resultados del focus group se muestran en las Tablas 17 y 18. Estos resultados permiten reconocer las características que consideran conveniente los padres de familia en el servicio de educación inicial. Las variables del estudio cualitativo sirven de base para elaborar el cuestionario de la investigación cuantitativa.

Los resultados muestran que los aspectos que valoran los padres de familia para seleccionar un colegio son la infraestructura y la cercanía. Respecto a las actividades consideradas para los padres se tiene fundamentalmente las reuniones de padres en donde el docente da a conocer sobre las actividades de los alumnos buscando la integración entre alumnos y padres de familia en el proceso de aprendizaje.

Otro resultado importante es la enseñanza del idioma inglés, al cual los padres solo desean que se imparta clases en ingles pero no desean que el programa sea bilingüe. Respecto a la atención del niño se busca que exista atención psicológica constituyéndose en un elemento clave en el servicio.

Finalmente, en ambos casos (padres con hijos en educación inicial y los padres que aún no tienen matriculados a sus hijos) desean que se les envié la comunicación del nuevo colegio a través del correo electrónico. 
Tabla 17

Resumen respuestas de padres de familia con hijos en colegio de educación inicial

Componentes

Variable

Total Respuestas

\section{Conocimiento del servicio}

Quien toma la decisión en la familia para el colegio que asiste (ió) su hijo

Persona que decide sobre - Padres: 6

el colegio $\quad$ Con ayuda de abuelos: 1

- Cercanía al hogar: 3

Aspectos que valoró para seleccionar el colegio

Aspectos para la selección - Infraestructura: 3 del colegio

- Vigilancia: 1

Actividades para los padres de familia que realizan en el

Actividades para los

colegio

padres de familia

- Reunión de padres: 7

Modalidad de pago de la

mensualidad del colegio

Modalidad de pago actual $\bullet$ Mensual: 7

Monto total (mensual) que se

pagó al colegio

Precio del servicio actual • Entre 300 y 400: 7

\section{Características del servicio}

Factores del servicio al alumno que son importantes para seleccionar un colegio

Servicio al alumno

- Talleres: 4

- Psicología: 3

Factores del servicio al padre

que son importantes para seleccionar un colegio

Servicio al padre de familia

- Escuela de padres: 5

- Reunión de integración: 2

Factores determinantes considerados para seleccionar un colegio

Criterios de selección de un colegio

- Cercanía al hogar: 3

- Infraestructura: 4

Certificación de los

docentes

- Importante: 7

Razones si considera que el

colegio inicial debe estar integrado con uno de primaria

Integración con colegio de primaria

- Importante: 3

- No importante: 4

- Taxi: 3

- Movilidad propia: 2

- A pie: 2
Medio de transporte al colegio 
al colegio

- En vehículos 5 a 10 minutos:

2

- En vehículo más de 10 minutos: 3 
- A pie 5 a 10 minutos: 2

- No es importante ser bilingue

- Como talleres o clases de cuatro horas semanales: 2

- Como talleres o clases de más de cuatro horas

El colegio debe ser bilingüe Enseñanza Bilingüe semanales: 5

\section{Características del Colegio Presentado}

Motivo para seleccionar este

colegio en caso de estar

funcionando

Monto de pago mensual que

estaría dispuesto a pagar

Forma de pago deseada de la mensualidad del colegio

Factores determinantes para

cambiar a su hijo a este colegio

Lo que no le gusta del colegio Aspectos a modificar

Diferencias entre el colegio

actual de su hijo y el colegio presentado

Diferencias entre otros colegios y el colegio presentado

Mejoras sugeridas para el

colegio presentado

Medio de comunicación de preferencia para recibir información sobre el colegio
Diferencias con colegio seleccionado

Motivos para seleccionar colegio

Precio

Forma de pago

Factores para matricular en el colegio

Diferencias con otros colegios

Aspectos a mejorar
- Propuesta innovadora: 3

- Infraestructura: 4

- Número de talleres: 2

- Entre 300 y 350: 2

- Entre 351 y 400: 3

- Más de 400: 2

- Debitado en cuenta: 7

- Docentes certificados: 5

- Los talleres: 4

- Áreas verdes: 3

- Acceso a movilidad certificada: 4

- Las aulas deben ser más amplias: 5

- Ser de un solo piso: 7

- Aulas coloridas: 4

- Áreas verdes dentro del colegio: 5

- Talleres y Deportes: 4

- Área de Piscología: 3

- Clases de Inglés: 4
- correo electrónico: 3

- Internet: 2

- Otros medios: 2 
Interés en recibir promoción o publicad del colegio Interés en recibir presentado publicidad - Si: 7

Habría seleccionado este colegio para su hijo Aceptación del servicio $\quad$ Si: 7

Tabla 18

Resumen (Padres de Familia sin hijos en Colegio de Educación Inicial)

Componentes Variable Total Respuestas

\section{Conocimiento del servicio}

Quien toma la decisión en la familia Persona que decide para el colegio que asiste (ió) su hijo sobre el colegio

Aspectos que valoró para seleccionar el colegio

Aspectos para la selección del colegio

Actividades para los padres de familia familia que realizan en el colegio

Modalidad de pago de la mensualidad del colegio actual

Monto total (mensual) que se pagó al colegio

Precio del servicio actual
- Infraestructura: 1

- Cercanía: 3

- Recomendación: 1

- Trato personalizado: 1

- Reunión de padres: 6

- Efectivo: 4

- Debitado de cuenta de ahorros: 2

- Entre 300 y 450: 7

\section{Características del servicio}

Factores del servicio al alumno que son importantes para seleccionar un colegio

Factores del servicio al padre que son importantes para seleccionar un colegio
Servicio al alumno

Servicio al padre de familia

- Actividades

extracurriculares: 2

- Infraestructura y áreas verdes: 3

- Juegos recreativos: 4

- Docentes capacitados: 3

- Infraestructura adecuada: 2

- Inculcan valores: 1

Criterios de selección de un colegio
- Seguridad: 5

- Cercania a domicilio: 2 
Certificación en educación inicial de los docentes del colegio

Razones si considera que el colegio inicial debe estar integrado con uno de primaria

Modo en que lleva su hijo al colegio

Distancia que recorre para llevar su hijo al colegio

El colegio debe ser bilingüe
Certificación de los docentes
- Docente certificado: 6

- Auxiliar certificado: 4
Integración con colegio - Si: 3

de primaria $\quad$ No: 4
Distancia al colegio

Enseñanza Bilingüe
- A pie: 2

- Vehículo: 5

- De 5 a 10 minutos: 3•

De 10 a 20 minutos: 4

- Si: 0

- No: 7

- Talleres de Ingles: 7

\section{Características del Colegio Presentado}

\begin{abstract}
Motivo para seleccionar este colegio en caso de estar funcionando

Monto de pago mensual que estaría

dispuesto a pagar

Forma de pago deseada de la mensualidad del colegio
\end{abstract}

Factores determinantes para cambiar a su hijo a este colegio

Lo que no le gusta del colegio

Diferencias entre el colegio actual de su hijo y el colegio presentado

Diferencias entre otros colegios y el colegio presentado

Mejoras sugeridas para el colegio presentado
Motivos para
seleccionar colegio

Precio

Forma de pago

Factores para matricular en el colegio

Aspectos a modificar

Diferencias con colegio seleccionado

Diferencias con otros colegios

Aspectos a mejorar
- Inclusión de los niños: 3

- Talleres: 4

- De 250 a 300 soles: 2

- De 301 a 350 soles: 3

- De 351 a 400 soles: 2

- Debitado de cuenta de ahorros: 5

- Transferencia electrónica: 2

- Infraestructura: 4

- Áreas Verdes: 2

- Integración: 1

- Tamaño de las aulas: 2

- Falta de seguridad: 2

- Espacio de las aulas: 3

- Infraestructura: 4

- Talleres: 3

- Área de enfermería psicopedagogía deben ser permanentes

- Juegos interactivos deben estar fuera del salón 
Medio de comunicación de preferencia para recibir información sobre el colegio Interés en recibir promoción o publicad del colegio presentado
Medio de

comunicación para recibir información

Interés en recibir publicidad
- correo electrónico: 7

- Si: 7

Habría seleccionado este colegio para su hijo

Aceptación del servicio $\bullet \mathrm{Si}: 7$

\subsection{Investigación Cuantitativa}

La investigación cuantitativa según Malhotra (2008), es una "metodología de investigación que busca cuantificar los datos y que, por lo general, aplica algún tipo de análisis estadístico”. (p.143) Por consiguiente, se puede señalar que la investigación cuantitativa busca cuantificar los datos obtenidos a partir de algún análisis estadístico. La técnica más usada en ésta investigación es la encuesta, la cual se usará en este estudio. El instrumento que corresponde a esta técnica es el cuestionario.

Los objetivos de la investigación cuantitativa son:

a) Determinar la demanda existente del servicio de un colegio de educación inicial para sus hijos entre tres a cinco años.

b) Indagar sobre la aceptación del colegio de educación inicial propuesto por parte de los padres de familia.

c) Determinar los factores que toman en cuenta los padres de familia para seleccionar un colegio de educación inicial.

d) Identificar el perfil de los padres de familia que buscan un colegio inicial para sus hijos entre tres a cinco años.

e) Identificar las características de un colegio de educación inicial que consideran como fundamentales con relación a los padres de familia. 


\subsubsection{Proceso de muestreo.}

La investigación es no experimental, ya que no se manipularon variables para obtener un resultado y es de tipo transversal, en tanto los datos se obtuvieron a partir de una encuesta en un momento dado del tiempo (octubre 2016).

Asimismo, el estudio es de tipo exploratorio dado que no hay investigaciones similares referentes para la apertura de un colegio inicial para niños entre tres a cinco años aplicados en la ciudad de Chiclayo y en el cual se busca identificar las características y la aceptación por parte de los padres de familia que envían a sus hijos a un colegio de educación inicial.

No se usaron estratos de la muestra dado que no se esperaba un comportamiento distinto de la población por edad o por nivel socioeconómico con relación a las variables del servicio.

\section{Población.}

Esta dado por el total de familias en los niveles socioeconómico $\mathrm{AB}$ que residen en la zona urbana de la ciudad de Chiclayo (Distrito de Chiclayo, Distrito, y cuya edad promedio está entre 26 a 35 años.

a) Población de los distritos de Chiclayo, José Leonardo Ortiz y La Victoria de la ciudad de Chiclayo INEI (2014): 575,555.

b) Población en rango de edad 26 a 35 años APEIM (2014): 13.7\%.

c) Población en estado civil o conviviente APEIM (2014): 47.1\%. 
d) Población en nivel socioeconómico AB APEIM (2014): 11.7\%.

Con estos datos el total de la población es:

Total de población $=575,555 * 0.137 * 0.471 * 0.117$

Total de la población: 4,346 personas

Por tanto, la población se considera finita. Por consiguiente, el tamaño de la muestra lo podemos calcular mediante la siguiente formula:

$\mathrm{n}=\mathrm{N} * \mathrm{Z}^{2} * \mathrm{p} * \mathrm{q} /\left[\mathrm{e}^{2 *}(\mathrm{~N}-1)+\mathrm{Z}^{2 *} \mathrm{p} * \mathrm{q}\right]$

donde:

Total de la población $(\mathrm{N}):$ 4,346

Probabilidad de ocurrencia (p): 0.50

Probabilidad de no ocurrencia (q): 0.50

Nivel de confianza del 95\% $(Z)=1.96$

Grado de error (e): 0.05

Reemplazando datos, se tiene:

$\mathrm{n}=4,346 * 0.50 * 0.50 /\left[0.05^{2} *(2,203-1)+1.96^{2} * 0.50 * 0.50\right]$

$\mathrm{n}=354$ 
Con estos datos se calculó que el tamaño de la muestra debe ser de 354 personas a quienes se les aplicará la encuesta. Dado que podría ocurrir algún error durante la aplicación de la encuesta (preguntas no respondidas, doble respuesta, entre otras) se aplicará un $10 \%$ más de encuestas. Por tanto, el número de encuesta a aplicar será de 390 encuestas.

\section{Selección de la muestra.}

Para la selección de los elementos de la muestra se planeó realizarlo de manera aleatoria. Sin embargo, dado que existieron dificultades en la selección de la muestra para la aplicación de la encuesta se realizó un muestreo por conveniencia. De este modo, la encuesta se aplicó a los padres de familia que tienen sus hijos en las cunas de los distritos indicados.

\subsubsection{Diseño de instrumento.}

\section{Cuestionario.}

Para la recolección de los datos se construyó un cuestionario (Ver Anexo 13) Este instrumento elaborado contiene 23 preguntas cuyas opciones de respuestas en general se presentan en una escala Likert. Las preguntas son, principalmente, cerradas y se incorporaron algunas preguntas semi-abiertas con la finalidad de captar información adicional relevante. 


\subsubsection{Análisis y procesamiento de datos.}

Los resultados de la encuesta se obtienen luego del procesamiento de la información. A partir de estos resultados se han elaborados algunas gráficas para mostrar los principales resultados con relación a las variables del estudio.

\section{Visitas a Colegios.}

Se preguntó a las personas entrevistadas si han visitado algún colegio inicial para matricular a su hijo. De total de encuestados un $68.88 \%$ han visitado colegios, mientras que un $31.12 \%$ no han visitado ningún colegio, según se muestra en la Figura 5. Los colegios iniciales más visitados han sido los colegios Manuel Pardo y Santa Ángela. (Ver Figura 6).

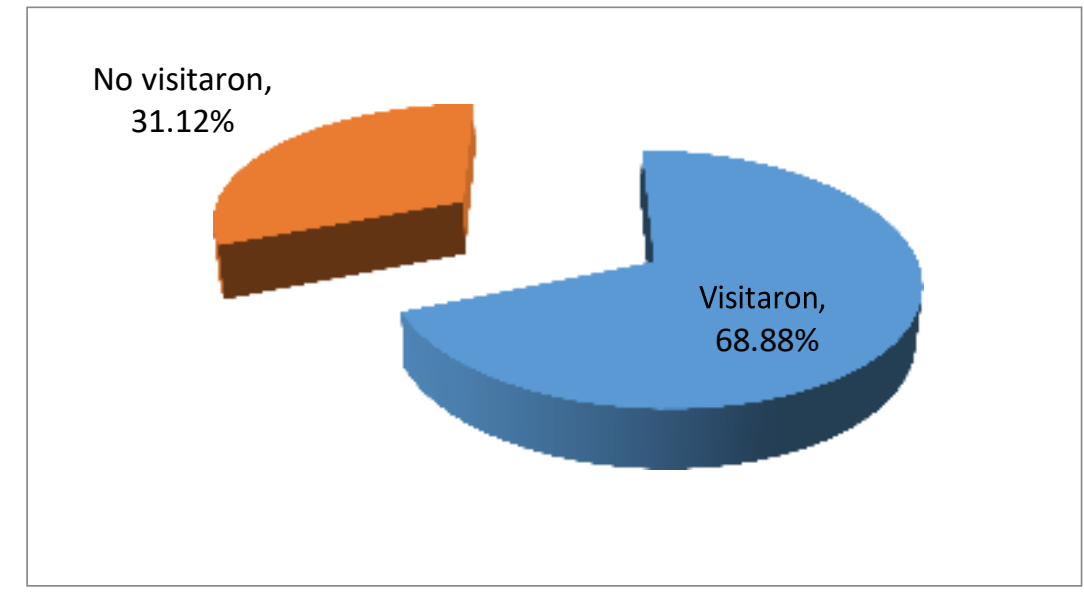

Figura 5. Visitas a Colegios 


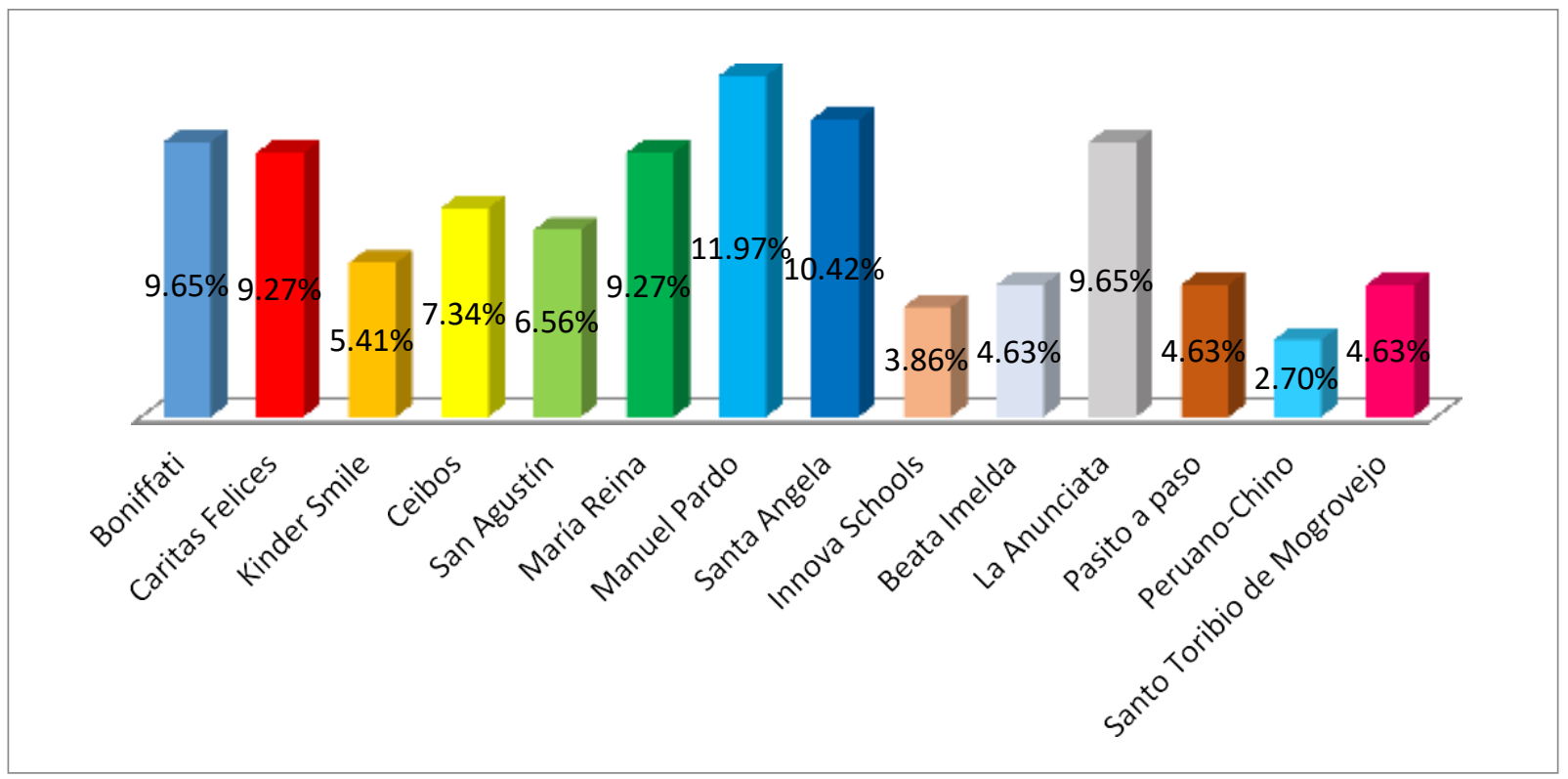

Figura 6. Colegios Visitados

\section{Colegios seleccionados.}

Respecto a los colegios seleccionados para matricular se tiene que los entrevistados prefieren en mayor proporción a los Colegios Caritas Felices con un 10,64\%, Ceibos con un $10.37 \%$ y al María Reina con un $9.57 \%$ junto con el Colegio Pasito a Paso para matricular a sus hijos, tal como se muestra en la Figura 7.

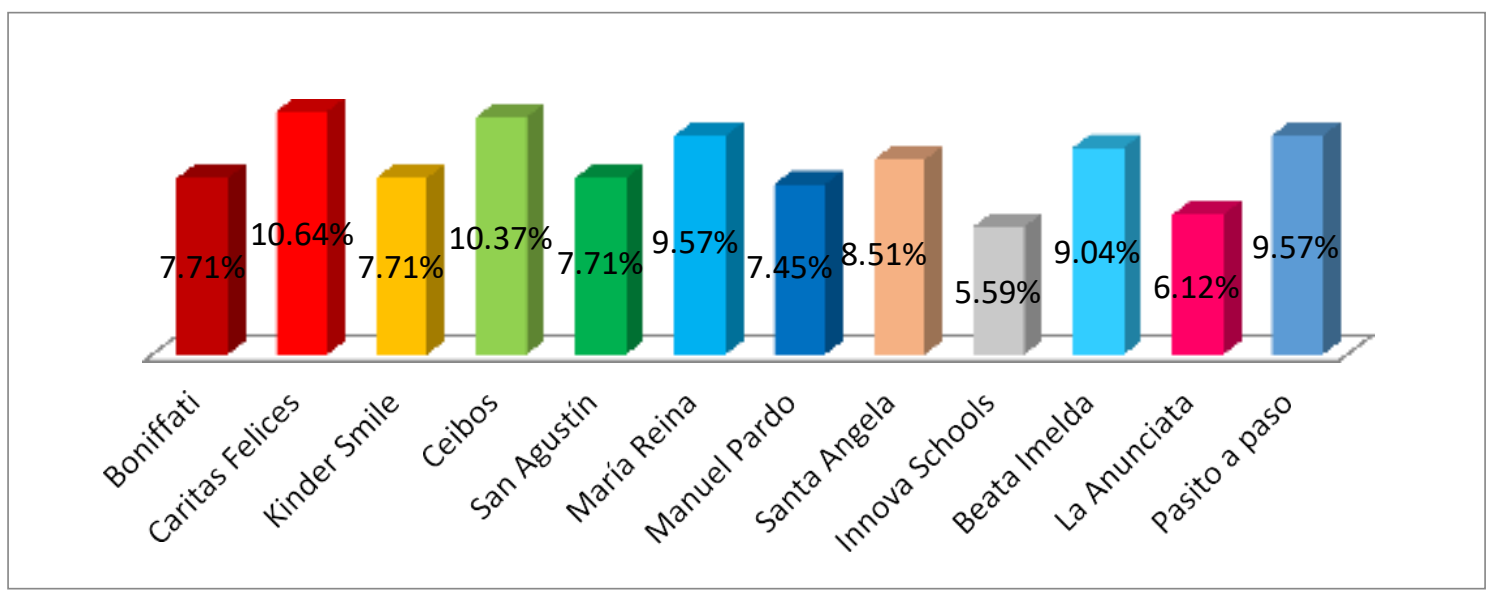

Figura 7.Colegios Seleccionados 


\section{Característica del colegio seleccionada que más valora.}

Respecto a esta variable, la característica más valorada fue el número de alumnos por salón con una calificación promedio de 7.69. El segundo lugar fue el servicio al padre de familia con una calificación promedio de 7.63, tal como se puede apreciar en la Figura 8.

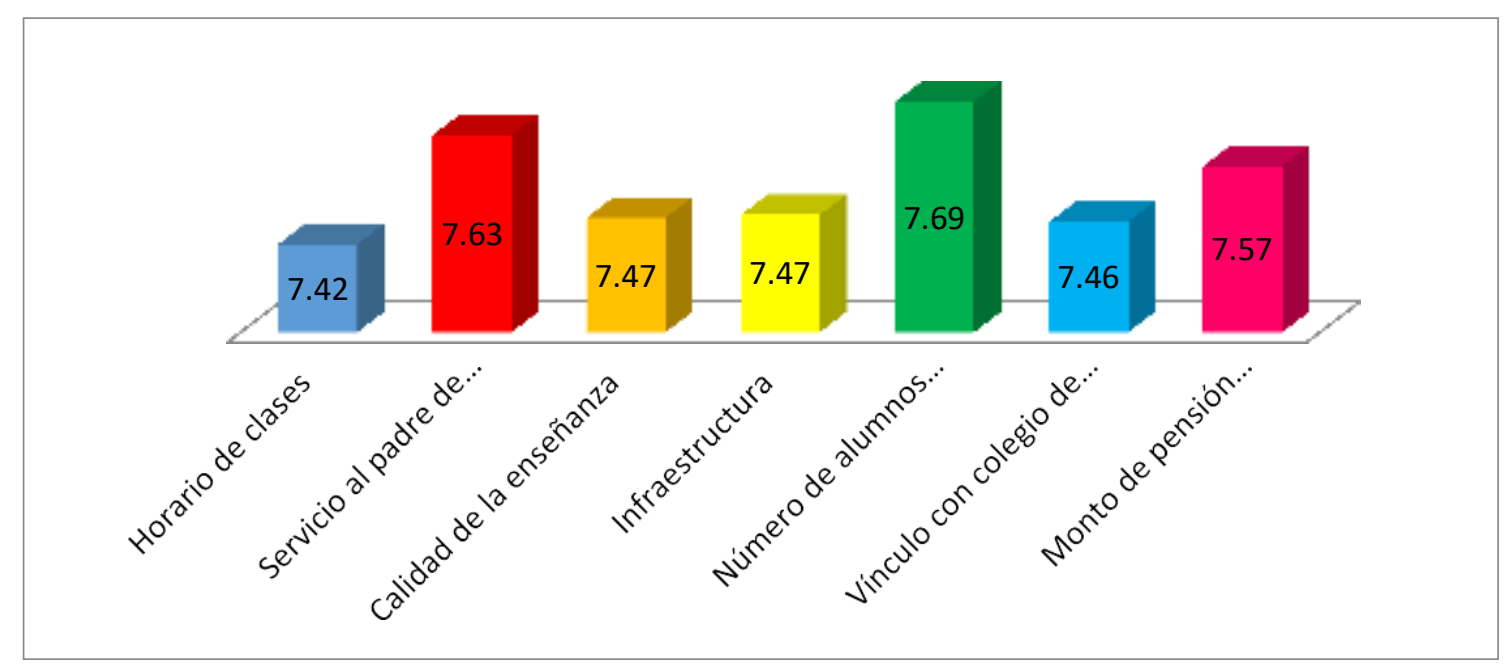

Figura 8. Característica más valorada

\section{El mejor colegio de la ciudad de Chiclayo.}

Según un $22.34 \%$ de los entrevistados el mejor Colegio Inicial en la ciudad de Chiclayo es el Colegio Ceibos, mientras que el Colegio San Agustín con 19.41\% se ubica en el segundo lugar, tal como se puede ver en la Figura 9. 


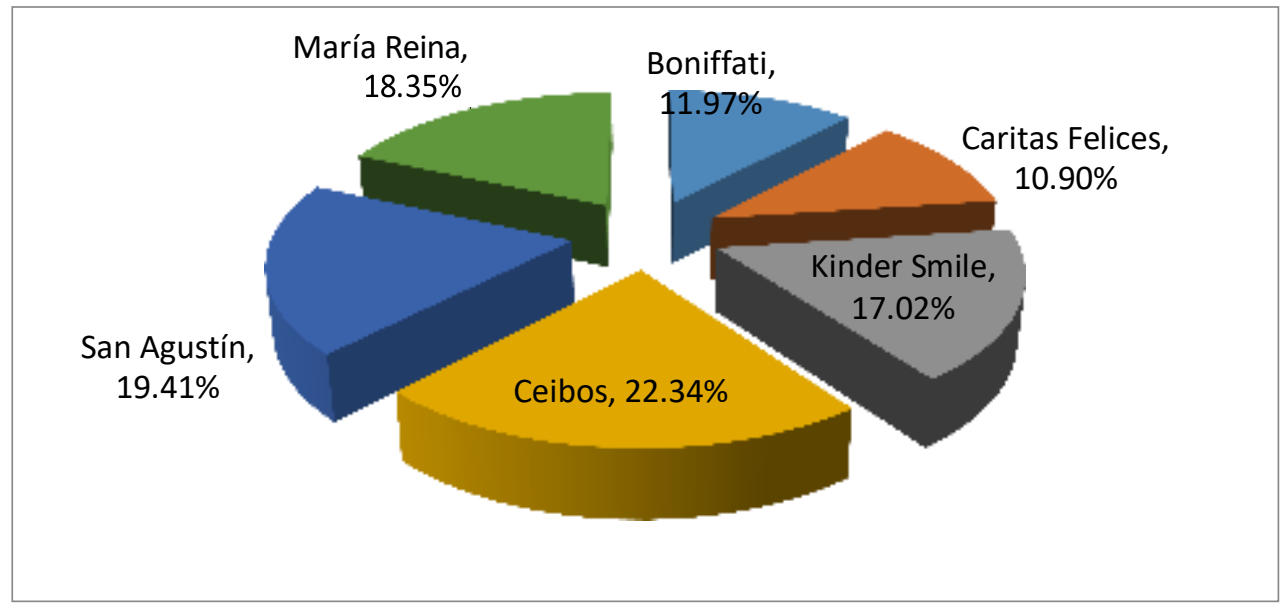

Figura 9. Mejor Colegio en la ciudad de Chiclayo

\section{Característica que más se valora en el mejor Colegio.}

La característica más valorada en el Colegio considerado el mejor es el número de alumnos por salón con una calificación promedio de 7.68 en una escala de uno a diez, mientras que el monto de pensión mensual (7.66) y el vínculo con un colegio de primaria (7.45) son otras de las características más valoradas del colegio considerado el mejor. En la Figura 10 se muestra en una escala de uno a diez las características más valoradas. 


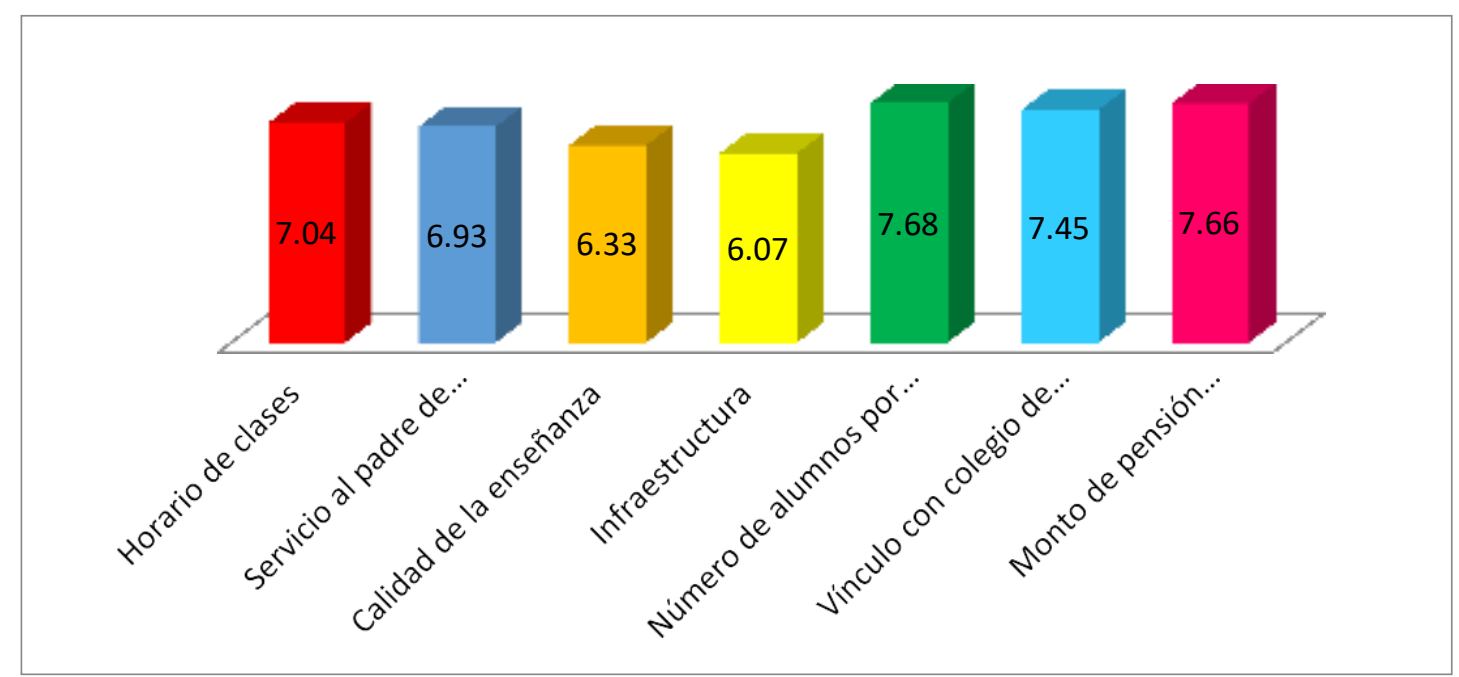

Figura 10. Característica más valorada del mejor Colegio

\section{Medio que permitió enterarse sobre el colegio seleccionado.}

El principal medio que permitió que los padres de familia conocieran al colegio en donde planean matricular a su hijo fue la recomendación familiar con un $61.7 \%$, mientras que el brochure del Colegio con un 18,09\% fue reconocido como el segundo medio para dar a conocer la institución educativa, según se muestra en la Figura 11.

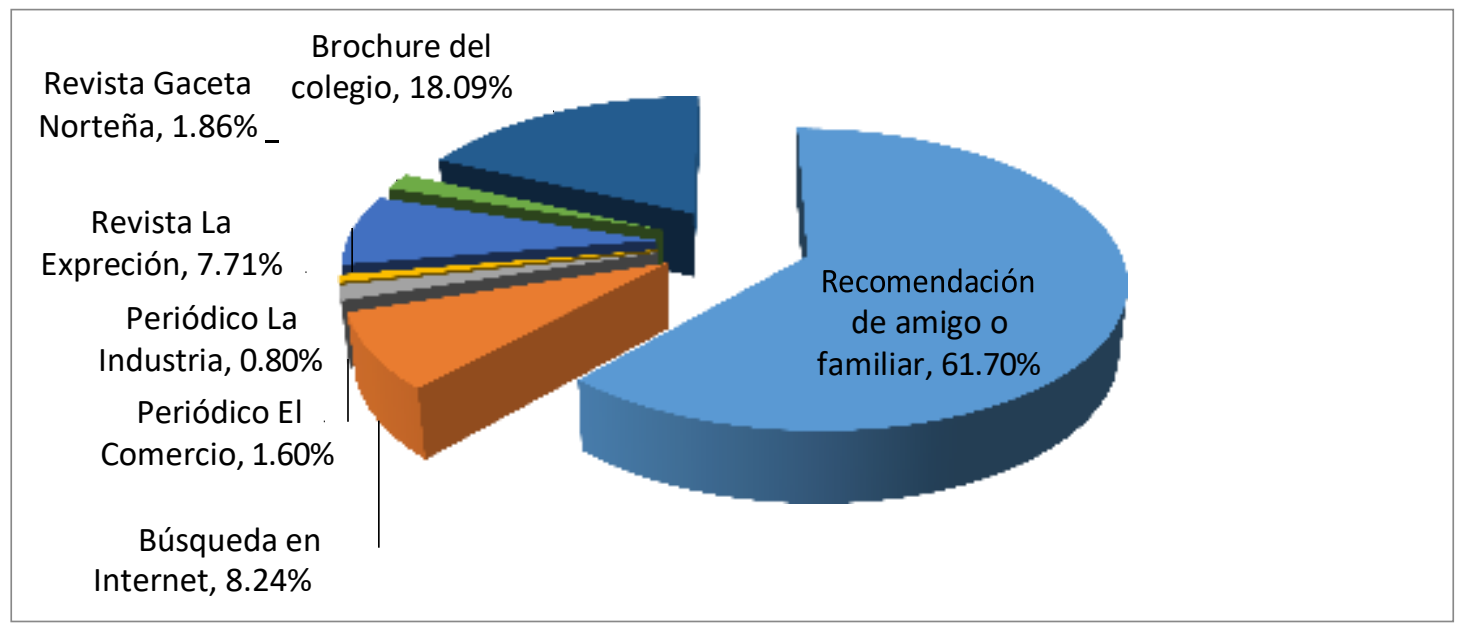

Figura 11. Medio de información que permitió dar a conocer el colegio 


\section{Precio del colegio seleccionado.}

El precio promedio de la mensualidad que están pagando los padres de familia en el colegio de su elección es de 411 soles (410.59), mientras que el valor de la mensualidad que más se repite es de 350 soles.

\section{Matrícula y derecho de admisión.}

El monto de la matrícula promedio es de 422 soles, mientras que el valor más común para el pago de la matrícula es de 400 soles. Por su parte, el derecho de admisión promedio es de 1,742 soles, pero el valor que más se repite entre los entrevistados es de 3000 soles.

\section{Persona que decide sobre la matrícula.}

La decisión sobre la elección del Colegio a cual asistirá el niño depende de ambos padres (53.99\%), mientras que la persona que toma la decisión en segundo lugar es la madre (25\%). (Ver figura 12).

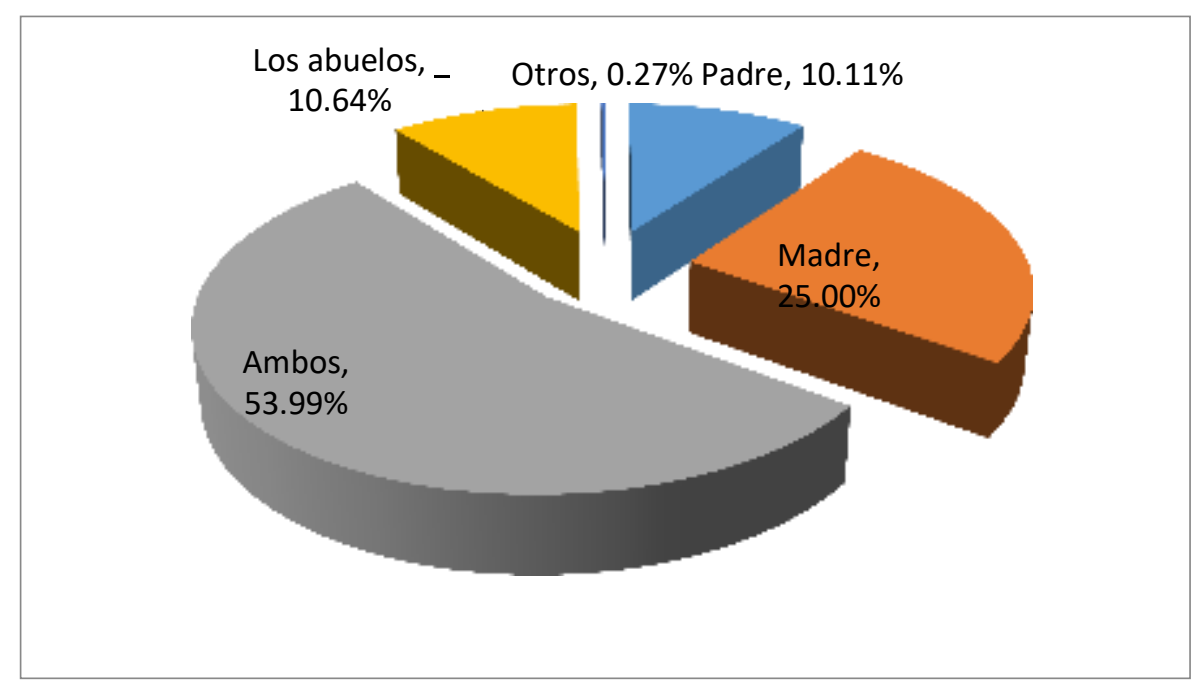

Figura 12. Persona que decide sobre la matrícula 


\section{Factores para cambiar a su hijo de Colegio}

Según se muestra en la Figura 13, los factores fundamentales según los encuestados para cambiar a su hijo de colegio son la calidad de la enseñanza (26.60\%) e infraestructura (23.94\%). Existen otros factores cuyos valores son significativos como el número de alumnos por salón de clase $(20,48 \%)$, los que se deben de tomar en cuenta durante el diseño del servicio que se ofrecerá en el Colegio.

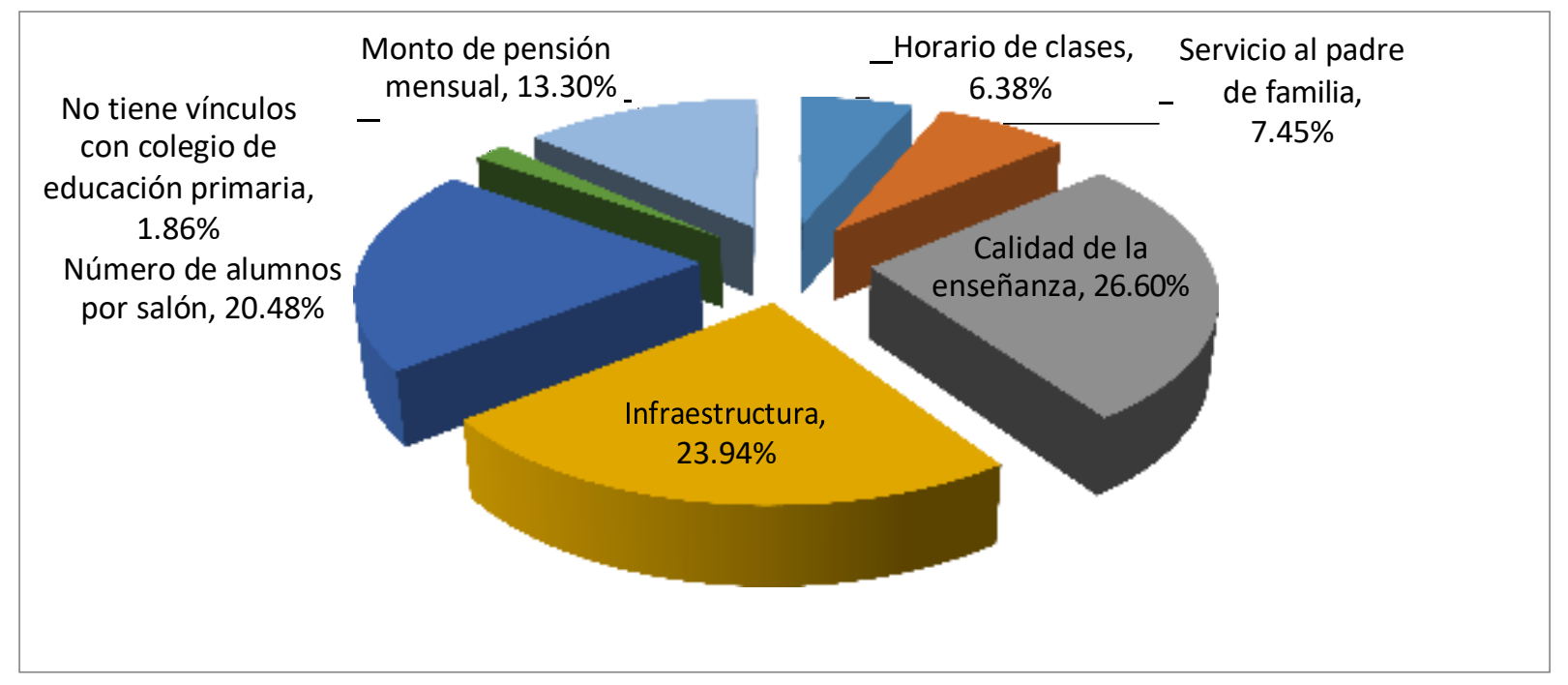

Figura 13. Factores para cambiar de colegio

\section{Aceptación del nuevo Colegio.}

Según la entrevistados existe un 56.65\% interesados en aceptar el nuevo servicio considerando tanto los que definitivamente están interesados más los que probablemente aceptarían el servicio. En la Tabla 19 se muestra el nivel de aceptación de servicio.

Tabla 19

Aceptación del nuevo colegio

\begin{tabular}{lr}
\hline Alternativa & $\%$ \\
\hline Definitivamente si & $\mathbf{1 0 , 1 1 \%}$ \\
\hline Probablemente si & $46,54 \%$ \\
\hline Indiferente & $16,49 \%$
\end{tabular}




\begin{tabular}{ll}
\hline Probablemente no & $14,89 \%$ \\
\hline Definitivamente no & $11,97 \%$ \\
\hline
\end{tabular}

\section{Ubicación del nuevo Colegio.}

Con relación a la ubicación del nuevo colegio la mayoría de los entrevistados prefiere que el Colegio este ubicado en la zona de Santa Victoria $(38,83 \%)$, mientras que un $32.71 \%$ prefiere que el Colegio se ubique en la zona de Los Parques. En la Tabla 20 se muestra el total de preferencias sobre la ubicación.

Tabla 20

Ubicación del nuevo Colegio

\begin{tabular}{lc}
\hline Alternativa & $\%$ \\
\hline Santa Victoria & $38,83 \%$ \\
Los Parques & $32,71 \%$ \\
Carretera a Pimentel & $5,32 \%$ \\
Patazca & $22,87 \%$ \\
Otro & $0,27 \%$ \\
\hline
\end{tabular}

Entrega de reporte sobre el desempeño y comportamiento.

Con relación a la entrega de los reportes de desempeño y comportamiento, los padres de familia prefieren que se les entregue personalmente en el colegio (71.54\%). La otra alternativa es la entrega de dicho reporte a través del correo electrónico con un $18.09 \%$ de las preferencias. En la Tabla 21 se muestran las alternativas seleccionadas para la entrega del reporte.

Tabla 21

Entrega del reporte de desempeño y comportamiento

\begin{tabular}{lc}
\hline Alternativa & $\%$ \\
\hline Personalmente en el colegio & $71,54 \%$ \\
En su correo electrónico & $18,09 \%$ \\
En una carta a su domicilio & $3,19 \%$ \\
En una carta a recoger en el colegio & $6,65 \%$ \\
Por teléfono & $0,53 \%$ \\
\hline
\end{tabular}




\section{Características del nuevo colegio.}

Las características más apreciadas del nuevo colegio son el modelo de enseñanza que permite la participación de los padres de familia en el proceso de formación de sus hijos, la sala de juegos especiales a fin de lograr un mejor aprendizaje por parte de los niños, biblioteca especializada que permite fomentar el aprendizaje y los docentes certificados en educación inicial. En la Tabla 22 se presentan las características del nuevo colegio apreciándose que el modelo de enseñanza es considerado como muy importante en un mayor porcentaje.

Tabla 22

Características del nuevo colegio

\begin{tabular}{ll}
\hline Característica & $\%$ \\
\hline Conexión para video vía Internet a fin de observar a su hijo realizando & \\
algunas actividades en el salón de clase & $58,24 \%$ \\
$\begin{array}{l}\text { Docentes certificados en educación inicial } \\
\text { Modelo de enseñanza que permita la participación de los padres de }\end{array}$ & $74,73 \%$ \\
familia & $82,18 \%$ \\
Salas de juego especiales para los niños que permitan lograr un mejor & \\
aprendizaje & $77,66 \%$ \\
Un biohuerto que fomente el aprendizaje & $59,57 \%$ \\
Una biblioteca especial para niños que fomenten el aprendizaje & $75,27 \%$ \\
\hline
\end{tabular}

\section{Enseñanza de inglés.}

La enseñanza del idioma inglés en el colegio es apreciada por la mayoría de los entrevistados con $75.53 \%$ de las preferencias, mientras que las clases solamente en español es preferida por un $19.15 \%$ tal como se aprecia en la Tabla 23.

Tabla 23

Enseñanza del idioma inglés

\begin{tabular}{lr} 
Alternativa & $\%$ \\
Enseñar inglés como un curso & $75,53 \%$ \\
No, solamente clases en español & $19,15 \%$ \\
Me es indiferente & $5,32 \%$ \\
\hline
\end{tabular}




\section{Traslado al nuevo Colegio.}

En el caso de tener un hijo en un colegio inicial un 58.09\% está de acuerdo con trasladar a su hijo al nuevo colegio (considerando las alternativas definitivamente si y probablemente sî), mientras que un 5,84\% no trasladaría su hijo a este nuevo colegio. En la Figura 14 se muestra el porcentaje de padres de familia relacionado con la posibilidad de cambio de colegio

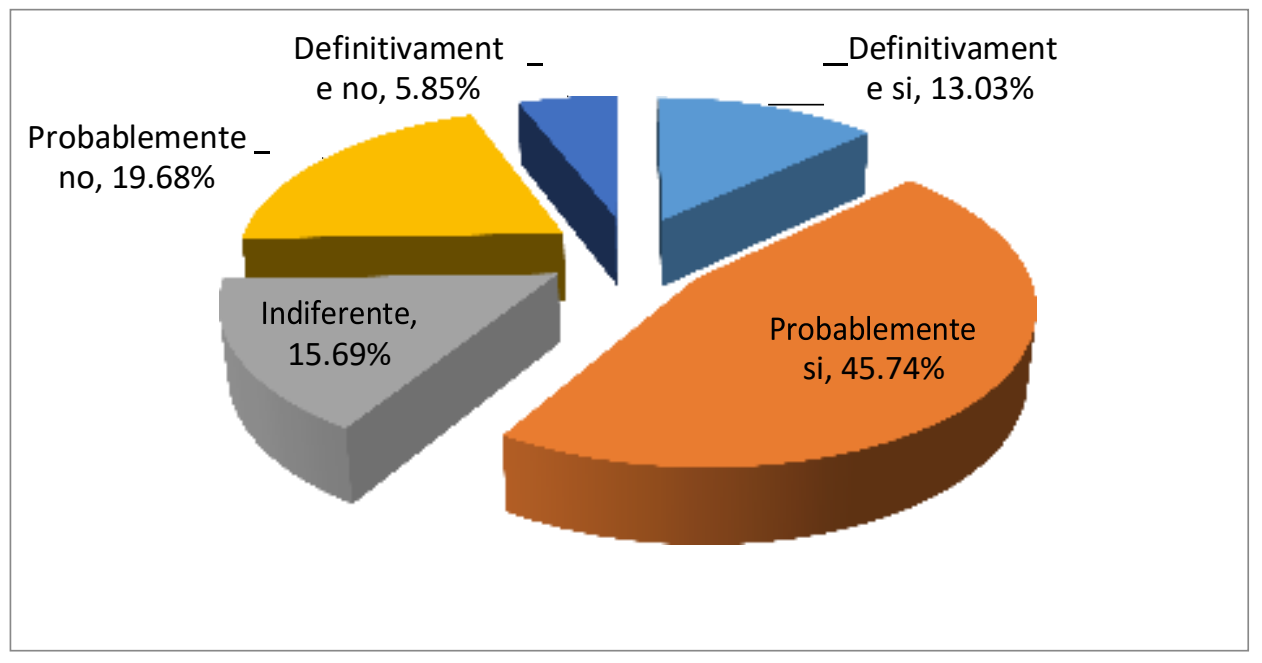

Figura 14. Traslado al nuevo Colegio

\section{Mensualidad del colegio.}

La mensualidad que estarían dispuestos a pagar los padres de familia en el nuevo colegio es de 360 soles, mientras que el valor de la mensualidad que más se repite es de 320 soles.

\section{Matrícula y derecho de admisión.}

El monto de la matrícula promedio que estarían dispuestos a pagar es de 349 soles, mientras que el valor más común para el pago de la matrícula es de 350 soles. Por su parte, el derecho de admisión promedio es de 517 soles, pero el valor que más se repite entre los entrevistados es de 500 soles. 


\section{Recomendación del colegio.}

Con relación a la recomendación del nuevo colegio a un amigo o familiar que se encuentre buscando un colegio inicial un $62.5 \%$ estuvo de acuerdo en recomendarlo, mientras que $37.5 \%$ no estuvo de acuerdo en recomendar el nuevo colegio.

\section{Medios para recibir información del nuevo colegio.}

Los medios preferidos para recibir información del nuevo colegio son el correo electrónico (43.88\%) y el Facebook (26.33\%). Mientras que el Twiter y la entrega del brochure del colegio en casa son los medios menos preferidos. En la Figura 15 se nuestros los medio preferidos para recibir información del nuevo colegio.

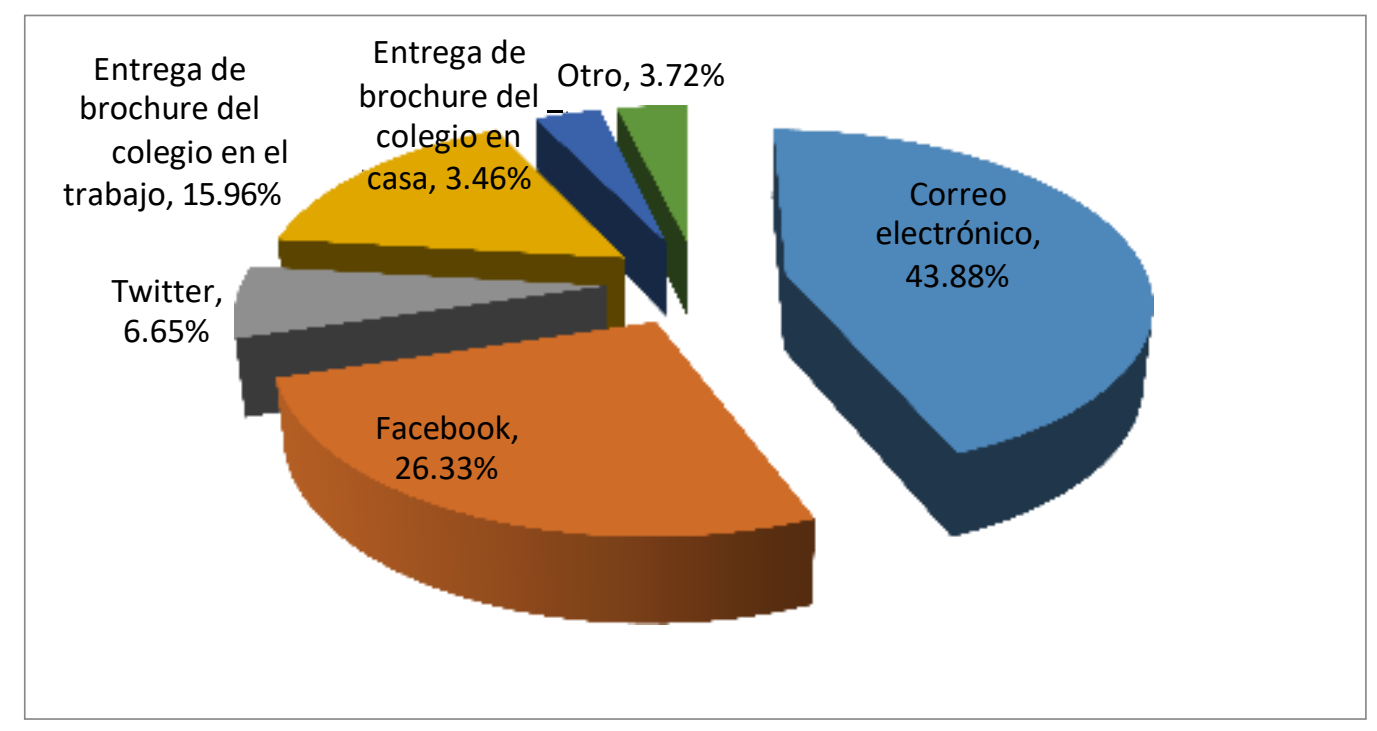

Figura 15. Medios para recibir información del colegio

\section{Nombre del Colegio.}

El nombre seleccionado para el nuevo colegio por parte de los entrevistados es de Estrellitas de Jesús (31.65\%). El otro nombre seleccionado fue de Gotitas de Amor 
con un $25.80 \%$. En la Figura 16 se puede apreciar los nombres seleccionados para el colegio y su nivel de aceptación.

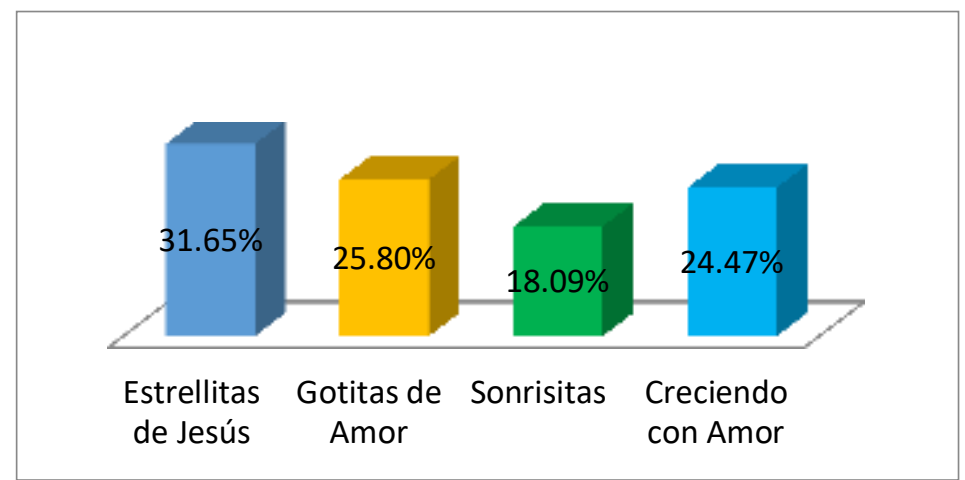

Figura 16. Nombre del nuevo colegio

\section{Sugerencias para el nuevo colegio.}

Se recibieron sugerencias para implementar en el nuevo colegio. Dichas sugerencias se agruparon y luego se estableció el porcentaje para cada de ellas. Así, la sugerencias con mayor porcentaje fue brindar movilidad para el traslado de los alumnos y que se brinde asesoría psicológica. En la figura 17 se puede apreciar las sugerencias formuladas para el nuevo colegio.

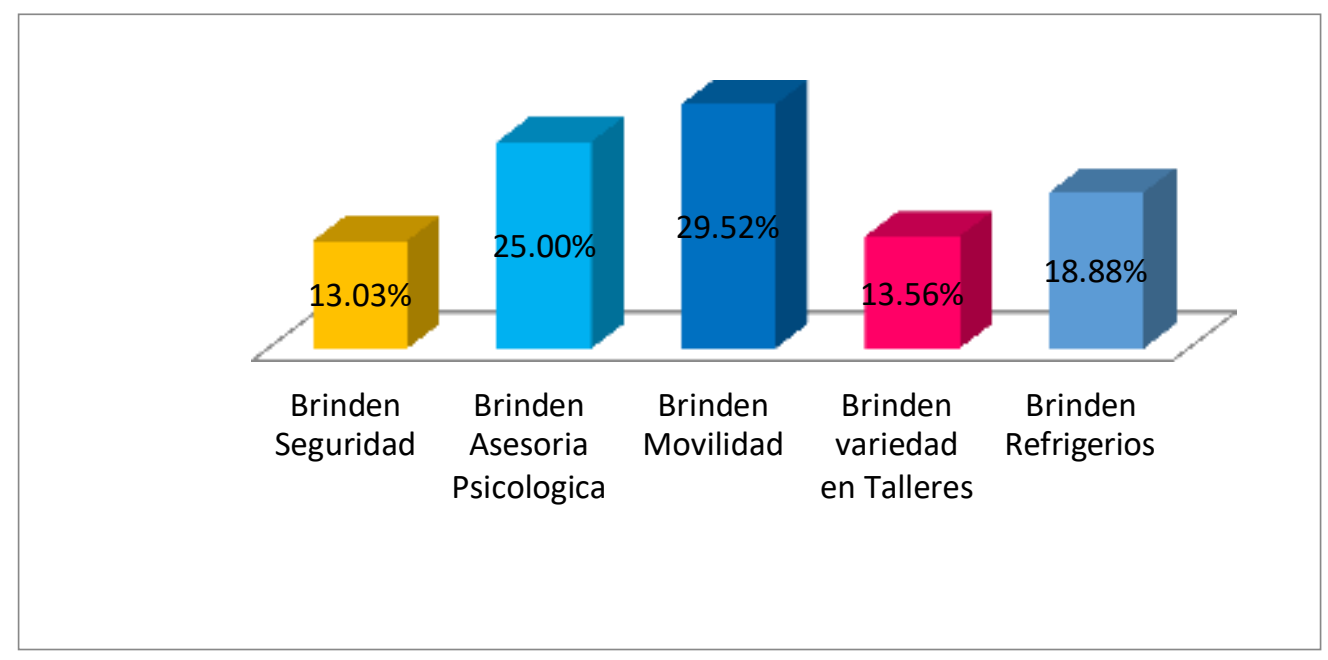

Figura 17. Sugerencias para el nuevo colegio 


\subsection{Conclusiones y recomendaciones del estudio cualitativo y cuantitativo}

El estudio de mercado realizado ha permitido reconocer las características deseadas del servicio educativo, así como la aceptación del nuevo servicio. En general existen coincidencias entre ambos estudios, dado que en ambos se señala aspectos similares para el servicio como: apoyo psicológico para los niños, infraestructura, cercanía al colegio, enseñanza de inglés como cursos, monto de mensualidades similares. Asimismo, el medio preferido para recibir información del nuevo colegio es el correo electrónico.

Entre las características del nuevo servicio tenemos las siguientes:

a) El modelo de enseñanza con la participación de los padres de familia que será importante para consolidar la preferencia del colegio en el mercado.

b) Las salas de juego como parte del proceso de enseñanza a fin de consolidar mediante actividades lúdicas el proceso de aprendizaje del alumno.

c) Los docentes con especialidad en educación inicial y la biblioteca especializada son aspectos del servicio que prefieren los padres de familia.

d) Un aspecto importante que se debe considerar en el número de alumnos por salón y la infraestructura general del colegio, que fueron elementos importantes del colegio seleccionado para matricular a su hijo.

Por otro lado, las sugerencias recibidas permiten consolidar las características a ofrecer por el colegio. Entre las sugerencias más preferidas son el de brindar movilidad para el transporte de los niños y la asesoría psicológica para los niños. Las características deseadas se acentúan cuando se realiza el cruce de las personas que 
aceptan el servicio con las sugerencias planteadas para el nuevo colegio. (Ver Figura $18)$.

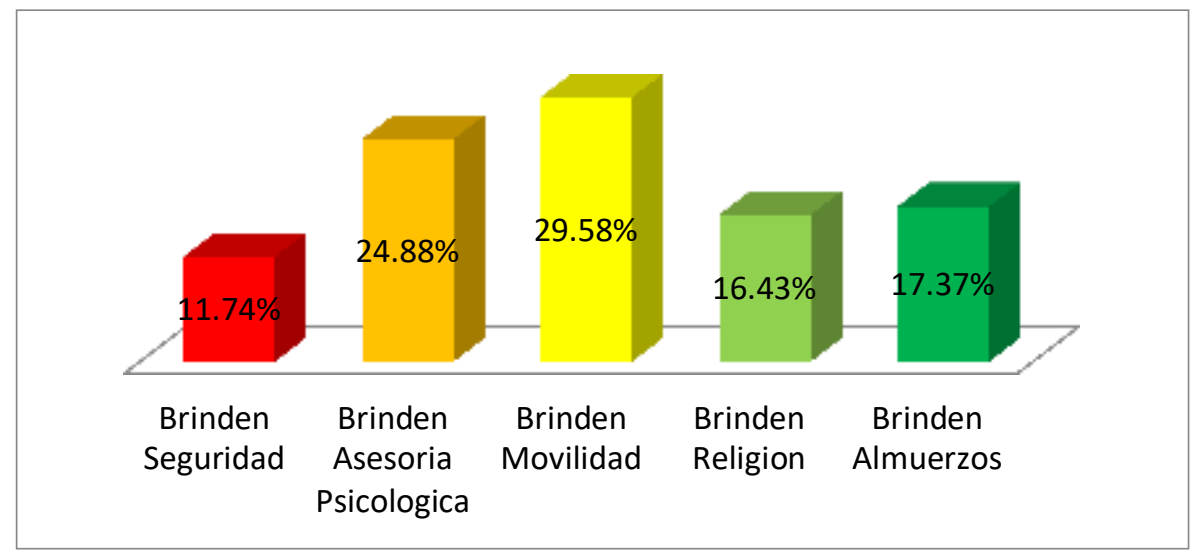

Figura 18. Aceptación del colegio versus sugerencias para el nuevo servicio

Respecto al sistema de entrega de información del nuevo colegio los interesados en el colegio prefieren la entrega a través del correo electrónico y el facebook, sin olvidarse que prefieren la entrega del brochure en su centro laboral. En la Figura 19 se muestra los que aceptarían el servicio con el sistema de entrega de información preferido.

Figura 19. Aceptación del colegio versus sistema de entrega de información

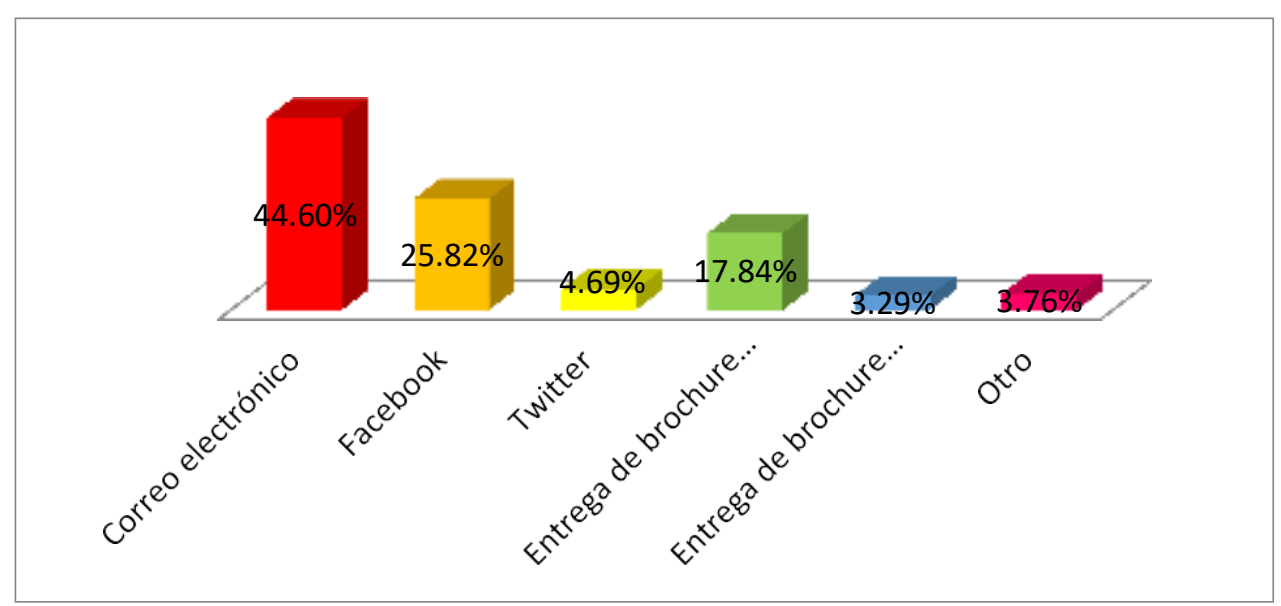


Con relación a la ubicación del nuevo colegio, los interesados en este servicio prefieren que el colegio se ubique en la zona de la Victoria. Otra alternativa es la zona de los Parques. Por consiguiente, el colegio se debería localizar en alguna de dichos lugares mencionados. Ver Figura 20.

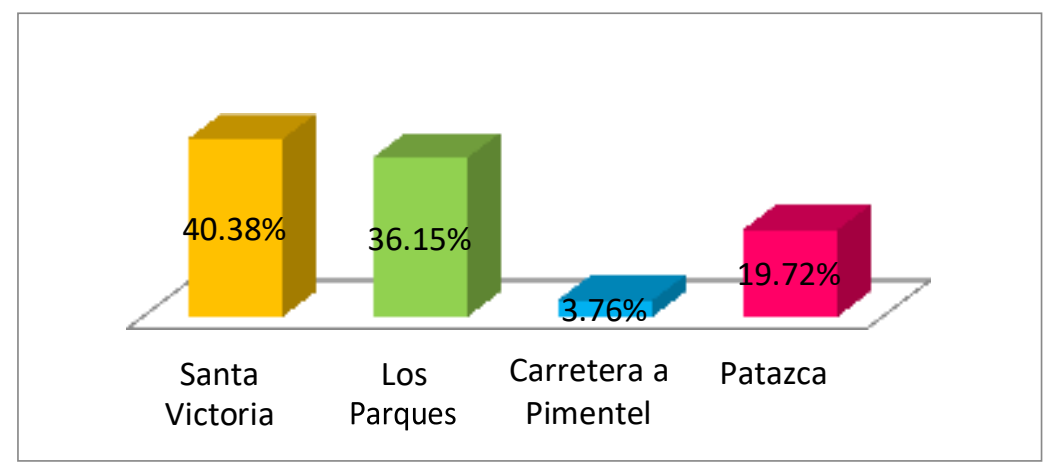

Figura 20. Aceptación del colegio versus ubicación del colegio

El monto de la mensualidad, así como el pago de la matrícula y el derecho de admisión relacionado con los que prefieren el servicio son los siguientes:

a) Mensualidad: 360 soles (cerca al promedio de 363 indicado y el valor de 350 que más se repite).

b) Matricula: 350 soles (similar a los valores promedio de 347 y los 350 que más se repite).

c) Admisión: 1600 soles (igual que el valor que se indica de 1,500 y distinto a los 510 soles que más se repite).

Finalmente, los que están interesados en el servicio prefieren que el nombre del Colegio sea Estrellitas de Jesús. En segundo lugar se coloca el nombre de Gotitas de Amor. A fin de seleccionar el nombre del Colegio se presentarán ambas alternativas a los inversionistas a fin que tomen la decisión final. (Ver Figura 21). 


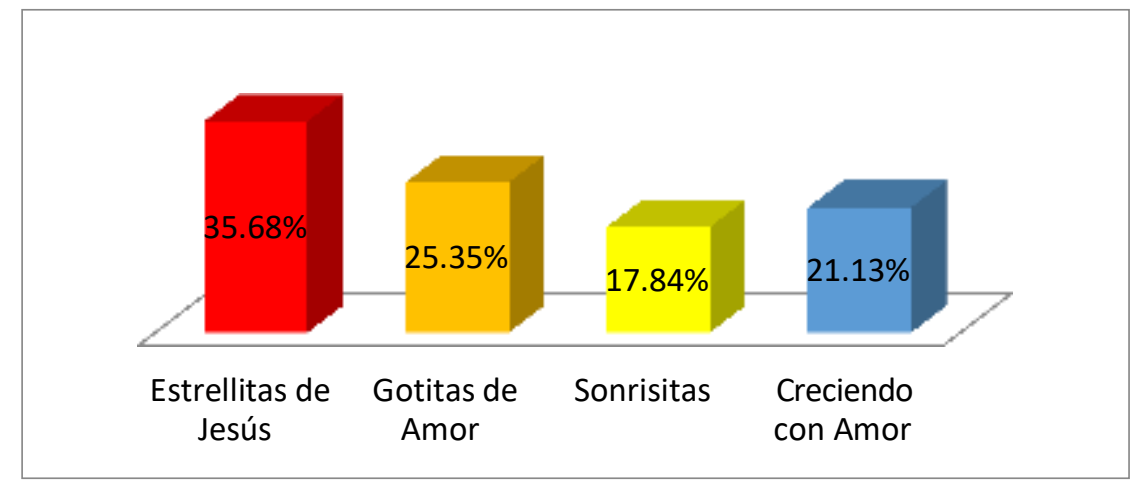

Figura 21. Aceptación del colegio versus nombre del colegio.

\subsection{Perfil del consumidor tipo y sus variantes.}

Con relación a los que prefieren el servicio del colegio con el rango de edad se observa que los que tienen una edad entre 26 a 30 años prefieren en mayor proporción al colegio en contraste con los que tienen ente 31 a 35 años. En la Figura 22 se muestra la relación de los que aceptan el servicio con la edad.

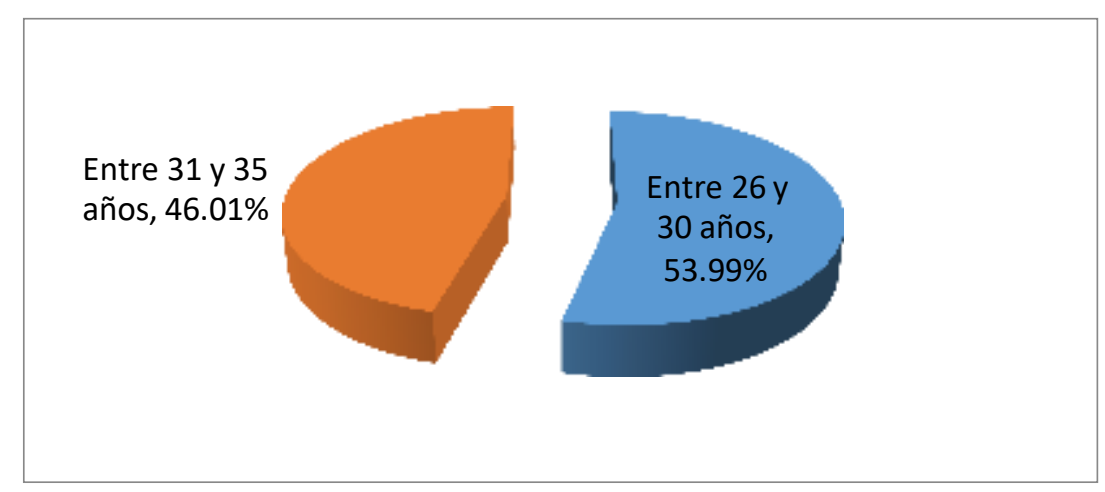

Figura 22. Aceptación del colegio versus rango de edad de los interesados

Respecto al nivel de ingreso coincide con los supuestos iniciales sobre el ingreso con los que prefieren el servicio. (Ver Figura 23). 


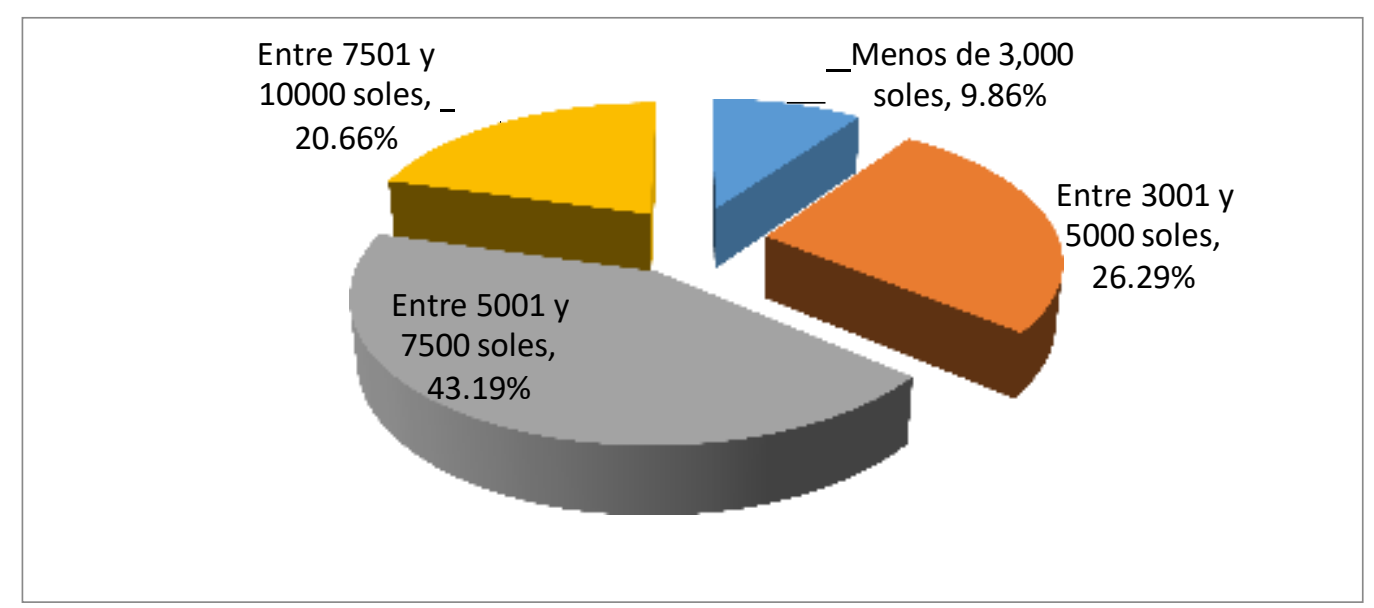

Figura 23. Aceptación del colegio versus rango de ingreso de los interesados

Por tanto, el colegio de educación inicial estará enfocado a padres de familia de los niveles socioeconómico A/B que residan en la zona urbana de la ciudad de Chiclayo, que tengan niños entre tres y cuatro años. En general, los padres de familia a los que se planea ofrecer el servicio del colegio inicial son personas entre 26 a 35 años de edad. 


\section{Capítulo IV \\ Proyección del mercado objetivo}

\subsection{El ámbito de la proyección}

La proyección de la demanda para el servicio educativo que ofrecerá el nuevo colegio está basada en la información de la población que reside en la zona urbana de la ciudad de Chiclayo proporcionada por el Instituto Nacional de Estadística e Información (INEI). Asimismo, se usa información de mercado que pública la Asociación Peruana de Empresas de Investigación de Mercados (2015), y el estudio de mercado realizado que se muestra en el capítulo anterior. El tiempo proyectado para la demanda es de diez años desde el año 2018 al 2027.

\subsection{Selección del método de proyección}

\subsubsection{Mercado Potencial}

El mercado potencial comprende a todos los clientes que están interesados en el servicio educativo inicial.

El mercado potencial se calcula en función del perfil definido del cliente: padres de familia que residen en zona urbana de la ciudad de Chiclayo, con edad comprendida entre 26 a 35 años y que están interesados en el servicio de educación inicial para sus hijos que tienen entre tres a cinco años. El nivel socioeconómico de los clientes es AB y viven en la zona urbana de la ciudad. Se considera personas casadas o convivientes solamente, dado que en las fuentes de información revisadas no se encuentra el porcentaje de personas solteras con hijos.

La fórmula para realizar el cálculo de la demanda potencial es la siguiente: 
Mercado Potencial: Población de Chiclayo * Nivel socioeconómico A/B * personas casadas o convivientes * personas en edad de 26 a 35 años

Para proyectar la demanda se toma en cuenta la población de la zona urbana de la provincia de Chiclayo (comprende los distritos de Chiclayo, José Leonardo Ortiz y la Victoria) publicada por el Instituto Nacional de Estadística e Información (INEI, 2014) que se muestra en la Tabla 24. Con esta información se proyecta la población de la provincia de Chiclayo hasta el año 2027 ver Tabla 25, tomando como tasa de crecimiento el valor indicado por el INEI (2014) de $0.86 \%$ anual.

Por otro lado, se tiene que los hogares de la población en el área urbana del Departamento de Lambayeque que se encuentra en el nivel socioeconómico $\mathrm{AB}$ es de 12,9\% (Asociación Peruana de Empresas de Investigación de Mercados [APEIM] 2015). Asimismo, según APEIM (2015) el porcentaje de personas casadas o convivientes según nivel socioeconómico son:
a) Nivel A: $51.5 \%$
b) Nivel B: $48.6 \%$

Mientras, que el porcentaje de personas que se encuentran en el rango de edad de 26 a 35 años según nivel socioeconómico son:
a) Nivel A: $13.4 \%$
b) Nivel B: $13.8 \%$ 
Tabla 24

Población de los distritos de Chiclayo, José Leonardo Ortiz y la Victoria de la Provincia de Chiclayo 2000 - 2015

\begin{tabular}{|c|c|c|c|}
\hline Año & Población Chiclayo & Población & Población La Victoria \\
\hline 2000 & 256,332 & 149,008 & 73,376 \\
\hline 2001 & 259,622 & 152,263 & 74,723 \\
\hline 2002 & 262,639 & 155,393 & 76,001 \\
\hline 2003 & 265,455 & 158,435 & 77,227 \\
\hline 2004 & 268,111 & 161,430 & 78,423 \\
\hline 2005 & 270,694 & 164,417 & 79,606 \\
\hline 2006 & 273,176 & 167,380 & 80,770 \\
\hline 2007 & 275,514 & 170,288 & 81,901 \\
\hline 2008 & 277,741 & 173,163 & 83,009 \\
\hline 2009 & 279,891 & 176,026 & 84,104 \\
\hline 2010 & 282,004 & 178,899 & 85,197 \\
\hline 2011 & 284,084 & 181,782 & 86,287 \\
\hline 2012 & 286,105 & 184,660 & 87,369 \\
\hline 2013 & 288,063 & 187,530 & 88,440 \\
\hline 2014 & 289,956 & 190,388 & 89,499 \\
\hline 2015 & 291,777 & 193,232 & 90,546 \\
\hline
\end{tabular}

Nota. INEI (2016). Población 2000 al 2015. Perú.

A partir de la información anterior y la tasa de crecimiento de la población de la provincia de Lambayeque estimada por el INEI (2015), se estima la población para la zona urbana de la ciudad de Chiclayo (comprende los distritos de Chiclayo, José Leonardo Ortiz y la Victoria) para los años 2016 al 2027, según se muestra en la Tabla 25.

El número de habitantes considerado para estimar la demanda potencial provienen de los distritos de la zona urbana de la ciudad de Chiclayo. Así, se considera solamente para el año 2018, el Distrito de Chiclayo con una población de 299,370, el Distrito José Leonardo Ortiz con 198,260 habitantes y el Distrito La Victoria con 92,902 pobladores. El total de la población de estos distritos es de 590,532 habitantes. 
Tabla 25

Población Proyecta de la Provincia de Chiclayo 2016 - 2027

\begin{tabular}{|c|c|c|c|c|}
\hline \multicolumn{5}{|c|}{ Proyección Población } \\
\hline Año & Población & Chiclayo & Población JLO & Población La Victoria \\
\hline 2016 & & 294,286 & 194,894 & 91,325 \\
\hline 2017 & & 296,817 & 196,570 & 92,110 \\
\hline 2018 & & 299,370 & 198,260 & 92,902 \\
\hline 2019 & & 301,944 & 199,965 & 93,701 \\
\hline 2020 & & 304,541 & 201,685 & 94,507 \\
\hline 2021 & & 307,160 & 203,420 & 95,320 \\
\hline 2022 & & 309,802 & 205,169 & 96,140 \\
\hline 2023 & & 312,466 & 206,933 & 96,966 \\
\hline 2024 & & 315,153 & 208,713 & 97,800 \\
\hline 2025 & & 317,864 & 210,508 & 98,641 \\
\hline 2026 & & 320,597 & 212,318 & 99,490 \\
\hline 2027 & & 323,354 & 214,144 & 100,345 \\
\hline
\end{tabular}

El mercado potencial para el año 2018 al que se ofrecerá el servicio del colegio de educación inicial en la ciudad de Chiclayo es de 5,148 personas. El cálculo del mercado potencial se muestra en la Tabla 26.

Tabla 26

Cálculo del Mercado Potencial

\begin{tabular}{lllll}
\hline Población & $\begin{array}{l}\text { Nivel } \\
\text { socioeconómico } \\
12.9 \%\end{array}$ & $\begin{array}{l}\text { Personas casadas } \\
\text { o convivientes } \\
\text { Nivel A: } 51.5 \%\end{array}$ & $\begin{array}{l}\text { Personas en edad de } \\
\text { 26 a 35 años }\end{array}$ & $\begin{array}{l}\text { Mercado } \\
\text { Pivel A: } 13.4 \%\end{array}$ \\
& & Nivel B: $48.6 \%$ & Nivel B: $13.6 \%$ & \\
\hline 590,532 & 76,179 & 38,128 & 5,148 & 5,148 \\
\hline
\end{tabular}

\subsubsection{Mercado Disponible.}

El mercado disponible es el conjunto de padres de familia interesados en el servicio de educación inicial impartido por colegios privados. Para estimar el mercado potencial, tenemos la siguiente formula:

Mercado disponible: mercado potencial * usuarios del servicio colegios privados 
El porcentaje de matrícula de niños de tres años en educación inicial según el INEI (2015) para el año 2015 ha sido de 78.5\%. Con relación a los alumnos que asisten a los colegios de nivel inicial privados tenemos que según la UGEL - Chiclayo (2015) el $60 \%$ de los alumnos de este nivel asisten a los colegios privados.

En la Tabla 27 se muestra el cálculo del mercado disponible para los colegios de educación inicial para el año 2018.

Tabla 27

Cálculo del Mercado Disponible

\begin{tabular}{lll}
\hline Mercado Potencial & $\begin{array}{l}\text { Porcentaje de matrícula de } \\
\text { niños de } 3 \text { años en } \\
\text { educación inicial: } 78.5 \%\end{array}$ \\
& $\begin{array}{l}\text { Matrícula a nivel inicial en } \\
\text { colegios privados: } 60 \%\end{array}$ \\
\hline 5,148 & \multicolumn{2}{l}{ Misponible } \\
\hline
\end{tabular}

4.2.3. Mercado Efectivo.

El mercado efectivo es el conjunto de padres de familia del mercado disponible que efectivamente están interesadas en el servicio del colegio de educación inicial. Para estimar el mercado efectivo tenemos la siguiente formula:

Mercado efectivo: mercado disponible * porcentaje de padres de familia que aceptan el servicio

El porcentaje de padres de familia que están interesados en el servicio se obtiene de las respuestas afirmativas a la pregunta 15 del cuestionario. Sin embargo, aplicando el criterio de ponderación expresado por Jeffrey Pope (1996) para el porcentaje de padres de familia que aceptan el servicio se obtiene un nuevo valor para la aceptación del servicio (p. 160), tal como se muestra en la Tabla 28. 
Tabla 28

Ponderación de pruebas de concepto

\begin{tabular}{lcrr}
\hline Alternativa & $\begin{array}{l}\text { Respuesta de la } \\
\text { Prueba }\end{array}$ & $\begin{array}{l}\text { Puntaje } \\
\text { Ponderaciones }\end{array}$ & $\begin{array}{l}\text { Ponderado } \\
\text { Definitivamente }\end{array}$ \\
si & $10,11 \%$ & & \\
rrobabiemente & $46,54 \%$ & 0,75 & $7,58 \%$ \\
si & $16,49 \%$ & 0,25 & $11,64 \%$ \\
Indiferente & $14,89 \%$ & 0,1 & $1,65 \%$ \\
Probablemente no & $11,97 \%$ & 0,03 & $0,45 \%$ \\
Definitivamente no & $100,00 \%$ & 0,02 & $0,24 \%$ \\
\hline Total & \multicolumn{3}{c}{$21,55 \%$} \\
\hline
\end{tabular}

La Tabla 29 muestra el cálculo del mercado potencial para el colegio de educación inicial para el año 2018.

Tabla 29

Cálculo del Mercado Efectivo

\begin{tabular}{lll}
\hline Mercado Disponible & $\begin{array}{l}\text { Porcentaje de aceptación } \\
\text { del nuevo colegio de } \\
\text { educación inicial: } 21.55 \%\end{array}$ & Mercado Efectivo \\
\hline 2,425 & 523 & 523 \\
\hline
\end{tabular}

\subsubsection{Mercado Objetivo.}

El mercado objetivo es el conjunto de padres de familia, a quienes el nuevo colegio puede ofrecer sus servicios de educación inicial en función de la capacidad planeada del colegio, número de docentes, número de aulas, los que estarán en función de la inversión a realizar. En este caso se está considerando que el colegio puede atender en un inicio el $5 \%$ de este mercado.

La fórmula usada para calcular el mercado objetivo es la siguiente:

Mercado Objetivo: mercado efectivo * porcentaje de captación de alumnos El porcentaje de captación de alumnos para este primer año se considera que puede ser un $5.0 \%$ del total del mercado. 
La Tabla 30 muestra el cálculo del mercado objetivo para el colegio de educación inicial para el año 2018.

Tabla 30

Cálculo del mercado objetivo

\begin{tabular}{lll}
\hline Mercado Disponible & $\begin{array}{l}\text { Porcentaje de captación de } \\
\text { matrícula de niños de 3 a 5 } \\
\text { años para el colegio: }\end{array}$ & Mercado Efectivo \\
& $7.5 \%$ & \\
\hline 523 & 40 & 40 \\
\hline
\end{tabular}

Los alumnos que ingresen al colegio lo pueden hacer en los diferentes niveles que se ofrecen en el colegio. Así, considerado el porcentaje de alumnos que ingresan en los diferentes niveles de educación básica tenemos que los alumnos estimados para ingresar el primer año a nuestro colegio son:

Tabla 30A

Cálculo de los alumnos ingresantes

\begin{tabular}{ll}
\hline Nivel educativo & Niños de 3-5 años \\
\hline Primer grado & 50 \\
Segundo grado & 25 \\
Tercer grado & 25 \\
\hline
\end{tabular}

\subsection{Pronóstico de Ventas}

Para estimar el pronóstico de ventas mensual se ha considerado lo siguiente:

a) La tasa de crecimiento para los siguientes años es del $15 \%$, dado que el sector de educación privado ha tenido un crecimiento del $18 \%$ en los años anteriores. Esta tasa es para los alumnos del primer ingreso. 
b) El precio estimado de mensualidad es 480 soles por alumno, que se paga durante 10 meses al año.

c) Los alumnos que ingresan el primer año continúan durante el segundo y tercer año considerando la tasa de deserción promedio. De esta manera la tasa de crecimiento del primer año al segundo en total de alumnos es de casi el 100\%, pero en los siguientes años cuando el colegio completa sus tres años el crecimiento es el señalado del $15 \%$.

La Tabla 31 muestra el cálculo de las ventas para el colegio de educación inicial para el año $2018-2027$.

Tabla 31

Cálculo de ventas para el colegio de educación inicial

\begin{tabular}{lcccc}
\hline & $\begin{array}{l}\text { Proyección } \\
\text { alumnos } \\
\text { primer año }\end{array}$ & $\begin{array}{l}\text { Alumnos } \\
\text { segundo } \\
\text { año }\end{array}$ & $\begin{array}{l}\text { Alumnos } \\
\text { tercer año }\end{array}$ & $\begin{array}{l}\text { Total } \\
\text { alumnos }\end{array}$ \\
\hline $\mathbf{2 0 1 8}$ & 50 & 25 & 25 & 100 \\
$\mathbf{2 0 1 9}$ & 50 & 25 & 25 & 100 \\
$\mathbf{2 0 2 0}$ & 50 & 25 & 25 & 100 \\
$\mathbf{2 0 2 1}$ & 50 & 25 & 25 & 100 \\
$\mathbf{2 0 2 2}$ & 75 & 50 & 25 & 150 \\
$\mathbf{2 0 2 3}$ & 75 & 50 & 25 & 150 \\
$\mathbf{2 0 2 4}$ & 75 & 50 & 25 & 150 \\
$\mathbf{2 0 2 5}$ & 75 & 75 & 50 & 200 \\
$\mathbf{2 0 2 6}$ & 75 & 75 & 50 & 200 \\
$\mathbf{2 0 2 7}$ & 75 & 75 & 50 & 200 \\
\hline
\end{tabular}

\subsection{Aspectos críticos que impactan el pronóstico de ventas}

Los aspectos críticos que podrían impactar en el pronóstico de ventas estimado son los siguientes: 


\section{Factores externos.}

a) La economía no crece lo que determina que los padres de familia busquen alternativas en los colegios públicos para la matrícula de sus hijos.

b) Disminución de la tasa de crecimiento de niños en la ciudad de Chiclayo.

c) Que ingresen colegios de Lima que tiene un mejor posicionamiento.

d) Los conflictos sociales en la Región se agudicen lo que implicaría un incremento en los costos del servicio.

e) Los maestros de educación inicial no cubran la demanda existente.

\section{Factores internos.}

a) El colegio no logre posicionarse en el mercado.

b) El colegio no cumpla con los estándares ofrecidos a los padres de familia.

c) Que el modelo educativo propuesto no tenga aceptación entre los padres de familia.

d) Se presenten actividades internas no planeadas que determinen un incremento en los costos del colegio. 


\section{Capítulo V}

Ingeniería del proyecto

\subsection{Estudio de ingeniería}

El desarrollo del proyecto del Colegio requiere de un estudio técnico relacionado con sus principales procesos, equipamiento necesario para operar, distribución del colegio y la ubicación en la ciudad de Chiclayo.

\subsubsection{Modelamiento y selección de procesos productivos.}

El servicio de educación que brindará el Colegio Inicial se divide en cuatro grandes procesos: (Ver Figura 24)

a) Proceso de Admisión.

b) Proceso de Matricula.

c) Proceso de enseñanza aprendizaje.

d) Proceso de evaluación.

Los procesos indicados incluyen las principales actividades que se llevan a cabo en el colegio, desde la captación del alumno hasta su evaluación de su desempeño.

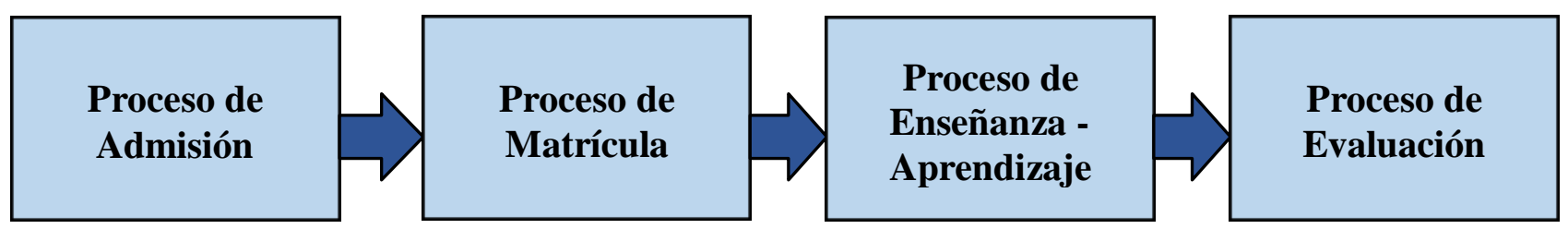

Figura 24. Proceso General del Colegio

\section{El Proceso de Admisión.}

Se inicia con la determinación del número de vacantes para el periodo escolar por parte de la Dirección del Colegio. Esta información se comunica al área de admisión 
del colegio a fin que inicie el proceso de captación de los padres de familia interesados en recibir el servicio de educación inicial para sus hijos.

A fin de llevar a cabo el proceso de captación de los alumnos se debe enviar primero la información sobre el Colegio y los requisitos para el ingreso a los padres de familia a través de los canales de comunicación tradicionales como volantes, brochures, periódicos, revistas, programas radiales, entre otros; y no tradicionales como redes sociales, internet, correo electrónico, entre otros. Asimismo, se organizan visitas de los padres de familia al Colegio a fin de brindarles información "in situ” sobre las características del colegio y las ventajas que sus hijos estudien en el mismo.

Luego, que los padres de familia han tomado la decisión de matricularse en el colegio, se inicia el proceso de selección a fin de escoger a los alumnos que cumplan con el perfil que busca el Colegio, según se muestra en la Figura 27. Este proceso incluye la evaluación de los documentos entregados y una entrevista con el padre de familia, para finalmente enviar una comunicación indicando si el alumno fue admitido.

\section{Proceso de Matricula}

Si el postulante fue admitido al Colegio se debe iniciar el proceso de matrícula, que consiste en registrarlo como alumno. Las actividades que incluye son la entrega de la documentación solicitada, el pago de la matrícula según la tasa vigente, el registro en el sistema académico de la Universidad y la comunicación a la UGEL de la zona.

El proceso de matrícula culmina con la entrega del calendario escolar a los padres de familia de modo que puedan conocer fecha de inicio y termino de la clase, así 
como las fechas de reuniones de los padres de familia con la Dirección del Colegio y las fechas de feriados escolares. (Ver Figura 25).

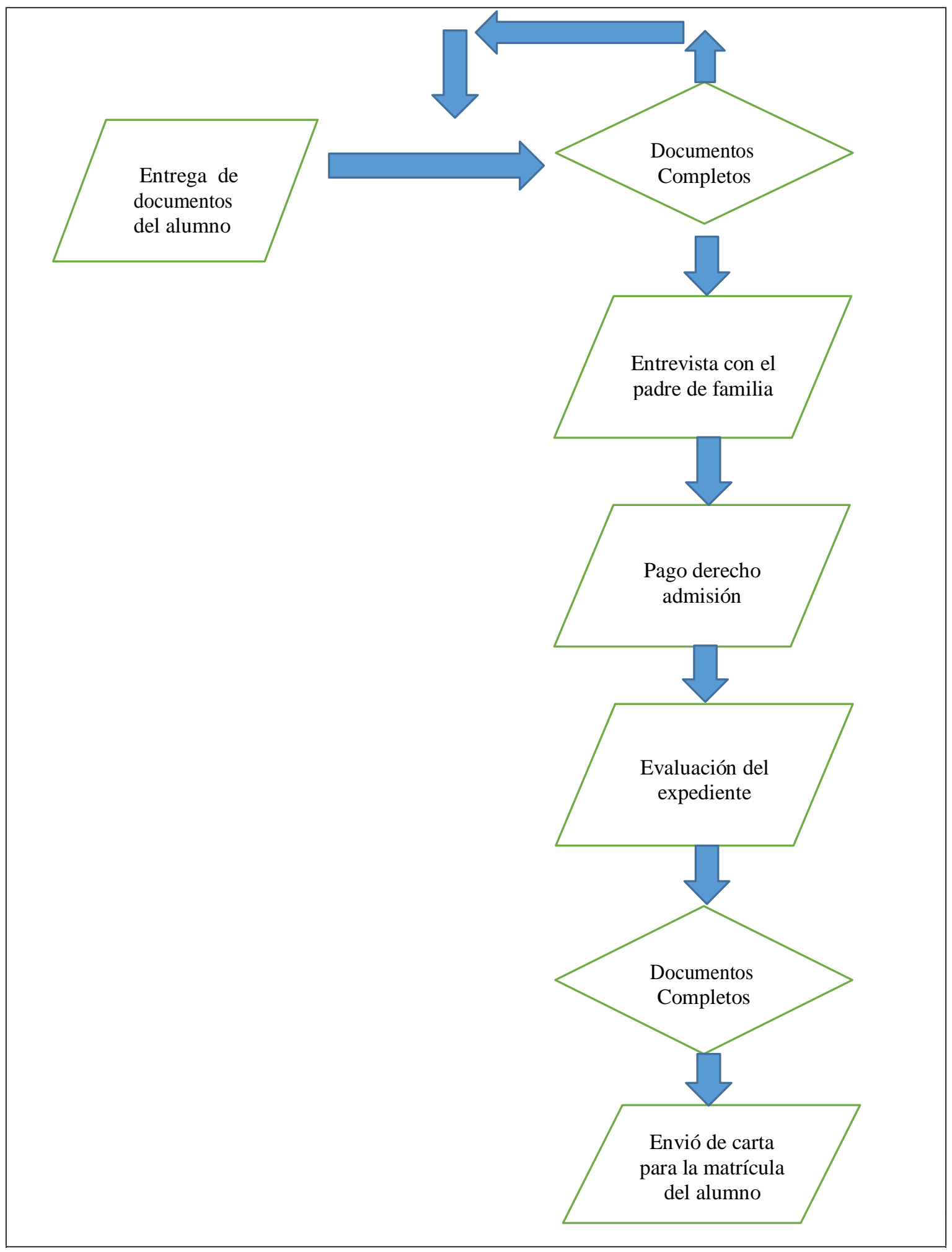

Figura 25. Proceso de Admisión 


\section{Proceso de Enseñanza Aprendizaje.}

Incluye el diseño y la ejecución de las diferentes actividades educativas que se llevan a cabo el aula de clase por el docente y los alumnos durante del proceso de enseñanza. También, a fin de soportar este proceso se consideran las actividades que se realizan para la selección de profesores.

\section{Modelo de aprendizaje.}

A fin de desarrollar las actividades educativas, los colegios deben contar con un modelo de aprendizaje que permita la formación integral de los alumnos durante el tiempo que permanecen en el colegio. En general, los modelos educativos existentes para este nivel se orientan a favorecer el desarrollo del niño a partir de ciertas actividades previamente definidas, pero en algunos casos a estos modelos les falta consolidar al proceso de aprendizaje la formación de los valores de manera conjunta con los padres de familia.

En este marco, el Colegio ha seleccionado un modelo educativo con un enfoque activo basado en el enfoque por competencias que permite una interacción entre los alumnos y el docente a través de una serie de dinámicas y actividades lúdicas orientadas a lograr que los alumnos alcancen un desarrollo integral. Este propósito se alcanza cuando los estudiantes entienden los elementos básicos del lenguaje, realizan actividades para fortalecer el desarrollo de sus capacidades motoras, fomentan los valores que se transmiten en el hogar y logran consolidar la realización de ciertas actividades básicas que son parte de la vida cotidiana. (Ver Anexo 14). 
El modelo educativo propuesto para el Colegio está basado en un aprendizaje activo y busca la interacción entre los distintos elementos que lo conforman. Se muestra en la Figura 26.

- En primer lugar las actividades lúdicas se basan en el principio de aprender jugando para el desarrollo de las capacidades intelectuales al niño. Estas actividades sirven de base para establecer la relación que existe entre determinados juegos y el objetivo académico de aprendizaje a partir de los temas que se imparten en el grado respectivo.

- Luego, las actividades lúdicas que se llevan a cabo sirven para fomentar la interacción entre los alumnos, lo cual permite desarrollar los aspectos afectivos, sociales y emocionales del estudiante. La interacción se lleva a cabo a través de dinámicas que permiten la socialización orientada al aprendizaje de la actitud de compartir entre los niños, trabajos conjuntos, entre otros.

- Posteriormente, se busca fortalecer la relación en el hogar entre el alumno y los padres de familia a partir del proceso de socialización anterior. Este elemento se orienta a lograr que los padres puedan transmitir los valores a los niños como parte del proceso de aprendizaje que se lleva a cabo en el hogar.

- Finalmente, la tecnología respalda el desarrollo de las actividades educativas, facilita las interacciones y apoya para lograr los objetivos de aprendizaje que se esperan alcanzar en el grado respectivo. 


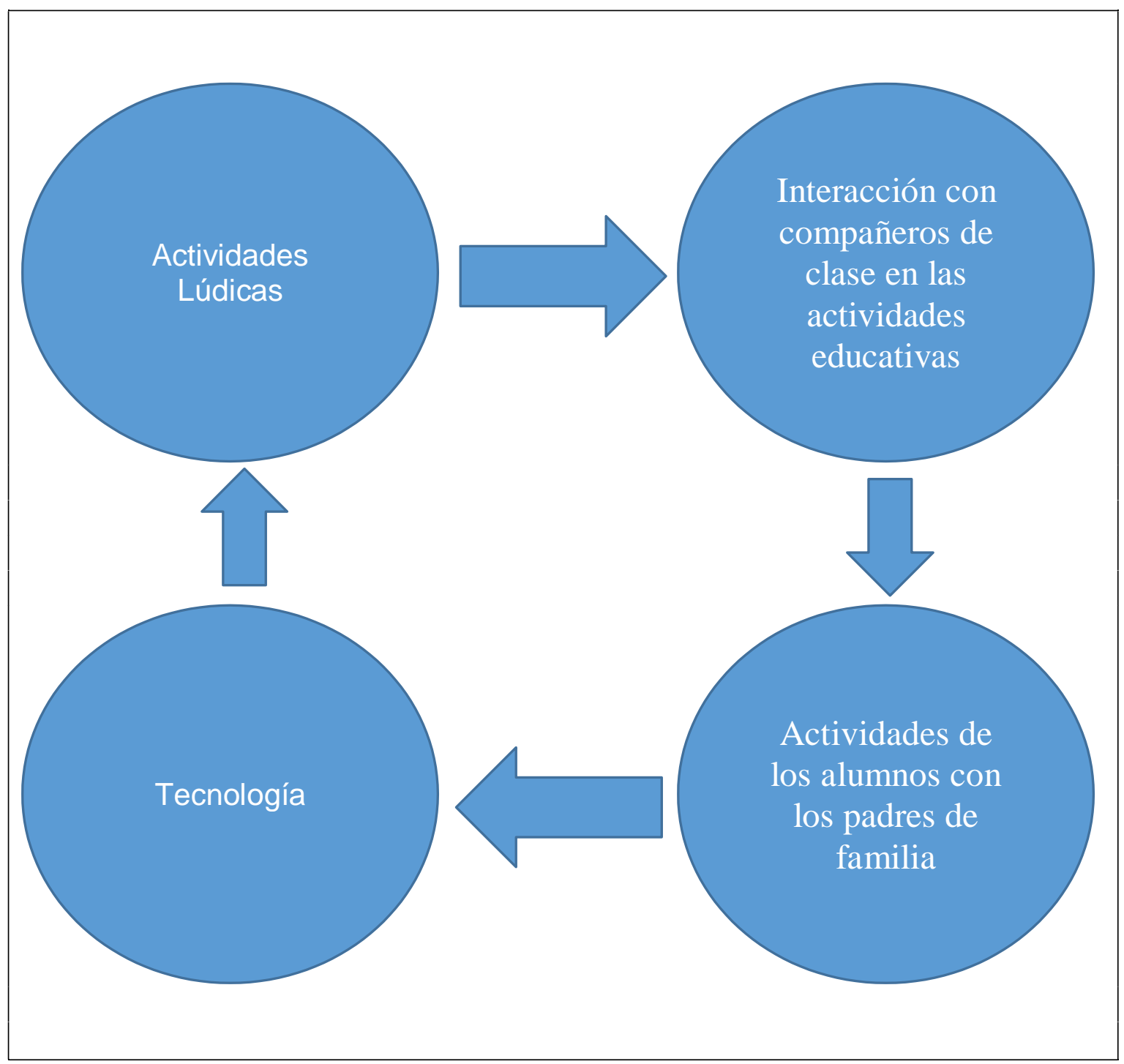

Figura 26. Modelo Educativo

El diseño y adaptación del modelo de aprendizaje para aplicar en el aula es realizado en forma conjunta con los docentes y la dirección del colegio. Las etapas que comprende son:

- Preparación de los aspectos didácticos para la clase, basados en el modelo lúdico de aprendizaje.

- Entrega del plan de actividades educativas y recursos necesarios para llevar a cabo la implantación del modelo educativo en el aula durante el año académico.

- Aprobación del plan propuesto por parte de la Dirección del Colegio. 
- Implementación por parte del docente en el salón de clase.

- Evaluación del aprendizaje alcanzado por los niños.

Por su parte, el proceso de selección de profesores comprende una serie de actividades que empieza con la convocatoria de los docentes, según el perfil definido. Luego, se realiza la recepción de los documentos de todos los postulantes para verificar si cumplen con los requisitos solicitados. Los docentes que cumplen con los requerimientos pasan por una entrevista en donde se evalúa si cuentan con las competencias para la labor docente con niños de tres a cinco años. Posteriormente, los docentes que han aprobado la entrevista, deberán presentar una clase modelo ante el Director del Colegio y el personal académico que cuentan con experiencia docente. Finalmente, los que muestran las competencias docentes en la clase modelo son seleccionados para ingresar a laborar en el Colegio. A los docentes seleccionados se les comunica su aceptación para laborar en el Colegio y se inicia su proceso de contratación.

Los docentes incorporados deben iniciar un proceso de inducción sobre el modelo educativo adoptado por el colegio, los valores organizacionales, las metas organizaciones que se esperan alcanzar, entre otros. (Ver Anexo 14)

\section{Proceso de matrícula.}

El proceso de matrícula se lleva cabo para registrar a todos los alumnos admitidos al colegio. El proceso se muestra en la Figura 27.

El proceso se inicia con la entrega los documentos completos por parte del área de admisión al área Registros, quienes deberán verificar que los documentos estén 
según los requerimientos del colegio. En caso de faltar algún documento se regresa el expediente al área de admisión.

El alumno declarado apto para matricularse deberá pagar el derecho de matrícula y el derecho de admisión para los de primer ingreso.

Una vez realizado el pago el alumno es registrado en el sistema del Colegio. A los padres de familia se les entregará su calendario escolar en donde se indica la fecha de inicio el año escolar, periodo de vacaciones, fecha de término, así como el calendario de pago de las mensualidades.

Finalmente la relación de los alumnos matriculados se envía al Ministerio de Educación para su registro. 


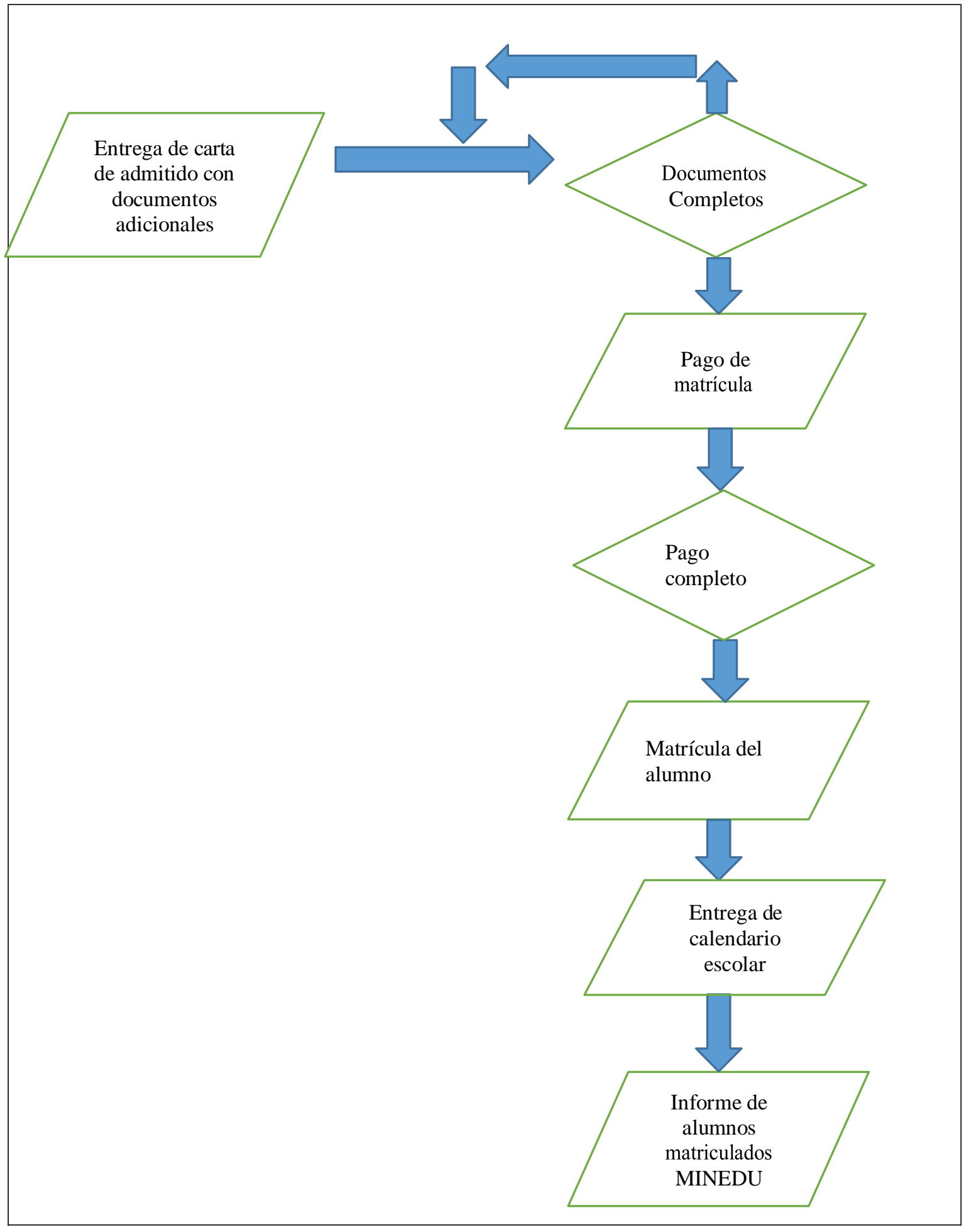

Figura 27. Proceso de Matricula

\section{Proceso de Evaluación}

Este proceso comprende todas las actividades orientadas tanto a la evaluación del rendimiento escolar de los alumnos, así como el desempeño docente. El propósito es 
tomar acciones para una corrección rápida si los resultados alcanzados no se ajustan a los esperados.

En el caso de evaluación del rendimiento escolar de los alumnos las actividades que comprende son: cumplimiento de los objetivos académicos que se esperaban alcanzar en el año escolar, cumplimiento del plan de trabajo anual, revisión de los instrumentos que permitían medir el desempeño académico, comunicaciones a la UGEL sobre el plan de trabajo y de otros informes sobre el rendimiento académico del alumno, medición del desempeño del alumno según los indicadores seleccionados, evaluación del resultado obtenido, formulación de planes de mejora.

La evaluación docente a su vez comprende las siguientes actividades: establecer los indicadores para la medición del desempeño, en caso que existan se revisa y se mejoran los indicadores propuestos si fuera el caso, revisión de los instrumentos de medición del desempeño docente, aplicación del instrumento de medición, evaluación de resultados, acciones de mejora para mejorar el desempeño mediante la capacitación docente, entre otros.

\subsubsection{Selección del equipamiento.}

Las instalaciones del Colegio comprenden aulas para impartir las clases, así como el área administrativa, admisión y biblioteca. A fin de implementar los ambientes indicados, se deberá invertir para la adquisición en equipo y maquinaria para cada una de las instalaciones propuestas. Las cotizaciones de los equipos y de los muebles se han 
obtenido mediante consulta telefónica o través de las páginas web de algunas empresas comerciales.

En las tablas $32,33,34,35,36,37,38$ y 39 se muestran los equipos y muebles que se deben adquirir, la cantidad a comprar de cada uno de ellos y el costo total en soles.

Tabla 32

Muebles y Equipos de la Oficina de Admisión

\begin{tabular}{lrrr}
\hline Mueble / Equipo & Cantidad & Costo Unitario & \multicolumn{1}{c}{ Costo soles } \\
\hline Módulo de recepción & 1 & 500 & 500 \\
Sillas & 3 & 120 & 360 \\
Computadora & 1 & 1200 & 900 \\
Central telefónica & 1 & 800 & 800 \\
Impresora & 1 & 600 & 600 \\
Estante & 1 & 500 & 500 \\
\hline Total & & & 3660 \\
\hline
\end{tabular}

Tabla 33

Muebles y Equipos de la Dirección

\begin{tabular}{lrrr}
\hline Mueble / Equipo & Cantidad & Costo Unitario & Costo soles \\
\hline Escritorio & 1 & 500 & 500 \\
Silla giratoria con brazos & 1 & 320 & 320 \\
Computadora/Laptop & 1 & 1200 & 1200 \\
Escritorio pequeño & 1 & 350 & 350 \\
Sillas & 3 & 120 & 360 \\
Teléfono & 2 & 120 & 360 \\
Impresora & 1 & 800 & 800 \\
Estante & 1 & 500 & 500 \\
\hline Total & & & 4390 \\
\hline
\end{tabular}


Tabla 34

Muebles y Equipos de la Oficina Administrativa / Docentes

\begin{tabular}{lrrr}
\hline Mueble / Equipo & Cantidad & Costo Unitario & Costo soles \\
\hline Escritorio & 1 & 350 & 350 \\
Silla giratoria con brazos & 1 & 320 & 320 \\
Computadora/Laptop & 1 & 1200 & 1200 \\
Mesa & 1 & 500 & 500 \\
Sillas & 5 & 120 & 600 \\
Teléfono & 3 & 120 & 360 \\
Impresora & 1 & 800 & 800 \\
Estante & 1 & 500 & 500 \\
\hline Total & & & 4630 \\
\hline
\end{tabular}

Tabla 35

Muebles y Equipos de la Oficina de Registros

\begin{tabular}{lrrr}
\hline Mueble / Equipo & Cantidad & Costo Unitario & \multicolumn{1}{c}{ Costo soles } \\
\hline Escritorio & 1 & 350 & 350 \\
Silla giratoria con brazos & 1 & 320 & 320 \\
Mesa & 1 & 500 & 500 \\
Sillas & 5 & 120 & 600 \\
Impresora & 1 & 800 & 800 \\
Estante & 1 & 500 & 500 \\
\hline Total & & & 3070 \\
\hline
\end{tabular}

Tabla 36

Muebles y Equipos de las Aulas

\begin{tabular}{lrrr}
\hline Mueble / Equipo & Cantidad & Costo Unitario & Costo soles \\
\hline Mesa & 4 & 120 & 480 \\
Silla & 4 & 120 & 480 \\
Computadora/Laptop & 4 & 1200 & 4800 \\
Proyector & 4 & 1425 & 5700 \\
Carpetas & 100 & 120 & 12000 \\
Estante & 4 & 350 & 1400 \\
\hline Total & & & 24,860 \\
\hline
\end{tabular}


Tabla 37

Muebles y Equipos de la Sala de Juegos

\begin{tabular}{lrrr}
\hline Mueble / Equipo & Cantidad & Costo Unitario & \multicolumn{1}{c}{ Costo soles } \\
\hline Mesa & 1 & 120 & 120 \\
Silla & 1 & 120 & 120 \\
Kit de Juegos & 1 & 7690 & 7690 \\
Estante & 1 & 500 & 500 \\
\hline Total & & & 8,430 \\
\hline
\end{tabular}

Tabla 38

Muebles y Equipos del Área de Refrigerio

\begin{tabular}{lrrr}
\hline Mueble / Equipo & Cantidad & Costo Unitario & \multicolumn{1}{c}{ Costo soles } \\
\hline Mesa & 4 & 120 & 480 \\
Silla & 25 & 120 & 3000 \\
Refrigeradora 318 L & 1 & 1800 & 1800 \\
Hervidor eléctrico & 1 & 100 & 100 \\
Cafetera & 1 & 180 & 180 \\
Microonda & 1 & 250 & 250 \\
Platos/vasos/cubiertos & 1 & 300 & 300 \\
Estante & 1 & 500 & 500 \\
Estante pequeño & 1 & 350 & 350 \\
\hline Total & & & 6,960 \\
\hline
\end{tabular}

Tabla 39

Muebles y Equipos de la Biblioteca

\begin{tabular}{lrrr}
\hline Mueble / Equipo & Cantidad & Costo Unitario & Costo soles \\
\hline Mesa & 1 & 120 & 120 \\
Silla & 25 & 120 & 3000 \\
Estante & 4 & 500 & 2000 \\
Estante pequeño & 1 & 350 & 350 \\
\hline Total & & & 5470 \\
\hline
\end{tabular}

La inversión total para el equipamiento de las oficinas administrativas, aulas, biblioteca, sala de juegos y el área de refrigerios sería de: 61,470 soles según se muestra en la Tabla 40. 
Tabla 40

Inversión Total en Muebles y Equipos para el Colegio

\begin{tabular}{lr}
\hline Área & Inversión soles \\
\hline Admisión & 3660.0 \\
Dirección & 4390.0 \\
Administración & 4630.0 \\
Registros & 3070.0 \\
Aulas & 24860.0 \\
Sala de Juegos & 8430.0 \\
Biblioteca & 5470.0 \\
Área de Docentes & 6960.0 \\
\hline Total & 61470.0 \\
\hline
\end{tabular}

\subsubsection{Lay out.}

Es la disposición física de la infraestructura del colegio. El lay out permite representar de forma gráfica el ambiente físico del colegio. Así, se prevé contar con un área de oficinas administrativas (dirección, administración, admisión, registros), áreas académicas (aulas, biblioteca, sala de juegos), área de refrigerio, jardines, depósito de material de mantenimiento, jardines y estacionamiento. (Ver Figura 28 Y 29).

En el inicio se contará con cuatro aulas equipadas que servirán para recibir a los alumnos durante los dos primeros años de operación del colegio. Posteriormente, se construirá cuatro aulas adicionales a fin cubrir la demanda originada por el ingreso de nuevos alumnos en el periodo.

El Colegio deberá invertir en un local de $750 \mathrm{~m} 2$ como área mínima a fin operar como sede del colegio y cumplir con el área mínima que establece el marco legal para las instituciones de educación inicial. 


\section{PRIMER NIVEL}

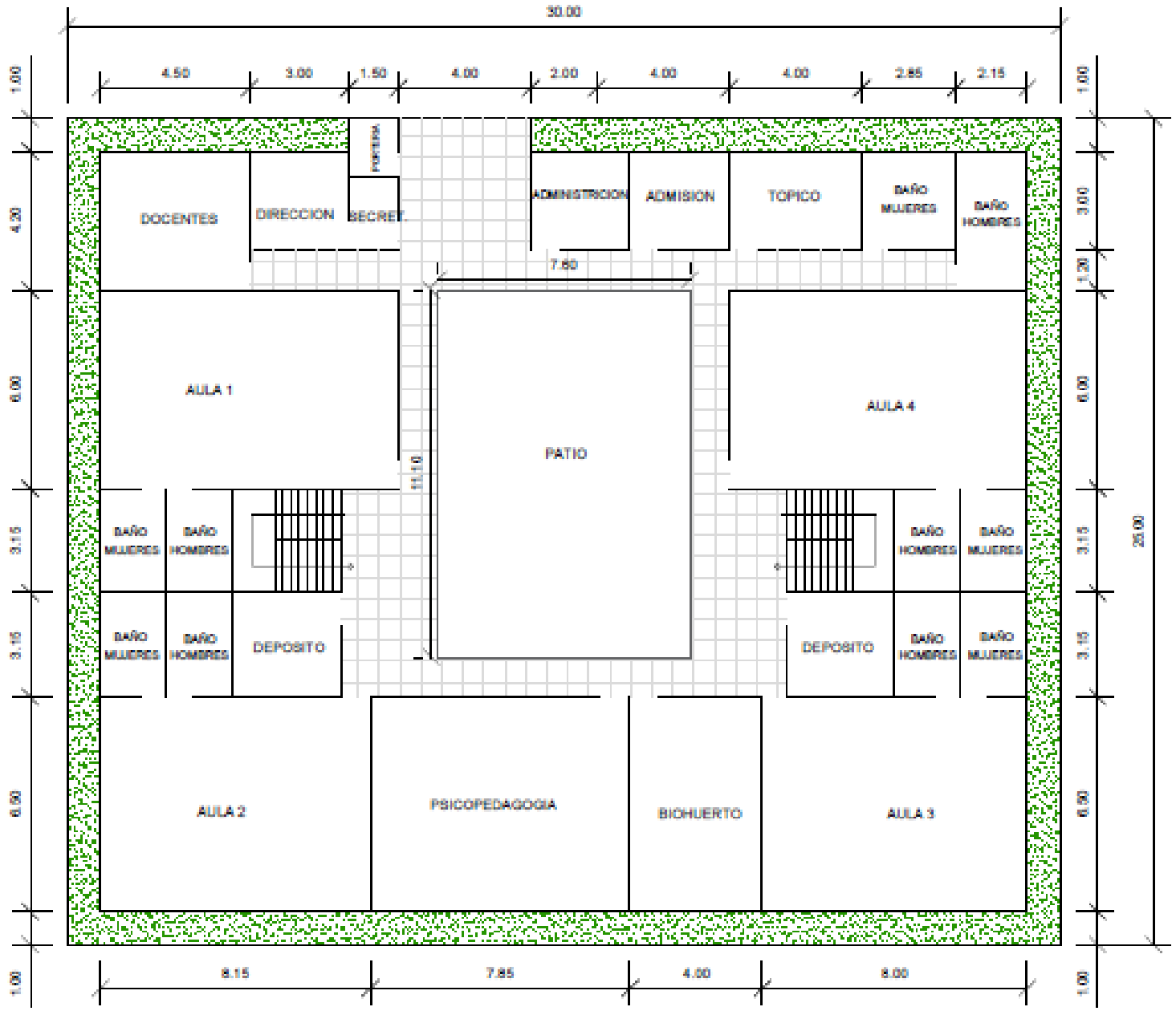

Figura 28. Distribución de las Oficinas y Aulas primer nivel 


\section{SEGUNDO NIVEL}

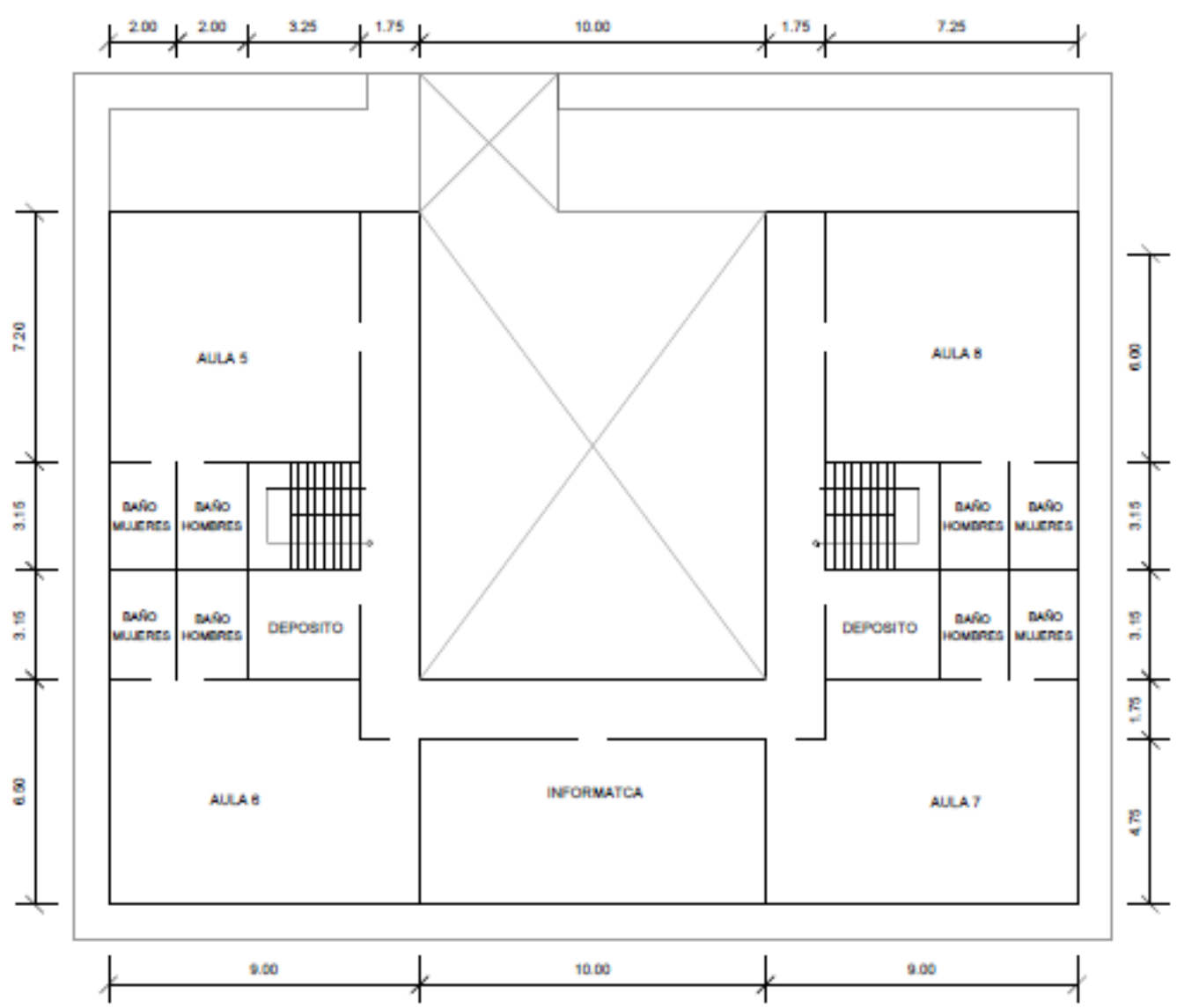

Figura 29. Distribución de las Oficinas y Aulas segundo nivel

\subsection{Determinación del Tamaño}

El tamaño del colegio estará en función de la demanda que se estima para los próximos años. Así, según el pronóstico de ventas tenemos que la demanda esperada tiene un crecimiento de $15 \%$. 
Si estimamos empezar con 40 alumnos en promedio, se espera que para el año 2021 se debiera incrementar la capacidad en casi un 100\%. Por tanto, se deberá ejecutar el plan de inversiones en ese año para la construcción de ocho aulas.

\subsubsection{Proyección de crecimiento.}

Según la demanda se espera un crecimiento en los alumnos que requieren el servicio de educación inicial de 40 el primer año, 62 el segundo año, 95 el tercer año, 110 el cuarto año, 126 el quinto año y así sucesivamente hasta el año diez. Ver Tabla 41 que muestra la proyección hasta el año diez de operación.

Tabla 41

Proyección de crecimiento

\begin{tabular}{|c|c|c|c|c|c|}
\hline Año de operación & $\begin{array}{l}\text { Número } \\
\text { de } \\
\text { alumnos }\end{array}$ & $\begin{array}{l}\text { Número } \\
\text { de aulas } \\
\text { Primer } \\
\text { grado }\end{array}$ & $\begin{array}{l}\text { Número } \\
\text { de aulas } \\
\text { Segundo } \\
\text { grado }\end{array}$ & $\begin{array}{l}\text { Número } \\
\text { de aulas } \\
\text { Tercer } \\
\text { grado }\end{array}$ & $\begin{array}{l}\text { Total } \\
\text { aulas }\end{array}$ \\
\hline Primer año & 100 & 2 & 1 & 1 & 4 \\
\hline Segundo año & 100 & 2 & 1 & 1 & 4 \\
\hline Tercer año & 100 & 2 & 1 & 1 & 4 \\
\hline Cuarto año & 100 & 2 & 1 & 1 & 4 \\
\hline Quinto año & 150 & 3 & 2 & 1 & 6 \\
\hline Sexto año & 150 & 3 & 2 & 1 & 6 \\
\hline Séptimo año & 150 & 3 & 2 & 1 & 6 \\
\hline Octavo año & 200 & 3 & 3 & 2 & 8 \\
\hline Noveno año & 200 & 3 & 3 & 2 & 8 \\
\hline Décimo año & 200 & 3 & 3 & 2 & 8 \\
\hline
\end{tabular}


Respecto al incremento de personal, se considera que se aumentará solamente en el número de docentes y auxiliares, dado que según los requerimientos se debe contar con un docente y un auxiliar por aula. Con relación al personal administrativo, se considera que es suficiente para brindar atención a los alumnos hasta el décimo año de operación del Colegio.

\subsubsection{Recursos.}

Por el tipo de servicio que se brinda, el colegio debe crecer principalmente en el número de aulas adecuadamente equipadas, lo cual significa que para el año cinco de operación del colegio se debe planear el aumento de cuatro aulas con su respectivo equipamiento.

La inversión para la construcción por aula es de 6,215 soles por metro cuadrado a precios actuales, según se muestra en la Tabla 42. Asimismo, se deberá contar con un terreno con capacidad para crecer en infraestructura de 100 metros cuadrados a partir del quinto año de operación del colegio.

Tabla 42

Muebles y Equipos por Aula

\begin{tabular}{lll}
\hline Mueble / Equipo & Cantidad & Inversión soles \\
\hline Mesa & 1 & 120.00 \\
Silla & 1 & 120.00 \\
Computadora/Laptop & 1 & $1,200.00$ \\
Proyector & 1 & $1,425.00$ \\
Carpetas & 25 & $3,000.00$ \\
Estante & 1 & 350.00 \\
\hline Total & & $6,215.00$ \\
\hline
\end{tabular}




\subsubsection{Tecnología.}

La tecnología necesaria para brindar el servicio educativo está relacionada con los equipos de cómputo, proyectores y software educativo. En relación a este rubro se estima que el crecimiento será en el área de registros, lo que demandará la compra de nuevos equipos de computación para aumentar el soporte a partir del tercer año de operación. (Ver Tabla 43).

Tabla 43

Muebles y Equipos para el Área de Registros

\begin{tabular}{lll}
\hline Mueble / Equipo & Cantidad & Inversión soles \\
\hline Computadora/Laptop & 1 & $1,200.00$ \\
Estante & 1 & 350.00 \\
\hline Total & & $1,550.00$ \\
\hline
\end{tabular}

\subsubsection{Flexibilidad.}

El colegio tiene la posibilidad de impartir clases en un horario ampliado si fuera el caso. Si se presentará demanda por este tipo de servicio el Colegio podría ofrecer este servicio, para lo cual deberá contar con un servicio de comedor para niños que lo puede realizar considerando una inversión de 6,960 soles según se muestra en la Tabla 44

Tabla 44

Muebles y Equipos del Área de Refrigerio

\begin{tabular}{lrrr}
\hline Mueble / Equipo & Cantidad & Costo Unitario & Costo soles \\
\hline Mesa & 4 & 120 & 480 \\
Silla & 25 & 120 & 3000 \\
Refrigeradora 318 L & 1 & 1800 & 1800 \\
Hervidor eléctrico & 1 & 100 & 100 \\
Cafetera & 1 & 180 & 180 \\
Microonda & 1 & 250 & 250
\end{tabular}




\begin{tabular}{llrr} 
Platos/vasos/cubiertos & 1 & 300 & 300 \\
Estante & 1 & 500 & 500 \\
Estante pequeño & 1 & 350 & 350 \\
\hline Total & & 6,960 \\
\hline
\end{tabular}

\subsubsection{Selección del tamaño ideal.}

El tamaño ideal del Colegio deberá ser calculado en función de la demanda del servicio educativo inicial. Asimismo, se debe considerar que el Colegio para este nivel debe tener un máximo de 342 alumnos que determina que el tamaño máximo sea de ocho aulas en total.

Con la infraestructura inicial el Colegio tiene la capacidad de brindar atención a 100 alumnos como máximo. En caso de continuar con el crecimiento proyectado se debe alcanzar una cantidad de alumnos de 200 como máximo, lo cual está de acuerdo tanto al personal administrativo y la infraestructura inicial considerando solamente el aumento en aulas y docentes.

\subsection{Estudio de localización}

La localización del Colegio depende de la evaluación de las alternativas que se tiene para ubicarlo. Las alternativas propuestas son evaluadas con ciertos factores que determinan en donde es el lugar más conveniente para ubicar el colegio en la ciudad de Chiclayo.

\subsubsection{Definición de factores locacionales.}

La ubicación del colegio "Estrellitas de Jesús" depende de cinco factores locacionales, los que están vinculados con las facilidades que se deben ofrecer a nuestro mercado objetivo. 
a) Cercanía: el colegio debe estar ubicado en una zona en donde los padres de familia puedan llevar o recoger a sus hijos fácilmente. Asimismo, el colegio debe estar ubicado en una zona que permita a los padres de familia visitar a la institución educativa para solicitar información.

b) Acceso: el colegio debe estar localizado en una zona en donde los padres de familia pueden acceder sin problemas y que no presente dificultades en el ingreso al colegio sea por la congestión vehicular o la restricción en el ingreso a la zona. También se debe considerar que la zona donde esté ubicado el colegio sea accesible para los empleados a través del transporte público.

c) Seguridad: la zona donde esté ubicado el colegio, debe ser segura. Asimismo, sus alrededores deben estar protegidos mediante vigilancia policial o del serenazgo local a fin de evitar asaltos a los padres de familia o al personal que labora en el colegio. El colegio debe brindar seguridad adicional para los padres de familia que usan nuestro servicio educativo.

d) Estacionamientos: el colegio debe estar ubicado en una zona en la que se encuentre playas de estacionamiento rápidamente, de modo que el padre de familia cuente con este tipo de facilidad si desea reunirse con el personal docente o autoridades. La calle donde esté ubicado el colegio debe ser amplia a fin que los padres de familia puedan dejar y recoger a su hijo con facilidad.

e) Precio: El precio del terreno donde estará ubicado el colegio es de 80 dólares en promedio el metro cuadrado y debe tener un área de al menos 750 metros a fin de construir el edificio que albergará al Colegio. 
A fin de determinar la ubicación exacta del colegio se han considerado tres propuestas, las cuales serán evaluadas con los cinco factores locacionales considerando un porcentaje para cada factor y una escala de calificación en donde cinco es muy bueno y uno muy malo.

Las alternativas para ubicar el colegio se muestran en la Tabla 45, en donde se presenta la descripción de cada una de las opciones.

Tabla 45

Alternativas para el Colegio

\begin{tabular}{|c|c|c|c|}
\hline & Alternativa 1 & Alternativa 2 & Alternativa 3 \\
\hline $\begin{array}{l}\text { Ubicación de } \\
\text { los terrenos }\end{array}$ & $\begin{array}{l}\text { Esquina Calle } \\
\text { Pacasmayo y } \\
\text { Prolongación Talara. } \\
\text { Urbanización Santa } \\
\text { Victoria. }\end{array}$ & $\begin{array}{l}\text { Esquina Calle Ayar } \\
\text { Manco y Loreto } \\
\text { Urbanización Patazca. }\end{array}$ & $\begin{array}{l}\text { Avenida .... } \\
\text { Distrito laVictoria }\end{array}$ \\
\hline Acceso & $\begin{array}{l}\text { Zona céntrica } \\
\text { Transporte público. }\end{array}$ & Transporte público. & $\begin{array}{l}\text { Vías de acceso fáciles. } \\
\text { Transporte público. }\end{array}$ \\
\hline Seguridad & $\begin{array}{l}\text { cámara de seguridad } \\
\text { externa. }\end{array}$ & No tiene. & $\begin{array}{l}\text { cámara de seguridad } \\
\text { externa. }\end{array}$ \\
\hline $\begin{array}{l}\text { Estacionamie } \\
\text { nto }\end{array}$ & Si. & Si. & Si. \\
\hline Precio & US \$ $500 \mathrm{~m} 2$ & US \$ 450 & US \$ 80 \\
\hline Fotografía & 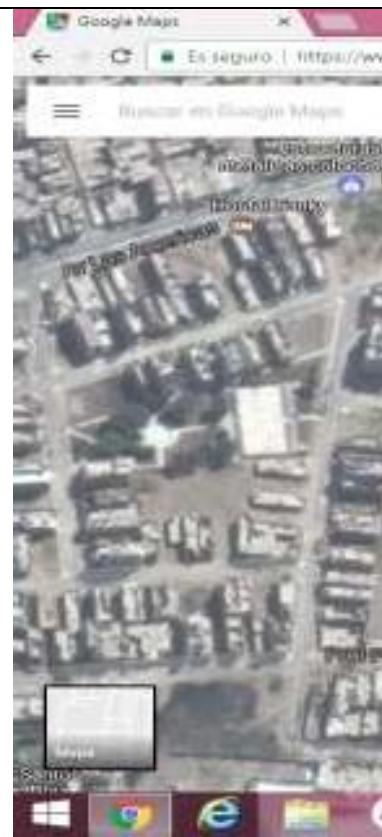 & 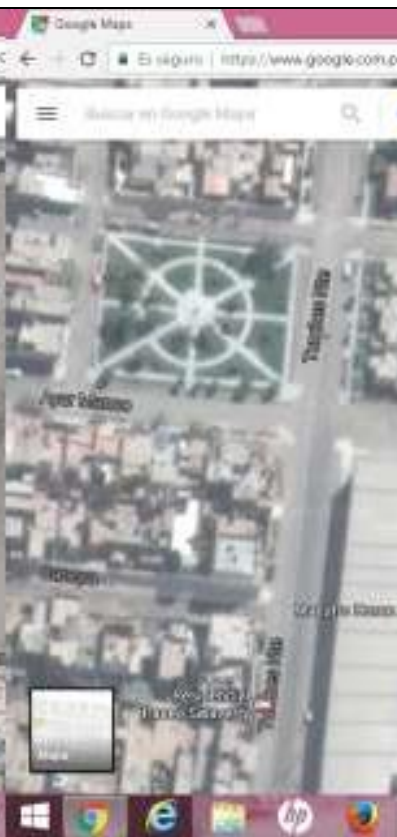 & 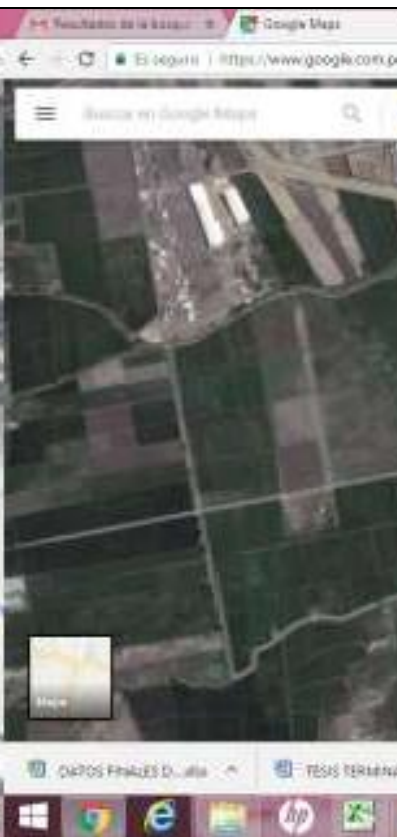 \\
\hline
\end{tabular}


La evaluación de las alternativas presentadas se realiza con los factores locacionales, según se muestra en el Tabla 46. El porcentaje asignado a cada una de los factores se realizó tomando en cuenta la opinión de personas relacionados con el sector urbanístico.

Tabla 46

Cálculo de ubicación del colegio

\begin{tabular}{|l|l|l|l|l|}
\hline & Peso \% & Alternativa 1 & Alternativa 2 & Alternativa 3 \\
\hline $\begin{array}{l}\text { Ubicación del } \\
\text { terrenos }\end{array}$ & $20 \%$ & $5 / 1.00$ & $4 / 0.80$ & $5 / 1.00$ \\
\hline Acceso & $25 \%$ & $4 / 1.00$ & $3 / 0.75$ & $3 / 0.75$ \\
\hline Seguridad & $20 \%$ & $4 / 0.80$ & $4 / 0.80$ & $4 / 0.80$ \\
\hline Estacionamiento & $10 \%$ & $4 / 0.40$ & $4 / 0.40$ & $4 / 0.40$ \\
\hline Precio & $25 \%$ & $3 / 0.75$ & $3 / 0.75$ & $5 / 1.25$ \\
\hline Total & & 3.95 & 3.75 & 4.20 \\
\hline
\end{tabular}

El resultado alcanzado indica que la localización más conveniente para el Colegio "Estrellitas de Jesús" es en la esquina de la calle Pacasmayo con la prolongación Talara en la Urbanización Santa Victoria del Distrito de la Victoria.

\subsubsection{Consideraciones legales.}

El inicio de operaciones del Colegio "Estrellitas de Jesús" esta normado por determinado marco legal que servirá de base para iniciar el trámite ante la Municipalidad Provincial de Chiclayo.

\subsubsection{Identificación del marco legal.}

El procedimiento para tramitar la licencia de funcionamiento está regulado por las consideraciones legales que se encuentra en:

a) Ley N² 28976: Ley Marco de Licencia de Funcionamiento. 
b) D.S. No 066-2007-PCM : Reglamento de Inspecciones Técnicas de Seguridad en Defensa Civil

c) Ordenanza 2005-GPCH: Ordenanza que regula el otorgamiento de la Licencia Municipal de Funcionamiento a Establecimientos Comerciales, Industriales y/o de servicios dentro de la Jurisdicción de la Municipalidad Provincial de Chiclayo.

d) Ordenanza N 013-2007GPCH: Simplificación Administrativa para Otorgamiento y Regulación de las Licencias de Funcionamiento en la Ciudad de Chiclayo.

Los requisitos para solicitar la licencia de funcionamiento según la Municipalidad de Chiclayo (http://www.munichiclayo.gob.pe) son:

a) Presentar el formato de trámite interno (FTI) $\mathrm{N}^{\circ} 4207$, firmado por el solicitante o su representante legal, que tendrá carácter de declaración jurada.

b) Copia fedateada de D.N.I.

c) Ficha R.U.C.

d) Vigencia de poder del representante legal expedido por SUNARP, con una antigüedad no mayor a 30 días calendarios, en el caso de personas jurídicas.

e) TASA por el tipo de licencia de funcionamiento que solicita.

f) Para el caso de colegios se solicita además la autorización de la Dirección Regional de Educación de Lambayeque.

Con respecto a defensa civil se solicita el Certificado de INDECI REGIONAL, que requiere una inspección de detalle o multidisciplinaria a cargo del Comité Regional de INDECI). 
En relación con la legislación que regula el ámbito laboral se tiene el siguiente marco legal:

a) Constitución Política del Perú: que establece la jornada laboral máxima de ocho horas diarias y los descansos remunerados.

b) Decreto Legislativo $N^{o} 728$, Ley de Productividad y Competitividad Laboral y el Reglamento de dicha Ley: que permite fomentar la capacitación y formación laboral de los trabajadores como un mecanismo de mejoramiento de sus ingresos y la productividad del trabajo, garantizar los ingresos de los trabajadores, así como la protección contra el despido arbitrario respetando las normas constitucionales.

c) Ley de Seguridad y Salud en el Trabajo: que tiene como objetivo promover una cultura de prevención y riesgos laborales en el país.

d) Decreto Legislativo $\mathrm{N}^{\circ} 892$ que regula el derecho de participación de los trabajadores en las utilidades de la empresa.

e) Ley General de Inspección del Trabajo (LEY No 28806, 2006) que tiene "por objeto regular el Sistema de Inspección del Trabajo, su composición, estructura orgánica, facultades y competencias, de conformidad con el Convenio $\mathrm{N}^{\mathrm{o}} 81$ de la Organización Internacional del Trabajo".

Otro aspecto a considerar por el Colegio está vinculado con la legislación tributaria que se presenta en el Decreto Legislativo No 771 (1994). Este dispositivo legal ha recibido la denominación de "Ley Marco del Sistema Tributario Nacional" que regula la estructura básica del sistema tributario. En este contexto, el Colegio deberá pagar el impuesto a la renta, que se considera como un $30 \%$ anual, el cual se estima como un $2 \%$ mensual de las ventas. 


\subsubsection{Ordenamiento jurídico de la empresa.}

El ordenamiento jurídico que debe considerar el Colegio es la Ley General de Sociedades, Ley $N^{\circ} 26887$ (1997). Según este dispositivo el Colegio deberá organizarse como Sociedad Anónima Cerrada o por su abreviatura como S,A.C.

En este tipo de sociedad, los socios solo responden con su patrimonio personal por las deudas sociales del Colegio. Es decir, la responsabilidad de los socios se encuentra limitada por el monto de sus aportes.

\subsection{Determinación de la localización óptima}

En la Figura 30 se muestra la ubicación del colegio en la urbanización Santa Victoria en la ciudad de Chiclayo. Por consiguiente la implementación del colegio será en la esquina de la calle Pacasmayo con la prolongación Talara en la Urbanización Santa Victoria.

Este lugar permite estar cerca a los principales servicios, centros comerciales, transporte público que permite un acceso rápido al lugar. También se cuenta con facilidades para el estacionamiento de los vehículos de los padres de familia cuando visiten el colegio. 


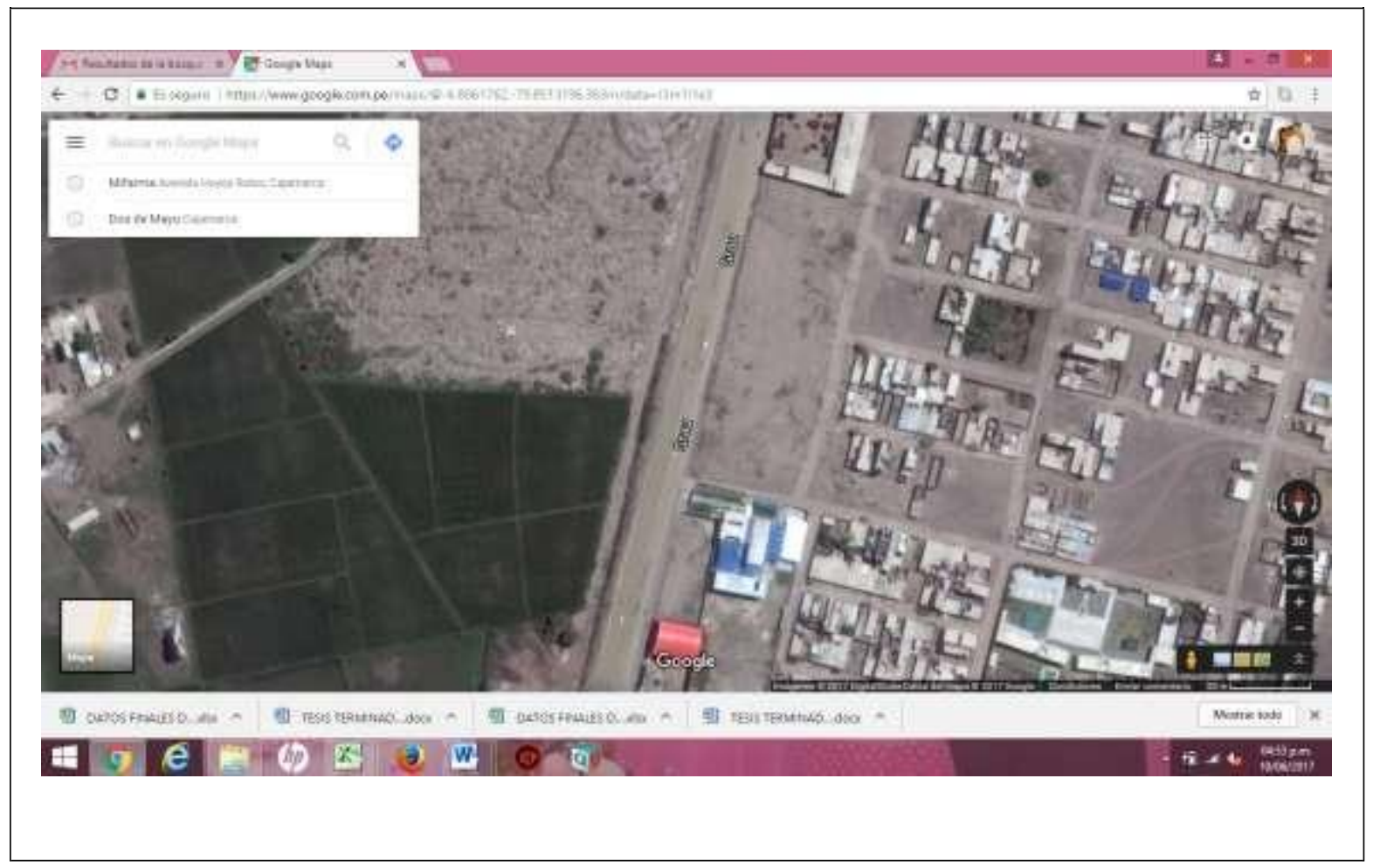

Figura 30. Ubicación del colegio 


\section{Capítulo VI \\ Aspectos organizacionales}

\subsection{Caracterización de la cultura organizacional deseada}

La cultura organizacional del colegio estará basada en tres elementos esenciales para su operación. David (2013) define los elementos que permiten brindar una dirección estratégica la organización:

a) Visión: a fin de reconocer por todo el personal lo que aspira a llegar a ser el colegio en el futuro. La visión permite que todos los integrantes de la organización tengan un objetivo general común.

b) Misión: para conocer los elementos que deben estar presente en las operaciones diarias del colegio. La misión permite establecer el propósito permanente de la organización.

c) Principios: permiten establecer los pilares organizacionales que servirán de base para la toma de decisiones relacionadas con la operación del colegio. Los principios se expresan en los valores organizacionales del colegio 


\subsubsection{Visión.}

Según David (2013), la visión de una organización debe expresar los que quiere llegar a ser en el largo plazo. Así, la visión planteada para el Colegio Inicial propuesto, debe responder a ésta pregunta y dar a conocer los que esperamos se convierta el colegio en el futuro.

La visión debe presentar elementos que permitan reflejar lo que desea alcanzar el Colegio en los próximos años:

a) Objetivo General: Ser reconocido entre los diez primeros colegios de educación en la ciudad de Chiclayo por su calidad académica.

b) Producto: educación inicial en la ciudad de Chiclayo

c) Fuente de ventaja competitiva: innovación en sus programas y uso de la tecnología.

La visión propuesta es la siguiente:

"Ser reconocido por su calidad académica como uno de los primeros colegios de educación inicial en la región norte del país, a partir de ofrecer una educación integral para la formación de los niños basada en la innovación de sus programas y en el uso de la tecnología".

Esta visión permite establecer el futuro deseado para nuestra organización y servirá de base para el desarrollo y crecimiento de nuestro colegio.

\subsubsection{Misión.}

La misión es el propósito permanente de la organización y expresa la razón del negocio. Para formular una misión se debe incluir los siguientes elementos: "clientes; 
productos y servicios; mercados; tecnología; preocupación por la supervivencia, el crecimiento y la rentabilidad; filosofía; concepto que tiene la empresa de sí misma; preocupación por su imagen pública; y preocupación por los empleados” (David, 2013, p. 70).

a) Clientes: padres de familia y niños menores de 6 años

b) Productos y Servicios: servicio de educación inicial e integración familiar

c) Mercado: ciudad de Chiclayo

d) Tecnología: tecnología de vanguardia en la educación inicial

e) Preocupación por la supervivencia

f) Concepto que tiene la empresa de sí misma: servicio de excelencia

g) Preocupación por su imagen pública: fortalecer vínculos con la comunidad

h) Preocupación por los empleados: docentes especializados.

A partir de los elementos indicados la misión propuesta para el colegio es la siguiente:

"Brindar un servicio de educación inicial basado en la tecnología de vanguardia para niños menores de seis años que permitirá lograr su integración familiar y fortalecer sus vínculos con la comunidad en la ciudad de Chiclayo. Se ofrecerá un servicio de excelencia al padre de familia y una formación básica para los niños con docentes especializados en educación inicial”.

Así, la misión propuesta permite definir claramente el servicio educativo a ofrecer y reconocer los elementos claves para su desempeño, en los cuales se deberá 
enfocar el colegio a fin de establecer su diferenciación con otras instituciones educativas de la región.

\subsubsection{Principios.}

Los principios están determinados por los valores que adopta la organización como base para la ejecución de sus operaciones. Según Thompson, Strickland y Gamble (2012 p. 27) los valores son "las ideas, rasgos, y normas de conducta que se espera que el personal manifieste al trabajar y perseguir su visión estratégica y su estrategia general”.

Los valores propuestos para el colegio son:

a) Excelencia en el servicio: se debe buscar ofrece un servicio a los niños y padres de familia que supere sus expectativas.

b) Respeto a los empleados: se debe respetar a los colaboradores del negocio de modo que actúen con libertad en el negocio.

c) Innovación: los colaboradores deberán orientarse a la innovación permanente el servicio que brindamos, así como en los procesos del colegio.

d) Calidad en la educación: los estándares de la educación que brinda el colegio deben ser superiores a otras instituciones de la región.

e) Ética: se debe actuar con honestidad e integridad en todas las decisiones que se toma y las actividades que lleva a cabo el colegio.

Los valores propuestos son la base fundamental para la ejecución de las actividades que se llevan a cabo en el colegio. 


\subsection{Formulación de Estrategias del Negocio}

Las estrategias del negocio se plantean en función del análisis del entorno, el análisis del sector educativo en la región y las expectativas de los padres de familia sobre el servicio de educación que demandan.

\subsubsection{Estrategia de Negocios.}

Según Porter (1985) la estrategia de negocios para una organización que compite en el mercado puede ser la diferenciación o liderazgo en costos. En este marco, la estrategia de negocios seleccionada por el Colegio es la diferenciación basada en la calidad del servicio educativo y la excelencia en el servicio de atención a los padres de familia y comunidad.

Esta estrategia permitirá enfocarnos en lo que buscan los padres de familia para la educación de sus hijos: educación de calidad que permita una formación adecuada de los niños y excelencia en la atención a fin que el padre conozca y participe en el proceso de aprendizaje de sus hijos.

\subsubsection{Estrategia de Marketing.}

La estrategia de marketing a implementar será el desarrollo del producto, según Ansoff mencionado David (2013). Es decir, la estrategia de este nivel permitirá diseñar e implementar un nuevo servicio educativo de calidad y en donde los padres de familia participen en la formación de sus hijos. Asimismo, la estrategia de este nivel permitirá apoyar y soportar la estrategia de diferenciación del negocio. 
Por consiguiente, mediante esta estrategia se desarrollara un servicio educativo que permitirá mejorar o modificar algunas características actuales del servicio de los colegios a nivel inicial del que actualmente que se ofrece en el mercado. Estas mejoras en el producto que ofrece el colegio están dadas fundamentalmente en ofrecer un servicio educativo basado en los elementos que valoran los padres de familia durante el proceso de selección de un colegio para sus hijos. Estos elementos son:

- Número de alumnos por salón de clase

- Infraestructura moderna

- Calidad de la enseñanza

\subsubsection{Estrategia de Recursos Humanos.}

La estrategia de recursos humanos deberá estar orientada al desarrollo de los docentes y personal del colegio. El desarrollo del talento humano de la empresa permitirá contar con personal comprometido con la organización y que brinde su mejor esfuerzo en la búsqueda de la excelencia en el servicio.

El desarrollo del personal será logrado mediante programas de capacitación y un plan de vida para todos los que pertenecen a la organización.

\subsection{Determinación de las ventajas competitivas críticas.}

Las ventajas competitivas a desarrollar en el colegio están relacionadas con las competencias que soportan la estrategia. Las ventajas que se consideran críticas en el servicio educativo son: 
a) Servicio de atención a los padres de familia: basado en una operación del colegio enfocada en los clientes.

b) Servicio de atención al alumno: soportado en un conjunto de actividades que permitan que el alumno encuentre facilidad en los servicios de educación y en los servicios complementarios.

c) Comunicación con los padres de familia: a partir del uso de la tecnología y del proceso relacionado con comunicación del colegio con los padres de familia.

d) Innovación de los procesos de aprendizaje: basado en el modelo educativo del colegio, que debe estar orientado a integrar el aprendizaje del niño con los docentes, padres de familia y comunidad.

e) Eficiencia en los procesos del colegio: a partir de sistemas de información que busquen una gestión integral de los procesos.

\subsection{Diseño de la estructura organizacional deseada}

La estructura organizacional del colegio está orientada a soportar las actividades que se deben llevar a cabo para implementar las estrategias propuestas. A fin de contar con una estructura sencilla y de fácil manejo se ha definido para el Colegio la estructura lineal, que se ajusta más para las pequeñas organizaciones.

Según Chiavenato (2009) la estructura de carácter lineal tiene claramente definidas las responsabilidades de los cargos que se consideran en la organización y tiene como finalidad establecer los niveles de autoridad y jerárquicos, así como fijar la cadena de mando. 
Los elementos a tomar en cuenta para definir el diseño organizacional del Colegio, son los siguientes:

a) Atender las disposiciones normativas de ley de educación.

b) Apoyo al cumplimiento de los objetivos y las estrategias institucionales.

c) Agrupación de unidades de trabajo considerando los aspectos funcionales.

d) Distribuyendo funciones en la organización.

e) Establecer funciones por área.

f) Definir cargas de trabajo.

g) Usar de manera efectiva el soporte tecnológico.

h) Establecer o áreas de trabajo por afinidad en la labor realizada.

Los niveles organizacionales considerados para nuestro Colegio se muestran en la Figura 31. Así, se tiene que la Dirección del Colegio tiene a su cargo el área académica y administrativa.

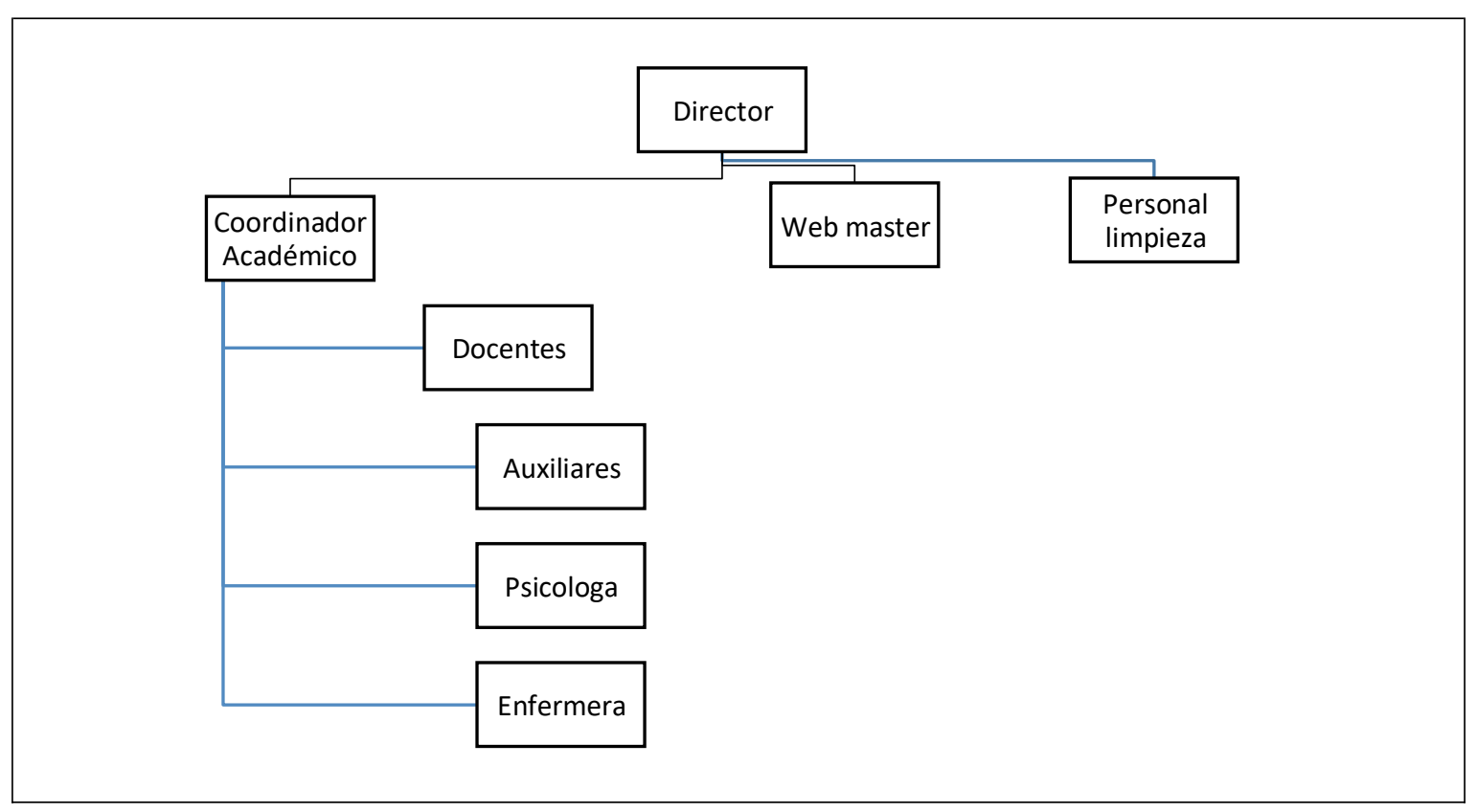

Figura 31. Organigrama del Colegio 


\subsection{Diseño de los perfiles de puestos clave}

Los puestos que se han propuesto para el personal del colegio deberán tener el siguiente perfil.

\section{Director del colegio.}

a) Objetivo: Dirigir el colegio estableciendo las estrategias para el desarrollo de la organización.

b) Descripción del puesto: Es la persona encargada de establecer y proponer las estrategias del colegio y de ejecutar los planes aprobados por la Promotoría, así como dirigir el personal de todas las unidades del Colegio a su cargo.

c) Principales responsabilidades: Se encarga de implementar los planes de inversión propuestos, establecer planes para el desarrollo de la infraestructura y del crecimiento del colegio.

d) Requisitos de puesto: Deberá ser licenciado(a) en educación con maestría en gestión académica.

e) Otros requisitos: Deberá contar con experiencia en la dirección o gestión académica de un colegio inicial de al menos cinco años.

f) Competencias: Profesional con capacidad de liderazgo y trabajo en equipo.

g) Remuneración: De 2500 a 3500 soles. Además, se menciona que tendrá un bono de desempeño a partir del segundo año en relación al aumento en las metas de captación.

h) Fecha de incorporación: Al inicio de las operaciones del colegio. 


\section{Docentes.}

a) Objetivo: Personal que debe llevar a cabo el proceso educativo de los niños matriculados en el colegio.

b) Descripción del puesto: Profesional que tiene a su cargo el proceso de enseñanza de los niños del colegio. Reporta al Coordinador Académico con quien coordina la elaboración del plan de trabajo anual.

c) Principales responsabilidades: Impartir las clases para los niños en el horario acordado. También debe reunirse con los padres de familia para informar sobre las actividades académicas de los niños y de presentar las evaluaciones del desempeño en el aula de los niños.

d) Requisitos del puesto: Deberá ser licenciado(a) en educación con especialización en nivel inicial.

e) Otros requisitos: Debe poseer experiencia en docencia a nivel inicial.

f) Competencias: Profesional con capacidad para la enseñanza a niños y de trabajo en equipo.

g) Remuneración: De 1300 a 1800 soles.

h) Fecha de incorporación: Al inicio de las actividades del colegio.

\section{Psicóloga.}

a) Objetivo: Atender a los niños del colegio que presentan alguna conducta anormal en su comportamiento.

b) Descripción del puesto: Persona que tiene una especial capacidad para conocer el carácter de los niños y padres de familia a fin de comprender las causas de su comportamiento y establecer mejores relaciones. Reporta al coordinador académico. 
c) Principales responsabilidades: Profesional que interviene en el comportamiento humano en situaciones educativas desarrollando sus capacidades intentando de aumentar la eficiencia del aprendizaje en las escuelas, mediante la aplicación de sus conocimientos.

d) Requisitos del puesto: licenciado(a) en psicología.

e) Otros requisitos: Debe poseer experiencia en psicología del aprendizaje y motivación en el nivel inicial.

f) Competencias: Debe contar con capacidad de liderazgo y trabajo en equipo. Debe ser sensible a los problemas de los padres de familia.

g) Remuneración: De 1400 a 1700 soles.

h) Fecha de incorporación: Al inicio de las actividades escolares.

\section{Enfermera.}

a) Objetivo: Atender a los niños del colegio que necesiten atención inmediata sobre su salud.

b) Descripción del puesto: Persona que tiene una especial capacidad para conocer el estado de salud de los niños. Reporta al coordinador académico.

c) Principales responsabilidades: Profesional que interviene en el seguimiento y la mejora de la salud de los niños, mediante la aplicación de sus conocimientos.

d) Requisitos del puesto: licenciado(a) en psicología.

e) Otros requisitos: Debe poseer experiencia en enfermería infantil y motivación en el nivel inicial.

f) Competencias: Debe contar con capacidad de liderazgo y trabajo en equipo. Debe ser sensible a los problemas de los padres de familia.

g) Remuneración: De 1400 a 1700 soles. 
h) Fecha de incorporación: Al inicio de las actividades escolares.

\section{Coordinador Académico.}

a) Objetivo: profesional que tiene como propósito llevar a cabo las labores administrativas del colegio.

b) Descripción del puesto: Encargado de coordinar todas las actividades administrativas del colegio con la dirección y con las áreas de webmaster y mantenimiento.

c) Principales responsabilidades: Ejecutar las actividades administrativas del colegio como: cobro de las mensualidades, compras de los insumos y materiales educativos, pago a proveedores, pago a docentes, entre otros.

d) Requisitos del puesto: Deberá ser licenciado(a) en administración y/o educación con especialización en gestión académica a nivel inicial.

e) Otros requisitos: Debe poseer experiencia en gestión académica en colegios y docente.

f) Competencias: Profesional con capacidad de trabajar en equipo y de comunicación.

g) Remuneración: De 1200 a 1600 soles.

h) Fecha de incorporación: Al inicio de las actividades del Colegio.

\section{Auxiliar.}

a) Objetivo: Tiene como propósito realizar la comunicación con los padres de familia a solicitud de la dirección del colegio y velar por la seguridad de los alumnos.

b) Descripción del puesto: Coordinar con la Dirección del Colegio y los padres de familia para mantener la seguridad de los alumnos. 
c) Principales responsabilidades: vigila la seguridad de los alumnos y complementa las enseñanzas del docente.

d) Requisitos del puesto: Deberá ser licenciado(a) en educación con especialización en gestión académica a nivel inicial.

e) Otros requisitos: Debe poseer experiencia en gestión académica o de registro de información a nivel de educación básica.

f) Competencias: Profesional con capacidad de trabajar en equipo y coordinación.

g) Remuneración: De 900 a 1200 soles.

h) Fecha de incorporación: Desde el inicio de las actividades del colegio.

\section{Web master.}

a) Objetivo: Tiene como propósito realizar la comunicación del colegio a través de los medios virtuales.

b) Descripción del puesto: Tiene a cargo la página web del colegio y coordina con el jefe administrativo.

c) Principales responsabilidades: tiene como función diseñar, actualizar y administrar la página web del colegio.

d) Requisitos del puesto: Deberá ser técnico en informática con especialización en diseño de páginas web o portales.

e) Otros requisitos: Debe poseer experiencia en administración de páginas web y de plataformas educativas.

f) Competencias: Persona con capacidad de trabajar en equipo y de innovación.

g) Remuneración: De 1000 a 1800 soles.

h) Fecha de incorporación: desde el inicio de las actividades del colegio. 


\section{Personal de limpieza.}

a) Objetivo: Mantener el orden y la limpieza de las instalaciones del colegio.

b) Descripción del puesto: Reporta al Jefe Administrativo a fin de coordinar los horarios de mantenimiento y limpieza del colegio.

c) Principales responsabilidades: Realizar las operaciones de limpieza y de mantenimiento del colegio.

d) Requisitos del puesto: Deberá tener estudio de secundaria incompleta.

e) Otros requisitos: Debe poseer experiencia en mantenimiento de centros educativos a nivel básico.

f) Competencias: Persona con capacidad de trabajar en equipo y de ejecución de tareas básica.

g) Remuneración: de 850 a 980 soles.

h) Fecha de incorporación: desde el inicio de las actividades del Colegio.

\section{Personal de Seguridad.}

a) Objetivo: Garantizar el resguardo de las instalaciones del colegio y seguridad de los niños.

b) Descripción del puesto: Reporta al Coordinador Académico a fin de coordinar los horarios de seguridad.

c) Principales responsabilidades: Realizar la vigilancia de la institución y velar por la seguridad de los niños.

d) Requisitos del puesto: Deberá tener estudio de secundaria incompleta.

e) Otros requisitos: Debe poseer experiencia en seguridad de centros educativos a nivel básico. 
f) Competencias: Persona con capacidad de trabajar en equipo y de ejecución de tareas básica.

g) Remuneración: de 850 a 980 soles.

h) Fecha de incorporación: desde el inicio de las actividades del Colegio.

Asimismo, tenemos a los siguientes grupos relacionados con el Colegio:

a) Promotoría: conformado por los accionistas del negocio y donde se aprueban los planes propuestos para el desarrollo del colegio.

b) APAFA: La Asociación de Padres de Familia es una organización estable de personas naturales, sin fines de lucro, con personería jurídica de derecho privado, que tiene por finalidad propiciar la participación de los padres de familia, docentes y directores en el proceso educativo de sus hijos, pupilos y curados, matriculados en la Institución Educativa. Su razón de ser está ligada a la existencia de la Institución Educativa y del servicio educativo que brinda.

\subsection{Remuneraciones, compensaciones e incentivos}

Las remuneraciones propuestas para el personal de colegio se basan en el sueldo promedio que reciben las personas a cargo de puestos similares en otros colegios iniciales en la ciudad de Chiclayo. Con relación a los beneficios a recibir por el personal se ha tomado en cuenta lo establecido por la Ley de Promoción y Formalización de la Micro y Pequeña Empresa No 28015 (2003), en donde se establece el régimen laboral que se debe considerar en nuestro colegio por tener menos de10 trabajadores. 
Los sueldos y salarios propuestos para el personal directivo, docente y administrativo se muestran en la Tabla 47. El personal administrativo es suficiente para atender a los alumnos del colegio y solamente habrá un crecimiento en el número de docentes dado que se requiere un docente por aula.

Tabla 47

Sueldos y salarios del personal del Colegio

\begin{tabular}{llll}
\hline Personal & $\begin{array}{l}\text { No. de } \\
\text { personal }\end{array}$ & Sueldo & $\begin{array}{l}\text { Bonificación } \\
\text { Adicional }\end{array}$ \\
\hline Director del colegio & 1 & S/. 2,500 & Bono por desempeño \\
Coordinador Académico & 1 & S/. 1,500 & \\
Docentes & 4 & S/. 5,200 & \\
Auxiliar & 4 & S/. 3,720 & \\
Enfermera & 1 & S/. 1,500 & \\
Psicóloga & 1 & S/. 1,500 & \\
Web master & 1 & S/. 1,000 & \\
Seguridad & 1 & S/. 950 & \\
Personal de limpieza & 1 & S/. 930 & \\
\hline
\end{tabular}

El total de la planilla es de 18,800 soles mensuales en el primer año de operación de la empresa, los cuales se deberán pagar a fin de mes de mes, excepto en el caso del personal de limpieza y mantenimiento que se paga de forma semanal.

Respecto, al personal docente el incremento de la planilla es de 1 docente en el segundo año, un docente adicional en el cuarto año y así sucesivamente se contratará más docentes según la demanda. La cantidad de docentes se muestra en la Tabla 48 para todos los años proyectados de operación del Colegio.

Tabla 48

Personal docente del Colegio

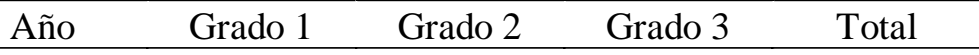




$\begin{array}{lllll}2018 & 2 & 1 & 1 & 4 \\ 2019 & 2 & 1 & 1 & 4 \\ 2020 & 2 & 1 & 1 & 4 \\ 2021 & 2 & 1 & 1 & 4 \\ 2022 & 3 & 2 & 1 & 6 \\ 2023 & 3 & 2 & 1 & 6 \\ 2024 & 3 & 2 & 1 & 6 \\ 2025 & 3 & 3 & 2 & 8 \\ 2026 & 3 & 3 & 2 & 8 \\ 2027 & 3 & 3 & 2 & \end{array}$

Con relación a los beneficios para los trabajadores la ley MYPE (2003) establece lo siguiente:

a) El descanso semanal obligatorio y el descanso en días feriados se rigen por las normas del régimen laboral común de la actividad privada.

b) El descanso vacacional como mínimo, de quince días calendario por cada año completo de servicios.

c) Los trabajadores según la norma son asegurados regulares

d) Indemnización por despido injustificado de quince remuneraciones diarias por cada año completo de servicios con un máximo de ciento ochenta remuneraciones diarias.

\subsection{Política de recursos humanos}

La política a seguir por el colegio con relación al personal estará basada en los siguientes lineamientos:

a) Igualdad de oportunidad en el empleo

Durante el proceso de reclutamiento, selección y contratación se debe considerar la igualdad de oportunidades de empleo para todos los interesados en el puesto de trabajo que requiere el colegio. Es decir, no debe existir discriminación por género, religión, raza, color, nacionalidad, estado civil o cualquier otra causa. 
b) Comunicación

El colegio debe establecer los canales de comunicación pertinentes (boletines, periódicos, revistas, noticias digitales) que permitan dar a conocer las políticas generales, así como las decisiones y acciones que sean de interés general y que afecten la labor de la organización.

c) Integración

El colegio debe buscar la integración de sus colaboradores mediante reuniones extralaborales de los trabajadores y su familia. Estas reuniones se deben llevar a cabo en las fiestas tradicionales como navidad, día del padre, día de la madre, día del maestro y el aniversario del colegio. Asimismo, la integración se realizará mediante reuniones de trabajo en donde se respete la opinión de todos los colaboradores del colegio.

Finalmente, el colegio deberá elaborar los siguientes instrumentos de supervisión y gestión:

a) Reglamento de Trabajo: que servirá para establecer las políticas de trabajo en el colegio, así como las obligaciones de los trabajadores como: hora de entrada y salida, sanciones en caso de incumplimiento en sus funciones, permisos y licencias, fecha de vacaciones, entre otros.

b) Reglamento de Seguridad: a fin de establecer las condiciones y normas de seguridad que se debe considerar durante el desempeño de sus funciones.

c) Manual de Funciones: con el objetivo de establecer las funciones de cada uno de los puestos del colegio. 


\section{Capítulo VII \\ Plan de marketing}

\subsection{Estrategias de marketing}

La estrategia seleccionada para el nuevo colegio es la diferenciación basada en la calidad del servicio educativo y en la excelencia en la atención a los padres de familia y comunidad. A partir de esta estrategia se formula la estrategia de marketing que tiene como propósito comunicar de manera integral a los padres de familia las características del nuevo colegio como un servicio educativo y de atención a los padres de familia diferentes a los que existen en el mercado.

En este marco, según David (2013) la estrategia de marketing para el Colegio será el desarrollo del servicio educativo que permitirá mejorar o modificar algunas características actuales del servicio de los colegios a nivel inicial del que actualmente que se ofrece en el mercado. Estas mejoras en el producto que ofrece el colegio están dadas fundamentalmente en ofrecer un servicio educativo basado en los elementos que valoran los padres de familia durante el proceso de selección de un colegio para sus hijos. Estos elementos son:

- Número de alumnos por salón de clase

- Infraestructura moderna

- Calidad de la enseñanza 


\subsubsection{Estrategia de Producto.}

La estrategia de este nivel tiene como objetivo dar a conocer las características del servicio que se ofrece en el nuevo colegio a los padres de familia interesados, las cuales según el estudio de mercado realizado son las siguientes:

a) Modelo de enseñanza que permite la participación de los padres de familia.

b) Salas de juego especiales para los niños que permitan lograr un mejor aprendizaje.

c) Una biblioteca especial para niños que fomenten el aprendizaje.

Asimismo, según el estudio de mercado los padres de familia buscan que el colegio brinde asesoría psicológica para sus hijos, movilidad y refrigerios entre otros elementos sugeridos. En este sentido, se deberá poner énfasis en contar con estos requerimientos desde el inicio de las actividades del colegio.

Por consiguiente, durante el diseño del servicio educativo a brindar por el colegio se han considerado algunas características que buscan los padres de familia. Así, las aulas se encontraran diseñadas para un máximo de 25 alumnos, siendo culminadas la construcción de las primeras 04 aulas antes del inicio de operaciones en el primer año de funcionamiento, y el restante de aulas a partir del quinto año de funcionamiento de la institución educativa, existiendo salas para juegos especiales como parte del proceso de aprendizaje, contando con una biblioteca con material educativo para los niños de modo que sea un soporte para el aprendizaje, se ha seleccionado un modelo educativo en donde los docentes buscan la participación de los padres de familia.

Las características que se deberán enfatizar durante el proceso de selección del colegio se muestran en el Tabla 49. 
Tabla 49

Características del nuevo colegio

\begin{tabular}{ll}
\hline Variable & Características \\
\hline Docentes & Certificados en educación inicial \\
Modelo de aprendizaje & $\begin{array}{l}\text { Orientado a fomentar las competencias de los niños con } \\
\text { participación de los padres de familia } \\
\text { Juegos educativos especiales como parte del proceso } \\
\text { aprendizaje }\end{array}$ \\
& $\begin{array}{l}\text { Biblioteca con material educativo para niños } \\
\text { Biohuerto donde los niños podrán entrar en contacto con } \\
\text { la naturaleza }\end{array}$
\end{tabular}

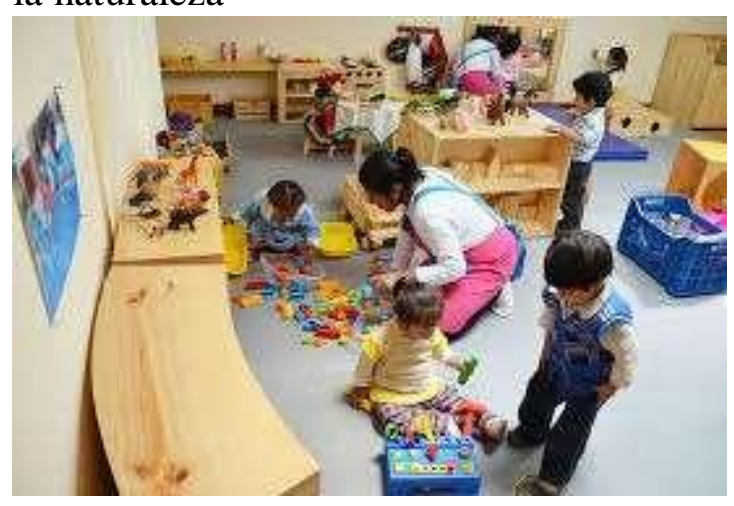

Alumnos por salón de clase

Aulas diseñadas para un máximo de 25 alumnos por salón de clase.

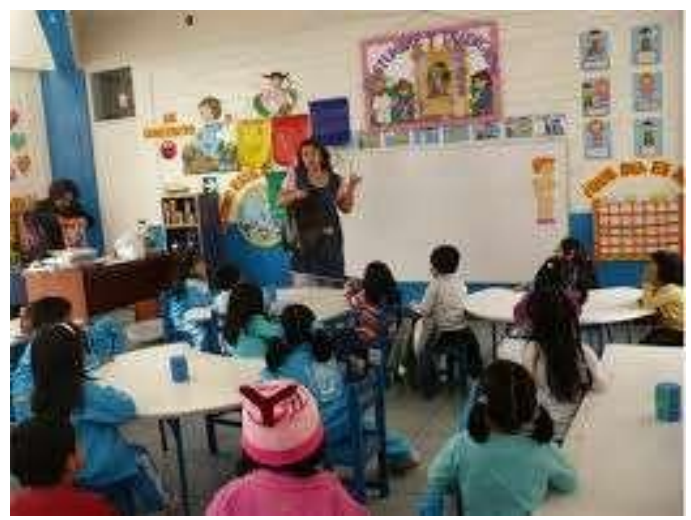

Infraestructura

Moderna con aulas diseñadas para un fácil acceso y salida de los niños

Patio para que los alumnos puedan realizar actividades guiadas por los docentes

Nota. http://www.andina.com.pe/agencia/noticia-minedu-presenta-aula-modelo-paraeducacion-inicial-557635.aspx

http://www.educpe.com/clases-para-ninos-de-inicial-sugerencias-para-elaborar-unaclase.html 


\subsubsection{Estrategia de Presencia Física.}

A partir de las características a comunicar del nuevo colegio, se formulará la estrategia de presencia física que consiste en contar con una página Web dinámica que permita ofrecer información sobre el colegio, la que se encontrara diseñada y publicada antes del inicio del proceso de promoción de la institución educativa.

La página web del colegio tendrá la información general del colegio, de los programas de educación que ofrece, de la infraestructura que posee para el proceso de enseñanza, descripción del modelo educativo, calendario académico: fecha de inicio y de término del año académico y una lista de los docentes especializados.

La dirección electrónica de la página web del colegio será la siguiente: www.colegioestrellitasdejesus.edu.pe. Esta página tendrá un diseño inicial, que será actualizada por el web master a fin de colocar información sobre los nuevos programas y talleres a implementar en el Colegio.

En la página de Facebook se planea colocar información sobre los aspectos relevantes del colegio que lo diferencian de otros de la localidad, así como opiniones de los padres de familia que están recibiendo el servicio. El diseño estará orientado a brindar información a los padres jóvenes que buscan una nueva alternativa para la educación de sus hijos. 
Asimismo, como parte de la estrategia presencia física del colegio se ha considerado posicionar el logotipo de la institución entre los padres de familia de la comunidad. El logotipo del colegio se muestra en la Figura 32.

Como parte de la información obtenida por las visitas se podrá obtener las preferencias de los padres de familia sobre el contenido ofrecido, siendo la revisión de esta información de manera mensual.

El logotipo se ha diseñado con una estrella en donde se coloca el nombre del nuevo colegio y con la siguiente frase:

\section{"Donde empieza el desarrollo de tu niño"}

Esta frase permitirá transmitir a los padres de familia el propósito del colegio de desarrollar a sus hijos desde el nivel inicial de educación.

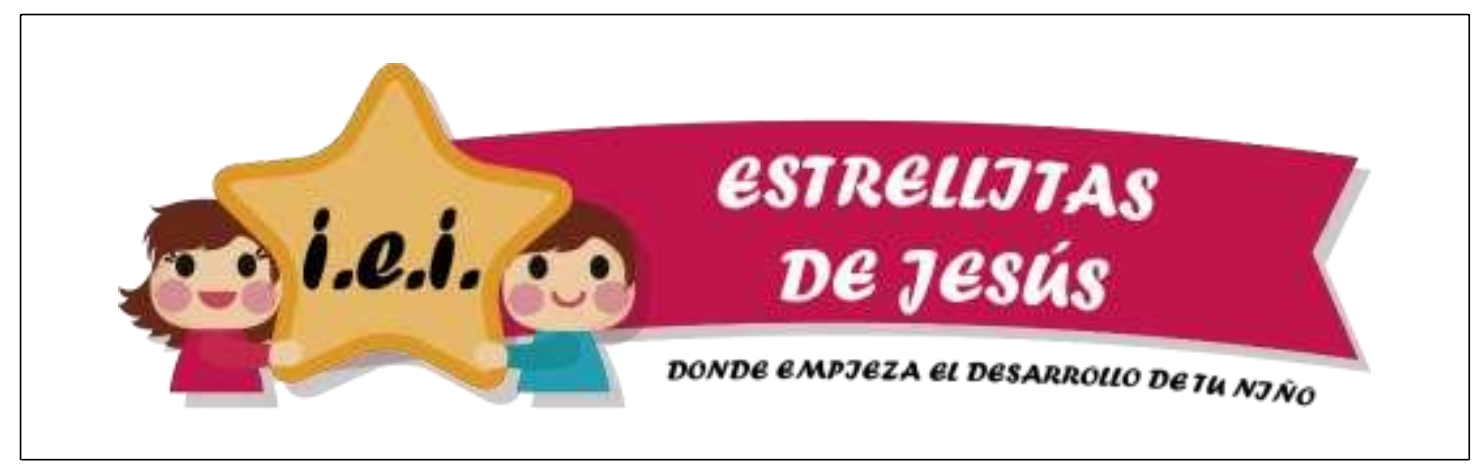

Figura 32. Logo del Colegio

\subsubsection{Estrategia de Personal.}

La estrategia de este nivel tiene como objetivo fortalecer y desarrollar las características de las personas que prestan el servicio educativo en el nuevo colegio a los niños matriculados. En este caso, las personas que están directamente relacionadas 
con el servicio son los docentes del colegio y las personas que se comunican con los padres de familia durante el proceso de admisión.

Por consiguiente, la estrategia deberá estar orientada a mejorar las habilidades de enseñanza de los docentes a fin que presten el servicio educativo con los niveles de calidad esperados por el padre de familia. Según el estudio de mercado realizado los padres de familia consideran que los docentes que imparten clases en el colegio deberán estar certificados y capacitados en educación inicial. Asimismo, se requiere que los docentes tengan una orientación hacia el servicio y atención a los padres de familia a fin que trabajen de manera conjunta en el proceso de formación de los niños.

En este sentido, se requiere que los profesores los cuales deben estar certificados y capacitados en educación inicial. los cuales deberán ser contratados con 30 de anticipación del inicio de las labores. El colegio debe capacitar de manera continua con un mínimo de 24 horas lectivas a los docentes de modo que puedan estar preparados para impartir sus clases y atender a los padres de familia para que participen en el proceso. La capacitación deberá estar orientada a desarrollar habilidades docentes para el aprendizaje de los niños, atención a los padres de familia, conocimiento y aplicación del modelo educativo adoptado por el colegio, diseño de syllabus, aprendizaje a través del modelo lúdico, atención a niños con problemas de aprendizaje, entre otros.

La certificación de los maestros se debe comunicar a los padres de familia de modo que conozcan que el Colegio cuenta con personal docentes que cumple con sus expectativas. 
Desde el inicio se deberá implementar un Programa de Formación y

Capacitación Permanente, que tenga por finalidad, según el artículo 39 de la ley No.29062 (Ley que Modifica la Ley del Profesorado en lo Referido a la Carrera Pública Magisterial), “organizar y desarrollar, a favor de los profesores en servicio, actividades de actualización, capacitación y especialización. Dichas actividades deben responder a las exigencias de aprendizaje de los estudiantes y de la comunidad o a la gestión de la Institución Educativa y a las necesidades reales de capacitación de los profesores”.

\subsubsection{Estrategia de Proceso.}

A fin de brindar el servicio educativo de una manera adecuada para los alumnos, se requiere contar con un proceso integral que permita ofrecer el servicio de acuerdo a un conjunto de actividades alineadas, debiendo contar con una respuesta para el padre de familia en un plazo no mayor de 72 horas.

Así, se requiere que las actividades relacionadas con la atención a los alumnos y los padres de familia deben ser implementadas de manera que se perciba por los usuarios como un servicio consistente y que ofrece información de manera confiable y oportuna. Este procesos deberá ser supervisado por el personal administrativo encargo de los aplicativos de fiscalización del Ministerio de Educación. El proceso de atención a los padres de familia de muestra en la Figura 33 y comprende las siguientes actividades: 


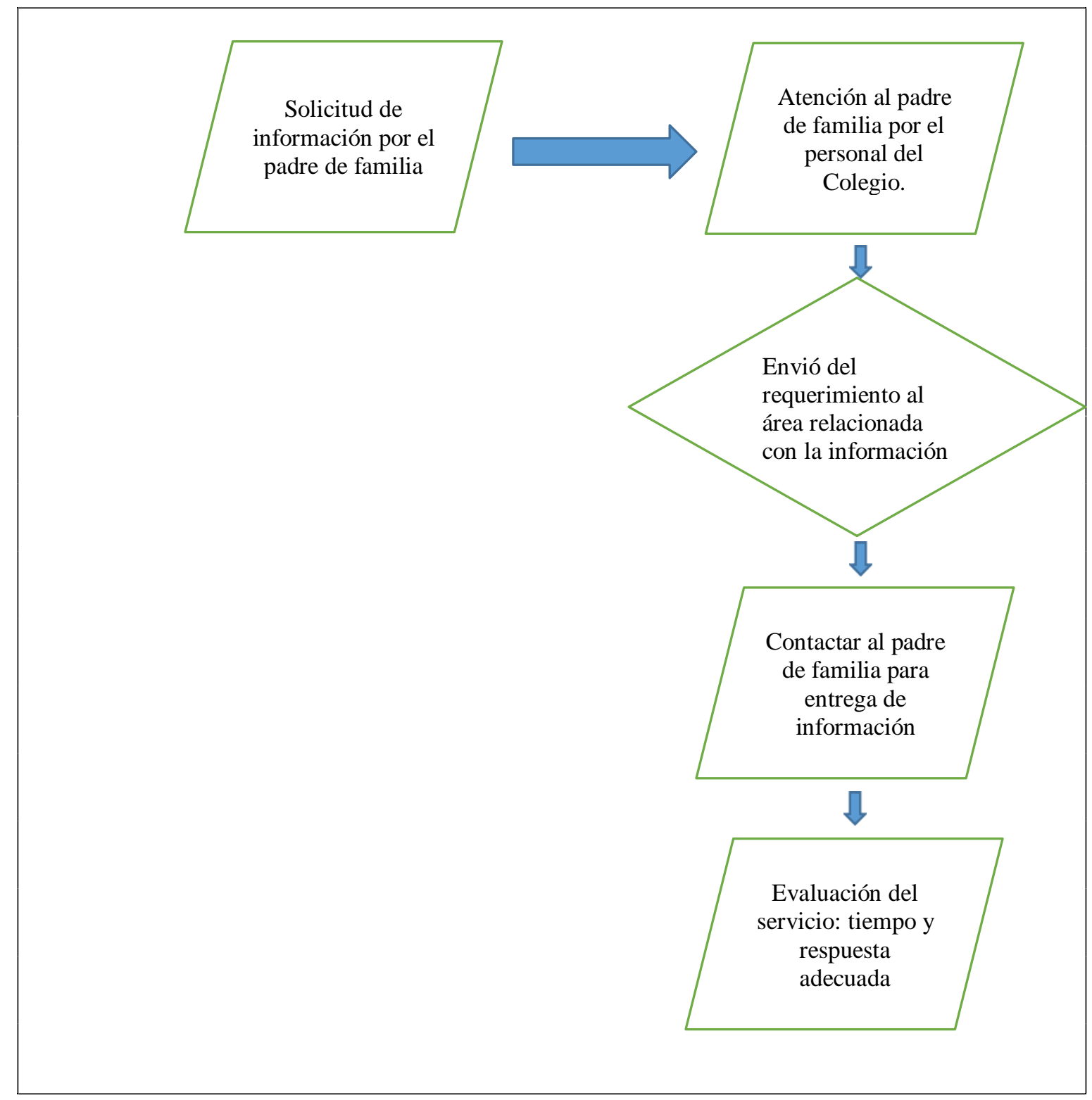

Figura 33. Servicio de Atención al Padre de Familia 


\subsubsection{Estrategia de Precio.}

La estrategia de precio tiene como propósito comunicar a los padres de familia que la calidad por el servicio educativo a brindar por el nuevo colegio tiene un precio competitivo con relación a los demás colegios de educación inicial la ciudad de Chiclayo.

El precio por el servicio educativo a brindar por el nuevo colegio tiene tres componentes:

a) Admisión: los colegios privados de educación inicial tienen un precio relacionado con la admisión y está orientado a cubrir los gastos ocasionados durante el proceso de selección del niño al colegio. El derecho de admisión, según el INDECOPI, se cobra una sola vez y se realiza cuando el alumno ingresa al Colegio.

b) Matrícula: este precio permite que los padres de familia realicen un pago como derecho de matrícula al inicio del año escolar. El monto de la matrícula, según lo establece el INDECOPI no debe ser mayor al monto de la mensualidad que se paga todos los meses.

c) Pensión mensual: el precio mensual que debe pagar el padre de familia está relacionado con el concepto de la enseñanza que recibe el alumno. El monto de la mensualidad es durante todos los meses que dura el servicio educativo y según lo indica el INDECOPI, no puede ser cobrada de manera adelantada.

El monto de las tarifas para los tres pagos a realizar por el padre de familia se muestra en la Tabla 50. Este precio fue obtenido durante el estudio de mercado realizado a los padres de familia y de comparar los precios con otros colegios de la ciudad de Chiclayo. 
Tabla 50

Precio por el servicio educativo

\begin{tabular}{|l|l|}
\hline Rubro & Monto en soles \\
\hline Derecho de Admisión & 2,500 \\
\hline Matrícula & 500 \\
\hline Pensión mensual & 500 \\
\hline
\end{tabular}

Tal como se puede apreciar los precios fijados para los tres rubros son competitivos en el mercado.

Así, el precio por derecho de admisión de algunos colegios en la ciudad de Chiclayo es de tres mil soles, mientras que el derecho que usualmente pagan los padres de familia es de mil setecientos soles. En este caso, como se puede apreciar el monto relacionado con este rubro para el nuevo colegio está por debajo del precio de los colegios de este nivel en la ciudad de Chiclayo.

Por su parte la matrícula tiene un precio en el mercado que varía entre 350 soles y más de 450 soles. En relación con este rubro el nuevo colegio tiene un precio para la matrícula que es común entre los colegio de la localidad.

Finalmente, el monto de la pensión mensual también está en el rango de los precios de los colegios de educación inicial en la ciudad de Chiclayo. Así, el precio es similar al precio máximo de 480 soles y cercano al valor que más repite en el mercado de 450 soles.

Por consiguiente, la estrategia relacionada con el precio está orientada a comunicar que el precio del nuevo colegio es similar a los demás colegios de la 
localidad, pero con un mejor servicio educativo de los demás colegios y una mejor atención al padre de familia.

\subsubsection{Estrategia de distribución.}

La estrategia de distribución deberá estar orientada a comunicar que el nuevo colegio cuenta con una sede central para el desarrollo de sus actividades y con un módulo de información en los principales centros comerciales de la ciudad de Chiclayo para ofrecer un servicio educativo diferenciado al resto de instituciones educativas de la localidad.

El colegio estará ubicado en el distrito de la Victoria de la ciudad de Chiclayo de acuerdo a la preferencia señalada por los padres de familia en el estudio de mercado realizado. La sede principal del nuevo colegio estará localizada en la zona indicada, en donde el padre de familia tendrá acceso a un espacio para entregar a un encargado del colegio a su hijo y luego poder recogerlo al finalizar el periodo diario de clases.

Con relación a la seguridad que se ofrece a los padres de familia (madre o padre) para recoger a su hijo, se ha considerado que los progenitores deberán portar una credencial otorgada por el nuevo colegio. En caso que lo recoja otra persona (sea un familiar o personal que labora en la casa) el padre de familia deberá comunicar al colegio a fin que se le otorgue una credencial adicional a la persona indicada. Si existiese un retraso para recoger al niño del colegio, los padres de familia deberán comunicar oportunamente al colegio a fin de tomar las acciones necesarias para cuidar al niño hasta que el padre de familia o la persona encargada lo recojan. 
Respecto al contacto con las personas interesadas en el nuevo colegio se plantea contar con módulos de orientación y de información en los centros comerciales: Real Plaza, Boulevard y Open Plaza. El mayor énfasis para difusión del nuevo colegio estará en el Centro Comercial Real Plaza en donde se instalará un módulo de atención con personal capacitado para brindar información sobre las nuevas características del Colegio y realizar la inscripción de los padres de familia interesados en el servicio educativo inicial. El horario de atención en dicho módulo será de 11:00 am hasta las 8:00 pm.

\subsubsection{Estrategia de promoción y publicidad.}

La estrategia de promoción y publicidad estará orientada a dar a conocer los elementos de diferenciación del nuevo colegio a los padres de familia. Estos aspectos a comunicar deberán reflejar las características del nuevo colegio como son: la manera en que se lleva a cabo el proceso de aprendizaje, la infraestructura del colegio, las salas de juegos, los docentes especializados en educación inicial, las áreas de apoyo al proceso de formación, entre otros.

La estrategia permitirá informar a los padres de familia mediante los siguientes medios de comunicación
a) Avisos en los diarios locales como: la Industria y el Comercio
b) Avisos en las revistas locales como: Expresión y Gaceta Norteña.
c) Página web del Colegio "Estrellitas de Jesús".
d) Página Facebook del Colegio.
e) Brochure.
f) Volantes. 
g) Merchandising.

h) Módulos de atención en los centros comerciales.

Los avisos en los medios de comunicación como periódicos y revistas serán colocados al inicio de la campaña de captación de padres de familia la cual tendrá una duración de 06 meses contabilizados a partir del mes de Setiembre del año anterior. En estos avisos se resaltará las principales bondades del colegio como número limitado de alumnos por salón de clase, infraestructura moderna, docentes especializados y modelo de aprendizaje en donde se involucra al padre de familia en el proceso aprendizaje. Los avisos se colocarán en tamaños pequeños (1/16 de plana) cuyo precio promedio sea de 300 soles.

El brochure será de cuatro páginas y deberá constar de información específica en cada una de ellas. La información será la siguiente:

a) Carátula: en donde se muestre una imagen de niños entre tres a cuatro años, el nombre del colegio en un ambiente totalmente libre para los niños, tal como se muestra en la Figura 34.

b) Páginas del centro: se colocarán fotografías de las aulas y de la sala de juegos del colegio. En el texto a colocar se hará énfasis en el modelo educativo en donde se plantea la participación de los padres de familia, la especialización de los docentes en educación inicial, y el número de alumnos no mayor de 25 alumnos por salón de clase.

c) Página posterior: deberá colocarse datos para mayor información como: número de teléfono del área de admisión, dirección electrónica en donde se brinda información adicional: información@colegioestrellitasdejesus.como.pe, la dirección de la página electrónica del colegio, la dirección del colegio en el distrito de la Victoria. 
Asimismo, deberá señalarse que el precio de derecho de admisión, matrícula y pensión mensual son competitivos con relación a los demás colegios.

\section{Inversión en Branding y Brand Equity}

Un aspecto que permitirá reforzar la presencia física de la institución es buscar el posicionamiento del nombre del colegio en el mercado objetivo, como una institución educativa que ofrece educación inicial con estándares de excelencia.

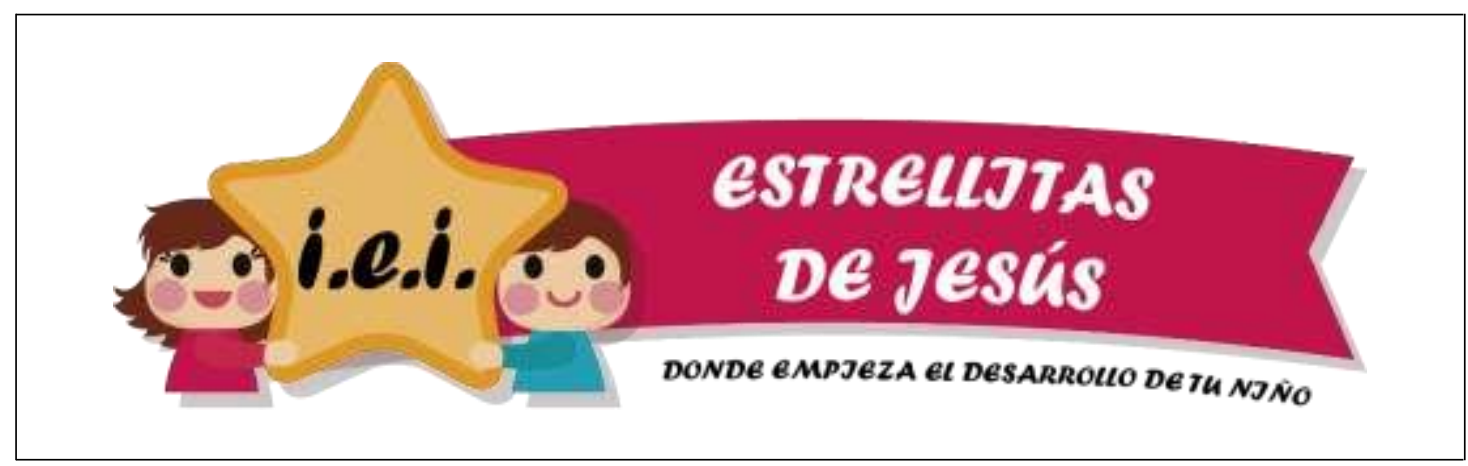

Figura 32. Logo del Colegio

Asimismo, el merchandising que tiene como propósito que las personas recuerden al colegio y a través de elementos promocionales a los padres de familia interesados y que además sean útiles para quienes lo reciben. En esta primera etapa de inicio del nuevo colegio, se plantea para la promoción ofrecer como merchandising lápices, cuadernos, tomatodos, mandiles entre otros. Estos materiales promocionales tendrán grabado el nombre del colegio y serán elaborados con materiales ligeros a fin de facilitar su traslado por parte del personal encargado de la promoción del Colegio. El material del merchandising a entregar se muestra en la Figura 35. 


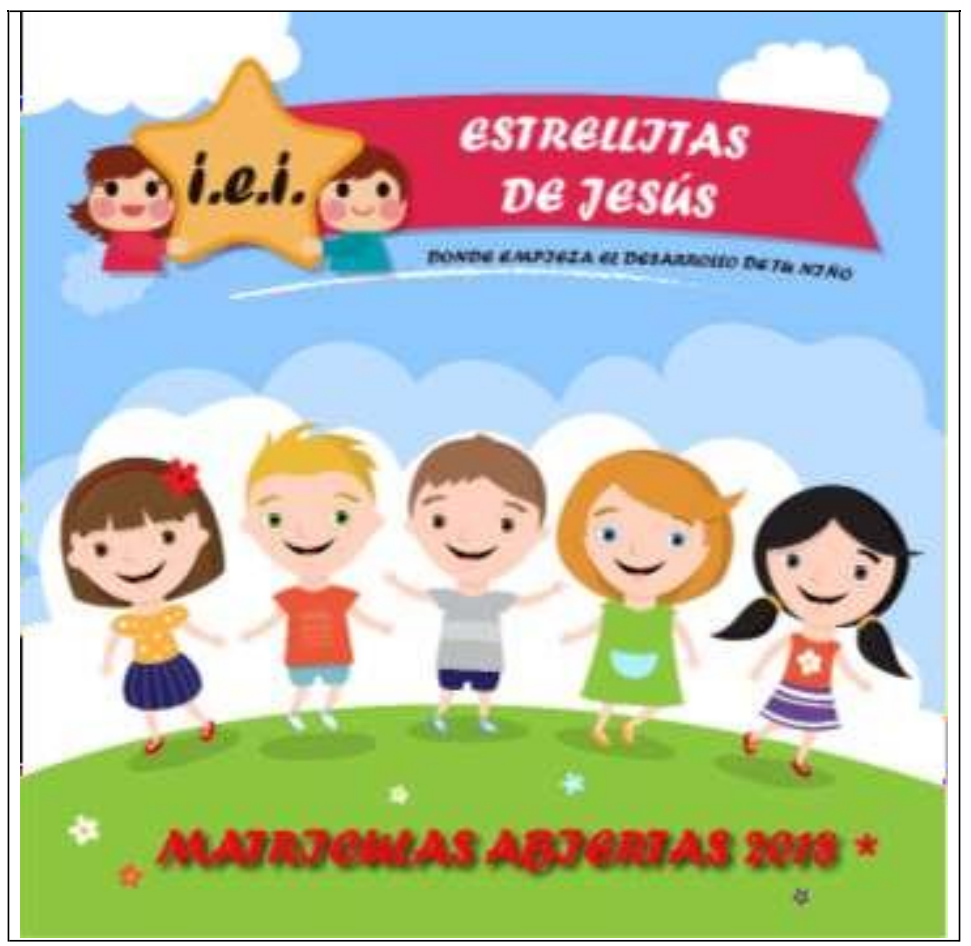

Figura 34. Brochure del colegio

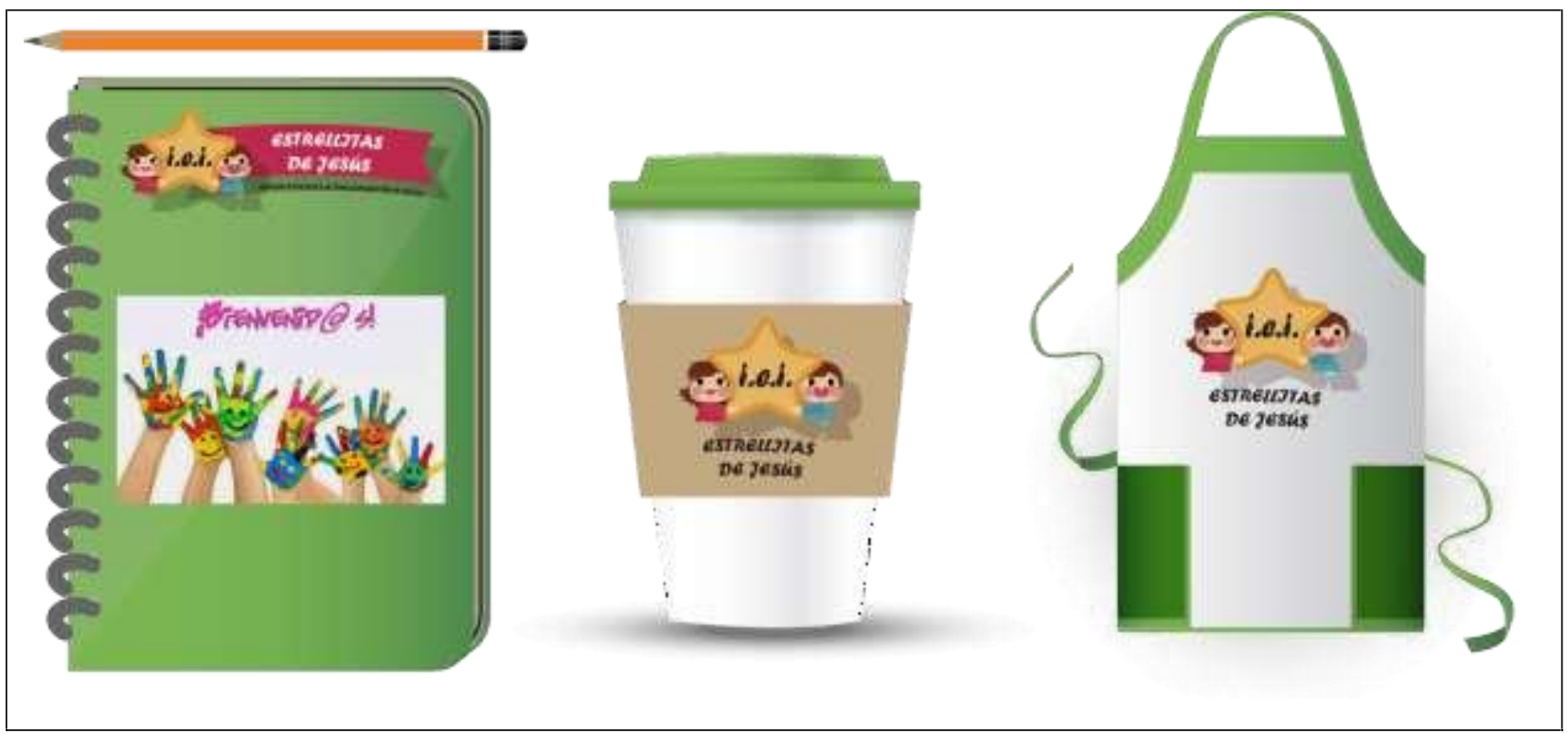

Figura 35. Merchandising 
El presupuesto de marketing y ventas corresponde al gasto de las actividades relacionadas con el branding de la marca del colegio y la comunicación permitirá que se lleven a cabo para dar a conocer a los padres de familia sobre el nuevo colegio y los aspectos diferenciales del servicio.

Comprende el monto que se gasta en la elaboración del video institucional, publicidad en periódicos y revistas, merchandising, realización de charlas, entre otros, tal como se muestra en la Tabla 69.

\subsection{Estrategia de ventas}

La estrategia de ventas tiene como propósito incrementar el número de alumnos en el colegio. La estrategia de ventas estará enfocada a mostrar los aspectos relevantes del producto por parte del personal de ventas a los padres de familia. En ese sentido, debemos desarrollar al personal de ventas a fin que se encuentre capacitado para realizar la venta del servicio educativo del nuevo colegio resaltando los elementos diferenciales del nuevo servicio educativo inicial.

\subsubsection{Plan de ventas.}

El plan de ventas a desarrollar tiene como objetivo promover la captación de nuevos alumnos mediante la comunicación directa enfocada en mostrar los aspectos diferenciales del colegio a los padres de familia. Esta decisión de orientarse en ambos padres de familia se establece a partir el estudio de mercado realizado, en donde se obtuvo que la selección del colegio lo realiza ambos padres del niño y en segundo lugar la persona que decide sobre el colegio para el niño es la madre de familia. 
A fin de llevar a cabo el plan de ventas se contempla en primer lugar contratar personal, establecer un programa capacitación y fijar el monto de las comisiones.

a) Contratación del personal de ventas: permite contratar personal de ventas a fin de ofrecer el producto directamente a las personas interesadas. El personal de ventas a contratar debe contar con experiencia en ventas relacionada con el servicio educativo de colegios de educación inicial, una actitud de servicio al cliente y conocer los aspectos claves del servicio educativo inicial que brindará el colegio.

b) Capacitación del personal de ventas: se deberá capacitar al personal de ventas en atención al cliente, características diferenciales del nuevo colegio, técnicas de cierre de venta, entre otros.

c) Fijación de comisiones: se debe establecer un porcentaje del precio del derecho de admisión como comisión de venta. La comisión tiene como finalidad incentivar la venta por parte del personal encargada de la misma. En esta primera etapa del colegio la comisión de ventas será de 3\% del derecho de admisión por alumno matriculado.

Para el desarrollo del plan de venta se considera llevar a cabo una serie de actividades entre las que podemos señalar a las siguientes:

a) Entrega de información del colegio: en los módulos de información instalados en los centros comerciales se entregará brochures y volantes del colegio por parte del personal de venta.

b) Información en el colegio: a los padres de familia que visiten el colegio se le entregará información específica sobre requisitos de admisión o traslado, el inicio de las actividades lectivas del colegio y el precio del derecho de admisión, matrícula y monto de la pensión mensual. 
c) Visitas al Colegio: se llevará a cabo para los padres de familia interesados en conocer la infraestructura del colegio como las aulas, la sala de juegos, biblioteca y biohuerto. Durante la visita un docente del colegio podrá mostrar las instalaciones y resolver dudas sobre el modelo educativo.

d) Charlas de información: que serán llevadas a cabo por la persona encargada de admisión en el colegio con apoyo del personal de venta y serán acompañadas por personal docente con experiencia en educación inicial, tal como se muestra en la Figura 36. Los aspectos a informar serán sobre la operación del colegio y como se lleva a cabo el proceso de enseñanza-aprendizaje. En los lugares donde se brinde ésta información se contará un módulo con un banner, así como brochures y volantes del colegio para entregar a los padres de familia interesados.

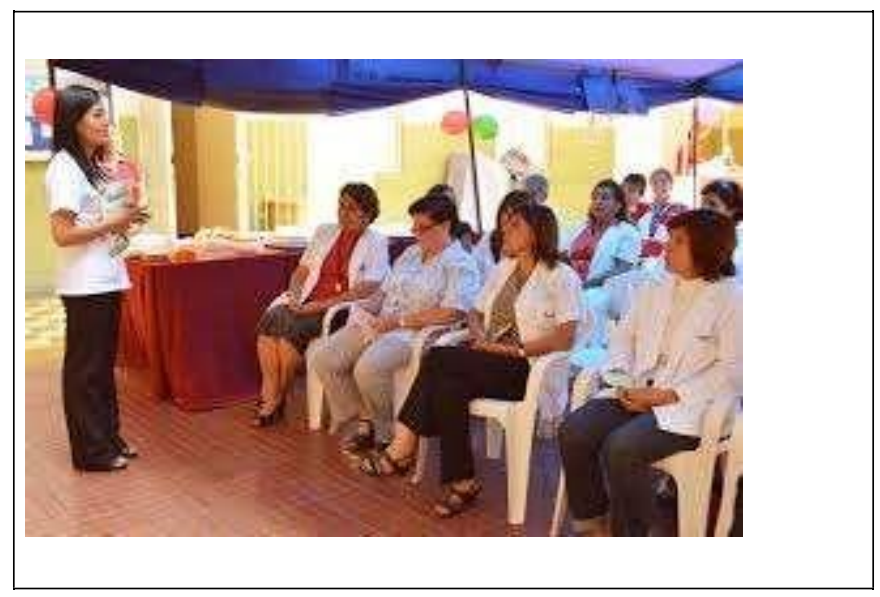

Figura 36. Charlas informativas http://www.insn.gob.pe/content/mamis-preparacampa\%C3\%B1-de-difusi\%C3\%B3n-en-colegios-para-evitar-el-maltrato-infantil

e) Convenios con centros laborales: este convenios estarán dirigidos a los centros laborales en donde existan padres de familia jóvenes. Los acuerdos son fundamentalmente para que los centros laborales brinden facilidades de acceso al personal de ventas para promocionar el producto. Como contraparte el nuevo 
colegio ofrecerá descuentos a los padres de familia que trabajen en ese centro laboral y que matriculen sus hijos en el colegio.

f) Visitas a padres de familia: se plantea realizar visitas directas a los padres de familia interesados por parte del personal de ventas. Estas visitas tendrán como objetivo brindar información específica del nuevo colegio a los muy interesados en el servicio educativo del colegio.

g) Visitas a Cunas: se visitará a cunas para niños de tres meses a dos años que no tengan continuidad con el servició de educación inicial para niños a partir de los tres años. Estas visitas tendrán como objetivo brindar información a los padres de familia que deberán seleccionar un colegio de educación inicial para continuar con la educación de sus hijos.

Las actividades formuladas como parte del plan de trabajo se realizaran de acuerdo al siguiente cronograma de trabajo:

a) Agosto - Octubre: estas actividades de información general se iniciaran en el mes de agosto y tendrán como propósito brindar información sobre el nuevo colegio a través de los módulos de información. El personal de ventas deberá contar con una base de datos de los padres de familia interesados para su seguimiento posterior a través del envió de información adicional mediante el correo electrónico.

b) Noviembre - Diciembre: durante este periodo se llevarán a cabo charlas informativas en los módulos de información, en el colegio, en los centros laborales con los cuales se cuenta con un convenio y en las cunas que no cuenten con un colegio inicial. Asimismo, en esta fase se organizarán visitas directas por parte del personal de venta a los padres de familia muy interesados. También se llevarán a 
cabo vistitas al colegio guiadas por una docente del colegio a los padres de familia interesados en el servició educativo.

c) Enero: en este mes se realizará las entrevistas con los padres de familia que hayan realizado la preinscripción de sus hijos en el colegio. Las entrevistas a los padres de familia se realizarán por la persona a cargo de la dirección del colegio.

d) Febrero: se convocará a los padres de familia a fin de comunicarles sobre la admisión de su hijo al colegio si fuera el caso, a fin de proceder a la matrícula y la entrega del cronograma de las actividades lectivas.

e) Marzo: se realizará el inicio de las clases con una ceremonia de apertura del año escolar en donde se entregará un polo del colegio a todos los niños ingresantes. También en este periodo se programará la apertura del periodo de traslados para los niños que provengan de otros colegios.

Los gastos implicados con las actividades de marketing están relacionados con la compra de polos, elaboración de los brochures y de los volantes, los banners, los materiales de merchandising, y la compra de los módulos de atención.

Los costos estimados para las actividades de marketing se muestran en el Tabla 51

Tabla 51

Gastos de marketing

\begin{tabular}{rlrrr}
\hline Item & \multicolumn{1}{c}{ Rubro } & Cantidad & $\begin{array}{c}\text { Precio } \\
\text { unitario }\end{array}$ & $\begin{array}{c}\text { Precio } \\
\text { total }\end{array}$ \\
\hline $\mathbf{1}$ & Polo bordado con el logo del colegio & 100 & 20 & 2000 \\
$\mathbf{2}$ & Lápices & 500 & 0.25 & 125 \\
$\mathbf{3}$ & Tomadotos & 100 & 3.5 & 350 \\
$\mathbf{4}$ & Agendas & 100 & 9 & 900 \\
$\mathbf{5}$ & Mandiles & 100 & 7.5 & 750 \\
$\mathbf{6}$ & Volantes medio oficio & 1000 & 0.15 & 150 \\
$\mathbf{7}$ & Brochure oficio & 1000 & 0.75 & 750 \\
$\mathbf{8}$ & Banner del colegio & 3 & 150 & 450 \\
$\mathbf{9}$ & Módulo de atención & 2 & 440 & 880 \\
\hline & Total Soles & & & 6355 \\
\hline
\end{tabular}


Los costos estimados para realizar las actividades del plan de ventas consideran el costo de los avisos en los medios de comunicación, el alquiler de espacio en los centros comerciales (un metro cuadrado), coffee break para las charlas informativas y durante la visita al colegio, tal como se muestra en el Tabla 52.

Tabla 52

Gastos del plan de ventas

\begin{tabular}{llrr}
\hline Item Rubro & Cantidad & Precio unitario & Precio total \\
\hline 1 Alquiler de espacio centro comercial 2 $\mathrm{m}^{2}$ & 6 meses & $100 \mathrm{~m}^{2}$ & 3600 \\
2 Avisos en periódicos & 6 veces & 300 & 1800 \\
3 Cofee break charlas 30 personas & 10 veces & 150 & 1500 \\
4 Cofee break visitas & 100 padres & 5 & 500 \\
\hline Total Soles & & & 7400 \\
\hline
\end{tabular}

La proyección de captación de alumnos para el primer año de operación del nuevo colegio es de 40 alumnos, para los siguientes años la proyección se muestra en la Tabla 53.

Tabla 53

Captación de alumnos del plan de ventas

\begin{tabular}{ccccc}
\hline Año & Grado 1 & Grado 2 & Grado 3 & Total \\
\hline $\mathbf{2 0 1 8}$ & 50 & 25 & 25 & 100 \\
$\mathbf{2 0 1 9}$ & 50 & 25 & 25 & 100 \\
$\mathbf{2 0 2 0}$ & 50 & 25 & 25 & 100 \\
$\mathbf{2 0 2 1}$ & 50 & 25 & 25 & 100 \\
$\mathbf{2 0 2 2}$ & 75 & 50 & 25 & 150 \\
$\mathbf{2 0 2 3}$ & 75 & 50 & 25 & 150 \\
$\mathbf{2 0 2 4}$ & 75 & 50 & 25 & 150 \\
$\mathbf{2 0 2 5}$ & 75 & 75 & 50 & 200 \\
$\mathbf{2 0 2 6}$ & 75 & 75 & 50 & 200 \\
$\mathbf{2 0 2 7}$ & 75 & 75 & 50 & 200 \\
\hline
\end{tabular}

Tal como se puede apreciar se estima un crecimiento constante en el ingreso de alumnos al colegio hasta llegar a doscientos el año 2027. 


\subsubsection{Políticas de servicios y garantías.}

El nuevo colegio como parte de su operación presta servicios educativos y de atención al padre de familia que deben guiarse por ciertas políticas establecidas por la dirección del nuevo Colegio. Entre las políticas a desarrollar tendremos las siguientes:

a) El Colegio Estrellitas de Jesús presta un servicio educativo basado en la excelencia y la vinculación permanente con el padre de familia.

b) Se debe asegurar que todos los docentes que impartan clases en el colegio deben contar con especialidad en educación inicial.

c) El personal de ventas debe estar capacitado sobre las características del nuevo colegio. En caso de preguntas más específicas se debe apoyar en los docentes del colegio o en la coordinación académica.

d) En caso de un retiro voluntario de alumno del colegio se debe realizar una entrevista a los padres de familia a fin de conocer el motivo del retiro y si fuera el caso implementar programas de mejora

e) Se debe realizar encuestas entre los padres de familia a fin de conocer su grado de satisfacción con el servicio educativo prestado.

f) Considerar que todo el personal en contacto con los padres de familia tenga un perfil orientado a la atención y servicio.

g) Cuidar que los docentes tengan un trato cordial con todos los alumnos matriculados en el colegio.

h) El personal de ventas debe comunicar sobre el servicio educativo del colegio en concordancia con lo que realmente se ofrece.

i) La seguridad para la entrega de los niños a los padres de familia debe llevarse según el protocolo establecido para tal caso. 


\section{Capítulo VIII \\ Planificación financiera}

\subsection{La inversión}

La inversión a realizar para el inicio y desarrollo de las operaciones del Colegio "Estrellitas de Jesús" comprende el monto de inversión en activos fijos, inversión preoperativa, inversión en capital de trabajo.

El monto se calcula considerando los montos de inversión en el activo fijo, el cual fue explicado en el estudio de ingeniería del proyecto, y de la inversión inicial para el inicio de las operaciones del colegio según lo presentado en el plan de marketing y ventas.

La inversión en activos fijo está integrado por:

a) Compra del terreno, construcción del edificio, tal como se muestra en el Tabla 54 y asciende a un total de 589,644 soles.

b) Mobiliario y equipo para la operación del colegio, tal como se muestra en el Tabla $55 \mathrm{y}$ asciende a un total de 74,330 soles.

Tabla 54

Inversión Terreno y Construcción

\begin{tabular}{lrrr}
\hline Mueble / Equipo & Cantidad & Costo Unitario & Costo Total \\
\hline Terreno & 750 & 80 & S/. 198,000 \\
Construcción aulas & 216 & 230 & S/. 163,944 \\
Construcción sala de juegos & 50 & 230 & S/. 37,950 \\
Construcción área administrativa & 250 & 230 & S/. 189,750 \\
\hline Total & & & S/. 589,644 \\
\hline
\end{tabular}


Tabla 55

Inversión Mobiliario y equipo: Oficinas y Aulas

\begin{tabular}{lrrr}
\hline Mobiliario / Equipo & Cantidad & Costo Unitario & Costo soles \\
\hline Carpetas & 100 & 120 & $\mathrm{~S} / .12,000$ \\
Estante pequeño & 6 & 350 & $\mathrm{~S} / .2,100$ \\
Proyector & 5 & 2500 & $\mathrm{~S} / .12,500$ \\
Mesa pequeña & 10 & 120 & $\mathrm{~S} / .1,200$ \\
Sillas & 71 & 120 & $\mathrm{~S} / .8,520$ \\
Kit de Juegos & 1 & 7690 & $\mathrm{~S} / .7,690$ \\
Computadora/Laptop & 4 & 1500 & $\mathrm{~S} / .6,000$ \\
Central telefónica & 1 & 800 & $\mathrm{~S} / .800$ \\
Teléfono & 6 & 180 & $\mathrm{~S} / .1,080$ \\
Computadora/PC & 6 & 1200 & $\mathrm{~S} / .7,200$ \\
Escritorio grande & 1 & 500 & $\mathrm{~S} / .500$ \\
Escritorio pequeño & 3 & 350 & $\mathrm{~S} / .1,050$ \\
Silla giratoria con brazos & 3 & 320 & $\mathrm{~S} / .960$ \\
Estante Grande & 10 & 500 & $\mathrm{~S} / .5,000$ \\
Módulo de recepción & 1 & 500 & $\mathrm{~S} / .500$ \\
Impresora & 1 & 1200 & $\mathrm{~S} / .1,200$ \\
Impresora pequeña & 3 & 800 & $\mathrm{~S} / .2,400$ \\
Mesa grande & 2 & 500 & $\mathrm{~S} / .1,000$ \\
Microonda & 1 & 250 & $\mathrm{~S} / .250$ \\
Platos/vasos/cubiertos & 1 & 300 & $\mathrm{~S} / .300$ \\
Hervidor eléctrico & 1 & 100 & $\mathrm{~S} / .100$ \\
Cafetera & 1 & 180 & $\mathrm{~S} / .180$ \\
Refrigeradora 318 L & 1 & 1800 & $\mathrm{~S} / .1,800$ \\
\hline Total & & & $\mathrm{S} / .74,330$ \\
\hline & &
\end{tabular}

\subsubsection{Inversión pre-operativa.}

La inversión pre operativa está integrada por la inversión a realizar en la instalación de servicios, licencia y trámites, los costos de marketing para el lanzamiento del Colegio y el sueldo de tres meses el personal, tal como se muestra en el Tabla 56 y asciende a un total de 99,380 soles. 
Tabla 56

Inversión en intangibles y pre operativos

\begin{tabular}{lrr}
\hline \multicolumn{1}{c}{ Rubro } & \multicolumn{1}{c}{$\begin{array}{c}\text { Costo } \\
\text { Unitario }\end{array}$} & \multicolumn{1}{c}{ Costo soles } \\
\hline Instalación de línea telefónica & $\mathrm{S} / .100$ & $\mathrm{~S} / .100$ \\
Instalación de software & $\mathrm{S} / .3,400$ & $\mathrm{~S} / .3,400$ \\
Licencia funcionamiento Municipalidad & $\mathrm{S} / .1,350$ & $\mathrm{~S} / .1,350$ \\
Licencia funcionamiento & & \\
UGEL & $\mathrm{S} / .150$ & $\mathrm{~S} / .150$ \\
Gastos para licencia & $\mathrm{S} / .850$ & $\mathrm{~S} / .850$ \\
Costos de Marketing & $\mathrm{S} / .8,250$ & $\mathrm{~S} / .8,250$ \\
Gastos de selección de personal & 3500 & $\mathrm{~S} / .3,500$ \\
Sueldo Personal (3 meses) & $\mathrm{S} / .27,260$ & $\mathrm{~S} / .81,780$ \\
\hline Total & & $\mathrm{S} / .99,380$ \\
\hline
\end{tabular}

\subsubsection{Inversión en capital de trabajo.}

La inversión en capital de trabajo se determina por el método de déficit acumulado máximo indicado por Sapag (2013). Este método consiste en el cálculo del máximo déficit que se produce entre la diferencia entre ingresos y gastos en un periodo dado. Para obtener este monto se proyecta los ingresos y los egresos mensuales para un periodo de 12 meses.

Los ingresos comprenden los pagos de inscripción, matrícula y pagos mensuales; así como los ingresos por renta del local. Los egresos están conformados por el monto de sueldos para el personal del colegio, pago de servicios, gastos de operación y un monto para mantener un efectivo inmediato para contingencias. El monto a invertir en capital de trabajo se presenta en el Tabla 57 y asciende a un monto de 77,898 soles. 
Tabla 57

Inversión en capital de trabajo

\begin{tabular}{|c|c|c|c|c|c|c|c|c|c|c|c|c|}
\hline Rubro & mes 1 & mes 2 & mes 3 & mes 4 & mes 5 & mes 6 & mes 7 & mes 8 & mes 9 & mes 10 & mes 11 & mes 12 \\
\hline Ingresos & S/. 0 & S/. 0 & $\begin{array}{r}\mathrm{S} / \\
225,000\end{array}$ & $\begin{array}{r}\mathrm{S} / . \\
50,000\end{array}$ & $\begin{array}{r}\mathrm{S} / . \\
50,000\end{array}$ & $\begin{array}{r}\mathrm{S} / . \\
50,000\end{array}$ & $\begin{array}{r}\mathrm{S} / . \\
50,000\end{array}$ & $\begin{array}{r}\mathrm{S} / . \\
50,000\end{array}$ & $\begin{array}{r}\mathrm{S} / . \\
50,000\end{array}$ & $\begin{array}{r}\mathrm{S} / . \\
50,000\end{array}$ & $\begin{array}{r}\mathrm{S} / . \\
50,000\end{array}$ & $\begin{array}{r}\mathrm{S} / . \\
50,000\end{array}$ \\
\hline Otros ingresos & S/. 0 & $\mathrm{~S} / .0$ & $\begin{array}{l}\text { S/. } 0 \\
\text { S/. }\end{array}$ & $\begin{array}{r}\text { S/. } 0 \\
\text { S/. }\end{array}$ & $\begin{array}{l}\text { S/. } 0 \\
\text { S/. }\end{array}$ & $\begin{array}{r}\text { S/. } 0 \\
\text { S/. }\end{array}$ & $\begin{array}{r}\mathrm{S} / .0 \\
\mathrm{~S} / .\end{array}$ & $\begin{array}{r}\text { S/. } 0 \\
\text { S/. }\end{array}$ & $\begin{array}{r}\text { S/. } 0 \\
\text { S/. }\end{array}$ & $\begin{array}{r}\text { S/. } 0 \\
\text { S/. }\end{array}$ & $\begin{array}{r}\mathrm{S} / .0 \\
\mathrm{~S} / .\end{array}$ & $\begin{array}{r}\mathrm{S} / .0 \\
\mathrm{~S} / .\end{array}$ \\
\hline Total ingresos & S/. 0 & S/. 0 & 225,000 & 50,000 & 50,000 & 50,000 & 50,000 & 50,000 & 50,000 & 50,000 & 50,000 & 50,000 \\
\hline Costo de ventas & $\begin{array}{r}\mathrm{S} / . \\
14,885 \\
\mathrm{~S} /\end{array}$ & $\begin{array}{r}\mathrm{S} / . \\
14,885 \\
\mathrm{~S} /\end{array}$ & $\begin{array}{r}\mathrm{S} / . \\
14,885 \\
\mathrm{~S} /\end{array}$ & $\begin{array}{r}\mathrm{S} / . \\
14,885 \\
\mathrm{~S} /\end{array}$ & $\begin{array}{r}\mathrm{S} / . \\
14,885 \\
\mathrm{~S} /\end{array}$ & $\begin{array}{r}\mathrm{S} / . \\
14,885 \\
\mathrm{~S} /\end{array}$ & $\begin{array}{r}\mathrm{S} / . \\
14,885 \\
\mathrm{~S} /\end{array}$ & $\begin{array}{r}\mathrm{S} / . \\
14,885 \\
\mathrm{~S} /\end{array}$ & $\begin{array}{r}\mathrm{S} / . \\
14,885 \\
\mathrm{~S} /\end{array}$ & $\begin{array}{r}\mathrm{S} / . \\
14,885 \\
\mathrm{~S} /\end{array}$ & $\begin{array}{r}\mathrm{S} / . \\
14,885 \\
\mathrm{~S} /\end{array}$ & $\begin{array}{r}\mathrm{S} / . \\
14,885 \\
\mathrm{~S} /\end{array}$ \\
\hline Gastos de Venta & 6,582 & 6,582 & 6,582 & 6,582 & 6,582 & 6,582 & 6,582 & 6,582 & 6,582 & 6,582 & 6,582 & 6,582 \\
\hline Gastos & S/. & S/. & $\mathrm{S} /$. & $\mathrm{S} /$. & S/. & $\mathrm{S} /$ & S/. & $\mathrm{S} /$. & S/. & $\mathrm{S} /$. & S/. & S/. \\
\hline Administrativos & 17,482 & 17,482 & 17,482 & 17,482 & 17,482 & 17,482 & 17,482 & 17,482 & 17,482 & 17,482 & 17,482 & 17,482 \\
\hline Flujo Operación & $\begin{array}{r}-\mathrm{S} / . \\
38,949\end{array}$ & $\begin{array}{r}-\mathrm{S} / . \\
38,949\end{array}$ & $\begin{array}{r}\mathrm{S} / . \\
186,051\end{array}$ & $\begin{array}{r}\mathrm{S} / . \\
11,051\end{array}$ & $\begin{array}{r}\mathrm{S} / . \\
11,051\end{array}$ & $\begin{array}{r}\mathrm{S} / . \\
11,051\end{array}$ & $\begin{array}{r}\mathrm{S} / . \\
11,051\end{array}$ & $\begin{array}{r}\mathrm{S} / . \\
11,051\end{array}$ & $\begin{array}{r}\mathrm{S} / . \\
11,051\end{array}$ & $\begin{array}{r}\mathrm{S} / . \\
11,051\end{array}$ & $\begin{array}{r}\mathrm{S} / . \\
11,051\end{array}$ & $\begin{array}{r}\mathrm{S} / . \\
11,051\end{array}$ \\
\hline Capital de Trabajo & & & $\begin{array}{r}\mathrm{S} / . \\
77,898\end{array}$ & & & & & & & & & \\
\hline
\end{tabular}

\subsubsection{Inversiones futuras.}

Debido a la proyección de la demanda del servicio educativo se planean inversiones futuras para la ampliación del edificio dado que el colegio contará solamente con cuatro aulas al inicio de operación. Estas cuatro contaran con toda su infraestructura y a partir del año cuatro se estima que se realizará inversiones para equipar las cuatro aulas con su respectivo equipamiento (sillas, mesas, proyector, entre otros). El monto de la inversión es de 238,274 soles en el año 5 y representados en valor presente es 81,025 soles y se muestra en el Tabla 58.

Tabla 58

Inversión Construcción Aulas, Mobiliario y Equipo

\begin{tabular}{lcc}
\hline Rubro & Costo soles & \multicolumn{1}{c}{ VP } \\
\hline Inversión aulas & S/. 163,944 & S/. 55,749 \\
Inversión equipo y mobiliario & S/. 74,330 & S/. 25,276 \\
\hline
\end{tabular}




\subsubsection{Costo del proyecto.}

El costo del proyecto está determinado por la inversión en activo fijo, intangibles y pre operativos, y la inversión en capital de trabajo. La inversión total del proyecto es de 923,256 soles tal como se muestra en el Tabla 59

Tabla 59

Inversión Total

\begin{tabular}{lrr}
\hline Rubro & \multicolumn{2}{c}{ Monto soles } \\
\hline Tangibles & $\mathrm{S} /$. & 663,974 \\
Intangibles y preoperativo & $\mathrm{S} /$. & 99,380 \\
Capital de trabajo & $\mathrm{S} /$. & 78,876 \\
Inversión en el año 5 - Valor Presente & $\mathrm{S} /$. & 81,025 \\
\hline Inversión Total & $\mathrm{S} /$. & 923,256 \\
\hline
\end{tabular}

\subsection{Financiamiento}

Para el inicio de las operaciones se requiere cubrir la cantidad de 923,256 soles que corresponde a la inversión total del proyecto. Este monto se planea cubrir con fondos propios de los inversionistas, tal como se muestra en el Tabla 60.

Tabla 60

Financiamiento del proyecto

\begin{tabular}{clc}
\hline Rubro & \multicolumn{2}{l}{ Monto soles } \\
\hline Aporte propio & S/. & 923,256 \\
Socio 1 & S/. & 230,814 \\
Socio 2 & S/. & 230,814 \\
Socio 3 & S/. & 230,814 \\
Socio 4 & S/. & 230,814 \\
\hline Inversión Total & S/. & 923,256 \\
\hline
\end{tabular}




\subsubsection{Capital y costo de oportunidad.}

El aporte de los inversionistas es de 923,256 soles. El costo de oportunidad mide el rendimiento del proyecto en el largo plazo y será calculado tomando en cuenta los factores de la fórmula considerada, tales como, tasa libre del riesgo, Beta del negocio, riesgo país, entre otros. La fórmula usada para cálculo de costo de oportunidad es el siguiente:

$\mathrm{COK}=\mathrm{r}_{\mathrm{f}}+\beta_{\text {proyecto }} \mathrm{x}\left(\mathrm{r}_{\mathrm{m}}-\mathrm{r}_{\mathrm{f}}\right)+$ riesgo país

Donde:

rf: $\quad$ tasa libre de riesgo

$\mathrm{r}_{\mathrm{m}}$ : rendimiento de mercado

$\mathrm{r}_{\mathrm{m}}-\mathrm{r}_{\mathrm{f}}$ : prima por riesgo de mercado

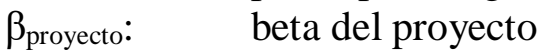

$\mathrm{r}_{\mathrm{p}}$ : riesgo país

COK soles $=$ COK $($ inflación Perú/ inflación USA)

El $\beta$ del proyecto se estima con la información de Beta por sector, ubicando el proyecto en el sector de educación. Ver Tabla 61.

Tabla 61

Beta del sector educación

\begin{tabular}{lll}
\hline Sector & Beta & $\beta$ desapalancada \\
\hline Educación & 1.28 & 1.04
\end{tabular}

Nota. http://pages.stern.nyu.edu/ adamodar/New_Home_Page/datafile/Betas.html

a) La tasa libre de riesgo tomando el promedio de los 10 últimos años del rendimiento de los bonos del tesoro es de $2.459 \%$ (http://es.investing.com/rates-bonds/u.s.-10year-bond-yield). 
b) La tasa de rendimiento del mercado se estimó del promedio de los 10 últimos años de la tasa de rendimiento del Estándar \& Poor y es igual a: $13.79 \%$ (https://es.finance.yahoo.com/q/pm?s=SPY).

c) El riesgo país se obtuvo del promedio de los 10 últimos años, para Perú publicado por BCRP y es igual a 1.82 (https://estadisticas.bcrp.gob.pe/estadisticas/series/mensuales/resultados/PN01137X $\mathrm{M} / \mathrm{html})$.

d) Para la inflación de Perú se obtuvo el promedio de la misma de los últimos 10 años lo cual es de $2.70 \%$ (https://www.bcrp.gob.pe/publicaciones/reporte-de-inflacion.html)

e) Para la inflación de USA se obtuvo el promedio de la misma de los últimos 10 años lo cual es de $1.80 \%$ (https://es.inflation.eu/tasas-de-inflacion/estados-unidos/inflacion-historica/ipcinflacion-estados-unidos.aspx)

Por tanto, el valor del costo de capital en soles corrientes es de: $16.87 \%$

\subsection{Presupuesto Base}

El presupuesto base está conformado por el presupuesto de ventas, presupuesto de costos de producción, presupuesto de compras, presupuesto de costo de ventas, presupuesto de gastos administrativos, presupuesto de marketing y ventas y el presupuesto de gastos financieros.

\subsubsection{Presupuesto de ventas.}

El presupuesto de ventas se estima multiplicando la cantidad de alumnos por el monto recibido por el costo de la admisión al colegio (una sola vez), valor de la 
matrícula al inicio del periodo académico (anual) y el pago de la mensualidad (10 meses).

a) Las ventas para los primeros cinco de operación del nuevo colegio se muestran en la Tabla 62. Los supuestos considerados para realizar este presupuesto son: 
b) Se utiliza la capacidad total de la infraestructura para el servicio educativo, iniciando con 4 aulas, luego en el año 5 se habilitará 2 aulas y finalmente en el año 9 se habilitará 2 aulas más.

c) Derecho de admisión de 2,500 soles, monto de la matrícula de 500 soles y monto de la mensualidad de 500 soles. Los precios se consideran que se incrementarán a partir del tercer año.

Asimismo, se ha considerado ingresos adicionales, que se generan durante la impartición de talleres en los meses de verano y el alquiler del local para llevar a acabo fiestas infantiles.

Tabla 62

Presupuesto de ventas

\begin{tabular}{|c|c|c|c|c|c|c|c|c|c|c|}
\hline & 1 & 2 & 3 & 4 & 5 & 6 & 7 & 8 & 9 & 10 \\
\hline \multicolumn{2}{|c|}{ Ingresos por admisión S/. 125,000 } & S/. 125,000 & S/. 125,000 & S/. 125,000 & S/. 225,000 & S/. 225,000 & S/. 225,000 & S/. 225,000 & S/. 262,500 & S/. 262,500 \\
\hline \multicolumn{2}{|c|}{ Ingresos por pago mensual S/. 500,000 } & S/. 500,000 & S/. 500,000 & S/. 500,000 & S/. 825,000 & S/. 825,000 & S/. 825,000 & S/. $1,100,000$ & S/. $1,200,000$ & S/. $1,200,000$ \\
\hline \multirow{2}{*}{$\begin{array}{r}\text { Otros ingresos: Talleres } \\
\text { Otros ingresos: fiestas } \\
\text { infantiles }\end{array}$} & S/. 0 & S/. 72,600 & S/. 87,846 & S/. 106,294 & S/. 128,615 & S/. 155,625 & S/. 188,306 & S/. 227,850 & S/. 275,698 & S/. 333,595 \\
\hline & S/. 6,000 & S/. 6,600 & S/. 7,260 & S/. 7,986 & S/. 11,713 & S/. 12,884 & S/. 14,172 & S/. 15,590 & S/. 21,436 & S/. 23,579 \\
\hline
\end{tabular}




\subsubsection{Presupuesto de costos de producción.}

Los costos de producción están relacionados con el costo de todas las actividades relacionadas con la enseñanza. En este caso se considera los costos relacionados con el uso de las aulas (depreciación del área de las aulas); sala de juegos (depreciación del área de las aulas); servicios relacionados con las aulas como luz, agua e internet; materiales de enseñanza como plumones, papelería, entre otros; pago de docentes y el pago del coordinador académico, tal como se muestra en el Tabla 63.

Tabla 63

Costos de producción

\begin{tabular}{|c|c|c|c|c|c|c|c|c|c|c|}
\hline & 1 & 2 & 3 & 4 & 5 & 6 & 7 & 8 & 9 & 10 \\
\hline Pago docentes & S/. 90,480 & S/. 90,480 & S/. 90,480 & S/. 90,480 & S/. 135,720 & S/. 135,720 & S/. 135,720 & S/. 180,960 & S/. 180,960 & S/. 180,960 \\
\hline Pago auxiliares & S/. 64,728 & S/. 64,728 & S/. 64,728 & S/. 64,728 & S/. 97,092 & S/. 97,092 & S/. 97,092 & S/. 129,456 & S/. 129,456 & S/. 129,456 \\
\hline Depreciación aulas & S/. 9,266 & S/. 9,266 & S/. 9,266 & S/. 9,266 & S/. 9,266 & S/. 14,731 & S/. 14,731 & S/. 14,731 & S/. 14,731 & S/. 14,731 \\
\hline Depreciación de mobiliario & S/. 2,400 & S/. 2,400 & $\mathrm{S} / .2,400$ & S/. 2,400 & S/. 2,400 & $\mathrm{S} / .2,400$ & S/. 2,400 & S/. 2,400 & $\mathrm{S} / .2,400$ & S/. 2,400 \\
\hline Depreciación sala de juegos & S/. 1,705 & S/. 1,705 & S/. 1,705 & S/. 1,705 & S/. 1,705 & S/. 1,705 & S/. 1,705 & S/. 1,705 & S/. 1,705 & S/. 1,705 \\
\hline Depreciación de juegos & S/. 1,538 & S/. 1,538 & S/. 1,538 & S/. 1,538 & S/. 1,538 & S/. 1,538 & S/. 1,538 & S/. 1,538 & S/. 1,538 & S/. 1,538 \\
\hline Depreciación de proyectores & S/. 2,500 & S/. 2,500 & S/. 2,500 & S/. 2,500 & S/. 2,500 & S/. 2,500 & S/. 2,500 & S/. 2,500 & S/. 2,500 & S/. 2,500 \\
\hline Material de enseñanza & S/. 6,000 & S/. 5,000 & S/. 5,000 & S/. 5,000 & S/. 5,000 & S/. 5,000 & S/. 5,000 & S/. 5,000 & S/. 5,000 & S/. 5,000 \\
\hline Total Costos de Producción & S/. 178,617 & S/. 177,617 & S/. 177,617 & S/. 177,617 & $\mathrm{S} / .255,221$ & S/. 260,686 & $\mathrm{S} / .260,686$ & $\mathrm{~S} / . \mathbf{3 3 8 , 2 9 0}$ & $\mathrm{S} / . \mathbf{3 3 8 , 2 9 0}$ & $\mathrm{S} / . \mathbf{3 3 8 , 2 9 0}$ \\
\hline
\end{tabular}




\subsubsection{Presupuesto de compras.}

El presupuesto de compras está conformado por los gastos incurridos en el servicio de contabilidad para el colegio, material de oficina, servicio de agua, servicio de energía eléctrica, servicio de telefonía, servicio de internet, mantenimiento del edificio, servicio de video vigilancia, tal como se muestra en la Tabla 66.

Tabla 64

Presupuesto de compras

\begin{tabular}{|c|c|c|c|c|c|c|c|c|c|c|}
\hline & 1 & 2 & 3 & 4 & 5 & 6 & 7 & 8 & 9 & 10 \\
\hline Servicios contables & S/. 8,000 & S/. 8,400 & $\mathrm{~S} / .8,820$ & S/. 9,261 & S/. 9,724 & S/. 10,210 & S/. 10,721 & S/. 11,257 & S/. 11,820 & $\mathrm{~S} / .12,411$ \\
\hline Mantenimiento del edificio & S/. 6,000 & S/. 6,300 & S/. 6,615 & S/. 6,946 & S/. 7,293 & S/. 7,658 & S/. 8,041 & S/. 8,443 & S/. 8,865 & S/. 9,308 \\
\hline $\begin{array}{r}\text { Mantenimiento de equipos de } \\
\text { computo }\end{array}$ & S/. 4,000 & S/. 4,200 & S/. 4,410 & S/. 4,631 & S/. 4,862 & S/. 5,105 & S/. 5,360 & S/. 5,628 & S/. 5,910 & S/. 6,205 \\
\hline Servicio de energía eléctrica & S/. 6,000 & S/. 6,300 & S/. 6,615 & S/. 6,946 & S/. 7,293 & S/. 7,658 & S/. 8,041 & S/. 8,443 & S/. 8,865 & S/. 9,308 \\
\hline Servicio de agua & S/. 1,800 & S/. 1,890 & S/. 1,985 & S/. 2,084 & S/. 2,188 & S/. 2,297 & S/. 2,412 & S/. 2,533 & S/. 2,659 & S/. 2,792 \\
\hline Servicio de telefonía & S/. 2,400 & S/. 2,520 & S/. 2,646 & S/. 2,778 & S/. 2,917 & S/. 3,063 & S/. 3,216 & S/. 3,377 & S/. 3,546 & S/. 3,723 \\
\hline Servicio de video vigilancia & S/. 2,000 & S/. 2,100 & S/. 2,205 & S/. 2,315 & S/. 2,431 & S/. 2,553 & S/. 2,680 & S/. 2,814 & S/. 2,955 & S/. 3,103 \\
\hline $\begin{array}{l}\text { Total } \\
\end{array}$ & $\mathrm{S} / . \mathbf{3 0 , 2 0 0}$ & $\mathrm{S} / . \mathbf{3 1 , 7 1 0}$ & $\mathrm{S} / . \mathbf{3 3 , 2 9 6}$ & $\mathrm{S} / . \mathbf{3 4 , 9 6 0}$ & S/. 36,708 & S/. 38,544 & S/. 40,471 & S/. 42,494 & S/. 44,619 & $\mathrm{S} / .46,850$ \\
\hline
\end{tabular}

\subsubsection{Presupuesto de Gasto de Ventas.}

El presupuesto de gasto de ventas corresponde a los gastos que se estarán incurriendo por llevar a cabo la venta del servicio educativo del colegio. Se incluye sueldo de vendedoras, pago de comisiones, movilidad supervisión del personal de ventas, tal como se muestra en el Tabla 65. 
Tabla 65

Presupuesto de gasto de ventas

\begin{tabular}{|c|c|c|c|c|c|c|c|c|c|c|}
\hline & 1 & 2 & 3 & 4 & 5 & 6 & 7 & 8 & 9 & 10 \\
\hline Sueldo personal de ventas & S/. 11,160 & S/. 11,160 & S/. 11,160 & S/. 11,160 & S/. 11,160 & S/. 11,160 & S/. 11,160 & S/. 11,160 & S/. 11,160 & S/. 11,160 \\
\hline Beneficios sociales vendedoras & S/. 5,022 & S/. 5,022 & S/. 5,022 & S/. 5,022 & S/. 5,022 & S/. 5,022 & S/. 5,022 & S/. 5,022 & S/. 5,022 & S/. 5,022 \\
\hline Movilidad & S/. 4,800 & S/. 4,800 & $\mathrm{~S} / .4,800$ & S/. 4,800 & S/. 4,800 & S/. 4,800 & S/. 4,800 & S/. 4,800 & S/. 4,800 & S/. 4,800 \\
\hline Comisiones & S/. 1,000 & S/. 1,000 & S/. 1,000 & $\mathrm{~S} / .1,000$ & S/. 1,500 & S/. 1,500 & S/. 1,500 & S/. 2,000 & S/. 2,000 & S/. 2,000 \\
\hline Total & S/. 21,982 & S/. 21,982 & S/. 21,982 & S/. 21,982 & $\mathrm{S} / .22,482$ & $\mathrm{~S} / .22,482$ & S/. 22,482 & S/. 22,982 & S/. 22,982 & S/. 22,982 \\
\hline
\end{tabular}

\subsubsection{Presupuesto de gastos administrativos.}

Los gastos administrativos son los gastos que se incurren durante la realización de las actividades que soportan al servicio educativo, tales como: sueldo integral del personal administrativo, depreciación de las oficinas, depreciación de equipo y el pago de los servicios que corresponde a esta área. Los gastos administrativos se muestran en el Tabla 66.

Tabla 66

Gastos administrativos

\begin{tabular}{|c|c|c|c|c|c|c|c|c|c|c|}
\hline & 1 & 2 & 3 & 4 & 5 & 6 & 7 & 8 & 9 & 10 \\
\hline Sueldo personal administrativo & S/. 118,560 & S/. 124,488 & S/. 124,488 & S/. 124,488 & S/. 124,488 & S/. 124,488 & S/. 124,488 & S/. 124,488 & S/. 124,488 & S/. 124,488 \\
\hline Beneficios sociales personal & S/. 53,352 & S/. 56,020 & S/. 56,020 & S/. 56,020 & S/. 56,020 & S/. 56,020 & S/. 56,020 & S/. 56,020 & S/. 56,020 & S/. 56,020 \\
\hline Depreciación edificio & S/. 8,683 & S/. 8,683 & S/. 8,683 & S/. 8,683 & S/. 8,683 & S/. 8,683 & S/. 8,683 & S/. 8,683 & S/. 8,683 & S/. 8,683 \\
\hline Depreciación equipos & S/. 4,864 & S/. 4,864 & S/. 4,864 & S/. 4,864 & S/. 4,864 & S/. 4,864 & S/. 4,864 & S/. 4,864 & S/. 4,864 & S/. 4,864 \\
\hline Total & $\mathrm{S} / . \mathbf{1 8 5 , 4 5 9}$ & $\mathrm{S} / . \mathbf{1 9 4 , 0 5 5}$ & S/. 194,055 & S/. 194,055 & $\mathrm{S} / . \mathbf{1 9 4 , 0 5 5}$ & S/. 194,055 & S/. 194,055 & S/. 194,055 & $\mathrm{S} / .194,055$ & S/. 194,055 \\
\hline
\end{tabular}




\subsubsection{Presupuesto de marketing y ventas.}

El presupuesto de marketing y ventas corresponde al gasto de las actividades que se llevan a cabo para comunicar a los padres de familia sobre el nuevo colegio y los aspectos diferenciales del servicio. Comprende el monto que se gasta en la elaboración del video institucional, publicidad en periódicos y revistas, merchandising, realización de charlas, entre otros, tal como se muestra en la Tabla 67.

Tabla 67

Presupuesto de marketing y ventas

\begin{tabular}{|c|c|c|c|c|c|c|c|c|c|c|}
\hline & 1 & 2 & 3 & 4 & 5 & 6 & 7 & 8 & 9 & 10 \\
\hline Brochure anual & S/. 5,400 & S/. 5,562 & S/. 5,729 & S/. 5,901 & S/. 6,078 & S/. 6,260 & S/. 6,448 & S/. 6,641 & S/. 6,841 & S/. 7,046 \\
\hline Volantes & S/. 1,200 & S/. 1,236 & S/. 1,273 & $\mathrm{~S} / .1,311$ & S/. 1,351 & S/. 1,391 & S/. 1,433 & S/. 1,476 & S/. 1,520 & S/. 1,566 \\
\hline Merchandising & S/. 6,000 & S/. 6,180 & S/. 6,365 & S/. 6,556 & S/. 6,753 & S/. 6,956 & S/. 7,164 & S/. 7,379 & S/. 7,601 & S/. 7,829 \\
\hline Elaboración video institucional & S/. 3,000 & $\mathrm{S} / .3,090$ & S/. 3,183 & S/. 3,278 & S/. 3,377 & S/. 3,478 & S/. 3,582 & S/. 3,690 & S/. 3,800 & S/. 3,914 \\
\hline Promoción centros comerciales & S/. 21,000 & S/. 21,630 & S/. 22,279 & S/. 22,947 & S/. 23,636 & S/. 24,345 & S/. 25,075 & S/. 25,827 & S/. 26,602 & S/. 27,400 \\
\hline Publicidad periódicos y revistas & S/. 14,400 & S/. 14,832 & S/. 15,277 & S/. 15,735 & S/. 16,207 & S/. 16,694 & S/. 17,194 & S/. 17,710 & S/. 18,241 & S/. 18,789 \\
\hline Charlas & S/. 6,000 & S/. 6,180 & S/. 6,365 & S/. 6,556 & S/. 6,753 & S/. 6,956 & S/. 7,164 & S/. 7,379 & S/. 7,601 & S/. 7,829 \\
\hline Total & S/. 57,000 & S/. 58,710 & S/. 60,471 & S/. 62,285 & S/. 64,154 & S/. 66,079 & S/. 68,061 & S/. 70,103 & S/. 72,206 & S/. 74,372 \\
\hline
\end{tabular}




\subsection{Presupuestos de Resultados}

El presupuesto de resultados comprende los tres estados financieros: el estado de ganancias y pérdidas, el balance general del colegio y el flujo de efectivo. Estos estados de resultados se proyectan para los siguientes 10 años.

\subsubsection{Estado de ganancias y pérdidas proyectado.}

El Estado de Resultados comprende los ingresos y gastos incurridos durante un periodo anual y se estima para los diez años de operación. Tal como se observa en la Tabla 68, el nuevo colegio proyecta ganancias desde el primer año. 
Tabla 68

Estado de Ganancias y Pérdidas

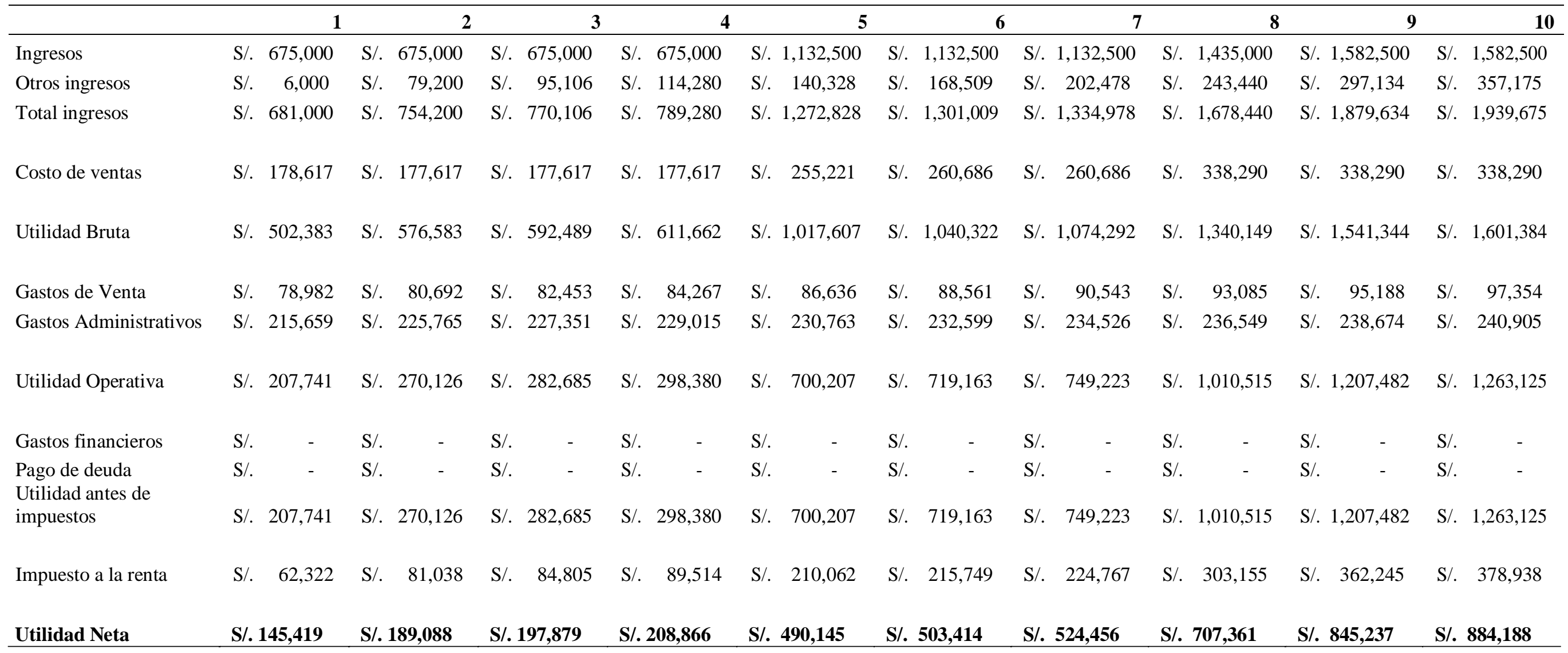




\subsubsection{Balance proyectado.}

El Balance General muestra la posición final de la empresa después de un año de operación. Se proyecta para los siguientes cinco años siguientes según se muestra en la Tabla 69.

Desde el primer año de operación se obtiene un aumento de capital por lo que existen utilidades en los siguientes diez años. Asimismo, el tiempo de vida considerado para la depreciación del edificio es de treinta años y los equipos y mobiliarios es de cinco años. 
Tabla 69

Balance General

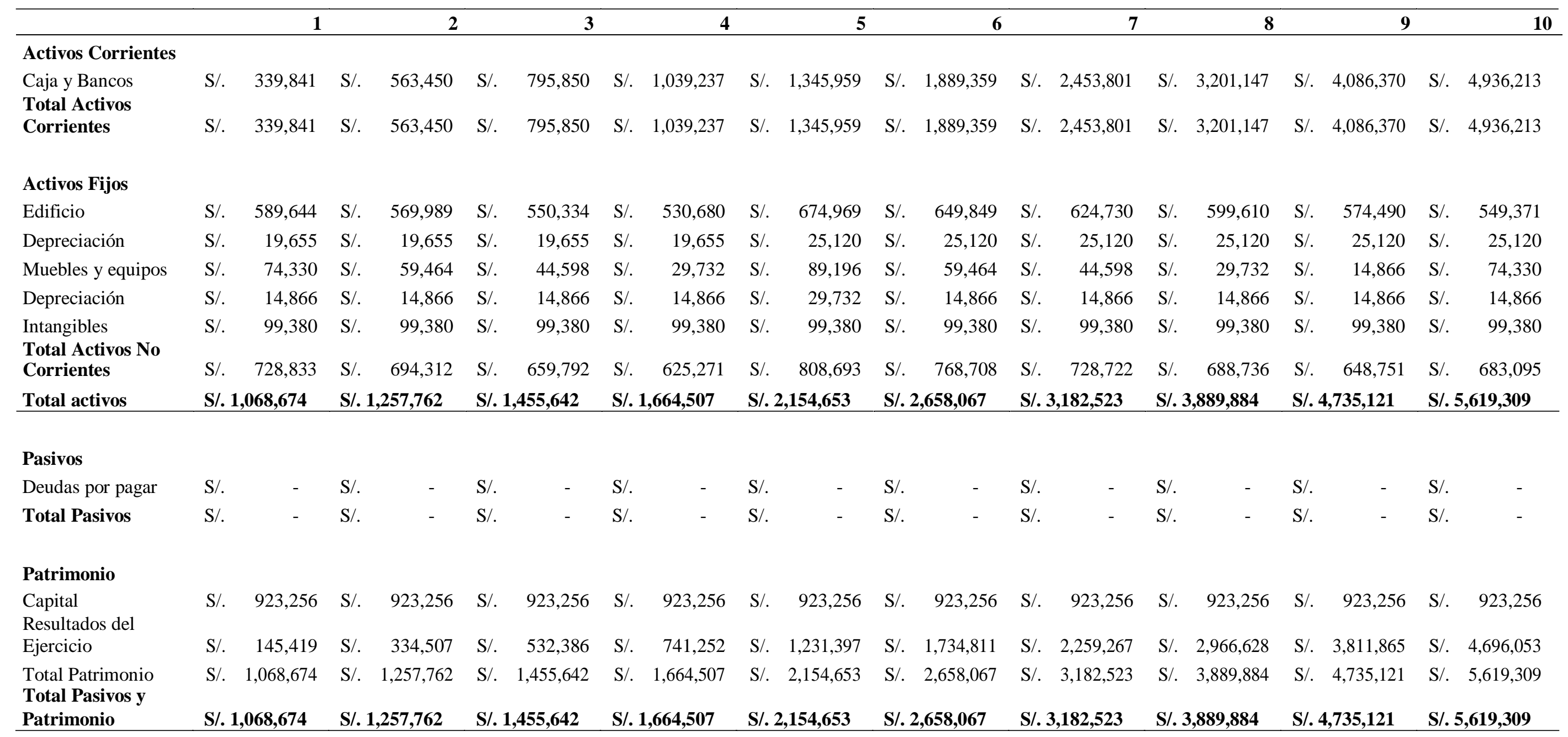




\subsubsection{Flujo de caja proyectado.}

El flujo de caja muestra lo que efectivamente recibió la empresa durante un periodo, así como lo que efectivamente gasto la empresa en las compras realizadas a los proveedores durante este mismo periodo. Para calcular el flujo de efectivo a la utilidad neta se le suma las depreciaciones, dado que los montos correspondientes a este rubro no fue un gasto real para el colegio.

- Flujo de Caja Económico: en la Tabla 70 se muestra el flujo de caja económico proyectado para los próximos diez años de operación de la empresa. En el año cero se muestra la inversión en capital de trabajo, el cual se recupera a partir del primer año de operación de la empresa. En el año cinco se proyecta una inversión para la construcción de cuatro aulas y otra para el mobiliario escolar a fin que el colegio continúe desarrollando sus actividades. 
Tabla 70

Flujo de caja económico proyectado

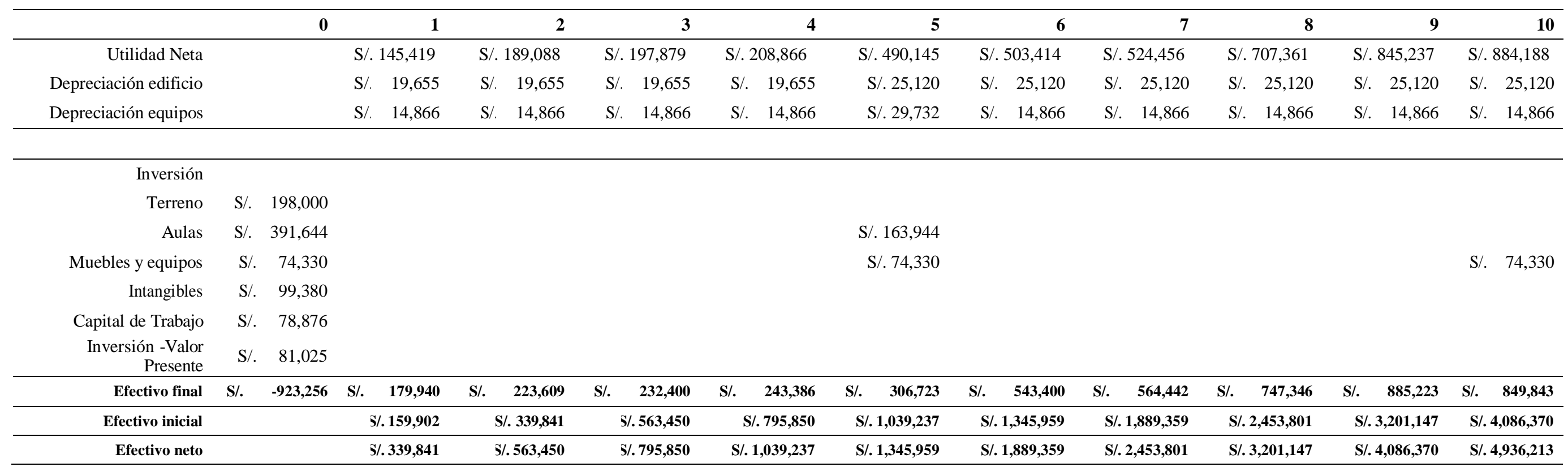




\subsubsection{Recuperación de Capital de Trabajo e Inversiones.}

El período de recuperación de la inversión no tiene en cuenta el valor del dinero en el tiempo, solo determina cuanto se tarda en recuperarlo en un periodo determinado. Tal como se muestra en la Tabla 71, en el año 5 se estaría recuperando la inversión total del proyecto.

Tabla 71

Recuperación de Capital de Trabajo e Inversiones

\begin{tabular}{|c|c|c|c|c|c|c|c|c|c|c|c|c|c|c|c|c|c|c|c|c|}
\hline & \multicolumn{3}{|c|}{$\mathbf{0}$} & \multicolumn{2}{|l|}{1} & \multicolumn{2}{|c|}{2} & \multicolumn{3}{|c|}{3} & \multirow{2}{*}{$\begin{array}{r}\mathbf{5} \\
490,145\end{array}$} & \multirow[t]{2}{*}{6} & & \multicolumn{2}{|c|}{7} & \multicolumn{2}{|l|}{8} & \multicolumn{2}{|c|}{9} & \multirow{2}{*}{$\begin{array}{r}\mathbf{1 0} \\
884,188\end{array}$} \\
\hline Utilidad Neta & & & $\mathrm{S} /$. & 145,419 & $\mathrm{~S} /$. & 189,088 & $\mathrm{~S} /$. & 197,879 & S/. 208,866 & $\mathrm{~S} /$. & & & $\mathrm{S} /$. & 524,456 & $\mathrm{~S} /$. & 707,361 & $\mathrm{~S} /$. & 845,237 & $\mathrm{~S} /$. & \\
\hline Depreciación edificio & & & $\mathrm{S} /$. & 19,655 & $\mathrm{~S} /$. & 19,655 & $\mathrm{~S} /$. & 19,655 & S/. $\quad 19,655$ & $\mathrm{~S} /$. & 25,120 & S/. 25,120 & $\mathrm{~S} /$. & 25,120 & $\mathrm{~S} /$. & 25,120 & $\mathrm{~S} /$. & 25,120 & $\mathrm{~S} /$. & 25,120 \\
\hline \multirow[t]{2}{*}{ Depreciación equipos } & & & $\mathrm{S} /$. & 14,866 & $\mathrm{~S} /$. & 14,866 & $\mathrm{~S} /$. & 14,866 & S/. 14,866 & $\mathrm{~S} /$. & 29,732 & S/. 14,866 & $\mathrm{~S} /$. & 14,866 & $\mathrm{~S} /$. & 14,866 & $\mathrm{~S} /$. & 14,866 & $\mathrm{~S} /$. & 14,866 \\
\hline & & & $\mathrm{S} /$. & 179,940 & S/. & 223,609 & $\mathrm{~S} /$. & 232,400 & $\mathrm{~S} / .243,386$ & S/. & 544,997 & $\mathrm{~S} / . \mathbf{5 4 3 , 4 0 0}$ & $\mathrm{S} /$. & 564,442 & S/. & 747,346 & S/. & 885,223 & $\mathrm{~S} /$. & 924,173 \\
\hline \multicolumn{21}{|l|}{ Inversión } \\
\hline Terreno & $\mathrm{S} /$. & 198,000 & & & & & & & & & & & & & & & & & & \\
\hline Aulas & $\mathrm{S} /$. & 391,644 & & & & & & & & $\mathrm{~S} /$. & 163,944 & & & & & & & & & \\
\hline Muebles y equipos & $\mathrm{S} /$. & 74,330 & & & & & & & & $\mathrm{~S} /$. & 74,330 & & & & & & & & $\mathrm{~S} /$. & 74,330 \\
\hline Intangibles & $\mathrm{S} /$. & 99,380 & & & & & & & & & & & & & & & & & & \\
\hline Capital de Trabajo & $\mathrm{S} /$. & 78,876 & & & & & & & & & & & & & & & & & & \\
\hline $\begin{array}{l}\text { Inversión -Valor } \\
\text { Presente }\end{array}$ & $\mathrm{S} /$. & 81,025 & & & & & & & & & & & & & & & & & & \\
\hline Acumulado & $\mathrm{S} /$. & 923,256 & $\mathrm{~S} /$. & $-743,316$ & $\mathbf{S} /$. & $-519,707$ & $\mathrm{~S} /$. & $-287,307$ & S/. - -43,921 & $\mathrm{S} /$. & 262,802 & $\mathrm{~S} / .806,202$ & $\mathrm{~S} / .1$ & $, 370,644$ & $\mathrm{~S} / .2$ & $, 117,990$ & $\mathrm{~S} / .3$ & $, 003,213$ & $\mathrm{~S} / .3$ & $, 853,056$ \\
\hline
\end{tabular}




\section{Capítulo IX \\ Evaluación económico financiera}

\subsection{Evaluación Financiera}

La evaluación financiera permite conocer si el proyecto del colegio es viable desde el punto de vista de rentabilidad. Es decir, que esta evaluación brinda información sobre el nivel de atractividad del proyecto a partir de la información financiera que se presentó en el capítulo anterior.

Los indicadores usados para evaluar la rentabilidad del proyecto son la tasa interna de retorno y el valor actual neto. Los datos que se requieren para realizar esta evaluación son: el flujo de efectivo de la empresa para los próximos diez años que se muestran en el Tabla 72, el costo de capital para el proyecto calculado a partir del COK y la tasa de interés efectiva.

Tabla 72

Flujo de efectivo

\begin{tabular}{crr}
\hline Año & \multicolumn{2}{c}{ Flujo } \\
\hline 0 & S/. & - \\
1 & S/. & 339,841 \\
2 & S/. & 563,450 \\
3 & S/. & 795,850 \\
4 & S/. & $1,039,237$ \\
5 & S/. & $1,345,959$ \\
6 & S/. & $1,889,359$ \\
7 & S/. & $2,453,801$ \\
8 & S/. & $3,201,147$ \\
9 & S/. & $4,086,370$ \\
10 & S/. & $4,936,213$ \\
\hline
\end{tabular}




\subsubsection{TIR.}

La tasa interna de retorno permite conocer la rentabilidad del proyecto tomado como base para el cálculo la inversión realizada en el año 0 y el flujo de efectivo desde el año uno al diez. La tasa obtenida se compara con el COK a fin de establecer si el proyecto es rentable o no.

Tasa Interna de Retorno Económico: Los flujos de efectivos que se consideran son aquellos relacionados con el total de ingresos y todos los gastos del proyecto. Según los cálculos realizado la tasa interna de retorno es de 31.69\%. El valor obtenido determina que el proyecto del colegio sea aceptable dado que el costo de capital es de $24.08 \%$.

Considerando el valor de rescate del edificio al año diez del proyecto, la tasa interna de retorno para el proyecto es de $32.70 \%$ que determina que sea factible desarrollar el colegio.

\subsubsection{VAN.}

El valor actual neto permite comparar los flujos del proyecto desde el año uno al diez con la inversión realizada el año 0. La tasa que se usa para estimar el valor presente de los flujos futuros es de $24.08 \%$, que fue obtenida como un promedio ponderado del COK.

Valor Actual Neto Económico: Se considera el flujo económico del proyecto para la evaluación y se usa para la tasa de descuento el costo del dinero sin apalancamiento financiero. El valor presente económico del proyecto es S/. 327,592.75 
lo que determina que el proyecto del colegio pueda ser aceptado. Esta decisión se toma dado que el criterio para que un proyecto sea aprobado es que el valor del VAN sea mayor que cero.

Si consideramos el valor de rescate del edificio en el año diez, el valor presente neto del proyecto es de S/. 392,871.14 este valor mayor que cero permite confirmar la aceptación del proyecto del colegio.

\subsubsection{ROE.}

El ROE es un indicador que permite conocer la rentabilidad obtenida de un proyecto. Este valor se estima dividiendo la utilidad neta sobre el capital durante el periodo de proyección del estado de resultados y el balance general.

En la Figura 37 se puede observar que el ROE del proyecto presenta un nivel de rentabilidad positiva hasta el año diez, donde obtiene una rentabilidad sobre el capital promedio de $16.47 \%$.

Asimismo, se puede calcular el ROA del proyecto. Este indicador mide la rentabilidad de un proyecto dividiendo la utilidad neta entre los activos durante el periodo de proyección.

En la figura 38 se muestra el ROA del proyecto. En todos los años el ROA es positivo alcanzado su máxima rentabilidad promedio en el año diez con un $16.47 \%$, 


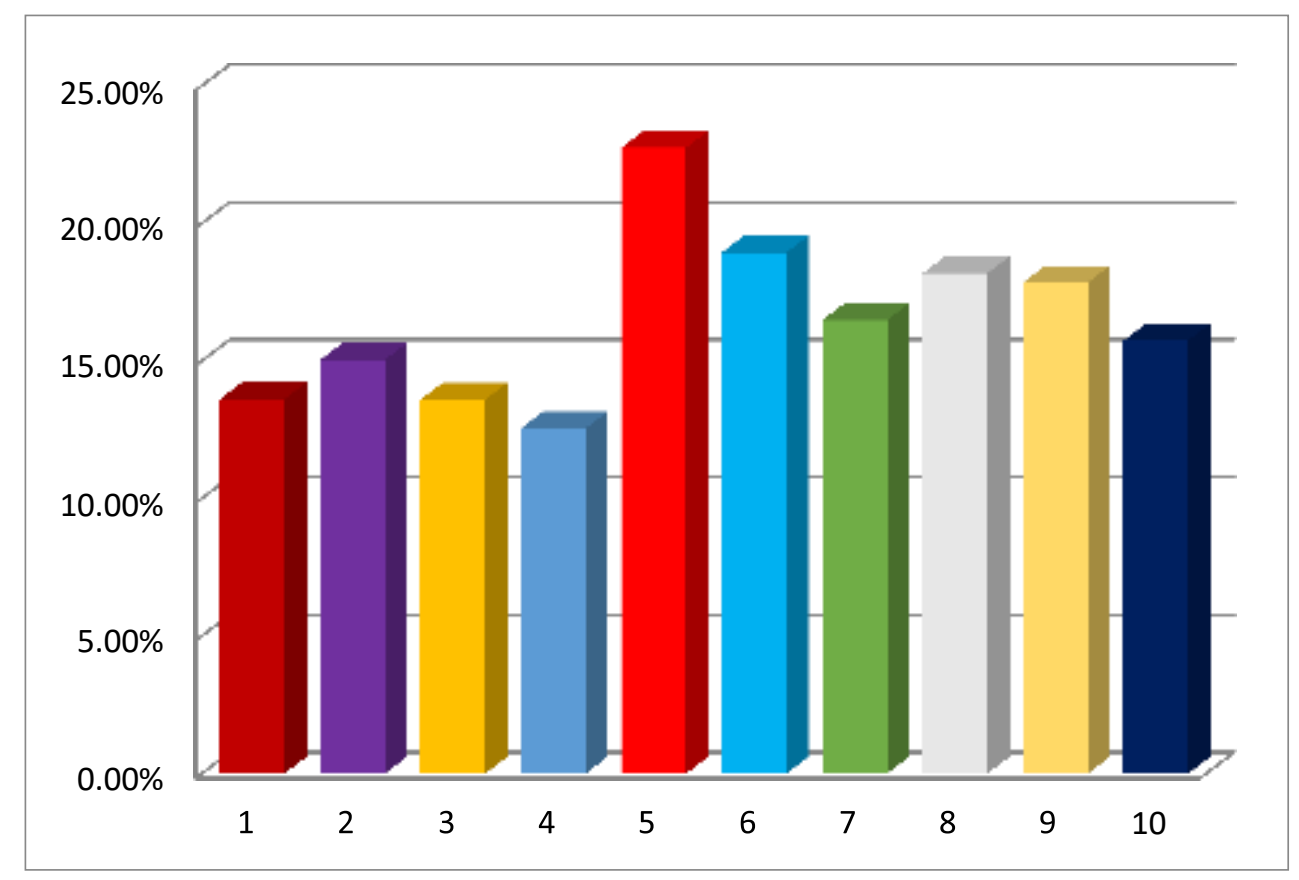

Figura 37. Indicador ROE del proyecto

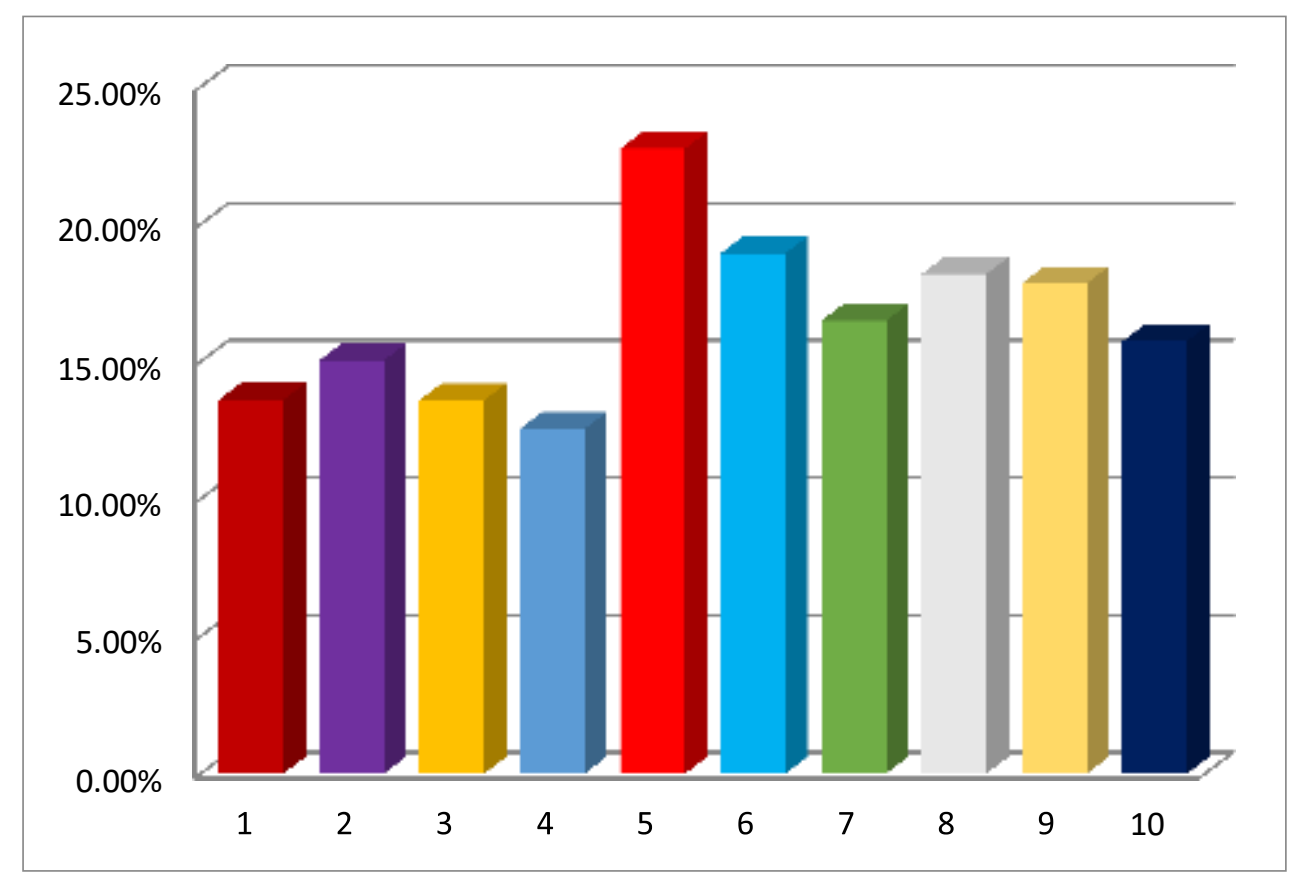

Figura 38. Indicador ROA del proyecto 


\subsubsection{Ratios.}

El proyecto se puede analizar usando dos indicadores de rentabilidad que permiten evaluar el proyecto antes de intereses e impuestos y sobre las ventas del periodo.

En el primer caso el proyecto presenta una rentabilidad positiva desde los primeros años, lo que determina que el proyecto sea atractivo para los inversionistas. En la Figura 39 se muestra la evolución de la rentabilidad del proyecto alcanzado un máximo valor el año 10 con $65 \%$.

En el segundo caso de la rentabilidad sobre ventas, también se obtiene una rentabilidad positiva los primeros años del proyecto, se alcanza una rentabilidad positiva de $47 \%$ en el año diez. En la Figura 40 se puede apreciar la rentabilidad sobre ventas hasta el año diez.

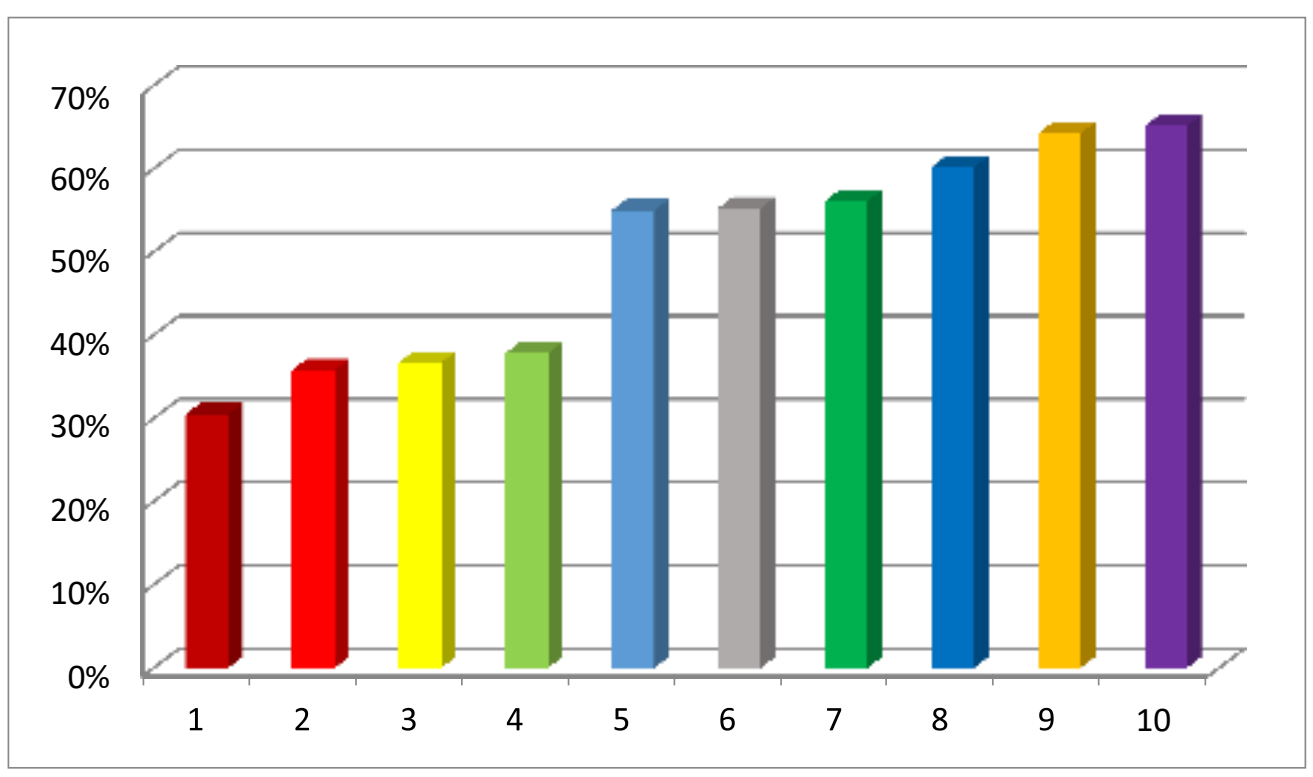

Figura 39. Indicador rentabilidad antes de intereses e impuestos 


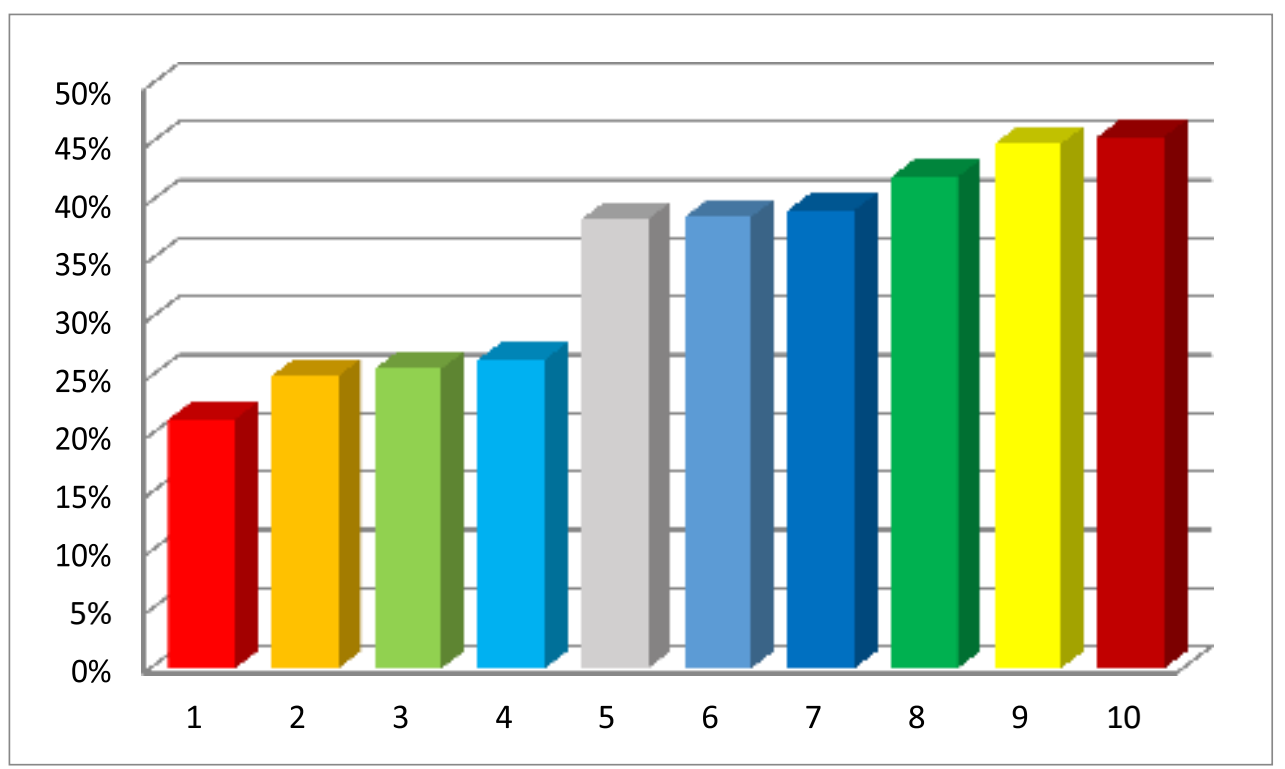

Figura 40. Indicador rentabilidad sobre ventas

\subsection{Análisis de Riesgo}

Este análisis permite reconocer las variables críticas que tienen un impacto en el proyecto, de manera tal que un cambio negativo en estas variables puede afectar la rentabilidad del proyecto.

\subsubsection{Análisis de punto de equilibrio.}

El punto de equilibrio es aquel en donde el proyecto tiene una utilidad de cero, dado que los ingresos son equivalentes a los costos. Se estimó que el punto de equilibrio del proyecto con las condiciones iniciales de precio y costos es de 51 alumnos.

Este valor puede cambiar si se modifica el precio del servicio educativo (conformado por derecho de admisión, matrícula y mensualidad), así como los principales costos del proyecto. Los costos deben agruparse en dos tipos: costos fijos que no cambia con la variación en los usuarios del servicio educativo y los costos variables que depende de la cantidad de usuarios servicio que se brinda. 
Los datos que se usaron para calcular el punto de equilibrio con los valores del primer año del proyecto se muestran en la Tabla 73 .

Tabla 73

Punto de equilibrio del proyecto

\begin{tabular}{|c|c|c|}
\hline Precio & $\mathrm{S} /$. & 8,000 \\
\hline Ingresos & $\mathrm{S} /$. & 675,000 \\
\hline \multicolumn{3}{|l|}{ Costos Fijos } \\
\hline Pago personal & S/. & 327,120 \\
\hline Pago intereses & $\mathrm{S} /$. & - \\
\hline Depreciación edificio & $\mathrm{S} /$. & 19,655 \\
\hline Depreciación & & \\
\hline mobiliario & $\mathrm{S} /$. & 14,866 \\
\hline Total Costos Fijos & $\mathrm{S} /$ & 361,641 \\
\hline \multicolumn{3}{|l|}{ Costos Variables } \\
\hline Servicios & $\mathrm{S} /$. & 12,200 \\
\hline Ventas & $\mathrm{S} /$. & 78,982 \\
\hline Material enseñanza & $\mathrm{S} /$. & 6,000 \\
\hline Total Costos & & \\
\hline \multirow{3}{*}{$\begin{array}{l}\text { Variables } \\
\text { Costo variable } \\
\text { unitario }\end{array}$} & $\mathrm{S} /$. & 97,182 \\
\hline & & \\
\hline & $\mathrm{S} /$. & 972 \\
\hline Punto de equilibrio & & 51 \\
\hline
\end{tabular}

\subsubsection{Análisis de sensibilidad.}

El análisis de sensibilidad permite conocer las variables que pueden afectar al proyecto, sea por la reducción en la captación de alumnos ó por el incremento en los costos del personal y los insumos para impartir el servicio. 
La variable crítica en el proyecto es el número de alumnos matriculados. Es decir, si el número de alumnos considerados se reduce entonces la rentabilidad del proyecto también. Por lo que, si no consigue iniciar el proyecto con los 51 alumnos considerados, entonces el primer año de operación del colegio tendría una pérdida que puede afectar las operaciones de los años siguientes. El número mínimo de alumnos al inicio debe ser de 51 alumnos.

En relación con los costos, el proyecto se puede ver afectado si cambia el precio del terreno. Así, el valor máximo a pagar por el terreno debe ser de 80 dólares el metro cuadrado. El mismo impacto negativo puede ocurrir si el precio de la construcción se incrementa hasta 230 dólares el metro cuadrado de construcción. Asimismo, dado que el precio del terreno esta cotizado en dólares un incremento en el tipo de cambio tendría un impacto significativo en el proyecto. 


\section{Conclusiones y recomendaciones}

\section{Conclusiones}

a) Según el estudio de mercado realizado los padres de familia valoran la calidad de las instituciones educativas para la formación de sus hijos. Además, se encontró que los padres de familia buscan participar en el proceso de formación de sus hijos durante la educación inicial.

b) Se desarrolló un análisis de la competencia, es decir de los colegios de educación básica en la ciudad. El análisis permitió reconocer las ventajas competitivas que puede plantear el colegio a fin de posicionarse en el mercado, así se puede señalar que es importante contar con un modelo educativo propio y de docentes especializados en educación básica.

c) El proyecto permitirá cubrir la demanda por una educación inicial de calidad en dicha ciudad, proponiendo una infraestructura adecuada en las diversas áreas académicas según el desarrollo del niño.

d) El plan de marketing se formula a partir de la estrategia seleccionada para iniciar operaciones en la ciudad de Chiclayo. La estrategia de marketing se basa en el desarrollo del producto o este caso en el servicio educativo a ofrecer basado en la calidad de la enseñanza y la atención al padre de familia. El plan de marketing, permite formular un conjunto de actividades para dar a conocer el producto y lograr el posicionamiento de la marca del colegio.

e) La inversión inicial requerida para empezar el proyecto es viable dado que se puede recuperar el capital invertido. Puesto que el proyecto comienza a generar ingresos a partir del segundo año de operación de manera sostenida, lo que asegura la viabilidad del proyecto. Ya que tenemos una TIR de $31.69 \%$ y un VAN de S/.327,592.75 


\section{Recomendaciones}

a) Se requiere implementar servicios adicionales que demanda el padre de familia como movilidad y almuerzos.

b) Se debe buscar alianzas con las cunas y con los colegios de nivel primarias a fin de buscar sinergias con ellos.

c) Se deben generar servicios adicionales a fin de incrementar el monto de otros ingresos para el proyecto aprovechando la infraestructura del colegio.

d) Se deberá contar con un sistema de monitoreo que permita conocer rápidamente el estado actual de las actividades del Colegio y conocer el avance educativo de los niños

e) Se debe buscar la posibilidad de buscar una integración con el servicio de cunas y educación primaria en los siguientes años. Además de estar atenta a los cambios del entorno que pueden afectar el desarrollo y crecimiento del colegio. 


\section{REFERENCIAS}

ANDERSON, D. SWEENEY, D. \& WILLIAMS, T. (2004). Métodos Cuantitativos para los Negocios. México. DF.: Thomson.

ARAGÓN SÁNCHEZ, A. FERNÁNDEZ ALLES, M. \& MARTÍN ALCAZAR, F. (2004). La gestión estratégica de los recursos humanos (2a ed.). España, Madrid: Pearson.

FRED, D. (2013). Conceptos de Administración Estratégica (14 ${ }^{\mathrm{a}}$ ed.). México: Pearson Educación.

HORNGREN, C. SRIKANT, M. DATAR, G. \& FOSTER, T. (2007). Contabilidad de Costos (12a ed.). México D.F: McGraw-Hill.

Ley 28044. (2003). Ley General de Educación. GOBIERNO DEL PERÚ. Perú.

KOTLER, P. KELLER, K. (2012). Dirección de Marketing, (14ª ed.). México: Editorial Pearson Educación-

MALHOTRA, N. (2008). Investigación de Mercados. (5 ${ }^{\mathrm{a}}$ ed.). México: Editorial Pearson Prentice Hall

MINISTERIO DE EDUCACIÓN. (2012). Programas Educativos para niños y niñas de O a 3 años Guía para la implementación y funcionamiento. Perú.

OFICINA DE ESTUDIOS IBEROAMERICANOS. SISTEMAS EDUCATIVOS NACIONALES - PERÚ. (2012). Educación Inicial. Perú.

PORTER, M. (1985). Ventaja Competitiva, (1ª ed.). México: CECSA.

SAPAG CHAIN, N. (2013) Proyectos de Inversión. Formulación y Evaluación.

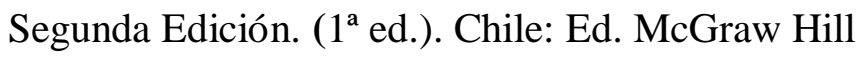
VEXLER TALLEDO, I. (2006). Informe Sobre la Educación Peruana Situación y Perspectivas, Perú: Ministerio de Educación. 


\section{Páginas de Internet}

Colegios en Perú. (2016). Centros de educación inicial particulares en Chiclayo (Chiclayo, Lambayeque). Recuperado de http://www.colegiosenperu.com/nidos_particulares_en_chiclayo_(chiclayolambayeque).htm.

Vigo, C. \& Torres, S. (2016). Educación Inicial y Primaria en el Perú. Recuperado de http://inversionenlainfancia.net/blog/entrada/entrevista/32/0

Especial Educación Inicial. (2016). 79 años de educación inicial en el Perú. Recuperado de http://inversionenlainfancia.net/blog/entrada/noticia/179/0

Asociación Peruana de Empresas de Investigación de Mercados. (2016). Niveles Socio Económicos. Recuperado de http://apeim.com.pe/ 


\section{Anexo 1 \\ Ficha técnica entrevista a profundidad: expertos del sector}

\section{PRODUCTO}

Colegio de educación inicial para niños entre tres a cinco años localizado en la ciudad de Chiclayo. El colegio será una institución privada que estará enfocado a brindar un servicio educativo a los niños (entre tres a cinco años), cuyos padres valoren la formación integral de sus hijos.

\section{Objetivo de la investigación}

a) Identificar la demanda existente de colegios de educación inicial para niños entre tres a cinco años en la ciudad de Chiclayo.

b) Reconocer las principales variables de comportamiento de los padres de familia que demandan el servicio de educación inicial.

c) Examinar la estructura actual del sector de colegios de educación inicial en Chiclayo.

d) Determinar los factores que toman en cuenta los colegios de educación inicial para su diferenciación.

e) Identificar las principales tendencias sobre el servicio y el modelo educativo de los colegios de educación inicial en el futuro.

f) Identificar las características del servicio de los colegios de educación inicial que demandan los padres de familia.

\section{Contenido}

Estructura del sector 
Colegios de educación inicial existentes y la manera en que compiten, características de los usuarios del servicio, estrategias predominantes de la empresas en el sector, requerimientos del Ministerio de Educación, requerimientos de otros sectores (como INDECI, Municipalidad, entre otros) barreras existente en el sector para nuevos ingresantes, posicionamiento de los colegios de educación inicial en la ciudad de Chiclayo, forma de publicidad que realizan, promociones que llevan a cabo los colegio del sector en Chiclayo, programa de lealtad de los colegios para los padres de familia. Características del servicio:

Características del servicio que ofrecen los colegios de educación inicial (horarios de los colegios, medios para el pago de la mensualidad, monto promedio de la mensualidad que cobran los colegios de este nivel en Chiclayo, calidad de la enseñanza, modelo de enseñanza predominante, certificación de los docentes del colegio de educación inicial en Chiclayo).

Demanda

Nivel de demanda existente para colegios de educación inicial, sectores de la población que demandan educación inicial privada, el tipo de comunicación que buscan recibir los padres por parte de los colegios, proceso de selección de un colegio inicial por parte de los padres de familia.

Tendencias

Modelos educativos existentes, nuevos modelos educativos para la educación inicial, nuevas características de los colegios de educación inicial, uso de la tecnología en la educación inicial, nuevos requerimientos por parte de las entidades del gobierno para este tipo de colegio, nuevas demandas sociales para los colegios de este nivel. 


\section{Perfil del Participante:}

Personas que investiguen o cuenten con experiencia laboral en la enseñanza y/o gestión de colegios de educación inicial. La experiencia que se requiere para ser considerado experto debe ser como mínimo diez años y que además ser reconocido en el medio por sus aportes en el ámbito de educación básica.

\section{Cuestionario, el cual comienza con la frase de presentación y luego las preguntas relevantes para la investigación:}

\section{Presentación}

Estimado Sr..., somos un grupo de alumnos del Programa de Maestría de Ciencias Empresariales de la Universidad San Ignacio de Loyola. Como parte del proceso de graduación, estamos elaborando un proyecto de investigación que tiene como objetivo analizar el nivel de la educación inicial para niños entre tres a cinco años, en la ciudad de Chiclayo. En ese sentido, nos gustaría conocer su opinión sobre las características del sector y de los colegios de educación inicial en la ciudad de Chiclayo. La información que nos proporcionen en esta entrevista será usada estrictamente para fines académicos.

\section{Preguntas a plantear en la entrevista.}

\section{SOBRE EL SECTOR}

1. ¿Cuál es su experiencia en el sector de educación y específicamente en el nivel de educación inicial?

2. ¿Cuál es su percepción sobre la evolución del sector de colegios de educación inicial en la ciudad de Chiclayo en los últimos 3 años?

3. ¿Cómo considera que será la evolución del sector de colegios de educación inicial privados en este nuevo gobierno? 
4. ¿Considera Usted que se requieren plantear nuevas políticas sobre la educación inicial privada en el país y/o en las regiones?

5. ¿Cuáles son los principales requerimiento y barreras que norma el Ministerio de Educación para colegios en el nivel inicial para los sectores público y privado?

6. ¿Existen normas adicionales a las que emite el Ministerio de Educación que deban cumplir los colegios de educación inicial privados en la ciudad de Chiclayo?

7. ¿Cuáles son los principales aspectos de la política que ha incentivado la creación de colegios de educación inicial que el Estado ha impulsado en los últimos cuatro años?

8. ¿Existen empresas privadas interesados en ingresar al sector de educación inicial en la región?

9. ¿Cuáles son los factores limitantes para el ingreso de nuevos colegios de educación inicial privados en la actualidad en la ciudad de Chiclayo?

10. ¿Qué opina de la calidad de la infraestructura de los colegios de educación inicial en la ciudad de Chiclayo?

\section{SOBRE EL MERCADO}

11. ¿Cuáles son los principales colegios de educación inicial en la ciudad de Chiclayo?

12. ¿Cuáles son los principales factores de competencia entre los colegios de educación inicial en la ciudad de Chiclayo?

13. ¿Cuáles son los elementos tecnológicos que usan los alumnos en su Colegio durante el desarrollo de sus clases? 
14. ¿Bajo qué criterios o variables se podrían segmentar los colegios de educación inicial privados en la ciudad de Chiclayo?

15. ¿Cuáles son los principales insumos que demandan los colegios de educación inicial?

16. ¿Cuáles son las empresas que proveen de los insumos que demandan los colegios de educación inicial?

\section{SOBRE EL SERVICIO}

17. ¿Cuáles son los modelos pedagógicos alternativos que se aplican en los colegios de educación inicial privados en la actualidad?

18. ¿Cuál es el modelo pedagógico que aplica usted en su institución? Indicar ¿Por qué?

19. ¿Cuál es el perfil académico de los docentes en el nivel inicial dentro de la ciudad de Chiclayo?

20. La norma técnica nos dice que en un colegio de educación inicial la capacidad no debe ser más de 25 niños por aula ¿Cuántos niños considera Usted que debe tener un aula de tamaño ideal?

21. En el Colegio que Usted dirige, ¿Cuál es la capacidad actual de sus aulas?

22. ¿De cuantas horas debería constar la jornada educativa diaria en los colegios de educación inicial privados?

23. ¿Conoce colegios de educación inicial privados que en la actualidad brindan el servicio de horario extendido?

24. ¿Qué ventajas y desventajas encuentra Usted en este servicio de horario extendido? 
25. ¿Cuáles son los ambientes que debe contar un colegio de educación inicial para un normal desenvolvimiento de los niños?

\section{SOBRE EL CLIENTE}

26. ¿Cuál es el rango de edad de los padres de familia que demandan el servicio de educación inicial en los colegios de educación inicial privados en la ciudad de Chiclayo?

27. ¿Quién es el que se encarga de hacer seguimiento diario de las labores escolares de sus hijos, el padre o la madre?

28. ¿Cuáles son los aspectos relacionados con el servicio y la enseñanza que buscan los padres de familia en los colegios de educación inicial?

29. ¿Cuál es el nivel socio-económico de los padres que matriculan a sus hijos en Colegios de educación inicial privados en la actualidad?

30. ¿Qué distancia en promedio suelen trasladarse los alumnos hacia sus colegios de educación inicial en la actualidad?

31. ¿A los niños lo trasladan sus padres al colegio o son llevados por una movilidad particular contratada por estos? 


\section{Anexo 2}

\section{Ficha técnica investigación cualitativa: focus group}

\section{Producto}

Colegio de educación inicial para niños entre tres a cinco años localizado en la ciudad de Chiclayo. El colegio será una institución privada que estará enfocado a brindar un servicio educativo a los niños (entre tres a cinco años).

\section{Objetivo de la investigación}

- Se busca conocer las variables que inciden en el comportamiento de compra del servicio de los padres de familia que buscan un colegio de educación inicial.

- Identificar el perfil de los padres de familia que buscan un colegio inicial con relación a sus características personales y familiares.

- Identificar las características de un colegio de educación inicial en relación con los requerimientos del servicio que son demandados por los padres de familia

- Validar la demanda del servicio de un colegio de educación inicial para padres de familia de nivel socioeconómico AB.

\section{Contenido}

El siguiente listado presenta los temas que se han planteado para ser formulado como preguntas a los padres de familia durante la sesión del focus group. Perfil del cliente

Perfil de los padres de familia que demandan un colegio privado de educación inicial: conocen por experiencia personal el servicio al alumno y padre de familia de un 
colegio inicial y padres de familia de otros colegios de educación inicial por referencia de amigos o parientes.

Comportamiento de compra del servicio:

Frecuencia de compra, uso del servicio en otros colegios, beneficios percibidos de un colegio de educación inicial, comunicación que han recibido de otros colegios iniciales de la localidad, medios donde investiga sobre colegios iniciales.

Características del servicio

Características deseadas del colegio de educación inicial (horario, monto de pago de la mensualidad de enseñanza, participación de los padres como apoyo durante la formación del niño, calidad de la enseñanza deseada, calidad de los docentes del colegio requerido)

Aceptación del servicio.

Aceptación del servicio del colegio inicial propuesto de modo que se pueda establecer una percepción de la demanda para el colegio.

\section{Perfil del Participante}

Padres de familia de niveles socioeconómico A/B y que tienen niños entre 1 y 2 años y que estén interesados en contar con el servicio de educación inicial para sus hijos. En general, los padres de familia a los que se planea ofrecer el servicio del colegio inicial son personas entre 26 a 35 años de edad y que valoran la calidad de la educación para sus hijos.

Datos a obtener en la ficha de reclutamiento (previo a la sesión del focus group): Edad, lugar donde viven, lugar donde laboran, escolaridad promedio, tiempo de actividad laboral, rango de sueldo, número de hijos que tienen o han tenido en un 
colegio de educación inicial, número de hijo que tienen para iniciar estudios en un colegio de educación inicial.

\section{Determinación de número de focus group que se realizarán}

A fin de obtener información de fuentes primarias se plantea realizar focus group con los padres de familia que cumplen con el perfil deseado. Los padres de familia que se invitarán a participar del focus group serán divididos en grupos no menor de seis ni mayor de ocho participantes.

En el caso de los grupos a formar para cada focus group se espera que los participantes sean similares en su perfil, lo que se consigue conformando grupos con características similares. En este sentido, se debe separar los padres de familia que pertenecen al nivel socioeconómico A/B .

A partir de esta separación, los grupos a conformar para llevar a cabo esta técnica de investigación serán los siguientes:

a) Padres de familia con experiencia por tener o haber tenido hijos en un colegio inicial. Dos focus group NSE AB rango de edad 26 a 35 años.

Por consiguiente, se formará dos grupos de padres de familia para llevar a cabo los focus group.

\section{Guía de Pautas, la cual tiene la siguiente secuencia:}

\section{Frase de presentación}

Estimados padres de familia, somos un grupo de alumnos del Programa de Maestría Ciencias Empresariales de la Universidad San Ignacio de Loyola. Como parte del proceso de graduación estamos elaborando un proyecto de investigación que tiene como objetivo analizar los elementos a tener en cuenta para crear un colegio de educación 
inicial para niños entre tres a cinco años. En ese sentido, nos gustaría conocer su opinión sobre el nivel de servicio que Uds. buscan en un colegio de educación inicial. La información que nos proporcionen será usada de manera confidencial y anónima para la presentación del proyecto.

\section{Diseño de fase de calentamiento:}

a) Presentación de los participantes

b) Indicar actividades de aprendizaje que Usted realiza con sus hijos.

c) Indicar actividades lúdicas en la participa su hijo. ¿Usted también participa?

d) Indicar los motivos que determino el nombre a sus hijos

\section{Listado de preguntas}

Para padres que tienen o han tenido hijos en un colegio inicial

Perfil del cliente: se plantearán preguntas sobre:

1. ¿A qué colegio de educación inicial (jardín) asiste o asistió su hijo? Indicar el periodo al que asistió su hijo al colegio de educación inicial.

2. ¿Cómo tomaron la decisión en la familia sobre el colegio inicial al que asiste o asistió su hijo?

3. ¿Qué aspecto fundamental valoró usted para seleccionar el colegio de educación inicial al que asiste o asistió su hijo?

4. ¿Cuáles son las actividades que el colegio que asiste (asistió) su hijo lleva (llevó) a cabo para los padres de familia?

5. ¿Qué tan satisfecho está con el servicio en general recibido por el colegio que asiste (asistió) su hijo? ¿Por qué?

6. ¿Cuál es la modalidad para el pago de la mensualidad en el colegio inicial al que asiste o que asistió su hijo? 
7. ¿Cuál es el monto aproximado que usted paga (o pagó) por el colegio al que asiste (o asistió) su hijo?

8. ¿Están considerando cambiar o están planeando cambiar a su hijo a otro colegio? Si es si, ¿Qué factores podrían motivar el cambio de colegio para su hijo?

Conocimiento de la competencia: se plantearan preguntas sobre

9. ¿Qué opina en general del nivel de enseñanza de los colegio de educación inicial privada en la ciudad de Chiclayo?

10. Sus amigos o familiares le recomendaron algún otro colegio de educación inicial. ¿Cuál? ¿Lo visitó?

11. ¿Cuántos centros de educación inicial visitó usted previo a la selección del colegio en donde matricularon a su hijo? ¿Cuáles?

12. Indicar, ¿Cuáles con los aspectos que le agradó de los colegios de educación inicial que visitaron? ¿Por qué?

13. Indicar, ¿Cuáles con los aspectos que no le agradó de los colegios de educación inicial que visitaron? ¿Por qué?

14. ¿Qué colegios de educación inicial usted considera los mejores en la ciudad de Chiclayo? ¿Por qué?

15. ¿A qué colegio de educación inicial usted no enviaría a su hijo en la ciudad de Chiclayo? ¿Por qué?

Características del servicio

16. ¿Cuáles son los factores del servicio al alumno que usted considera importantes en la búsqueda de un colegio de educación inicial?

17. ¿Cuáles son los factores del servicio al padre de familia que usted considera importantes en la búsqueda del colegio de educación inicial? 
18. ¿Cuáles son los factores determinantes que usted consideró para elegir un colegio de educación inicial? ¿Por qué?

19. ¿Considera Usted importante la certificación en educación inicial de los docentes en el colegio al que asiste su hijo?

20. ¿Considera Usted que el centro de educación inicial al que asiste (asistió) su hijo debe estar integrado con un colegio de educación primaria? ¿Por qué?

21. ¿Cómo lleva (llevó) a sus hijos al colegio: personalmente ó mediante un servicio de transporte escolar?

22. ¿Qué distancia debe (debió) recorrer su hijo para llegar al colegio?

23. ¿Considera usted que un colegio de educación inicial debe ser bilingüe?

24. En el colegio de educación inicial donde han estado o están sus hijos, ¿incentivaba la participación activa de los padres de familia en el proceso educativo? 


\section{Anexo 3 \\ Ficha técnica investigación cualitativa: focus group}

\section{Producto}

Colegio de educación inicial para niños entre tres a cinco años localizado en la ciudad de Chiclayo. El colegio será una institución privada que estará enfocado a brindar un servicio educativo a los niños (entre tres a cinco años).

\section{Objetivo de la investigación}

- Se busca conocer las variables que inciden en el comportamiento de compra del servicio de los padres de familia que buscan un colegio de educación inicial.

- Identificar el perfil de los padres de familia que buscan un colegio inicial con relación a sus características personales y familiares.

- Identificar las características de un colegio de educación inicial en relación con los requerimientos del servicio que son demandados por los padres de familia

- Validar la demanda del servicio de un colegio de educación inicial para padres de familia de nivel socioeconómico $\mathrm{AB}$.

\section{Contenido}

El siguiente listado presenta los temas que se han planteado para ser formulado como preguntas a los padres de familia durante la sesión del focus group.

Perfil del cliente

Perfil de los padres de familia que demandan un colegio privado de educación inicial: conocen por experiencia personal el servicio al alumno y padre de familia de un 
colegio inicial, conocen los servicios al alumno y padre de familia de otros colegios de educación inicial por referencia de amigos o parientes.

Comportamiento de compra del servicio:

Frecuencia de compra, uso del servicio en otros colegios, beneficios percibidos de un colegio de educación inicial, comunicación que han recibido de otros colegios iniciales de la localidad, medios donde investiga sobre colegios iniciales.

Características del servicio

Características deseadas del colegio de educación inicial (horario, monto de pago de la mensualidad de enseñanza, participación de los padres como apoyo durante la formación del niño, calidad de la enseñanza deseada, calidad de los docentes del colegio requerido).

Aceptación del servicio.

Aceptación del servicio del colegio inicial propuesto de modo que se pueda establecer una percepción de la demanda para el colegio.

\section{Perfil del Participante}

Padres de familia de niveles socioeconómico A/B que tienen niños entre uno y dos años y que estén interesados en contar con el servicio de educación inicial para sus hijos. En general, los padres de familia a los que se planea ofrecer el servicio del colegio inicial son personas entre 26 a 35 años de edad y que valoran la calidad de la educación para sus hijos.

Datos a obtener en la ficha de reclutamiento (previo a la sesión del focus group): Edad, lugar donde viven, lugar donde laboran, escolaridad promedio, tiempo de actividad laboral, rango de sueldo, número de hijos que tienen o han tenido en un 
colegio de educación inicial, número de hijo que tienen para iniciar estudios en un colegio de educación inicial.

\section{Determinación de número de focus group que se realizarán}

A fin de obtener información de fuentes primarias se plantea realizar focus group con los padres de familia que cumplen con el perfil deseado. Los padres de familia que se invitarán a participar del focus group serán divididos en grupos no menor de seis ni mayor de ocho participantes.

En el caso de los grupos a formar para cada focus group se espera que los participantes sean similares en su perfil, lo que se consigue conformando grupos con características similares. En este sentido, se debe separar los padres de familia que pertenecen al nivel socioeconómico A/B.

A partir de esta separación, los grupos a conformar para llevar a cabo esta técnica de investigación serán los siguientes:

b) Padres de familia que por primera vez van a demandar este tipo de servicio.

Dos focus group NSE AB rango de edad 26 a 35 años.

Por consiguiente, se formará dos grupos de padres de familia para llevar a cabo los focus group.

\section{Guía de Pautas, la cual tiene la siguiente secuencia:}

\section{Frase de presentación}

Estimados padres de familia, somos un grupo de alumnos del Programa de Maestría Ciencias Empresariales de la Universidad San Ignacio de Loyola. Como parte del proceso de graduación estamos elaborando un proyecto de investigación que tiene como objetivo analizar los elementos a tener en cuenta para crear un colegio de educación 
inicial para niños entre tres a cinco años. En ese sentido, nos gustaría conocer su opinión sobre el nivel de servicio que Uds. buscan en un colegio de educación inicial.

\section{Listado de preguntas}

$\underline{\text { Para padres que no tienen actualmente hijos en un colegio de educación inicial }}$

Perfil del cliente: se plantearán preguntas sobre:

1. ¿Cuál es el número de hijos que tiene en edad escolar inicial?

2. ¿Está usted planeando matricular a su hijo(s) en un colegio de educación inicial?

3. ¿Cómo tomarán la decisión en la familia sobre al colegio inicial al que asistirá su hijo?

4. ¿Qué valora usted como aspectos fundamentales para seleccionar el colegio de educación inicial al que asistirá su hijo?

Conocimiento de la competencia: se plantearán preguntas sobre

5. ¿Qué opina en general del nivel de enseñanza de los colegios de educación inicial privada en la ciudad de Chiclayo?

6. Sus amigos o familiares le han recomendado algún colegio de educación inicial ¿Cuál? ¿Lo ha visitado?

7. ¿Ha visitado algún centro de educación inicial? ¿Cuál? ¿Por qué?

8. Indicar, ¿Cuáles con los aspectos que le agradó de los colegios de educación inicial que han visitado? ¿Por qué?

9. Indicar, ¿Cuáles con los aspectos que no le agradó de los colegios de educación inicial que han visitado? ¿Por qué?

10. ¿Qué colegios de educación inicial considera los mejores en la ciudad de Chiclayo?

11. ¿A qué colegio no enviaría a su hijo en la ciudad de Chiclayo? 
12. ¿Ha decidido sobre el colegio al que planea matricular su hijo? Si es si ¿A qué colegio? ¿Por qué? Si es no ¿Tiene alguna alternativa?

Características del servicio

13. ¿Cuáles son factores en el servicio al alumno que usted considera importantes en la selección de un colegio de educación inicial?

14. ¿Cuáles son los factores del servicio al padre de familia que usted considera importantes en la selección de un colegio de educación inicial?

15. ¿Cuáles son los factores determinantes que usted consideraría para elegir un colegio de educación inicial?

16. ¿Considera usted importante la certificación en educación inicial de los docentes en el colegio al que asiste su hijo?

17. ¿Considera usted que el centro de educación inicial al que asistirá su hijo debe estar integrado con un colegio de educación primaria? ¿Por qué?

18. ¿Cómo planea llevar a su hijo al colegio: personalmente ó mediante un servicio de transporte escolar?

19. ¿Qué distancia considera conveniente que deberá recorrer su hijo para llegar al colegio?

20. ¿Considera Usted que un colegio de educación inicial debe ser bilingüe?

\section{Presentación del Colegio de Educación Inicial propuesto}

Estamos desarrollando un proyecto para formar un colegio de educación inicial ubicado en la ciudad de Chiclayo que cuente con las siguientes características:

a) Que busque incorporar la participación de los padres de familia en el desarrollo del niño en colaboración con los docentes del colegio.

b) Que permita observar a su hijo en clase a través de una cámara de internet. 
c) Que propicie la reunión con los docentes y con los padres de los compañeros de sus hijos.

d) Que envié información a su correo electrónico sobre algún cambio en el comportamiento del niño durante su permanencia en el colegio.

e) Que cuente con un modelo de aprendizaje basado en el desarrollo de competencias de los niños de tres a cinco años.

f) Que los docentes estén certificados en educación inicial.

g) Que cuente con la infraestructura adecuada de un colegio de educación inicial (apoyo de un psicólogo, salas de juego que apoyen el aprendizaje, un biohuerto, biblioteca especial para niños).

h) Que enseñe el idioma inglés.

Preguntas sobre el colegio presentado

21. De estar operando este centro de educación inicial en el momento que usted requiere el servicio ¿Usted seleccionaría este colegio para sus hijo(s)?

22. ¿Cuál sería el pago mensual que estaría dispuesto a efectuar por un centro de educación inicial de estas características?

23. ¿Cuál considera debería ser la forma de pago deseada?

24. ¿Cuál sería el factor determinante para matricular a su hijo en este colegio?

25. ¿Qué característica presentada no le gusta de este colegio?

26. ¿Qué diferencia considera que existe entre este colegio y el colegio que usted había considerado para matricular a su hijo? ¿Qué diferencia a este colegio inicial de los que usted ya conoce?

27. ¿Conoce algún colegio de características similares en la ciudad de Chiclayo o en otra ciudad? ¿Cuál?

28. ¿Tienen alguna sugerencia o propuesta de mejora al proyecto presentado? 
29. ¿Qué medio de comunicación prefiere para recibir información sobre este colegio de educación inicial?

30. En su momento, ¿Le gustaría recibir algún tipo de promoción o publicidad de este colegio de educación inicial? 


\section{Anexo 4}

Ficha técnica entrevista a profundidad: especialista en educación inicial de la

\section{UGEL}

\section{Producto}

Colegio de educación inicial para niños entre tres a cinco años localizado en la ciudad de Chiclayo. El colegio será una institución privada que estará enfocado a brindar un servicio educativo a los niños (entre tres a cinco años).

\section{Objetivo de la investigación}

a) Identificar los requerimientos para la apertura y operación de los colegios de educación inicial para niños entre tres a cinco años en la ciudad de Chiclayo.

b) Reconocer el rol de la UGEL en la apertura y supervisión de los colegios de educación inicial.

c) Examinar la estructura actual del sector de colegios de educación inicial en Chiclayo.

d) Determinar los factores que toman en cuenta los colegios de educación inicial para su diferenciación.

e) Identificar las principales tendencias sobre el servicio y el modelo educativo de los colegios de educación inicial en el futuro.

f) Identificar las características del servicio que ofrecen los colegios de educación inicial.

\section{Contenido}

Estructura del sector 
Colegios de educación inicial existentes y la manera en que compiten, características de los usuarios del servicio, estrategias predominantes de las empresas en el sector, posicionamiento de los colegios de educación inicial en la ciudad de Chiclayo, forma de publicidad que realizan, promociones que llevan a cabo los colegios del sector en Chiclayo, programa de lealtad de los colegios para los padres de familia.

Normatividad en el sector

Requerimientos del Ministerio de Educación para la apertura y funcionamiento de un colegio de educación inicial, trámites que se deben llevar a cabo en la UGEL Chiclayo de la Región Lambayeque, requerimientos de otros sectores (como INDECI, Municipalidad, entre otros), barreras existente en el sector para nuevos ingresantes,

\section{Características del servicio}

Características del servicio que ofrecen los colegios de educación inicial (horarios de los colegios, medios para el pago de la mensualidad, monto promedio de la mensualidad que cobran los colegios de este nivel en Chiclayo, calidad de la enseñanza, modelo de enseñanza predominante, certificación de los docentes del colegio de educación inicial en Chiclayo).

\section{Demanda}

Nivel de demanda existente para colegios de educación inicial, sectores de la población que demandan educación inicial privada, el tipo de comunicación que buscan recibir los padres por parte de los colegios, proceso de selección de un colegio inicial por parte de los padres de familia.

Tendencias 
Modelos educativos existentes, nuevos modelos educativos para la educación inicial, nuevas características de los colegios de educación inicial, uso de la tecnología en la educación inicial, nuevos requerimientos por parte de las entidades del gobierno para este tipo de colegio, nuevas demandas sociales para los colegios de este nivel.

\section{Perfil del Participante}

Personas que cuenten con experiencia laboral en el control y supervisión de colegios de educación inicial. La experiencia laboral que se requiere para ser considerado experto debe ser como mínimo diez años en la Dirección de una UGEL y/o que sea reconocido en el medio por sus aportes en el ámbito de educación básica inicial.

\section{Cuestionario}

\section{Presentación}

Estimado Sr... somos un grupo de alumnos del Programa de Maestría de Ciencias Empresariales de la Universidad San Ignacio de Loyola. Como parte del proceso de graduación, estamos elaborando un proyecto de investigación que tiene como objetivo analizar el nivel de la educación inicial para niños entre tres a cinco años, en la ciudad de Chiclayo. En ese sentido, nos gustaría conocer su opinión sobre las características del sector y de los colegios de educación inicial en la ciudad de Chiclayo. La información que nos proporcionen en esta entrevista será usada estrictamente para fines académicos.

\section{Preguntas a plantear en la entrevista.}

\section{SOBRE EL SECTOR}

1. ¿Cuál es su experiencia en el sector de educación y específicamente en el nivel de educación inicial? 
2. ¿Cómo considera que ha sido el crecimiento de los colegios de educación inicial públicos y privados en la ciudad de Chiclayo en los últimos 3 años?

3. ¿Cuál ha sido la tasa de crecimiento de los alumnos en los colegios de educación inicial públicos y privados en la ciudad de Chiclayo?

4. ¿Cuál es su percepción sobre la evolución del sector de colegios de educación inicial en la ciudad de Chiclayo en los últimos 3 años?

5. ¿Considera Usted que se requieren plantear nuevas políticas sobre la educación inicial privada en el país y/o en las regiones?

6. ¿Cuáles son los principales aspectos de la política educativa impulsados por el Estado que ha incentivado la creación de colegios de educación inicial en los últimos cuatro años?

7. ¿Qué opina de la calidad de la infraestructura de los colegios de educación inicial en la ciudad de Chiclayo? ¿Cuál considera usted que son las principales diferencia entre las instituciones públicas y privadas?

8. ¿Existen empresas privadas interesados en ingresar al sector de educación inicial en la región?

9. ¿Qué alternativas de capacitación y actualización docente existen actualmente en la ciudad de Chiclayo?

\section{NORMATIVIDAD}

10. ¿Cuáles son los principales requerimientos que norma el Ministerio de Educación para la apertura de un colegio de nivel inicial para el sector privado? (Infraestructura y ambientes mínimos)

11. ¿Cuáles son los principales aspectos que regula el Ministerio de Educación para la operación de un colegio de nivel inicial para el sector privado? 
12. ¿Cuáles son los trámites que se debe realizar en la UGEL para la apertura de un colegio de educación inicial en la ciudad de Chiclayo?

13. ¿Cómo se lleva a cabo el proceso de supervisión por parte de la UGEL para el control de un colegio de educación inicial en la ciudad de Chiclayo?

14. La licencia que se otorga para operar un colegio de educación inicial, ¿se debe renovar?, si es sí ¿En qué tiempo?

15. ¿Existen normas adicionales a las que emite el Ministerio de Educación que deban cumplir los colegios de educación inicial privados en la ciudad de Chiclayo?

16. ¿Cuáles son los factores limitantes para el ingreso de nuevos colegios de educación inicial privados en la actualidad en la ciudad de Chiclayo?

\section{SOBRE EL MERCADO}

17. ¿Cuáles son los principales colegios de educación inicial en la ciudad de Chiclayo?

18. ¿Cuáles son los principales factores de competencia entre los colegios de educación inicial en la ciudad de Chiclayo?

19. ¿Cuáles son los elementos tecnológicos que se ofrecen a los alumnos en un Colegio inicial para el desarrollo de sus clases?

20. ¿Bajo qué criterios o variables se podrían segmentar los colegios de educación inicial privados en la ciudad de Chiclayo?

21. ¿Cuáles son los principales insumos que demandan los colegios de educación inicial?

\section{SOBRE EL SERVICIO}

22. ¿Cuáles son los modelos pedagógicos alternativos que se aplican en los colegios de educación inicial privados en la actualidad? ¿Por qué? 
23. ¿Existen diferencia entre los modelos pedagógicos que usan los colegios de educación inicial privados con los que usan los colegios públicos?

24. ¿Cuál es el modelo pedagógico más común que aplican las instituciones de novel inicial en la Ciudad de Chiclayo? Indicar ¿Por qué?

25. ¿Cuál es el perfil académico de los docentes en el nivel inicial en los colegios de este nivel en la ciudad de Chiclayo?

26. La norma técnica nos dice que en un colegio de educación inicial la capacidad no debe ser más de 25 niños por aula ¿Cuántos niños en promedio asisten a los colegio de educación inicial en la ciudad de Chiclayo?

27. ¿Cuál es el rol que están cumpliendo las T.I en los colegios de educación inicial? ¿Cuál prevé que será su evolución?

28. ¿Cuál es la capacidad actual de las aulas en los colegios de educación inicial en la ciudad de Chiclayo?

29. ¿De cuantas horas debería constar la jornada educativa diaria en los colegios de educación inicial privados?

30. ¿Existen colegios de educación inicial privados que en la actualidad brindan el servicio de horario extendido?

31. ¿Qué ventajas y desventajas encuentra Usted en este servicio de horario extendido?

32. ¿Cuáles son los aspectos relacionados con el servicio y la enseñanza que buscan los padres de familia en los colegios de educación inicial? 


\section{Anexo 5 \\ Ficha técnica entrevista a profundidad: docente de educación inicial}

\section{Producto}

Colegio de educación inicial para niños entre tres a cinco años localizado en la ciudad de Chiclayo. El colegio será una institución privada que estará enfocado a brindar un servicio educativo a los niños (entre tres a cinco años).

\section{Objetivo de la investigación}

- Identificar las características del modelo educativo que usan los docentes a nivel de educación inicial

- Reconocer los factores que toman en cuenta para elegir su modelo educativo los colegios de educación inicial en la ciudad de Chiclayo.

- Reconocer las principales variables de comportamiento de los padres de familia que demandan el servicio de educación inicial.

- Determinar los factores que toman en cuenta los colegios de educación inicial para su diferenciación.

- Identificar las principales tendencias sobre el servicio y el modelo educativo de los colegios de educación inicial en el futuro.

- Identificar las características del servicio de los colegios de educación inicial que demandan los padres de familia.

\section{Contenido}

Estructura del sector

Colegios de educación inicial existentes y la manera en que compiten, características de los usuarios del servicio, estrategias predominantes de las empresas en 
el sector, posicionamiento de los colegios de educación inicial en la ciudad de Chiclayo, programa de lealtad de los colegios para los padres de familia.

Modelo Pedagógico

Modelos educativos existentes para el nivel de educación inicial, nuevos modelos educativos para la educación inicial, modelo pedagógico que se usa en los colegios de educación inicial en la ciudad de Chiclayo, características de los modelos de educación inicial.

Características del servicio:

Características del servicio que ofrecen los colegios de educación inicial (horarios de los colegios, medios para el pago de la mensualidad, monto promedio de la mensualidad que cobran los colegios de este nivel en Chiclayo, calidad de la enseñanza, modelo de enseñanza predominante, certificación de los docentes del colegio de educación inicial en Chiclayo), el tipo de comunicación que buscan recibir los padres por parte de los colegios.

Demanda

Nivel de demanda existente para colegios de educación inicial, sectores de la población que demandan educación inicial privada, proceso de selección de un colegio inicial por parte de los padres de familia.

Tendencias

Nuevas características de los colegios de educación inicial, uso de la tecnología en la educación inicial, nuevos requerimientos por parte de las entidades del gobierno para este tipo de colegio, nuevas demandas sociales para los colegios de este nivel.

\section{Perfil del Participante}

Docentes que investiguen o cuenten con experiencia laboral en la enseñanza en colegios de educación inicial. La experiencia en docencia que se requiere para ser 
considerado experto debe ser como mínimo diez años y/o que sea un docente reconocido en el medio por sus aportes en el ámbito de educación básica.

\section{Cuestionario}

\section{Presentación}

Estimado Profesor (a) ..., somos un grupo de alumnos del Programa de Maestría de Ciencias Empresariales de la Universidad San Ignacio de Loyola. Como parte del proceso de graduación, estamos elaborando un proyecto de investigación que tiene como objetivo analizar el nivel de la educación inicial para niños entre tres a cinco años, en la ciudad de Chiclayo. En ese sentido, nos gustaría conocer su opinión sobre las características del sector y de los colegios de educación inicial en la ciudad de Chiclayo. La información que nos proporcionen en esta entrevista será usada estrictamente para fines académicos.

\section{Preguntas a plantear en la entrevista.}

\section{SOBRE EL SECTOR}

1. ¿Cuál es su experiencia docente en el sector de educación y específicamente en el nivel de educación inicial?

2. ¿Cuál es su percepción sobre la evolución de la enseñanza en el sector de colegios de educación inicial en la ciudad de Chiclayo en los últimos 3 años?

3. ¿Considera Usted que se requieren plantear nuevas políticas sobre la educación inicial privada en el país y/o en las regiones?

\section{SOBRE EL MERCADO}

4. ¿Qué opina de la calidad de la calidad académica de los colegios de educación inicial en la ciudad de Chiclayo? 
5. ¿Cuáles son los principales colegios de educación inicial en la ciudad de Chiclayo?

6. ¿Qué opina de la calidad de la infraestructura de los colegios de educación inicial en la ciudad de Chiclayo?

7. ¿Cuáles son los principales factores de competencia entre los colegios de educación inicial en la ciudad de Chiclayo?

8. ¿Cuáles son los elementos tecnológicos que usan los alumnos en su Colegio durante el desarrollo de sus clases?

\section{SOBRE EL MODELO PEDAGÓGICO}

9. ¿Cuáles son los modelos pedagógicos que se aplican en los colegios de educación inicial privados en la actualidad? ¿Por qué?

10. ¿Existen diferencia entre los modelos pedagógicos que usan los colegios de educación inicial privados con los que usan los colegios públicos?

11. ¿Cuál es el modelo pedagógico más común que aplican las instituciones de nivel inicial en la Ciudad de Chiclayo? Indicar ¿Por qué y cuáles son sus características?

12. ¿Qué se requiere para implementar un modelo pedagógico de educación inicial en un nuevo colegio?

13. ¿Cuál es el modelo pedagógico que aplica usted en su institución? Indicar ¿Por qué?

14. ¿Cuáles son los ambientes que debe contar un colegio de educación inicial para un normal desenvolvimiento de los niños?

15. ¿Cómo se interrelacionan los estudiantes en un colegio de educación inicial? ¿Se requiere apoyo del docente? 
16. ¿Cuál es el perfil académico de los docentes en el nivel inicial dentro de la ciudad de Chiclayo?

17. ¿Cuáles son las competencias que se requieren para enseñar a nivel de educación básica?

\section{SOBRE EL SERVICIO}

18. ¿Cuáles son los aspectos relacionados con la enseñanza que buscan los padres de familia en los colegios de educación inicial?

19. ¿Cuáles son los aspectos relacionados con el servicio que buscan los padres de familia en los colegios de educación inicial?

20. ¿Cuáles son las actividades recreativas que se programan durante el año?

21. ¿Cuántos niños considera Usted que debe tener un aula de tamaño ideal? ¿Por qué?

22. ¿De cuantas horas debería constar la jornada educativa diaria en los colegios de educación inicial privados?

23. ¿Conoce colegios de educación inicial privados que en la actualidad brindan el servicio de horario extendido?

24. ¿Qué ventajas y desventajas encuentra Usted en este servicio de horario extendido?

\section{SOBRE EL CLIENTE}

25. ¿Cuál es el rango de edad de los padres de familia que demandan el servicio de educación inicial en los colegios de educación inicial privados en la ciudad de Chiclayo?

26. ¿Quién es el que se encarga de hacer seguimiento diario de las labores escolares de sus hijos, el padre o la madre? ¿Cuál es el grado de involucramiento en las actividades escolares de esta persona? 
27. ¿Cuál es el nivel socio-económico de los padres que matriculan a sus hijos en Colegios de educación inicial privados en la actualidad?

28. ¿Qué distancia en promedio suelen trasladarse los alumnos hacia sus colegios de educación inicial en la actualidad?

29. ¿A los niños lo trasladan sus padres al colegio o son llevados por una movilidad particular contratada por estos? 


\section{Anexo 6}

Desarrollo de entrevista a profundidad: expertos del sector- experto 1

\begin{tabular}{|l|l|}
\hline \multicolumn{2}{|c|}{ FICHA TECNICA DEL ENTREVISTADO } \\
\hline Nombre & Luz Eliana Pérez Montenegro. \\
\hline Nacionalidad & Peruana \\
\hline Ocupación & Directora \\
\hline Profesión & Docente en Educación Inicial \\
\hline Distrito de Residencia & Chiclayo \\
\hline & $\begin{array}{l}\text { Se desempeña como Directora I.E.I. Pasito a } \\
\text { Paso la cual se encuentra ubicada en la } \\
\text { urbanización los parques del distrito de } \\
\text { Chiclayo. Tiene más diez años de experiencia } \\
\text { en el sector de educación inicial. }\end{array}$ \\
\hline Breve Reseña & $\begin{array}{l}\text { Entrevista realizada el día 28 de setiembre a } \\
\text { las 6:00 pm. } \\
\text { ( Video disponible a solicitud) }\end{array}$ \\
\hline
\end{tabular}

\section{Preguntas a plantear en la entrevista.}

\section{SOBRE EL SECTOR}

1. ¿Cuál es su experiencia en el sector de educación y específicamente en el nivel de educación inicial?

Tengo más de diez años de experiencia en el sector de educación inicial.

2. ¿Cuál es su percepción sobre la evolución del sector de colegios de educación inicial en la ciudad de Chiclayo en los últimos tres años?

Los padres de familia están tomando mayor conciencia en cuanto a la inclusión de la educación inicial, se preocupan siendo más exigentes con los servicios que se deben brindan en estas instituciones.

3. ¿Cómo considera que será la evolución del sector de colegios de educación inicial privados en este nuevo gobierno? 
Muy buenas expectativas ya que desde el gobierno anterior se han dado capacitaciones y se están viendo buenos resultados.

4. ¿Considera Usted que se requieren plantear nuevas políticas sobre la educación inicial privada en el país y/o en las regiones?

Si se deben plantear nuevas políticas en el país y en las regiones, debido a que no se da un correcto seguimiento a las normas y políticas establecidas.

5. ¿Cuáles son los principales requerimientos y barreras que norma el Ministerio de Educación para colegios en el nivel inicial para los sectores público y privado? Infraestructura.

Aulas amplias.

Personal capacitado.

6. ¿Existen normas adicionales a las que emite el Ministerio de Educación que deban cumplir los colegios de educación inicial privados en la ciudad de Chiclayo? No, existen normas adicionales a las que emite el Ministerio de Educación.

7. ¿Cuáles son los principales aspectos de la política que ha incentivado la creación de colegios de educación inicial que el Estado ha impulsado en los últimos cuatro años?

La necesidad de educación inicial para los niños existiendo mercado potencial en este sector.

8. ¿Existen empresas privadas interesados en ingresar al sector de educación inicial en la región?

Si existen privadas interesadas en ingresar a este sector debido a la demanda existente que vemos en la actualidad. 
9. ¿Cuáles son los factores limitantes para el ingreso de nuevos colegios de educación inicial privados en la actualidad en la ciudad de Chiclayo?

Carencia de locales amplios en la ciudad de Chiclayo.

10. ¿Qué opina de la calidad de la infraestructura de los colegios de educación inicial en la ciudad de Chiclayo?

La gran mayoría cuenta con infraestructura deficiente para que brinde el servicio de educación inicial, debido a que no se respeta el área que debe tener para su adecuado funcionamiento.

\section{SOBRE EL MERCADO}

11. ¿Cuáles son los principales colegios de educación inicial en la ciudad de Chiclayo?

Considera que cada padre de familia acude al colegio que cumpla con sus expectativas y es ahí donde requiere del servicio.

12. ¿Cuáles son los principales factores de competencia entre los colegios de educación inicial en la ciudad de Chiclayo?

La implementación de talleres innecesarios que no están dentro de la curricula emitida por el gobierno y que los usan como estrategia para vender el servicio.

13. ¿Cuáles son los elementos tecnológicos que usan los alumnos en su Colegio durante el desarrollo de sus clases?

Las computadoras y sistemas multimedias.

14. ¿Bajo qué criterios o variables se podrían segmentar los colegios de educación inicial privados en la ciudad de Chiclayo?

Mediante los intereses de los padres y necesidades de los niños. 
15. ¿Cuáles son los principales insumos que demandan los colegios de educación inicial?

Principalmente el inmobiliario de sicomotricidad.

16. ¿Cuáles son las empresas que proveen de los insumos que demandan los colegios de educación inicial?

Hans Educa.

Kits House.

\section{SOBRE EL SERVICIO}

17. ¿Cuáles son los modelos pedagógicos alternativos que se aplican en los colegios de educación inicial privados en la actualidad?

Se utilizan el proyecto Optimits

18. ¿Cuál es el modelo pedagógico que aplica usted en su institución? Indicar ¿Por qué?

Se aplica el método point debido a que se trata de estimular a los niños en métodos de enseñanza vivencial y programas de motrocidad.

19. ¿Cuál es el perfil académico de los docentes en el nivel inicial dentro de la ciudad de Chiclayo?

Actualmente los docentes se vienen preparando con especialidades y maestrías e incluso otras carreas adicionales como psicología.

20. La norma técnica nos dice que en un colegio de educación inicial la capacidad no debe ser más de 25 niños por aula ¿Cuántos niños considera Usted que debe tener un aula de tamaño ideal? 
Se considera que se deben adoptar la cantidad de niños que el ambiente pueda acoger, considerando que en la actualidad la gran mayoría de colegios particulares tienen menos de veinticinco niños por aula.

21. En el Colegio que Usted dirige, ¿Cuál es la capacidad actual de sus aulas?

Se trabaja actualmente con doce niños por aula.

22. ¿De cuantas horas debería constar la jornada educativa diaria en los colegios de educación inicial privados?

Se debe trabajar con cinco horas pedagógicas diarias.

23. ¿Conoce colegios de educación inicial privados que en la actualidad brindan el servicio de horario extendido?

Si hay colegios privados que brindan horario extendido, como el peruano chino.

24. ¿Qué ventajas y desventajas encuentra Usted en este servicio de horario extendido?

Desventajas:

Que niño no socialice totalmente con su familia.

La infraestructura que debe tener un colegio para brindar este servicio debe ser completa.

La alimentación de los niños es distinta de uno con el otro.

25. ¿Cuáles son los ambientes que debe contar un colegio de educación inicial para un normal desenvolvimiento de los niños?

Áreas de psicomotricidad

Áreas de recreación.

Áreas verdes.

Áreas para talleres. 
26. ¿Cuál es el rango de edad de los padres de familia que demandan el servicio de educación inicial en los colegios de educación inicial privados en la ciudad de Chiclayo?

El rango de edad esta entre los veinte y cuarenta y cinco años.

27. ¿Quién es el que se encarga de hacer seguimiento diario de las labores escolares de sus hijos, el padre o la madre?

Se encarga de hacer el seguimiento de los niños es la madre y las abuelitas.

28. ¿Cuáles son los aspectos relacionados con el servicio y la enseñanza que buscan los padres de familia en los colegios de educación inicial? Apoyo psicológico.

Involucramiento de las familias en el desarrollo de aprendizaje.

29. ¿Cuál es el nivel socio-económico de los padres que matriculan a sus hijos en Colegios de educación inicial privados en la actualidad?

El nivel socio-económico de los padres que matriculan a sus niños en los colegios de educación inicial privados es A Y B.

30. ¿Qué distancia en promedio suelen trasladarse los alumnos hacia sus colegios de educación inicial en la actualidad?

La acogida que tiene este colegio es de padres que viven en distintos distritos ajenos a Chiclayo, entonces hay padres que suelen trasladarse de diez y veinte minutos para llegar al colegio con sus niños.

31. ¿A los niños lo trasladan sus padres al colegio o son llevados por una movilidad particular contratada por estos?

La gran mayoría llega a sus niños por ellos mismos, son pocos los que envían a sus menos niños en movilidad particular. 


\section{Anexo 6}

Desarrollo de entrevista a profundidad: expertos del sector - experto 2

\begin{tabular}{|c|c|}
\hline \multicolumn{2}{|c|}{ FICHA TECNICA DEL ENTREVISTADO } \\
\hline Nombre & Pilar Llontop. \\
\hline Nacionalidad & Peruana. \\
\hline Ocupación & Directora. \\
\hline Profesión & Docente en Educación Inicial. \\
\hline Distrito de Residencia & Chiclayo. \\
\hline Breve Reseña & $\begin{array}{l}\text { Se desempeña como Directora y docente en la } \\
\text { institución educativa C.E.I.P Victoria Barcia } \\
\text { Boniffatti ubicada en la urbanización Santa } \\
\text { Victoria, con más de } 25 \text { años de experiencia en } \\
\text { educación. }\end{array}$ \\
\hline Observaciones & $\begin{array}{l}\text { Entrevista realizada el día } 22 \text { de setiembre a las } \\
\text { 10:00 am. } \\
\text { (Video disponible a solicitud). }\end{array}$ \\
\hline
\end{tabular}

\section{Preguntas a plantear en la entrevista.}

\section{SOBRE EL SECTOR}

1. ¿Cuál es su experiencia en el sector de educación y específicamente en el nivel de educación inicial?

Tengo veintinueve años de experiencia en el sector de educación inicial.

2. ¿Cuál es su percepción sobre la evolución del sector de colegios de educación inicial en la ciudad de Chiclayo en los últimos tres años?

En el sector privado se ve una notoria evolución en cuanto a la adopción de nuevos programas pedagógicos como es el caso de Paice o antes llamado proyecto Optimist, el cual contempla programas de lectura, motricidad, estructurado debidamente a la edad de cada niño, para un eficiente aprendizaje en el nivel inicial. 
En el sector público, existe gran preocupación debido que no aplican bien el programa aprendiendo jugando, siendo unos de los mejores en nuestro país, los docentes de este nivel no le toman la debida importancia, dejando que los niños solo jueguen y esto genera una desventaja para los niños ya que cuando van a primer año de primaria no saben leer ni escribir.

3. ¿Cómo considera que será la evolución del sector de colegios de educación inicial privados en este nuevo gobierno?

Hay buenas expectativas, debiéndose reformular el sistema de educación inicial, donde se trabaje adecuadamente los programas y los docentes estén mejores capacitados.

4. ¿Considera Usted que se requieren plantear nuevas políticas sobre la educación inicial privada en el país y/o en las regiones?

Si se deben plantar nuevas políticas en el sector inicial privado, debido a que no se integra a los colegios privados en las reuniones que se hacen por parte del estado dejándolos de lado.

5. ¿Cuáles son los principales requerimiento y barreras que norma el Ministerio de Educación para colegios en el nivel inicial para los sectores público y privado? Los colegios de educación inicial privados no cuentan con respaldo del Ministerio de Educación, ni Indecopi, haciendo posible que algunos padres no cumplan con los pagos correspondientes a la educación de sus niños, pues no existe barreras para que los cambien de colegio sin que nido de origen de la autorización correspondiente.

6. ¿Existen normas adicionales a las que emite el Ministerio de Educación que deban cumplir los colegios de educación inicial privados en la ciudad de Chiclayo? 
Si, la Municipalidad Provincial de Chiclayo se encarga de inspeccionar constantemente que las instalaciones sean las adecuadas, la limpieza sea la correcta, y la licencia de funcionamiento este vigente.

7. ¿Cuáles son los principales aspectos de la política que ha incentivado la creación de colegios de educación inicial que el Estado ha impulsado en los últimos cuatro años?

\section{NO BRINDO INFORMACION.}

8. ¿Existen empresas privadas interesados en ingresar al sector de educación inicial en la región?

Si existen empresas que desean ingresar al sector de educación inicial, como es el caso de Interbank con sus colegios Innova, la universidad San Martin de Porras, Santo Toribio de Mogrovejo, ect.

9. ¿Cuáles son los factores limitantes para el ingreso de nuevos colegios de educación inicial privados en la actualidad en la ciudad de Chiclayo?

Un factor limitante para ingreso de nuevos colegios es el tamaño del terreno ya que se está solicitando 700 metros cuadrados, y la mayoría de colegios en la ciudad de Chiclayo son casas acondicionadas para brindar el servicio de educación inicial.

10. ¿Qué opina de la calidad de la infraestructura de los colegios de educación inicial en la ciudad de Chiclayo?

La calidad de infraestructura no es buena, el $90 \%$ son casas adaptadas y los espacios para los niños son pequeños, se suele con considerar $1 \mathrm{~m} 2$ en aula por niño el cual no siempre se cumple. 


\section{SOBRE EL MERCADO}

11. ¿Cuáles son los principales colegios de educación inicial en la ciudad de Chiclayo?

Considero a nuestra institución Boniffati como unas de las principales, también considero ha Caritas Felices y Kinder Smile que tienen un sistema similar al nuestro.

12. ¿Cuáles son los principales factores de competencia entre los colegios de educación inicial en la ciudad de Chiclayo?

Como competencia podemos considerar a Caritas Felices y dentro de los factores de competencia en nivel general vemos que los padres exigen más cosas que antes, como limpieza, plana docente calificada, seguridad. Cabe resaltar que los padres creen que por tener pensiones altas son mejores colegios y eso sucede con la competencia, pero cuando los padres nos visitan toman un concepto distinto.

13. ¿Cuáles son los elementos tecnológicos que usan los alumnos en su Colegio durante el desarrollo de sus clases?

Ahora a los niños debemos evitar que tenga constantemente contacto con la tecnología, pero si debemos estar a la par con la tecnología como institución, lo que tenemos en nuestra institución desde ya hace 20 años es una pizarra interactiva, cabe mencionar que los niños hasta los 7 años tienen que socializar, y si tienen una computadora o algún elemento tecnológico en mano el niño se va a individualizar. Nuestra pantalla interactiva es en grupo y los niños con el lapicero electrónico pueden aprender de los errores de los demás. Este es el mejor sistema para niños de estas edades. 
14. ¿Bajo qué criterios o variables se podrían segmentar los colegios de educación inicial privados en la ciudad de Chiclayo?

Infraestructura, programas pedagógicos acordes y últimos para los trabajos para los niños.

15. ¿Cuáles son los principales insumos que demandan los colegios de educación inicial?

Todo lo que es papelería, juegos pedagógicos y de entretenimiento, inmobiliario, actualmente hay equipos de tecnología por aula, instrumentos musicales.

16. ¿Cuáles son las empresas que proveen de los insumos que demandan los colegios de educación inicial?

La empresa donde compramos localmente es del Sr. Montenegro, mayormente nuestras compras se realizan con proveedores de Lima.

\section{SOBRE EL SERVICIO}

17. ¿Cuáles son los modelos pedagógicos alternativos que se aplican en los colegios de educación inicial privados en la actualidad?

Principalmente utilizamos el PEICE desconozco de otro programa que se esté aplicando.

18. ¿Cuál es el modelo pedagógico que aplica usted en su institución? Indicar ¿Por qué?

Nosotros trabajamos con el modelo pedagógico PEICE. Se utiliza este programa porque es personalizado, y desarrolla mucho en los niños la escritura la motricidad sin presionarlos. Tiene un programa estrella que es el pasaje neuro motor y es importante porque son $25 \mathrm{~m}$ de rutinas diarias que permitirá el desarrollo motriz y la sinapsis en el cerebro. Además tiene dentro el programa de desarrollo audiciones musicales que está estructurada para cada edad. 
19. ¿Cuál es el perfil académico de los docentes en el nivel inicial dentro de la ciudad de Chiclayo?

En estos últimos años los docentes de educación inicial se vienen preparando distintas especiales y maestrías debido a los concursos públicos que se vienen dando y requieren que estén más capacitados. Existen instituciones como CEPAL que brinda capacitaciones para mejorar el aprendizaje.

20. La norma técnica nos dice que en un colegio de educación inicial la capacidad no debe ser más de 25 niños por aula ¿Cuántos niños considera Usted que debe tener un aula de tamaño ideal?

Considera que se deben tener veinte niños por aula.

21. En el Colegio que Usted dirige, ¿Cuál es la capacidad actual de sus aulas?

Se cuenta con veinte niños por aula hasta la edad de cuatro años y en el aula de niños de cinco años alberga veintiocho los cuales están acompañados por dos profesoras y una auxiliar.

22. ¿De cuantas horas debería constar la jornada educativa diaria en los colegios de educación inicial privados?

Para niños de dos años debe ser de cuatro horas y media.

Para niños de tres a cinco años deber ser cinco horas.

23. ¿Conoce colegios de educación inicial privados que en la actualidad brindan el servicio de horario extendido?

No conoce colegios de educación inicial privados que brinden el servicio de horario extendido en Chiclayo.

Pero si sabe de la existencia de cunas albergues y centros de estimulación temprana que brindan este servicio de horario extendido. Considerando que es un nicho de mercado pues existe demanda. 
24. ¿Qué ventajas y desventajas encuentra Usted en este servicio de horario extendido?

Desventajas:

Influencia del núcleo familiar y no dejan que los padres sigan requiriendo el servicio durante todo el año.

La alimentación es un factor clave debido al cuidado que se debe tener con los niños.

El ambiente con el que debe contar el colegio debe tener la infraestructura adecuada.

Ventajas:

Padres que no tienen familia y salvaguardan la integridad de sus niños en estos centros para que cuiden de sus niños mientras trabajan.

25. ¿Cuáles son los ambientes que debe contar un colegio de educación inicial para un normal desenvolvimiento de los niños?

Aulas amplias.

Patios sicomotricidad.

Baños amplios.

Áreas verdes.

\section{SOBRE EL CLIENTE}

26. ¿Cuál es el rango de edad de los padres de familia que demandan el servicio de educación inicial en los colegios de educación inicial privados en la ciudad de Chiclayo?

Entre los veinticinco y treinta y cinco años está la mayor demanda. 
Existe también demanda por padres entre las edades de cuarenta y cincuenta, pero es mínima.

27. ¿Quién es el que se encarga de hacer seguimiento diario de las labores escolares de sus hijos, el padre o la madre?

Los abuelos son los que se encargan en la gran mayoría de hacer el seguimiento de las labores escolares de los niños, debido a que los padres jóvenes trabajan.

28. ¿Cuáles son los aspectos relacionados con el servicio y la enseñanza que buscan los padres de familia en los colegios de educación inicial?

Docentes bien capacitados.

El cuidado con el que se trate a los niños debe ser óptimo.

La limpieza debe ser la correcta.

29. ¿Cuál es el nivel socio-económico de los padres que matriculan a sus hijos en Colegios de educación inicial privados en la actualidad?

El nivel socio-económico de los padres que matriculan a sus niños en los colegios de educación inicial privados es A Y B.

30. ¿Qué distancia en promedio suelen trasladarse los alumnos hacia sus colegios de educación inicial en la actualidad?

Un promedio de cinco a diez minutos.

31. ¿A los niños lo trasladan sus padres al colegio o son llevados por una movilidad particular contratada por estos?

Algunos son llevados por movilidad particular, pero la gran mayoría son llevados por sus mismos padres. 


\section{Anexo 7}

Desarrollo de entrevista a profundidad: especialista de educación inicial UGEL

\begin{tabular}{|l|l|}
\hline \multicolumn{2}{|c|}{ FICHA TECNICA DEL ENTREVISTADO } \\
\hline Nombre & Elizabeth Paredes Ortiz. \\
\hline Nacionalidad & Peruana. \\
\hline Ocupación & Especialista de educación inicial UGEL \\
\hline Profesión & Docente en Educación Inicial. \\
\hline Distrito de Residencia & Chiclayo. \\
\hline & Cuenta con más de 20 años de experiencia en el \\
& sector educación inicial, y más de 10 años de \\
& como Directora de I.E Estatales y 4 años de \\
& experiencia como especialista del sector en la \\
& UGEL- Chiclayo dentro los que se ha efectuado \\
& la implementación de las políticas educativas que \\
implementa el MINEDU en el ámbito de la \\
Breve Reseña & provincia de Chiclayo. \\
\hline & Entrevista realizada el día 29 de noviembre a las \\
Observaciones & 05:30 pm. \\
& (Video disponible a solicitud). \\
\hline
\end{tabular}

\section{SOBRE EL SECTOR}

1. ¿Cuál es su experiencia en el sector de educación y específicamente en el nivel de educación inicial?

Cuento con 21 años de experiencia en la educación inicial, habiendo desarrollado dentro de mi carrera puestos como Director de I.E.I así como 4 años como especialista del Nivel Inicial en la Ugel Chiclayo.

2. ¿Cómo considera que ha sido la evolución del sector de colegios de educación inicial privados en la ciudad de Chiclayo?

Ha tenido un incremento vertiginoso pero dentro de este crecimiento no se han considerado aspectos técnico-pedagógicos así como de infraestructura, con una inmensa cantidad de colegios pero sin la calidad adecuada

3. ¿Cuál ha sido la tasa de crecimiento de los alumnos en los colegios de educación inicial públicos y privados en la ciudad de Chiclayo? 
Se ha contado con un incremento considerablemente dentro de los 3 últimos años debido a que los padres de familia han tenido un conocimiento dl nuevo enfoque que el MINEDU está brindando para los niños del nivel inicial, por lo que los padres ya tienen conocimiento de la labora y trabajo que se tiene que hacer, por lo que este sector su crecimiento ha sido mayor que el privado.

4. ¿Considera Usted que se requieren plantear nuevas políticas sobre la educación inicial privada en el país y/o en las regiones?

Si, se deben considerar nuevas políticas a fin de implementar mejores resultados en la calidad de la enseñanza de sus hijos en cuenta a la infraestructura y espacios que son importantes para los niños de educación inicial en su desarrollo infantil. ¿A qué se refiere con espacios? Que sea amplios permitiéndoles a los niños jugar, debido a que mediante el juego lúdico el niño mejora sus aprendizajes.

5. ¿Cuál es su percepción sobre la evolución del sector de colegios de educación inicial en la ciudad de Chiclayo en los últimos 3 años?

Se ha incrementado considerablemente debido en parte a los programas que ha implementado el gobierno como son Wasichay, FED (Fondo de estímulo al desempeño) y el Programa Acceso a la educación (PP 0091), gracias a estos mucho de los niños que no podían acceder al estudio hoy ya lo hacen, y estamos trabajando a fin que ningún niño sobre todo de 03 años se quede sin estudiar.

6. ¿Qué opina de la calidad de la infraestructura de los colegios de educación inicial en la ciudad de Chiclayo?

En cuanto a los estatales en realidad se ha mejorado en los últimos años a través de estos programas antes mencionados, por lo que hoy están mejor implementadas que las privadas, y en cuanto a estas no se ven cambios en 
cuanto a infraestructura y ambientes puesto que la mayoría funciona en casa y no tienen espacios pertinentes para una buena educación.

7. ¿Cuáles son los principales aspectos de la política educativa impulsados por el Estado que ha incentivado la creación de colegios de educación inicial en los últimos cuatro años?

Se han hechos diversos programas que han apoyado al mantenimiento y creación de nuevas I.E así como infraestructura y construcción de estas y a través del FED se ha adquirido mobiliario para aumentar la matrícula de niños sobre todo en distritos focalizados con alto número de años que no contaban con educación, por lo que ha estos distritos se han mejorados los índices de matricula

8. ¿Existen empresas privadas interesados en ingresar al sector de educación inicial en la región?

No tenemos empresas privadas que se preocupen por la educación en la región.

\section{NORMATIVIDAD}

9. ¿Cuáles son los principales requerimientos que norma el Ministerio de Educación para la apertura de un colegio de nivel inicial para el sector privado? Lo más importante es la infraestructura que es de 750.00 m2, que es el más cómodo y factible para los niños de educación inicial, luego los aspectos técnico pedagógico, ver si están implementados las aulas si tienen las mejores condiciones para los chicos, esto es lo más importante que busca el Minedu. Dentro de estos $750.00 \mathrm{~m} 2$ se buscan las siguientes áreas: Aras de recreación, SS.HH y las aulas que sean amplias contando con $2.00 \mathrm{~m} 2$. por niño y que el mobiliario sea de acuerdo a la edad del niño.

10. ¿Cuáles son los principales aspectos que regula el Ministerio de Educación para la operación de un colegio de nivel inicial para el sector privado? 
Son las Normas Técnica N 572 y 295-2014 del Ministerio de Educación.

11. ¿Cuál es la infraestructura que debe contar un colegio de educación inicial para su operación?

Es de $750.00 \mathrm{~m} 2$, contando con espacios pertinentes para el nivel, así como la infraestructura y construcción sea para una I.E.I

12. ¿Cuáles son los ambientes mínimos que se requiere en un colegio de educación inicial para un normal desenvolvimiento de los niños?

Cuente con un área de $2.00 \mathrm{~m} 2$, así como ambientes amplios sin perjudicar al niño en su desarrollo integral, contando con lo técnico pedagógico

13. ¿Cuáles son los trámites que se debe realizar en la UGEL para la apertura de un colegio de educación inicial en la ciudad de Chiclayo?

Los tramites son lo que se encuentran especificados en el Tupa y la directiva 295-2014 del Ministerio de Educación.

14. ¿Cómo se lleva a cabo el proceso de supervisión por parte de la UGEL para el control de un colegio de educación inicial en la ciudad de Chiclayo?

Nosotros hacemos tres rondas revisando la infraestructura y documentos de gestión pedagógica, haciendo un monitoreo viendo cómo se están desarrollando los niños de educación inicial

15. La licencia que se otorga para operar un colegio de educación inicial, ¿se debe renovar?, si es sí ¿En qué tiempo?

SI se debe renovar en especial a las privada ya que con estos verificamos cómo funcionan estas instituciones para saber si es que se mantienen las condiciones que presentaron al inicio de su funcionamiento y si cuentan con todos los maestros y niños en cuanto a su población revisando si es que cuentan con su 
plana docente de acuerdo al nivel cuidando la integridad del niño respetando los derechos de los niño.

16. ¿Existen normas adicionales a las que emite el Ministerio de Educación que deban cumplir los colegios de educación inicial privados en la ciudad de Chiclayo?

Sí. Dentro de las normas se cuentan con Defensa Civil, Indecopi y la municipalidad.

17. ¿Cuáles son los factores limitantes para el ingreso de nuevos colegios de educación inicial privados en la actualidad en la ciudad de Chiclayo? La falta de espacio y la infraestructura debido a las visitas que hemos realizado vemos que no cuentan con los espacios y condiciones necesarias para que los niños puedan estudiar allí, así como el espacio para que los niños se desenvuelvan en recreación porque los niños tienen mucha energía y por esto estaríamos agrediendo los derechos de los niños

\section{SOBRE EL MERCADO}

18. ¿Cuáles son los principales colegios de educación inicial en la ciudad de Chiclayo?

Dentro de los estatales que han sido focalizados por el MINEDU por los espacios pertinentes, por las condiciones de aprendizaje técnico-pedagógico que se están dando de acuerdo a características y nivel son las I.E Estatales 030, 022,004, 04, 119 a nivel de Chiclayo y en los privados tenemos el Santo Toribio de Mogrovejo, Ceibos, Manuel Pardo, Bonnifati y Luisa La Torre, que son I.E que tienen buena infraestructura hasta el momento.

19. ¿Cuáles son los principales factores de competencia entre los colegios de educación inicial en la ciudad de Chiclayo? 
Los factores de competencia son las condiciones de aprendizaje ya que en las I.E se está teniendo en cuenta el protagonismo de los niños teniendo en cuenta las teorías del constructivismo, y en los particulares las docentes no dejan de lado el protagonismo y las clases son muy dirigidas, teniendo en cuenta que la docente es la que desarrolla la clases y no hace actuar al niño, y generalmente son planas y o le dan al niño la posibilidad de que el mismo niño construya su espacio, es un niño que viene con muchas saberes previos y de allí debemos partir para dar un buen aprendizaje al niño.

20. ¿Cuáles son los elementos tecnológicos que se ofrecen a los alumnos en un Colegio inicial para el desarrollo de sus clases?

En los estatales muy pocos tienen computadora y televisión, pero en los particulares la mayoría usan computadoras, pero para este nivel no es importante el uso de la tecnología, es preferible el juego de niño de inicial, puesto que es una estrategia más interesante para que el niño aprenda, debemos hacer que el ritmo de vida del niño que es jugar no se pierda, a veces el niño con la tecnología se vuelve sedentario, es por esta razón que el MINEDU busca que el niño sea niño.

21. ¿Bajo qué criterios o variables se podrían segmentar los colegios de educación inicial privados en la ciudad de Chiclayo? La infraestructura, espacios y acondicionamiento de los sectores, mobiliario y una docente que tenga vocación de servicio.

22. ¿Cuáles son los principales insumos que demandan los colegios de educación inicial?

Material didáctico, concreto y lúdico debido a que se trabaja a través de la construcción permitiéndole interactuar con sus compañeros, así como los juegos 
recreativos en especial con los particulares que no cuentan con las áreas

destinadas para estos juegos, ya que necesitan para su desarrollo, un área libre es importante para ello.

\section{SOBRE EL SERVICIO}

23. ¿Cuáles son los modelos pedagógicos alternativos que se aplican en los colegios de educación inicial privados en la actualidad? ¿Por qué?

Aplicamos el optimis, monteori, debido a que hay una entidad que maneja estos sistemas de trabajo, pero se olvidan que hay otros enfoques para los niños de educación inicial.

24. ¿Existen diferencia entre los modelos pedagógicos que usan los colegios de educación inicial privados con los que usan los colegios públicos?

Los estatales estamos rescatando que el niño sea protagonista, que partamos de procesos pedagógicos pertinentes para los niños, como el constructivismo, que sean muchos más significativos sus aprendizajes.

25. ¿Cuál es el modelo pedagógico más común que aplican las instituciones de novel inicial en la Ciudad de Chiclayo? Indicar ¿Por qué?

El constructivismo y hay una variedad de teóricos como es el enfoque significativo, Piaget, Vegosky.

26. ¿Cuál es el perfil académico de los docentes en el nivel inicial en los colegios de este nivel en la ciudad de Chiclayo?

27. La norma técnica nos dice que en un colegio de educación inicial la capacidad no debe ser más de 25 niños por aula ¿Cuántos niños en promedio asisten al colegio de educación inicial en la ciudad de Chiclayo? 
En los colegios públicos se respeta esta norma pero en los privados hoy en día se maneja 23 niños en promedio

28. ¿Cuál es la capacidad actual de las aulas en los colegios de educación inicial en la ciudad de Chiclayo?

Hasta 25 alumnos por salón es lo que nos dice la norma en la actualidad.

29. ¿De cuantas horas debería constar la jornada educativa diaria en los colegios de educación inicial privados?

La jornada debe ser de 5 horas pedagógicas, debido a que más horas el niño se cansa, tenido actividades que se hacen durante estas horas como son las permanentes que forman hábitos en los niños, el juego lúdico por sectores en donde los niños desarrollan matemáticas, comunicación personal social y ciencia ambiente, también tenemos la actividad significativa que es la sesión de clases se pueden a esto asociar talleres.

30. ¿Existen colegios de educación inicial privados que en la actualidad brindan el servicio de horario extendido?

Si existe este servicio en los colegios privados debido a que en público quedan pocas I.E.I que brindan este servicio.

31. ¿Qué ventajas y desventajas encuentra Usted en este servicio de horario extendido?

Por el hecho que los padres pagan efectúan un horario muy extendido, pero cuando se ha efectuado monitoreo se encontraron a los niños sentados en su salón haciendo tareas, y no hay una actividad significativa para el niño, es necesario que el niño ya no este tantas horas en clases porque no aprende y solo está trabajando en forma mecánica. 
Adicionalmente a los niños se les aumenta el estrés y de acuerdo a últimos estudios a nivel nacional hay niños que ya cuentan con estrés en sus vidas debido al exceso de actividades de aprendizaje.

32. ¿Cuáles son los aspectos relacionados con el servicio y la enseñanza que buscan los padres de familia en los colegios de educación inicial?

Buscan una buena atención para sus niños, buena infraestructura y buen aprendizaje para sus hijos 


\section{Anexo 8}

Desarrollo de la entrevista a profundidad: experto del sector- docente de nivel inicial

\begin{tabular}{|l|l|}
\hline \multicolumn{2}{|c|}{ FICHA TECNICA DEL ENTREVISTADO } \\
\hline Nombre & Rossmery Mugerza Ortiz. \\
\hline Nacionalidad & Peruana. \\
\hline Ocupación & Docente y Directora. \\
\hline Profesión & Docente en Educación Inicial. \\
\hline Distrito de Residencia & Chiclayo. \\
\hline & $\begin{array}{l}\text { Cuenta con más de 20 años de experiencia en el } \\
\text { sector educación inicial, es Magister en } \\
\text { Educación y se ha desempeñado como docente } \\
\text { de Instituciones Educativas Particulares (I.E.P) y } \\
\text { estatales, contando adicionalmente con la } \\
\text { dirección de su propia institución. }\end{array}$ \\
\hline Breve Reseña & $\begin{array}{l}\text { Entrevista realizada el día 27 de Octubre a las } \\
\text { 08:30 pm. } \\
\text { (Video disponible a solicitud). }\end{array}$ \\
\hline Observaciones &
\end{tabular}

\section{SOBRE EL SECTOR}

1. ¿Cuál es su experiencia docente en el sector de educación y específicamente en el nivel de educación inicial?

Rossmery Mugerza Ortiz, laboro desde hace más de 20 años como docente de los niveles inicial en una entidad pública y privada, en la actualidad en la ciudad de Callanca y en la IEI Rosita de Jesús de la ciudad de Chiclayo.

2. ¿Cuál es el promedio de experiencia de los docentes de educación inicial en la ciudad de Chiclayo?

Es de 05 años como mínimo de experiencia

3. ¿Cuál es su percepción sobre la evolución de la enseñanza en el sector de colegios de educación inicial en la ciudad de Chiclayo en los últimos tres años? 
Centralismo más en el niño, debido a que se ha cambiado la forma de la enseñanza, ya que se cubría antes las expectativas de los padres de familia, no teniendo en cuenta las necesidades de los niños, por lo que ahora se ha creado una expectativa en los niños de asistir a su colegio.

4. ¿Considera Usted que se requieren plantear nuevas políticas sobre la educación inicial privada en el país y/o en las regiones?

Si es necesario, debido a que ahora hay una desvinculación entre la enseñanza estatal y privada, debido a que ahora se atiende a 2 formas de enseñanzas: Una que se brinda en las IEI públicas en las que se enseña a los niños con métodos lúdicos en los que se aprende jugando, pero en la privada los padres desean que se les enseñe a sumar, dictado entre otros, efectuando por lo que se ha creado un vacío ya que estas enseñanzas se brindan al momento de llegar a primer grado

\section{SOBRE EL MERCADO}

5. ¿Qué opina de la calidad de la calidad académica de los colegios de educación inicial en la ciudad de Chiclayo?

Hay realidades diversas, ya que hay colegios que están atendiendo los intereses que son necesarias para los niños, pero hay otras IEI que atienden solo lo que el padre quiere, y esto está ligado al nivel socio -económico del padre de familia, ya que los padres del nivel A Y B desea que su hijo se desarrolló en este nuevo modelo pedagógico

6. ¿Cuáles son los principales colegios de educación inicial en la ciudad de Chiclayo? 
Tienen que ver con el cuidado del personal, ya que los docentes de este nivel son los que brindan las primeras experiencias de los niños, brindando calor de hogar, ligado a una buena infraestructura, en donde prime el movimiento del niño, siendo San Agustín, Ceibos.

7. ¿Qué opina de la calidad de la infraestructura de los colegios de educación inicial en la ciudad de Chiclayo?

La calidad de la infraestructura es variada debido a que en su mayoría las IEI no cumplen con el área mínima para un normal movimiento de los niños.

8. ¿Cuáles son los principales factores de competencia entre los colegios de educación inicial en la ciudad de Chiclayo?

El aspecto emocional es el principal factor de competencia, ya que el niño es quien toma la decisión final, puesto que este se tiene que sentir cómodo con el ambiente del colegio, debido a que si no se siente cómodo este no tendrá deseos de asistir al colegio.

9. ¿Cuáles son los elementos tecnológicos que usan los alumnos en su Colegio durante el desarrollo de sus clases?

A los niños no se les puede desligar de los avances tecnológicos, es por eso que las IEI buscar ligar el uso de las tecnologías como el uso de las computadoras, aulas con computadoras, las exposiciones tecnológicas con Power Point, uso de programas de aprendizaje del inglés,

\section{SOBRE EL MODELO PEDAGÓGICO}

10. ¿Cuáles son los modelos pedagógicos que se aplican en los colegios de educación inicial privados en la actualidad? ¿Por qué?

Existe un mix de M.P como Optimus, los cuales no los he trabajado 
11. ¿Existen diferencia entre los modelos pedagógicos que usan los colegios de educación inicial privados con los que usan los colegios públicos?

12. ¿Cuál es el modelo pedagógico más común que aplican las instituciones de nivel inicial en la Ciudad de Chiclayo? Indicar ¿Por qué y cuáles son sus características?

Tienden a ser eclécticas, debido a que toman lo mejor de los modelos privados como el Optimus, y lo mejor de los M.P del estado y creamos el propio, dentro de las limitaciones que se tienen

13. ¿Qué se requiere para implementar un modelo pedagógico de educación inicial en un nuevo colegio?

Los enfoques se están consolidando, debido a que ahora se debe atender la necesidad de movimiento, el juego libre, ya que ahora se atiende independientemente al área de psicomotricidad.

Además, se requiere un líder pedagógico que conozca su trabajo, sabiendo cuales son las necesidades que tiene el niño y cuáles son los puntos que debe atender.

14. ¿Cuál es el modelo pedagógico que aplica usted en su institución? Indicar ¿Por qué?

Efectuamos una mixtura, debido a que tomamos como ejemplo el Montessori y diversos modelos ligados al movimiento y juego libre de los niños.

15. ¿Cuáles son los ambientes que debe contar un colegio de educación inicial para un normal desenvolvimiento de los niños?

Si somos conscientes que el niño debe moverse y con este movimiento aprende es necesario que cuente con áreas verdes, áreas libres de juego, debe tener 
espacios para que se sienta libre y desarrollo sus actividades lúdicas, recreativas, siendo estos lo principal, además asegurando la libertad del niño.

Es necesario además que el niño tenga acceso a la tecnología, además es importante que tenga un espacio para hacer juegos de roles puesto que esto desarrolla su yo interior, teniendo un lugar para poder hacer dramatización, juegos de roles.

16. ¿Cómo se interrelacionan los estudiantes en un colegio de educación inicial? ¿Se requiere apoyo del docente?

Son individualistas y egocentristas, puesto que mientras más pequeño sea más le va a costar compartir, y esto está ligado con las enseñanzas del hogar.

El docente tiene que ser una segunda madre, al enseñar la tolerancia en los niños.

17. ¿Cuál es el perfil académico de los docentes en el nivel inicial dentro de la ciudad de Chiclayo?

La docente de esta nivel debe tener una sintonía para con el niños, contando con la misma necesidad de escuchar al niño, desarrollando técnicas para que el niño se sienta escuchado, teniendo que ver los movimientos gestuales de los niños

18. ¿Cuáles son las competencias que se requieren para enseñar a nivel de educación básica?

La tolerancia, ya que la docente de este nivel nace y no se hace, puesto que tienen que tener un carisma que los hace crecer como profesional. Este docente debe escuchar a sus niños gozando con la satisfacción de los niños.

Ética al ser consecuente entre lo que dice y lo que hace, a este docente los padres de familia lo buscaran para hablar, o solo para ser escuchados.

\section{SOBRE EL SERVICIO}


19. ¿Cuáles son los aspectos relacionados con la enseñanza que buscan los padres de familia en los colegios de educación inicial?

Los padres de los niveles económicos altos buscan el nuevo modelo pedagógico por su crianza y enseñanza, puesto que este tipo de padre conoce y buscara un modelo que busque el conocimiento del niño.

Los padres de menor nivel económico buscaran que su hijo aprenda de la forma tradicional.

20. ¿Cuáles son las actividades recreativas que se programan durante el año?

En nuestro PACK se planifican los paseos que permitan la actividad libre del niño, se trabaja también la integración familiar que busca la integración entre familias.

21. ¿Cuántos niños considera Usted que debe tener un aula de tamaño ideal? ¿Por qué?

Depende de la clase de niños con lo que se trabajan, pero lo ideal es de 15 por aula, debido a que es necesario brindar una atención personalizada, de acuerdo a las estrategias que se aplican.

22. ¿De cuantas horas debería constar la jornada educativa diaria en los colegios de educación inicial privados?

La jornada debería ser de 5 horas:

En el estado:

De 7:30 a 8 se les brinda desayuno a los niños

De 8 a 9 se efectúan actividades de juegos en sectores donde los niños están libres explorando los sectores del colegio donde desarrollar sus actividades ese día.

9 a 10 se efectúa la primera sesión, después de esto tiene un recreo 
A las 11:15 se efectúan expresiones grafo-practicas hasta las 12:15

En el privado:

De 8 a 1

Una de las desventajas es que la mayoría de los colegios no tienen espacio para juegos.

De 8 a 9 se desarrollan actividades permanentes como los tallares puesto que los padres de los IEI privadas exige el desarrollo de estos talleres siendo los que se brindan en la mayoría de colegios: Danzas, Ballet, Ingles, Computación y Psicomotrocidad, fuera de los talleres de robótica, entre otros, contrarrestando el número de horas que deben está estudiando los niños.

23. ¿Conoce colegios de educación inicial privados que en la actualidad brindan el servicio de horario extendido?

24. ¿Qué ventajas y desventajas encuentra Usted en este servicio de horario extendido?

Tiene pro y contras debido a que este niño es necesario que desarrolle una mayor cercanía a los padres, puesto que los padres de familia piensan que este es el bálsamo ante las necesidades de trabajar, originándose que no haya una correcta atención a este niño.

\section{SOBRE EL CLIENTE}

25. ¿Quién es el que se encarga de hacer seguimiento diario de las labores escolares de sus hijos, el padre o la madre?

Hay padres jóvenes y no tan jóvenes, pero hay un crecimiento de los padres de 27 hacia adelante.

Son heterogéneos clasificando de la siguiente manera: 
Hay madres que son dependiente de los niño con la necesidad de saber que hacen los niños durante el día

Hay madres que son asertivas dando libertad a los niños para que sean autónomos.

Hay madres que no se interesan en el desarrollo de los niños, siendo sobre todo esto en los padres que trabajan o tienen suficiente tiempo libre que desarrollan otras actividades en vez de involucrase en el desarrollo del menor.

26. ¿Cuál es el nivel socio-económico de los padres que matriculan a sus hijos en Colegios de educación inicial privados en la actualidad?

Existen de todos los nivel, siendo la realidad de que en los niveles socioeconómicos medio lo que tienen un mayor grado de involucramiento con el docente.

27. ¿Qué distancia en promedio suelen trasladarse los alumnos hacia sus colegios de educación inicial en la actualidad?

En un rango de 15 cuadras como máximo.

28. ¿A los niños lo trasladan sus padres al colegio o son llevados por una movilidad particular contratada por estos?

El 95\% son trasladados por familiares, siendo la madre la principal persona que traslada al menor, siendo los abuelos y empleadas del hogar los que lo siguen. 


\section{Anexo 9}

\section{Desarrollo de focus group 1- padres con experiencia}

\begin{tabular}{|l|l|}
\hline \multicolumn{2}{|c|}{ FICHA TECNICA DE ENTREVISTADOS } \\
\hline & Carolina Mendoza García. \\
& Renzo Camacho Flores. \\
& Kathia Deza Rojas. \\
& Solayns Salazar Céspedes. \\
& Carla Rojas Aguirre. \\
& Jesenia Espino Carrasco. \\
& Ronald Perla Gastulo. \\
\hline Participantes & Peruana. \\
\hline Nacionalidad & Chiclayo. \\
\hline Distrito de Residencia & Entrevista realizada el día 24 de Setiembre a las \\
& 06:00 pm. \\
\hline Observaciones & (Video disponible a solicitud). \\
\hline
\end{tabular}

Perfil del cliente:

1. ¿A qué colegio de educación inicial (jardín) asiste o asistió su hijo? Indicar el periodo al que asistió su hijo al colegio de educación inicial.

Carolina: Mi hija asiste al colegio Manuel Pardo

Renzo: Mi hijo asiste al colegio Disneylandia.

Kathia: Asiste al colegio Santa Verónica.

Solayns: Mi hija asiste al colegio Manuel Pardo.

Carla: Mi hija asiste al colegio María Puga en San Juan.

Jesenia: Mi hija asiste al colegio Beata Imelda.

Ronald: Asiste al colegio Santa Verónica.

2. ¿Cómo tomaron la decisión en la familia sobre el colegio inicial al que asiste o asistió su hijo?

Renzo: En mi familia decidimos buscar una enseñanza personalizada, un ambiente acogedor y seguro para ellos. 
Solayns: Principalmente que este cerca de mi domicilio y calidad de la enseñanza.

Carla: inicialmente buscábamos un colegio que quede cerca de mi casa, que contara con infraestructura y áreas verdes, referencias de enseñanzas que se conocía.

3. ¿Qué aspecto fundamental valoró usted para seleccionar el colegio de educación inicial al que asiste o asistió su hijo?

Kathia: Principalmente la enseñanza y los juegos didácticos debido a que mi hija es muy iperativa y para que se canse.

Ronald: Recomendación de familiares que han tenido a sus hijas en ese colegio es por ello que la matricule.

4. ¿Cuáles son las actividades que el colegio que asiste (asistió) su hijo lleva (llevó) a cabo para los padres de familia?

Carolina: Escuela de padres.

Renzo: Día del niño, escuela de padres.

Kathia: Día del logro, escuela de padres.

Solayns: Festividades, escuela de padres.

Carla: Escuela de padres, la primavera.

Jesenia: Escuela de padres, día del niño, día del logro.

Ronald: Si, en los aniversarios, día del niño, escuela de padres.

5. ¿Qué tan satisfecho está con el servicio en general recibido por el colegio que asiste (asistió) su hijo? ¿Por qué?

Carolina: Lo que más me gusta es que tiene varios deportes para cada cosa un área como por ejemplo computación, ingles.

Renzo: En mi caso fue por un tema de recomendación y porque los docentes eran muy capacitados. 
Solayns: La experiencia es buena siendo el primer año de mi hija en este colegio y por tema de recomendación ya que tenía conocidos que sus hijos estudiaban ahí. Jesenia: En mi caso estoy satisfecha porque el colegio cuenta con lo principal para cada niño como son las cámaras en cada aula, el material que utiliza como son las pantallas interactivas, aulas de computo, talleres en caso a mi niña le gusta participara en varios de ellos, la enseñanza de los valores.

6. ¿Cuál es la modalidad para el pago de la mensualidad en el colegio inicial al que asiste o que asistió su hijo?

Carolina: El pago es en el banco Scotiabank, pero sería muy buena opción que el pago se haga debito automático de mi cuenta de ahorros o crédito.

Renzo: Seria excelente que sea por internet.

Kathia: Evitaríamos colas largas.

Solayns: En mi caso pagamos en el banco Scotiabank, pero me gustaría que el pago nos lo puedan debitar todos los meses.

Ronald: Me gustaría que se debite de mi cuenta de ahorros.

7. ¿Cuál es el monto aproximado que usted paga (o pagó) por el colegio al que asiste (o asistió) su hijo?

Carolina: 390 soles.

Renzo: en mi caso 350 nuevos soles.

Kathia: 390 soles.

Solayns: 390 soles.

Carla: 300 soles

Jesenia: 350 soles.

Ronald: 350 soles 
8. ¿Están considerando cambiar o están planeando cambiar a su hijo a otro colegio? Si es si, ¿Qué factores podrían motivar el cambio de colegio para su hijo?

Kathia: Si porque es netamente inicial.

Solayns: El tema del bullyng ya que es el día a día en realidad, que los profesores les enseñen más valores y sepan tratar a sus demás compañeritos.

Jesenia: No ya que ahí mismo hay primaria y secundaria. El tema de la discriminación por el color de piel a que uno sea morenito cholito y que tengas una discapacidad como que se cojito y que empiecen a burlarse de ellos, es por ello que se deben inculcar los valores del mismo colegio.

Ronald: Si debido a que yo estudie en el colegio Manuel Pardo y me gustaría pasarla a este colegio en el nivel primaria. El tema del bullyng de los profesores a los niños y entre ellos mismos.

Conocimiento de la competencia:

9. ¿Qué opina en general del nivel de enseñanza de los colegios de educación inicial privada en la ciudad de Chiclayo?

Carolina: el curso de inglés no debería darse como tan básico pues los niños jugando aprenden el idioma inglés, pero se olvidan por eso debe ser más reforzado y lo practiquen

Renzo: valoro el tema de la enseñanza bilingüe Kathia: los cursos de comunicación, lenguaje deberían darse en ingles el resto en español.

Carla: el tema de los idiomas es muy importante.

Ronald: me gustaría que las clases sean compartidas en inglés y español para una mejor enseñanza. 
10. Sus amigos o familiares le recomendaron algún otro colegio de educación inicial. ¿Cuál? ¿Lo visitó?

Carolina: En algún momento si, pero en mi caso por la cercanía. Aunque hay colegios más grandes que están fuera de la ciudad y son completos, pero origina un tema de lejanía donde sucede algo no me podría acercar rápidamente. Considero que por ser un niño pequeño debería estar más cerca. Renzo: visite cuatro colegios antes de matricular mi hijo.

Kathia: Si me recomendaron.

Solayns: Si.

Carla: Si.

Jesenia: Si.

Ronald: Si me han recomendado otro colegio de educación inicial, pero estoy conforme en el colegio que he matriculado a mi niña ya que le brindan todos los servicios que me ofrecieron. me gusta que no les dejan tareas a los niños pues considero que primero debe ser niña y pueda disfrutar su edad.

11. ¿Cuántos centros de educación inicial visitó usted previo a la selección del colegio en donde matricularon a su hijo? ¿Cuáles?

Carolina: Visite tres colegios antes de matricularla encontrando diferencias como por ejemplo el tema de los talleres uno si tenía lo que quería y el otro no, el tema de la atención era más personalizada mientras que en otras instituciones era otra cosa como por ejemplo el tema de la infraestructura.

Renzo: tres colegios

Kathia: tres colegios

Carla: visite tres colegios 
Jesenia: visite tres colegios, como el Santo Toribio de Mogrevejo, Manuel Pardo y Beata Imelda en el cual opte por matricular.

12. Indicar, ¿Cuáles con los aspectos que le agradó de los colegios de educación inicial que visitaron? ¿Por qué?

Carolina: Bueno la influencia de mi hijo ala querer elegir este colegio para estudiar e incluso dice que cuando pase a primaria quiere seguir en este mismo, pero ya se verá con el trascurso del tiempo, haciendo que él se sienta a gusto y cómodo.

Renzo: Que nos brindaban un servicio personalizado menos niños por aula es por ello que elegimos ese colegio.

Jesenia: Opte por matricular a mi niña debido a la currícula que tenían en la cual incluyen el curso de ciencia y ambiente en idioma inglés.

13. Indicar, ¿Cuáles con los aspectos que no le agradó de los colegios de educación inicial que visitaron? ¿Por qué?

Renzo: Distancia.

Carla: en mi caso vi que algunos colegios contaban con aulas pequeñas, además de tener muchos niños por aula e incluso solo los manejaba una maestra y no había auxiliar.

14. ¿Qué colegios de educación inicial usted considera los mejores en la ciudad de Chiclayo? ¿Por qué?

Carolina: Ceibos considero que es un buen colegio por el nivel de enseñanza. Renzo: Ceibos, Caritas Felices.

Kathia: Ceibos.

Carla: Caritas Felices teniendo buena referencia en el tema de la enseñanza es muy buena.

Jesenia: Ceibos. 
Ronald: Ceibos.

15. ¿A qué colegio de educación inicial usted no enviaría a su hijo en la ciudad de Chiclayo? ¿Por qué?

Renzo: El tema de la distancia hay varios colegios que están lejos y son buenos.

Ronald: Hay varios, pero por el tema de la distancia debido a que mi niña está muy pequeña y que se levante temprano es algo muy complicado, teniendo buenas referencias del colegio San Agustín, Ceibos, La Anunciata.

Características del servicio

16. ¿Cuáles son los factores del servicio al alumno que usted considera importantes en la búsqueda de un colegio de educación inicial?

Carolina: Lo primero que los niños ven son los juegos.

Renzo: Juegos recreativos.

Kathia: Que no dejen tareas.

Solayns: Juegos.

Carla: Juegos recreativos, áreas verdes amplias.

Jesenia: Juegos didácticos.

Ronald: Los niños en esta edad no quieren tanto ir a estudiar sino a jugar entonces que tenga varias áreas recreativas. Dentro del salón debe haber juegos didácticos y fuera de la institución áreas verdes.

17. ¿Cuáles son los factores del servicio al padre de familia que usted considera importantes en la búsqueda del colegio de educación inicial?

Carolina: El tema de la seguridad y la comunicación con los padres es primordial, que existan cámaras es importante pues podemos ver que les sucede e incluso que exista plataforma virtual para ver sus notas 
Renzo: el tema de seguridad interna como externa y docentes capacitados. Una sugerencia seria que los choferes estén capacitados y certificados.

Kathia: que los docentes estén bien capacitados que les tengan paciencia a los niños pues por el hecho de ser niños a veces se les dice que no y ellos lo van hacer pues están pequeños, se les debe tener la paciencia necesaria pues no está bien que los docentes los griten.

Solayns: Seguridad, ante todo y la infraestructura debido a que mi niña tiene tres añitos y todo el tiempo está jugando entonces se puede golpear entonces tengo que estar segura de que siempre está protegida.

Carla: Calidad de los maestros que enseñen. El tema de la seguridad pues como es colegio de nivel inicial las aulas deben estar en el primer piso. La paciencia es importante de los docentes a los niños pues hace algunas semanas he tenido un problema en este tema la promotora del colegio ya que le llamo la atención a mi niña y pues habido algunas diferencias y estoy evaluando, pero ahí vamos Jesenia: en mi caso las cámaras hay en las aulas, existencia de portero. Ronald: el tema de las cámaras por la seguridad, también es importante pero el tema de la seguridad tanto interna como externa es muy importante, a la hora de tomar la decisión de matricular a nuestro hijo debemos ver el tema de la cercanía o lejanía que existe.

18. ¿Cuáles son los factores determinantes que usted consideró para elegir un colegio de educación inicial? ¿Por qué?

Carolina: El tema de las áreas verdes, que todos los instrumentos que utilizan sean a su tamaño por lo mimo que son pequeños como por ejemplo los urinarios deben ser a su tamaño. 
Kathia: En mi caso es importante la seguridad pues tenemos un fotocket que cuenta con un código de barras y solo la persona que lo lleva puede recoger a mi hijo. Teniendo en una base o data quien es el apoderado o quienes podrían ir a recogerlo. Solayns: Se tiene que tener una base de datos autorizada de los padres de familia. Carla: La modalidad de quien recoge a los niños es muy importante que sepan a quien se los deben entregar, ha habido oportunidades de que yo no he podido recoger a mi niña y su papa ha ido, entonces si iba otra persona no se entregaban mientras no se comuniquen conmigo y yo autorice.

19. ¿Considera Usted importante la certificación en educación inicial de los docentes en el colegio al que asiste su hijo?

Carolina: Lo que sucede que ahora por el tema de la Ugel tienen que estar titulados en incluso tener una especialidad, teniendo en las aulas una docente y un auxiliar. Kathia: Dos docentes y una auxiliar estaría bien.

Renzo: Claro que es muy importante pues tenemos que ponernos a pensar en las manos de quien estamos dejando a nuestros niños para que los eduquen sin saber que no tienen el grado de instrucción adecuada por el hecho de que son carismáticos, pero lejos de enseñarles los puede llegar a confundir. Solayns: Es importante. Considero que deben tener dos docentes y una auxiliar. Carla: Es importante. En el aula debe haber dos docentes ya que son niños pequeños y de una forma u otra lo relacionan como una figura materna y estar seguros de que no se originen cambios a mitad de año pues algo chocante para los niños Jesenia: Es muy importante que estén certificados. Ronald: Es básico que estén titulados los maestros, tanto en el sector privado como público pues les exigen que lo estén por el tema de los concursos. Las docentes 
deben estar tituladas e incluso tener especialidad y la auxiliar podría ser la practicante.

20. ¿Considera Usted que el centro de educación inicial al que asiste (asistió) su hijo debe estar integrado con un colegio de educación primaria? ¿Por qué? Renzo: Seria ideal que el colegio tenga la integración de inicial a primaria y segundaria por el tema que los niños se acostumbran a una imagen e incluso con sus compañeros y darles seguridad de no tener que cambiarlos de un colegio a otro. Kathia: Debería funcionar solo para nivel inicial pues al estar integrado a un colegio de nivel primario muchas veces integran a los niños y se mezclan haciendo que los más grandecitos puedan pegarles a los más pequeñitos

Carla: Por ejemplo, mi niña estudia en un colegio de nivel inicial dedicado y contando con las áreas exclusivas para este nivel, sería bueno que tenga integración con un colegio de nivel inicial pues ahora para buscar la vacante va ser un tema más complicado.

Ronald: Considero que incluso deber ser solo de nivel inicial y no tener estimulación temprana pues si funciona para una sola línea va funcionar mejor centrándose en ello.

21. ¿Cómo lleva (llevó) a sus hijos al colegio: personalmente ó mediante un servicio de transporte escolar?

Carolina: Yo llevo a mi hija al colegio, Renzo: Sería bueno que se cuente con el servicio de movilidad el mismo colegio pues en sus manos quedaría el tema de la capacitación de los choferes e incluso el tema de las entrevistas para saber quiénes son.

Kathia: Yo a veces mi mamá. 
Solayns: Estaría muy bien que se brinde el servicio de movilidad escolar.

Carla: Yo personalmente llevo a mi hija al colegio. Que el mismo colegio brinde movilidad sería ideal pues el colegio sabría quiénes son los choferes que transportan a nuestros niños cumpliendo con los requisitos necesarios para hacer este trabajo como es el tema de las licencias.

Jesenia: En mi caso mi esposo lleva a mi niña al colegio. Pero sería ideal que el colegio brinde el servicio de movilidad, en el colegio que esta mi niña si se cuenta con este servicio haciendo que los padres estemos seguros de quienes están transportando a los niños

Ronald: En mi caso su mamá lleva al colegio a mi niña. Considero que se debería el colegio incluir una movilidad por el tema de control, sabiendo quienes, con sus padres, a quien se lo van a entregar entonces los padres vamos a estar más seguros e involucrados con el colegio en este tema, hace algún tiempo se empezó a regular el tema de las movilidades escolares básicamente en el número de niños que debían llevar y el orden de las mochilas para evitar los accidentes. En el tema de los precios de cuanto se paga no lo sé, pero considero que debe abordar los doscientos soles por un tema de seguridad.

22. ¿Qué distancia debe (debió) recorrer su hijo para llegar al colegio?

Carolina: Diez minutos.

Renzo: Diez minutos.

Kathia: Diez minutos.

Solayns: Diez minutos.

Carla: En mi caso está al frente de mi casa es cuestión de minutos.

Jesenia: En mi caso recorre diez minutos a lo mucho.

Ronald: Diez minutos, está cerca. 
23. ¿Considera usted que un colegio de educación inicial debe ser bilingüe?

Carolina: Lo que sucede es que los niños aprenden jugando y sin querer al cantar una canción ya están hablando ingles de a pocos, sin siquiera nosotros entender lo que dicen y solo atinamos a decirles que si está bien. En el extranjero les enseñan dos tres idiomas a más y es por su bien.

Renzo: Claro los niños aprenden jugando.

Kathia: Clases compartidas pues también creo que se aburrirían al comienzo y les chocaría bastante.

Solayns: Las clases deben ser compartidas tanto en inglés como español.

Carla: Considero que cien por ciento ingles no pues no va permitirme ayudarle en casa.

Jesenia: En mi caso me gustaría que mi niña siga ahí mismo al nivel primaria y desde ya la están preparando pues les enseñan bastante este curso siendo algo dificultoso pues son dos horas diarias que les enseñan siendo diez horas semanales. Ronald: Seria buena opción que reciban sus clases en español y la otra mitad en ingles pues los niños captan más rápido aprendiendo mejor y se les queda.

24. En el colegio de educación inicial donde han estado o están sus hijos, ¿incentivaba la participación activa de los padres de familia en el proceso educativo?

Carolina: Navidad, escuela de padres.

Renzo: Día de la primavera, día del niño, escuela de padres. Por el tema laboral la dedicación que le brindo a mi hijo es un par de horas, entonces considero que no es recomendable que les dejen tareas para la casa, pues están entrando a un mundo nuevo y si los saturas como que le agarran miedo y los aburren.

Kathia: Día del logro, escuela de padres.

Solayns: Festividades, escuela de padres. 
Carla: Escuela de padres, la primavera.

Jesenia: Escuela de padres, día del niño, día del logro. En mi caso la integración está basada con la profesora, los padres y el niño, tengo una profesora particular que le enseña a mi niña ingles por el tema de tiempo.

Ronald: Si, en los aniversarios, día del niño, escuela de padres. Esta muy pequeña para que le dejen tareas deben jugar más. Por ejemplo, hay niños que les gusta pintar a otros bailar como también cantar entonces es recomendable que lo refuercen en lo que más le agrada hacer, pues no todos tienen las mismas habilidades.

\section{Presentación del Colegio de Educación Inicial propuesto}

Estamos desarrollando un proyecto para formar un colegio de educación inicial ubicado en la ciudad de Chiclayo que cuente con las siguientes características:

a) Que incorpore la participación de los padres de familia en el desarrollo del niño en colaboración con los docentes del colegio.

b) Que permita observar a su hijo en clase a través de una cámara de internet.

c) Que propicie la reunión de los padres de familia con los docentes y con los padres de los compañeros de sus hijos.

d) Que envié información a su correo electrónico sobre algún cambio en el comportamiento del niño durante su permanencia en el colegio.

e) Que cuente con un modelo de aprendizaje basado en el desarrollo de competencias de los niños de tres a cinco años

f) Que los docentes estén certificados en educación inicial

g) Que cuente con la infraestructura adecuada de un colegio de educación inicial (apoyo de un psicólogo, salas de juego que apoyen el aprendizaje, un biohuerto, biblioteca especial para niños)

h) Que enseñe el idioma inglés 
Preguntas sobre el colegio presentado:

25. De haber estado operando este centro de educación inicial en el momento que usted requería el servicio, ¿Usted habría escogido este colegio para sus hijos?

Carolina:

Renzo: Si estaría dispuesto pues veo que tiene variedad de talleres.

Kathia: Me gusto el cine,

Carla: No vi que contaba con danzas le falta,

Jesenia: Cuenta casi con los mismos talleres del colegio de donde estudia mi hija, como son mini chef, talleres de actuación, pero a diferencia de este que si cuenta con natación y me agrada podría estar dispuesta a cambiarla pues veo que cuenta con aulas amplias, tiene áreas verdes, talleres.

Ronald: Consideraría tres cosas principales, ubicación, costos y el tema de agarrar una vacante.

26. ¿Cuál sería el pago mensual que estaría dispuesto a pagar por un centro de educación inicial de estas características?

Carolina: Considero que se tiene que ver la ubicación y según eso dar un precio por ejemplo si está en Santa Victoria seria los precios oscilan entre trecientos cincuenta y cuatrocientos cincuenta.

Renzo: Hay variedad y rangos de precios que se manejan y están entre los trecientos y quinientos soles.

Kathia: Trecientos cincuenta y cuatrocientos cincuenta.

Solayns: Trecientos cincuenta y cuatrocientos soles.

Carla: por la similitud que tiene el colegio en el que actualmente estudia mi hija excepto por el tamaño y la amplitud de las aulas majería un poco más el precio. 
Jesenia: Por el tema de la amplitud con la que cuenta considero que estaría entre cuatrocientos y quinientos soles.

Ronald: Entre trecientos y cuatrocientos.

27. ¿Cuál considera debería ser la forma de pago deseada?

Carolina: Debitarlo de la cuenta de ahorros.

Renzo: Debería ser debitada de la cuenta de ahorros.

Solayns: Con las aplicaciones que hoy se cuentan seria debitarlo directamente de tu cuenta.

Carla: Pago directo.

Jesenia: Pago mensual.

Ronald: Sería una buena opción que si pagamos todo el año nos podrían descontar una pensión como lo hacen otras instituciones.

28. ¿Cuál sería el factor determinante para cambiar a su hijo a este colegio?

Carolina: Que tenga algo más de lo que el colegio actualmente me proporciona.

Como por ejemplo los talleres de robótica

Renzo: Una clase modelo pues vamos a ver quién es la maestra, la infraestructura y la metodología que van a emplear para enseñarle a los niños.

Kathia: Me gustaría que se implemente el área de psicología, tópico.

Solayns: Que sea novedoso que el mismo ambiente te involucre.

Carla: Considero que nos deberían hacer una clase demostrativa y de ello depende.

Tiene que contar con cosas nuevas talleres que incentiven al niño.

Jesenia: Me gustaría que la enseñanza sea novedosa pues los niños aprenden más jugando, y visualmente con pantallas tecnológicas y ya no se utilicen pizarras. Ronald: Me comentaron alguna vez que en algunas instituciones hacían entrar al padre en el lugar del niño y te trataban como niño tipo clase modelo lo cual sería 
muy interesante, incluyendo a los padres en el desarrollo del aprendizaje de los niños.

29. ¿Qué característica presentada no le gusta de este colegio?

Carolina: Se debería trabajar con un aproximado de quince a veinte niños.

Renzo: No me agrado que los tachos de basura estaban cerca a la puerta del colegio en un desvió, por ser tan pequeños el tema de horario extendido no iría.

Carla: No me agrado que teniendo un aula tan grande utilicen un televisor tan pequeño. Por brindar un servicio para niños no puede haber tantas gradas pues mi hija se tira. Me gustaría que exista una nutricionista que nos oriente a las madres que debemos prepararles a nuestros niños.

Jesenia: Las cámaras serían muy importantes, se debe tener entre quince y veinte niños por aula no más. Si existiera horario extendido no accederia a ello Ronald: Las aulas no deben ser muy recargadas sino distraerían a los niños, además los niños deben usar buzo todos igual y zapatillas existiendo equidad entre todos. Un tema adicional el tema de las loncheras podría el colegio brindar este servicio adicional siempre y cuando este avalado por un nutricionista. No estoy de acuerdo con que se brinde horario extendido.

30. ¿Qué diferencia considera que existe entre este colegio y el colegio que usted utiliza actualmente para sus hijos?

Carolina: Áreas verdes.

Renzo: Que tiene más talleres.

Kathia: Es más amplio.

Solayns: Es grande.

Jesenia: La amplitud de sus aulas.

Ronald: Me agrada el tema de la guardería. 
31. ¿Qué diferencia a este colegio inicial de los que usted ya conoce?

Renzo: el tema del horario de la movilidad si es que la proporciona el mismo colegio,

Solayns: Interesante el tema de la guardería pues nos daría facilidades para el cuidado de nuestros niños.

Jesenia: Es amplio y es especialmente para niños de esta edad.

Ronald: Hay similitud con los demás colegios, pero si incluyen el tema de horario extendido sería bueno. Me agrado el tema de la inclusión de que incluyan a niños con capacidades distintas a las de otros enseñándoles a los niños a ser más nobles.

32. ¿Conoce algún colegio de características similares en la ciudad de Chiclayo o en otra ciudad? ¿cuál?

Se omitió pregunta

33. ¿Tienen alguna sugerencia o propuesta de mejora al proyecto presentado?

Carolina: El tema de las señalizaciones es muy importante pues si está en una avenida debe haber parámetros que indiquen y modifiquen el tráfico para el uso correcto de los niños.

Renzo: Todo entra por los ojos, entonces deber ser más llamativo.

Carla: No debe haber tantas gradas porque mi hija por ejemplo se tira y se puede lastimar. Mejorar un poco el tema de la seguridad deben estar cerradas bien las puertas.

Jesenia: Mejorar la seguridad.

Ronald: Considero que debe haber más seguridad en la entrada colocando una reja de plancha de bicarbonato. Otro tema seria que si es un colegio de educación inicial debe ser más pintoresco pues parece un colegio militar colocando más cosas llamativas. 
34. ¿Qué medio de comunicación prefiere para recibir información sobre este colegio de educación inicial?

Renzo: Deberían llegar reportes semanales.

Carla: Debería haber comunicación diría con las docentes para pue así nos enteramos si los niños estuvieron callados durante el día o si distrajeron, las notas si las podríamos ver mediante una página del mismo colegio.

Jesenia: Se deben incluir horarios por docentes para que los padres tengamos más comunicación y estemos atentos a lo que sucede con los niños e incluso programarse cita con la psicóloga escogiendo a un niño por asesoría.

Ronald: Deberían utilizar un intranet como utilizan las universidades, teniendo el padre acceso para poder ver que hizo o dejo de hacer su niño.

35. En su momento, ¿Le gustaría recibir algún tipo de promoción o publicidad de este colegio de educación inicial?

Carolina: Si claro.

Renzo: Claro que sí.

Kathia: Si.

Solayns: Si.

Carla: Si.

Jesenia: Claro que sí.

Ronald: Si claro. 


\section{Anexo 10}

\section{Desarrollo de focus group 2- padres con experiencia}

\begin{tabular}{|l|l|}
\hline \multicolumn{2}{|c|}{ FICHA TECNICA DE ENTREVISTADOS } \\
\hline & Arturo Farro. \\
& Celeste Moscoso. \\
& Yvonne Solís. \\
& Mario Puga. \\
& Grabiela Ponce. \\
& Sandra Soto. \\
& Danny Guerrero Rojas. \\
& Miguel Mercado. \\
\hline Participantes & Peruana. \\
\hline Nacionalidad & Chiclayo. \\
\hline Distrito de Residencia & Entrevista realizada el día 1 de Octubre a las \\
\hline & 06:00 pm. \\
& (Video disponible a solicitud). \\
\hline
\end{tabular}

\section{PARTICIPANTES}

Arturo Farro, Mi hija se llama María Alejandra y tiene 3 años, en la actualidad se encuentra estudiando en el Colegio Arbolito

Celeste Moscoso, mi hijo tiene 05 años y estudia en el Colegio Santa Verónica

Miriam Suyon su hija se llama Renata, tiene 04 años y se encuentra estudiando en el

\section{Colegio Santa María Reyna}

Yvonne Solís y mi hija se llama Macarena, tiene 03 años y estudia en el Colegio

Mario Puga de la Urbanización San Juan

Gabriela tiene una hija de 03 años y estudia en el Colegio Miss Rossy

Miguel Mercado y tengo una hija de 04 años que tengo una Hija de 03 años que estudia en el Colegio Santa María Reyna

Sandra Soto: Tengo una Hija de tres años y mi hija estudia en el colegio Santa María Reyna 
Dani Guerreo y tengo una hija de 03 años que se llama Ashley estudia en el Colegio Boniffati.

1. ¿A qué colegio de educación inicial (jardín) asiste o asistió su hijo? Indicar el periodo al que asistió su hijo al colegio de educación inicial.

Miriam: Mi hija tiene estudiando 03 años, debido a que ingreso desde los 02 años.

Gabriela: Mi hija se encuentra en su segundo año en esta I.E

Arturo: Este es su primer año

Celeste: Este es su primer año

Dany: Este es su primer año

Miguel: Mi hija tiene estudiando 03 años

Sandra: Este es su primer año

2. ¿Cómo tomaron la decisión en la familia sobre el colegio inicial al que asiste o asistió su hijo?

Celeste: Yo decidí por este colegio debido a que te brinda el servicio de guardería, debido a que por temas laborales busque este servicio, aquí le brindan el almuerzo y lo atienden hasta las 4:30 que salgo de mi trabajo.

Miriam yo decide por la ubicación del colegio que esta frente a mi centro laboral, por lo que era primordial era poder trasladarla y recogerla del colegio.

Gabriela: Por la experiencia de la profesora y directora que implementaron este colegio puesto que anteriormente trabajaron en una I.E de prestigio.

Miguel: Por la infraestructura y la educación es buena por referencias de mis amigos y sobre todo por el prestigio de este.

Arturo: Por la cercanía a mi domicilio, ya que está ubicado frente a mi domicilio, así como por la experiencia de la familia de mi esposa que estudio allí. 
Sandra : Por la educación basada en valores, experiencia de los profesores, y que está cerca de mi domicilio.

Yvonne: La cercanía a mi casa y a pesar de ser un jardín pequeño tienen los ambientes ideales como césped, y las áreas separadas dándome la tranquilidad de dejarlo.

Dany: La cercanía a mi domicilio, puesto que estoy a menos de 10 minutos

3. ¿Qué aspecto fundamental valoró Usted para seleccionar el colegio de educación inicial al que asiste o asistió su hijo?

Gabriela: La seguridad que me brinda el colegio ya que esta desde pre-kínder, al darme la confianza de que los docentes ya habían trabajo en un colegio grande y con la cantidad de niños mayores a los que manejan hoy día.

Miriam La infraestructura del colegio

Celeste: La cercanía a mi centro laboral

Arturo: La infraestructura es mejora a otros centro cercanos a mi colegio

Yvonne: Los ambientes del colegio son importantes, así como los juegos para ellos son más practico

Miguel: Por la infraestructura del colegio y apoyan el deporte de los alumnos.

Dany: No parecía una casa que ha sido transformada para colegio y segundo punto la cercanía a mi casa.

Sandra: Recomendación de familiares, seguridad y tiene certificación internacional

4. ¿Cuáles son las actividades que el colegio que asiste (asistió) su hijo lleva (llevó) a cabo para los padres de familia? 
Miguel: En mi caso hay una escuela de padre y lo principal es el trato que tienen para tu hija y saber resolver los problemas que se presentan en el caso de las niñas que son más delicadas

Celeste: Escuela de padres reuniones mensuales de liderazgo, de cómo educar a los hijos, de cómo enseñarle a los niños, de cómo reaccionar ante ciertas circunstancias. Arturo: Participación en los talleres de integración, por ejemplo con títeres, contarles cuentos.

Miriam: Las olimpiadas donde participan los padres.

Yvonne: Jornada de padres para ver cómo llevar la familia , la fe , la religión Gabriela: Charlas con la sicóloga, nos da tipos para resolver problemas. Sandra: Escuela de padres.

5. ¿Qué tan satisfecho está con el servicio en general recibido por el colegio que asiste (asistió) su hijo? ¿Por qué?

Gabriela: Si estoy satisfecha ya que veo que cada vez la bebe aprende más, el inglés, los números veo el avance progresivo en ella.

Miriam: Si estoy satisfecha, porque mi hija está aprendiendo y veo que los útiles que se piden los utilizan, para cada clase lleva algún material que han hecho. Celeste: Si estoy satisfecha, cada tema aprendido en la clase lo llevan a la práctica porque ellos aprenden jugando.

Arturo: Si estamos satisfechos porque es muy didáctica la educación inicial, se ve bastante mejoría y progreso en cada clase.

Miguel: Si porque veo que se le nota el progreso en la niña. 
6. ¿Cuál es la modalidad para el pago de la mensualidad en el colegio inicial al que asiste o que asistió su hijo?

Dany: Mensual, personalmente hay un beneficio que te lo pueden debitar de tu cuenta y así no estar preocupado por pagar la mensualidad.

Miguel: Mensual y en efectivo.

Gabriela: Efectivo en el mismo colegio

Yvonne: Efectivo en el mismo colegio

Celeste: En mi caso se hace el pago en efectivo en el mismo colegio

Miriam: En el banco con un código

Arturo: Efectivo en el colegio

Sandra: Efectivo en el colegio

7. ¿Cuál es el monto aproximado que Ud. paga (o pagó) por el colegio al que asiste (o asistió) su hijo?

Miguel: S/330

Dany: $S / 350$

Sandra: S/330

Gabriela: S/250

Miriam: S/330

Arturo: S/220

Celeste: S/290

Yvonne: S/ 220

8. ¿Están considerando cambiar o están planeando cambiar a su hijo a otro colegio? Si es si, ¿Qué factores podrían motivar el cambio de colegio para su hijo? Miguel: Estoy muy conforme no la cambiaria 


\section{Dany: Estoy conforme}

Sandra: Estoy conforme porque es una educación integral

Gabriela: Por el momento estoy satisfecha

Miriam: Yo no la cambiaria, estoy conforme

Arturo: Yo si la cambiaria porque dentro de unos años va a pasar a primaria, a los cinco años.

Yvonne: Yo sí porque en el colegio las auxiliares son chicas muy pequeñas que no saben atender un bebe y en el tema de la educación porque hay niños de cinco años que no salen leyendo ni escribiendo, por lo tanto, yo a los cuatro años la cambiaria a un colegio que le exija un poco más.

Conocimiento de la competencia:

9. ¿Qué opina en general del nivel de enseñanza de los colegio de educación inicial privada en la ciudad de Chiclayo?

Yvonne: Es bajo, hay un método que están aplicando en varios colegios de Lima y aquí solo lo aplican algunos es el Optimas, el cual hace que los niños estén muy habidos, el porcentaje que lo aplica aquí en Chiclayo en muy bajo.

Gabriela: La educación inicial se está volviendo muy comercial hay mucha cantidad y no calidad, se está volviendo un negocio porque no hay un control.

Miguel: Es bajo, pero es cuestión de gestión para que puedan aplicar nuevos métodos.

Celeste: Si es muy bajo, personalmente tiene muchas deficiencias, me gustaría que sean más sensibles con los niños con un mejor trato ya que ellos son inocentes. Miriam: Si es bajo

Dany: Se nota baja calidad en los colegios nacionales, los colegios particulares tienen más capacidad educativa 
Sandra: La educación en el Perú es baja les falta innovar

10. Sus amigos o familiares le recomendaron algún otro colegio de educación inicial. ¿Cuál? ¿Lo visitó?

Arturo: Si el Beata Imelda porque dicen que tiene muy buena enseñanza y las escuelas de padres son muy buenas.

Dany: Si el Manuel Pardo y Ceibos, pero cuando visitamos este colegio nos gustó la infraestructura, no es improvisado, tienes áreas verdes y hay cámaras que me dan seguridad.

Yvonne: Si el Manuel Pardo, Santa María Reyna, son varios factores para decidir por una recomendación.

Miriam: El San Agustín, porque incentivan bastante el deporte

11. ¿Cuántos centros de educación inicial visitó Ud. previo a la selección del colegio en donde matricularon a su hijo? ¿Cuáles?

Gabriela: Yo visite tres colegios, uno por cercanía a mi casa, otro por cercanía a mi centro laboral y el ultimo donde la matricule.

Sandra: Santa Ángela y Santa María Reyna

Celeste: Colegio Vianey no me gusto porque era una casa y le faltaban algunas cosas.

Arturo: Dos colegios, uno carretera a Pimentel.

12. Indicar, ¿Cuáles con los aspectos que le agradó de los colegios de educación inicial que visitaron? ¿Por qué?

Gabriela: De los que visite no me gustó nada eran improvisados sin la menor infraestructura y garantía para cuidar a los bebes

Danny: Casi la matriculo en los Ceibos, me gusto su infraestructura. 
Sandra: Por la infraestructura, es un poco chico

13. Indicar, ¿Cuáles con los aspectos que no le agradó de los colegios de educación inicial que visitaron? ¿Por qué?

Se omitió pregunta.

14. ¿Qué colegios de educación inicial Ud. considera los mejores en la ciudad de Chiclayo? ¿Por qué?

Gabriela: San Agustín, porque te brinda educación, talleres, formación en valores, me parece completo, también el Mogrovejo y el Reyna que reúne las condiciones. Yvonne: San Agustín, pero elegiré el colegio sobre todo que mi hija se sienta cómoda y a gusto.

Celeste: Santo Toribio de Mogrovejo, Ceibos

Sandra: San Agustín, Reyna

15. ¿A qué colegio de educación inicial Ud. no enviaría a su hijo en la ciudad de Chiclayo? ¿Por qué?

Arturo: Básicamente nacionales

Yvonne: Appul College no tiene infraestructura adecuada

Dany: Colegios Pre Universitarios

16. ¿Cuáles son los factores del servicio al alumno que Ud. considera importantes en la búsqueda de un colegio de educación inicial?

Miguel: El tema de seguridad, averiguar bien el trato que le dan a las criaturas que los puedan controlar.

Gabriela: Seguridad al saber que tu hija está bien cuidada.

Sandra: Seguridad.

Celeste: Seguridad y método de enseñanza. 
Yvonne: Seguridad por el tema de que cada padre por ejemplo le gustaría que en el colegio solo estudien con niñas, que no haya hombres a su alrededor.

17. ¿Cuáles son los factores del servicio al padre de familia que Ud. considera importantes en la búsqueda del colegio de educación inicial? Yvonne: Que mi hija se exprese en todas las áreas académicas, que sea motivado que exista la motivación completa para todos.

Dany: Que mi niña salga leyendo y escribiendo, que tenga una base fuerte.

Sandra: el trato personalizado ya que mi niña es un poco tímida y la tienen que ir motivando para que sociabilice.

Miriam: La participación de todas las niñas en distintas actividades

Celeste: Taller de oratoria, marinera con la participación de todos Arturo: Integración con los demás niños.

Gabriela: Es personalizado, tratan de sacar a flote sus habilidades y la participación de todos los niños sin dejar de lado a nadie.

18. ¿Cuáles son los factores determinantes que Ud. consideró para elegir un colegio de educación inicial? ¿Por qué?

Yvonne: Infraestructura

Gabriela: Infraestructura

Dany: Infraestructura.

Miriam: Infraestructura

Celeste: En mi caso que tenga guardería y talleres.

Arturo: Infraestructura.

Miguel: Infraestructura y que es colegio solo para mujercitas.

19. ¿Considera Ud. importante la certificación en educación inicial de los docentes en el colegio al que asiste su hijo? 
Gabriela: Es básico, creo que es lo mínimo que deben de tener es la garantía que te da que tu hija va a recibir un nivel de educación óptimo.

Miriam: Estudios y capacitaciones que puedan tener.

Celeste: Que sean certificadas.

20. ¿Considera Ud. que el centro de educación inicial al que asiste (asistió) su hijo debe estar integrado con un Colegio de educación primaria? ¿Por qué?

Gabriela: Es importante porque sabes que tu hija va a continuar con su curricula pedagógica.

Miguel: Depende del nivel que le hayan brindado a tu hija en el nivel inicial para que puedas decidir.

Miriam: Me parece primordial ya que cuando culmine vas a poder decidir si continua en ese colegio o enviarla a otro.

Sandra: Importante porque es un beneficio para los padres por el tiempo que tienes que ver para pasarla a otro colegio.

Arturo: Es importante para poder separar cupo, pero también ver que las cuotas que pagamos no se van a elevar mucho.

21. ¿Cómo lleva (llevó) a sus hijos al Colegio: personalmente o mediante un servicio de transporte escolar?

Arturo: Yo

Gabriela: Movilidad

Miguel: Yo la llevo, pero la recoge la movilidad

Miriam: Yo

Celeste: Yo

Dany: Yo

Sandra: Yo 
Yvonne: Yo

22. ¿Qué distancia debe (debió) recorrer su hijo para llegar al Colegio?

Arturo: Frente a mi casa

Gabriela: 10 minutos

Miguel: 15 minutos

Miriam: 10 minutos

Celeste: 05 minutos

Dany: 15 minutos

Sandra: 15 minutos

Yvonne: 10 minutos

23. ¿Considera Ud. que un colegio de educación inicial debe ser bilingüe?

Dany: Personalmente si, tiene que tener una interrelación con el inglés.

Yvonne: Para mí no, depende del factor, tiene tres años y quiero que aprenda jugando, quizás más adelante .

Celeste: Si es importante, lo básico nada más, igual ellos aprenden jugando.

Miriam: No me parece importante, no se les puede exigir tanto a una corta edad.

\section{Presentación del Colegio de Educación Inicial propuesto}

Estamos desarrollando un proyecto para formar un colegio de educación inicial ubicado en la ciudad de Chiclayo que cuente con las siguientes características:

a. Que incorpore la participación de los padres de familia en el desarrollo del niño en colaboración con los docentes del colegio.

b. Que permita observar a su hijo en clase a través de una cámara de internet.

c. Que propicie la reunión de los padres de familia con los docentes y con los padres de los compañeros de sus hijos. 
d. Que envié información a su correo electrónico sobre algún cambio en el comportamiento del niño durante su permanencia en el colegio.

e. Que cuente con un modelo de aprendizaje basado en el desarrollo de competencias de los niños de tres a cinco años

f. Que los docentes estén certificados en educación inicial

g. Que cuente con la infraestructura adecuada de un colegio de educación inicial (apoyo de un psicólogo, salas de juego que apoyen el aprendizaje, un biohuerto, biblioteca especial para niños)

h. Que enseñe el idioma inglés

Preguntas sobre el colegio presentado

24. De haber estado operando este centro de educación inicial en el momento que usted requería el servicio, ¿Ud. habría escogido este colegio para sus hijos?

Gabriela: Si lo matricularía a mi hija ya que el colegio ha sido diseñado para colegio inicial con talleres e instalaciones diseñadas para colegio.

25. ¿Cuál sería el pago mensual que estaría dispuesto a pagar por un centro de educación inicial de estas características?

Arturo: S/. 350

Celeste: S/. 300 hasta S/. 450

Gabriela: S/. 450

Miriam: hasta S/. 400

Sandra: S/. 350

Dany: 350

26. ¿Cuál considera debería ser la forma de pago deseada? Arturo: Mensual

Gabriela: Mensual, si se pudiera pagar con tarjeta de crédito mejor 
Miguel: Mensual, con un descuento si se paga todo el año, descuento si son hermanos.

Miriam: Mensual

Celeste: Mensual

Sandra: Mensual

Dany: Mensual

27. ¿Cuál sería el factor determinante para cambiar a su hijo a este colegio?

Yvonne: El tema económico, ya que ven talleres, infraestructura

Gabriela: La distancia que tan alejado esta, tiene que estar en un lugar estratégico.

Miriam: La ubicación del colegio.

28. ¿Qué característica presentada no le gusta de este colegio?

Celeste: El patio muy pequeño.

Sandra: El patio no tiene muchos juegos recreativos.

29. ¿Qué diferencia considera que existe entre este colegio y el colegio que Ud. utiliza actualmente para sus hijos?

Yvonne: Los talleres se ven más interesantes, robóticas, olimpiadas

Arturo: Infraestructura.

30. ¿Qué diferencia a este colegio inicial de los que Ud. ya conoce?

Gabriela: Este colegio tiene un teatro ya que otros colegios lo tienen en el auditorio, su propio ambiente para los talleres y explotar las habilidades de cada niño.

31. ¿Conoce algún colegio de características similares en la ciudad de Chiclayo o en otra ciudad? ¿cuál?

Arturo: San Agustín

Gabriela: San Agustín

32. ¿Tienen alguna sugerencia o propuesta de mejora al proyecto presentado? 
Gabriela: La movilidad que brinde en colegio, me parece seguro, ver la formación católica.

Sandra: Que tenga estacionamiento

Dany: La calidad de los profesores

33. ¿Qué medio de comunicación prefiere para recibir información sobre este colegio de educación inicial?

Gabriela: A través de internet

Sandra: Correo

Yvonne: Que tenga página web que sea manejado todos los días que el maestro

ingrese todos los días el avance del niño

Dany: Se necesita un colegio más tecnológico, que se envié a los correos.

34. En su momento, ¿Le gustaría recibir algún tipo de promoción o publicidad de este colegio de educación inicial?

Dany: Sí me gustaría.

Celeste: Sí me gustaría

Gabriela: Sí me gustaría

Miguel: Sí me gustaría

Yvonne: Sí me gustaría

Sandra: Sí me gustaría

Miriam: Sí me gustaría

Arturo: Sí me gustaría 


\section{Anexo 11}

\section{Desarrollo de focus group 1- padres sin experiencia}

Perfil del cliente:

\begin{tabular}{|l|l|}
\hline \multicolumn{2}{|c|}{ FICHA TECNICA DE ENTREVISTADOS } \\
\hline & Nataly Bravo. \\
& Carlos Mayorga. \\
& Vanessa Montalvo. \\
& Mercy Mendoza. \\
& Willy Montalvo. \\
& Miguel Tenorio. \\
\hline Participantes & Peruana. \\
\hline Dacionalidad & Chiclayo. \\
\hline & Entrevista realizada el día de 7 octubre a las \\
Obseridencia & 08:00 pm. \\
& (Video disponible a solicitud). \\
\hline
\end{tabular}

1. ¿Cuál es el número de hijos que tiene en edad escolar inicial?

Nataly: Un niño de dos años y medio

Carlos: Una bebe de cuatro meses

Vanessa: Un niño de una año tres meses

Mercy: Niña de un año 10 meses

Willy: Dos hijos uno de dos años y otro de cinco años

Miguel: Un hijo de año cuatro meses.

2. ¿Esta Ud. planeando matricular a su hijo(s) en un colegio de educación inicial?

Vanessa: Mi niño asiste a un centro de estimulación

Carlos: Mi bebe aún no está en edad para asistir, peo los centros de estimulación ayudan mucho para sociabilizar y relacionarse, les ayuda a desempeñarse mejor en determinadas situaciones.

Nataly: Mi niño también asiste a un centro de estimulación el cual le ha ayudado bastante ya que a él le gusta pintar, jugar, las vocales también le enseñan. 
Willy: La estimulación los ayuda a sociabilizar bastante.

Miguel: Mi niño asiste a un centro de estimulación temprana, lo ayuda a interrelacionarse con sus compañeritos.

3. ¿Cómo tomarán la decisión en la familia sobre al colegio inicial al que asistirá su hijo?

Vanessa: En pareja

Mercy: También en pareja

Nataly: En pareja y también lo consultamos siempre con mis suegros.

Carlos: Siempre se pide la opinión de algún conocido que haya tenido experiencia Willy: Amigos que hayan tenido experiencia.

Miguel: En pareja y con la recomendación de algunos amigos.

4. ¿Qué valora Ud. como aspecto fundamental para seleccionar el colegio de educación inicial al que asistirá su hijo?

Mercy: De mi parte veo que la estructura sea buena, que los profesores sean titulados, que tengan psicología, que haya escuela de padres, que exista un área de talleres, porque es a partir de los tres años que ya asisten al colegio y es importante que yo pueda ver como es el trato hacia mi niña, cual es la formación que les dan, como se desarrollan en el ambiente.

Vanessa: Una buena infraestructura, no en colegio tipo casa, que tengan ambientes amplios, que tengan docentes preparados con vocación de servicio y que dicten charlas para padres.

Carlos: Que tengan buenos profesores que sean A1, que tenga buena calidad. Nataly: Adicionalmente a los dicho yo pediría que tengan cámaras de seguridad para ver el desenvolvimiento de los niños en el aula, psicología y que se tenga trabajo de campo. 
Willy: Con el avance de la tecnología las cámaras son importantes.

Miguel: La infraestructura del colegio tiene que ser como una casa ya que en algún momento los niños se van a quedar solos, también la tecnología debe de ir de la mano, las cámaras, los juegos didácticos.

Conocimiento de la competencia

5. ¿Qué opina en general del nivel de enseñanza de los Colegio de educación inicial privada en la ciudad de Chiclayo?

Vanessa: Depende de la dirección del colegio debido a que muchos de los colegios preparan y evalúan a su personal antes de contratarlo efectuando pruebas como la psicológica entre otras.

Mercy: ha mejorado debido a que antes se les enseñaba aspecto básico que no les ayudaba a su transición a primaria, siendo las privadas las que usan ms la tecnología, el apoyo psicológico hacia el menor y padres, esto va de la mano con los objetivos de la institución.

Nataly: Está mejorando debido a que ahora ingresan desde los 2 años porque ya los preparan más, además mi hijo cumple años en setiembre por lo que pienso inscribirlo para que no pierda un año de estudios, lo que quiero es que le enseñen Ingles, Artes Marciales y otros talleres para que se preparen para el nivel primario

6. Sus amigos o familiares le han recomendado algún colegio de educación inicial ¿Cuál? ¿Lo ha visitado?

Vanessa: A mí La Anunciata

Nataly: La Vianney, Creciendo con amor, Manuel Pardo

Carlos: Un nido cerca a mi casa al cual asisten alginas sobrinas

Willy: Innova School

Mercy: Manuel Pardo y Santo Toribio de Mogrovejo 
Miguel: La Anunciata y estoy evaluando posibilidades.

7. ¿Ha visitado algún centro de educación inicial? ¿Cuál? ¿Por qué?

Vanessa: Manuel Pardo, pero al comprarlo entre los hijos de unas amigas noto que el nido del Manuel Pardo todavía no sabe leer, por lo que yo lo descalifico, y prefiero el Creciendo con Amor a pesar de ser más pequeño.

Nataly: Yo no he visitado ero por las razones que estamos conversando empezare a visitar.

Mercy: No he visitado, debido a que tengo a mi hijo en un Centro de estimulación, además de los que he visto por fuera descalificaría a muchos porque lo que se ve por fuera no me ha gustado.

Miguel: No he visitado.

Willy: Innova me han dicho que es muy bueno.

Carlos: No he visitado pero me gustaría revisar sus currículos para poder saber que avances tendrá así como comparar para ver cuál es mejor para mi hija antes de inscribirlo.

8. Indicar, ¿Cuáles con los aspectos que le agradó de los colegios de educación inicial que han visitado? ¿Por qué?

Ponente omitió esta pregunta

9. Indicar, ¿Cuáles con los aspectos que no le agradó de los colegios de educación inicial que han visitado? ¿Por qué?

Ponente omitió esta pregunta

10. ¿Qué colegios de educación inicial considera los mejores en la ciudad de Chiclayo? Mercy: Santo Toribio de Mogrovejo Nataly: Santo Toribio de Mogrovejo, Anunciata, Reyna 
Miguel: Anunciata

Willy: Innova

11. ¿A qué colegio no enviaría a su hijo en la ciudad de Chiclayo?

Vanessa: Lo que buscaría es revisar el compromiso del docente con mi hijo antes de elegir una institución

Mercy: Me gustaría ver la cantidad de niños que ingresan por aula ya que hay niños hiperactivos que no pueden sr controlados por el docente, así como el número de auxiliares por aula, buscando que no sean más de 15 por aula.

Miguel: Me gustaría ver la Infraestructura y la curricula, es importante ver también cuantos niños hay por aula para que el profesor pueda tener mayor compromiso con el niño.

Carlos: El problema es el docente mal pagado, así como los que los cuidan del bullying

12. ¿Ha decidió el colegio al que planea matricular su hijo? Si es si ¿A qué colegio? ¿Por qué? Si es no ¿Tiene alguna alternativa?

Ponente omitió esta pregunta

Características del servicio

13. ¿Cuáles son factores en el servicio al alumno que Ud. considera importantes en la selección de un colegio de educación inicial?

14. ¿Cuáles son los factores del servicio al padre de familia que Ud. considera importantes en la selección de un colegio de educación inicial? Vanessa: Que tenga todas las áreas debido a que un local con buena infraestructura deben tener todos los servicios como psicología, talleres, Charlas para los papas. 
Mercy: Que aprenda sobre la naturaleza, quiero que se desarrolle con Ciencia, Tecnología y Ambiente (CTA) ya que lo niños son muy hiperactivos, así como el área de psicología ya que es una ayuda para el niño y padre.

Natalia: Psicología y las otras áreas.

15. ¿Cuáles son los factores determinantes que Ud. consideraría para elegir un colegio de educación inicial?

Ponente omitió esta pregunta

16. ¿Considera Ud. importante la certificación en educación inicial de los docentes en el colegio al que asiste su hijo?

Miguel: Muy importante porque le permitirá desarrollar al niño.

Vanessa: Es importante ya que demostrara que es una persona preparada y podrá desenvolverse en el salón de clases, además puede tener a una auxiliar que sea practicante del nivel.

Mercy: He podido ver que en algunos casos enseñan profesores de primaria y otros que no son titulados por lo que exigiría que los profesores sean titulados en Educación Inicial, porque desarrollan en los niños psicomotriz, recreación, estimulación, y los profesores de primaria su enseñanza es más directa y no tienen la misma paciencia que los del nivel inicial, y estoy de acuerdo con que las auxiliares puedan ser practicantes.

Nataly: Los más importantes es que sepan llegar al niño, ya que un título les da el conocimiento, pero es necesario que sepan llegar al niño siendo amables, la técnica para enseñar al niño, es necesario que tengan vocación para el niño.

17. ¿Considera Ud. que el centro de educación inicial al que asistirá su hijo debe estar integrado con un Colegio de educación primaria? ¿Por qué? 
Nataly: Si me gustaría debido a que su aprendizaje arranca desde inicial, por lo que tendría la confianza de seguir una misma curricula, por lo que si me gustaría que fuera de los tres niveles.

Carlos: Si me gustaría, pero tendría que ver el tema economico puesto que debemos ver si la pensión y matricula son las mismas por lo que al tener una alianza es muy beneficiosa.

Miguel: Es importante, ya que todos buscamos que existan alianzas para que el niño se vaya adaptando al ambiente y ese mismo colegio mantiene el nivel primario adaptándose con mayor rapidez. Vanessa: Si el nivel primario es adecuada si me gustaría, pero tendría que analizar la enseñanza para que pueda seguir en este nivel.

Mercy: Si es que tienen alianza con otros colegios estoy de acuerdo, pero no deseo que mi hijo estudie en un colegio con los tres niveles o en todo caso que mantenga una área separada, ya que los niños no deben estar con niños más desarrollados, porque en la actualidad hay colegios en los que se comparten los ambientes con niños mayores.

Miguel: Si me gustaría que haya alianzas pero no que sean integrados.

18. ¿Cómo planea llevar a su hijo al Colegio: personalmente o mediante un servicio de transporte escolar?

Mercy: La llevaría yo o un familiar puesto que mi hijo está muy pequeño para movilidad.

Miguel: Cuando podamos llevarlo lo llevaríamos, aunque existe la confianza de una movilidad de confianza. 
Carlos: Al principio es necesario para darle confianza al niño, de acuerdo a la disponibilidad del tiempo, y de acuerdo a disponibilidad de tiempo si es una movilidad de confianza lo dejaría que lo traslade.

Natalia: Yo lo llevaría y recogería.

19. ¿Qué distancia considera conveniente que deberá recorrer su hijo para llegar al Colegio?

Miguel: Un máximo de $5 \mathrm{~km}$

Willy: 10 minutos de mi domicilio

Natalia: Máximo de 10 minutos

Mercy: 10 minutos.

20. ¿Considera Ud. que un colegio de educación inicial debe ser bilingüe?

Natalia: Clases de ingles

Vanessa: Es importante que conozcan otros idiomas

Willy: Por competencia es bueno que aprendan el idioma desde niños para que se desarrollen mejor de grandes.

Carlos: No me es importante ya que lo pueden aprender a través de otros medios en casa.

Mercy: Si me gustaría porque está en una edad en la que es más fácil el aprendizaje de este idioma, teniendo una base para el futuro y desarrollo.

\section{Presentación del Colegio de Educación Inicial propuesto}

Estamos desarrollando un proyecto para formar un colegio de educación inicial ubicado en la ciudad de Chiclayo que cuente con las siguientes características:

a. Que busque incorporar la participación de los padres de familia en el desarrollo del niño en colaboración con los docentes del colegio. 
b. Que permita observar a su hijo en clase a través de una cámara de internet.

c. Que propicie la reunión con los docentes y con los padres de los compañeros de sus hijos.

d. Que envié información a su correo electrónico sobre algún cambio en el comportamiento del niño durante su permanencia en el colegio.

e. Que cuente con un modelo de aprendizaje basado en el desarrollo de competencias de los niños de tres a cinco años

f. Que los docentes estén certificados en educación inicial.

g. Que cuente con la infraestructura adecuada de un colegio de educación inicial (apoyo de un psicólogo, salas de juego que apoyen el aprendizaje, un biohuerto, biblioteca especial para niños).

h. Que enseñe el idioma ingles

Preguntas sobre el colegio presentado

21. ¿De estar operando este centro de educación inicial en el momento que usted requiere el servicio? ¿Ud. seleccionaría este colegio para sus hijo(s)?

Vanessa: Si me gustaría, porque tiene todos los ambientes necesarios para el desarrollo del niño.

Nataly: Tiene amplio espacio para que pueda correr, áreas verdes, juegos, me parece que estuviera en una casa.

Mercy: Parece ambientes agradables, acogedor, todo está al alcance de los niños, para que cuando deje de jugar pueda guardar los juegos, así como si es que hay niños con habilidades especiales para que el niño pueda desarrollar nuevas capacidades.

Carlos: Me gustaría que sea de un solo sexo, no deseo un colegio mixto para mi hija. 
Miguel: Si me gustaría pero tendría que ver lo relacionado a la calidad de los docentes.

Willy: Si me gustaría que hubiera niños con habilidades especiales para que puedan desarrollar empatía con estos niños.

22. ¿Cuál sería el pago mensual que estaría dispuesto a pagar por un centro de educación inicial de estas características?

Mercy: Por la infraestructura y talleres que brindan entre 300 y 400

Natalia: 350

Carlos: 450

Willy: 350

23. ¿Cuál considera debería ser la forma de pago deseada?

Miguel: Al contado y si es que hubiera una promoción para aquellos que paguen todo el año adelantado.

Vanessa: Al contado

Carlos: Que se pueda pagar con tarjeta de crédito

Nataly: Al contado y con tarjeta de crédito

Miguel: Al contado, y que en caso de no cancelar un mes que no sea un limitante para que no pueda dar exámenes.

24. ¿Cuál sería el factor determinante para matricular a su hijo en este colegio?

Miguel: La infraestructura y seguridad que brinda el colegio.

25. ¿Qué característica presentada no le gusta de este colegio?

Miguel: Debe estar en una zona sin acceso por avenida, así como deben posicionarse en zonas con poco ruido ambiental.

Nataly: Zonas sin mucho trafico

Carlos: Que sea mixto 
Mercy: No puedo dar un comentario negativo porque las imágenes son bonitas pero es necesario que conozcamos toda la infraestructura del colegio.

26. ¿Qué diferencia considera que existe entre este colegio y el colegio que Ud. había considerado para matricular a su hijo?

Natalia: Con el Colegio Manuel Pardo que visite no me gusto porque no hay una separación de ambientes con el nivel primario y secundaria.

Mercy: Hay colegios donde el baño se encuentra dentro del salón de clases por lo que me gustaría que hubiera estos.

Miguel: Con la Anunciata no me gusta los accesos a estos porque no están asfaltados.

27. ¿Qué diferencia a este colegio inicial de los que Ud. ya conoce?

Ponente omitió esta pregunta.

28. ¿Conoce algún colegio de características similares en la ciudad de Chiclayo o en otra ciudad? ¿Cuál?

Natalia: El Colegio Santo Toribio de Mogrovejo tiene similares características pero el ingreso a este colegio hay que verlos desde un año antes Carlos: Hay colegios como el Peruano Chino, Ceibos, María Reyna entre otros.

29. ¿Tienen alguna sugerencia o propuesta de mejora al proyecto presentado? Miguel: Que cuente con piscina

Carlos: Que los docentes tengan un ambiente agradable y que estos se encuentren bien pagados e instruidos.

Natalia: Los docentes deben ser jóvenes para que tengan un mayor uso de las tecnologías. 
Mercy: Que tengan un buena área de juegos, y que no sean muchos niños en aulas y patios a la vez.

Miguel: Talleres de música.

Willy: Que se dicten talleres para potenciar las habilidades de los niños como son la danza, música entre otras

30. ¿Qué medio de comunicación prefiere para recibir información sobre este colegio de educación inicial?

Willy: Correo Electrónico o a través de una plataforma amigable Nataly: A través de internet

Miguel: A través de una invitación para conocer las instalaciones Mercy: A través de un brochour

31. En su momento, ¿Le gustaría recibir algún tipo de promoción o publicidad de este colegio de educación inicial?

Ponente omitió esta pregunta. 


\section{Anexo 12}

\section{Desarrollo de focus group 2- padres sin experiencia}

Perfil del cliente:

\begin{tabular}{|l|l|}
\hline \multicolumn{2}{|c|}{ FICHA TECNICA DE ENTREVISTADOS } \\
\hline & Lizet \\
& Jorge Luis \\
& Milagros \\
& Karina \\
& Saúl Pisfil \\
Participantes & Oscar Ríos \\
\hline Nacionalidad & Peruana. \\
\hline Distrito de Residencia & Chiclayo. \\
\hline & Entrevista realizada el día de 15 octubre a las \\
& $10: 00$ am. \\
Observaciones & (Video disponible a solicitud). \\
\hline
\end{tabular}

Perfil del cliente: se plantearán preguntas sobre:

1. ¿Cuál es el número de hijos que tiene en edad escolar inicial?

Lizet: Tengo dos hijos Yoryo y Marcelo que tiene dos años.

Jorge Luis: tengo una niña de dos años y se llama María Gracia

Milagros: Tengo un hijo de dos años y se llama Matías.

Karina: tengo una niña de año y medio y se llama Ana Belén.

Saúl: Tengo un hijo de dos años y se llama Thiago.

Oscar: Tengo un hijo de año ocho meses y se llama Cristian.

2. ¿Está usted planeando matricular a su hijo(s) en un colegio de educación inicial?

\section{Lizet: Si.}

Jorge Luis: Si, mi hija ira al colegio pronto.

Milagros: Si, mi hijo empezara a estudiar en el nivel inicial. 
Karina: Si, estoy planeando el próximo año matricular a mi niña en un colegio inicial.

Saúl: Si, su madre ya está buscando vacante en algún colegio.

Oscar: Estoy planeando matricular en buen colegio a mi hijo.

3. ¿Cómo tomarán la decisión en la familia sobre al colegio inicial al que asistirá su hijo?

Lizet: con mi pareja y visitando varios colegios, en mi caso yo ya he ido a varios centros iniciales y optar la mejor opción. He visitado el Santa Ángela, Boniffati, me quedaría con el primero pues cuenta con la infraestructura adecuada, tiene el espacio necesario que ellos necesitan un lugar donde jugar, desplazarse.

Jorge Luis: siempre las decisiones las hacemos en pareja, lo mejor que queremos para nuestra hija.

Milagros: bueno en cuanto a la decisión es en pareja, y nos informamos de cada posibilidad que se podría presentar, porque buscamos actividades o talleres extracurriculares.

Karina: la decisión es en pareja llegando a un acuerdo que queremos pata nuestro hijo.

Saúl: llegamos un consenso como pareja para saber cuáles son las mejores opciones para nuestro hijo.

Oscar: estoy de acuerdo con todos, las decisiones se toman en pareja para poder ver lo mejor para nuestro hijo.

4. ¿Qué valora usted como aspectos fundamentales para seleccionar el colegio de educación inicial al que asistirá su hijo? 
Lizet: los niños a pesar de ser pequeños deben ser respetados, también el compañerismo, la amistad es lo primordial para que los niños sean felices. Jorge Luis: Que formen a nuestros hijos buenos ciudadanos mejores que nosotros. Karina: El respeto hacia las demás personas, que disminuya la agresividad en los niños. Porque el respeto es hacia todos a los mayores, a sus compañeros y a sus padres.

Oscar: Transparencia en hacer lo que dicen, con amor con cariño y respeto hacia los niños. Otro punto fundamental es la infraestructura y número de niños por aula.

Conocimiento de la competencia:

5. ¿Qué opina en general del nivel de enseñanza de los colegios de educación inicial privada en la ciudad de Chiclayo?

Lizet: A quienes los referencian de las distintas instituciones, porque por muy buenos colegios que sean en muchos casos se han presentado problemas, esas son malas referencias que nosotros como padres nos hacen anular o descartar esa opción.

Jorge Luis: Los niveles más se determinan por el nivel económico, por ejemplo, los colegios Ceibos, San Agustín siendo de nivel más alto se perfeccionan en contratar a profesores con nivel mejor diferenciándose de otros. Ahora en la actualidad están siendo más profesionales que le puedan brindar mejor educación a nuestros niños. Milagros:

Karina: La educación de nivel inicial en Chiclayo esta en desarrollo, es importante la capacitación constante de los docentes, teniendo cuidado con los niños pequeños ya que estos deben tener un trato especial por lo mismo que están aprendiendo descubriendo. 
Oscar: Baja en cierto punto, porque solamente algunos colegios cumplen con los parámetros que uno busca para sus hijos, hay que tener mucho cuidado a la hora de ir a matricular a sus hijos, pero creo que hay colegios en los que se puede confiar.

6. Sus amigos o familiares le han recomendado algún colegio de educación inicial ¿Cuál? ¿Lo ha visitado?

Lizet: Si me han recomendado algunos familiares, pero la decisión final la tomo por cuenta propia.

Jorge Luis: uno de los colegios que me han recomendado es el Reina y el Santa Ángela y encontrado ciertas diferencias.

Milagros: son pocos los colegios que están brindando un buen servicio, porque algunos profesores no están especializados en la materia, a mí me han recomendado el Ceibos porque lo separan a los niños en diferentes mesas y van variando a los niños en diferentes mesas por lo que su atención es más especializada. Karina: Me recomendaron el Ceibos y el Reina.

Saúl: Me han recomendado por amigos y familiares porque saben cómo trabaja el colegio su plan de estudios, recomendándome el Santa Ángela y el Reina.

Oscar: Me han recomendado Pasito a Paso que queda en Los Parques.

7. ¿Ha visitado algún centro de educación inicial? ¿Cuál? ¿Por qué?

Lizet: Santa Ángela y María Reina

Jorge Luis:

Milagros:

Karina: María Reina y Manuel Pardo.

Saúl: 
Oscar: El Pasito a Paso y Monserrat

8. Indicar, ¿Cuáles con los aspectos que le agradó de los colegios de educación inicial que han visitado? ¿Por qué?

Lizet: La infraestructura del Santa Ángela es abierta y amplia.

Jorge Luis: La infraestructura y la enseñanza.

Milagros:

Karina:

Saúl: La infraestructura y los amplios ambientes para los niños.

Oscar: El Pasito a Paso porque tiene un número reducido de alumnos por aula y tienen un cuidado especial para cada niño.

9. Indicar, ¿Cuáles con los aspectos que no le agradó de los colegios de educación inicial que han visitado? ¿Por qué?

Lizet: El María Reina tiene una infraestructura encajonada y el Boniffati aprovecha un parque de la zona para sus actividades lo cual es peligroso.

Jorge Luis: No he percibido aspectos negativos.

Milagros:

Karina: Lo que no me gusto de los colegios visitados es la cantidad de alumnos por aula, porque es necesario un ambiente con pocos niños para un mejor trato.

Saúl: El trato de los profesores hacia los alumnos.

Oscar: La enseñanza de algunos colegios.

10. ¿Qué colegios de educación inicial considera los mejores en la ciudad de Chiclayo? Lizet: Santa Ángela 
Jorge Luis: San Agustín

Milagros: Ceibos y Manuel Pardo

Karina: Ceibos

Saúl: Cebos y Santa María Reina

Oscar: Pasito a Paso

11. ¿A qué colegio no enviaría a su hijo en la ciudad de Chiclayo?

Morador omitió pregunta

12. ¿Ha decidido sobre el colegio al que planea matricular su hijo? Si es si ¿A qué colegio? ¿Por qué? Si es no ¿Tiene alguna alternativa?

Lizet: Si, Santa Ángela por su infraestructura.

Jorge Luis: Si, Santa María Reina.

Milagros:

Karina: $\mathrm{Si}$, el colegio Ceibos tiene buena infraestructura.

Saúl: Si, Pasito a Paso

Oscar: Si, Pasito a Paso donde los alumnos no por aula son limitados.

Características del servicio

13. ¿Cuáles son factores en el servicio al alumno que usted considera importantes en la selección de un colegio de educación inicial?

Lizet: La infraestructura

Jorge Luis: Los valores, infraestructura y cercanía del colegio.

Milagros: La infraestructura y calidad de enseñanza.

Karina: Número de alumnos por aula. 
Saúl: La infraestructura

Oscar: Los números de alumnos por aula y la calidad de enseñanza.

14. ¿Cuáles son los factores del servicio al padre de familia que usted considera importantes en la selección de un colegio de educación inicial?

Lizet: Escuela de padres.

Jorge Luis: Dar constantes charlas a los padres de familia.

Milagros: La escuela de padres en primordial debido que aprendemos cosas nuevas como padres de familia.

Karina: Las reuniones y participación de los padres de familia para toda actividad. Saúl: Escuela de Padres.

Oscar: coincido con la mayoría que la escuela de padres es muy importante para poder aprender y desarrollar mejor la vida de nuestro niño.

15. ¿Cuáles son los factores determinantes que usted consideraría para elegir un colegio de educación inicial?

Lizet: La infraestructura

Jorge Luis: Los valores, infraestructura y cercanía del colegio.

Milagros: La infraestructura y calidad de enseñanza.

Karina: Número de alumnos por aula.

Saúl: La infraestructura

Oscar: Los números de alumnos por aula y la calidad de enseñanza.

16. ¿Considera usted importante la certificación en educación inicial de los docentes en el colegio al que asiste su hijo? 
Lizet: Las primeras experiencias serán con esos profesores por lo que deben tener certificación.

Jorge Luis: Con el simple grado de profesor no es suficiente.

Milagros: Las personas deben estar fundamentalmente especializadas.

Karina:

Saúl:

Oscar: Creo que todos deben tener la especialidad para poder enseñar a los niños.

17. ¿Considera usted que el centro de educación inicial al que asistirá su hijo debe estar integrado con un colegio de educación primaria? ¿Por qué?

Lizet: Tomaría la decisión cuando tenga que tomarla en el momento y de acuerdo a las circunstancias.

Jorge Luis: Seria buena opción pero las circunstancias podrían ser diferentes pero se determina en el tiempo, no es determinante ni obligatorio.

Milagros: Si hay colegios con esas facilidades pero no es algo determinante para poder elegir el colegio inicial.

Karina: Hay muchos colegios que funcionan como inicial y cuando entran a primaria no siempre es lo mismo, y es una decisión que se tomaría en adelante. Saúl:

Oscar:

18. ¿Cómo planea llevar a su hijo al colegio: personalmente ó mediante un servicio de transporte escolar?

Lizet: 
Jorge Luis: Es cuestión de calidad de vida y de los tiempos que uno maneja, creo que la una movilidad escolar es una buena opción o la levaría un familiar particularmente.

Milagros:

Karina: Creo que a todos los padres les gustaría llevar a sus hijos al colegio, pero en mi caso por tema de tiempo contrataría una movilidad.

Saúl: Estoy de acuerdo que a esa edad no es necesario la movilidad, podría levarlo yo, mi esposa o algún familiar.

Oscar: Es coordinar tiempo porque a esa edad no me gustaría la movilidad para los niños.

19. ¿Qué distancia considera conveniente que deberá recorrer su hijo para llegar al colegio?

Morador omitió pregunta.

20. ¿Considera Usted que un colegio de educación inicial debe ser bilingüe?

Lizet: Creo que el inglés es una buena opción, mientras más pequeños comiencen de acuerdo a su edad es mejor.

Jorge Luis: Hay que tener en cuenta que estamos en un mundo globalizado y competente y desde niños estén aprendiente el inglés es perfecto.

Milagros: Los niños de inicial se aprenden el inglés muy bien. Y hay muchas oportunidades que se pueden aprovechar porque es un plus.

Karina: Me parece importante que les estén impartiendo el inglés desde edad temprana manteniendo la concordancia con su edad.

Saúl: 
Oscar: Creo que hoy en día el inglés es importante y debe ser parte de nosotros, y que les enseñen a los niños desde edad muy tempana es importante.

\section{Presentación del Colegio de Educación Inicial propuesto}

Estamos desarrollando un proyecto para formar un colegio de educación inicial ubicado en la ciudad de Chiclayo que cuente con las siguientes características:

i) Que busque incorporar la participación de los padres de familia en el desarrollo del niño en colaboración con los docentes del colegio.

j) Que permita observar a su hijo en clase a través de una cámara de internet.

k) Que propicie la reunión con los docentes y con los padres de los compañeros de sus hijos.

1) Que envié información a su correo electrónico sobre algún cambio en el comportamiento del niño durante su permanencia en el colegio.

m) Que cuente con un modelo de aprendizaje basado en el desarrollo de competencias de los niños de tres a cinco años

n) Que los docentes estén certificado en educación inicial

o) Que cuente con la infraestructura adecuada de un colegio de educación inicial (apoyo de un psicólogo, salas de juego que apoyen el aprendizaje, un biohuerto, biblioteca especial para niños)

p) Que enseñe el idioma ingles

Preguntas sobre el colegio presentado

21. De estar operando este centro de educación inicial en el momento que usted requiere el servicio ¿Usted seleccionaría este colegio para sus hijo(s)? 
Lizet: Es una buena propuesta mejor aún si es un colegio inclusivo que nuestros niños compartan experiencias con niños especiales porque son seres humanos. Jorge Luis: El video es bonito porque te muestra toda la información, pero me gustaría saber más la infraestructura, sus áreas verdes.

Milagros: Se nota que existe el concepto de igualdad y aparte se observa la variedad en talleres lo cual es interesante.

Karina: Lo que más me ha gustado es donde los niños pueden compartir entre ellos mismos se les ve en diversos talleres, donde le muestran a ellos los valores y la parte pedagógica da mucho alcance para ellos, si me gustaría ver más la infraestructura y conocer los ambientes y los diversos servicios como tópico o movilidad propia.

Saúl: No se ha podido apreciar mucho la infraestructura del colegio todos los ambientes donde pueden estar los niños, lo que si me gusto es la inclusión que desde pequeños sepan nuestros hijos que hay niños con habilidades gerenciales y no exista temor hacia ellos.

Oscar: El video es muy interesante, lo que falto es cuál es la metodología con la se les van a enseñar a los niños, en qué forma se le va enseñar y pueden aprender, si es algo vivencial o son clases didácticas con proyectores son cositas en las cuales hay que profundizar. Hay que tener un espacio amplio de deportes para nuestros hijos.

22. ¿Cuál sería el pago mensual que estaría dispuesto a efectuar por un centro de educación inicial de estas características?

Lizet: Colegios con precios promedio S/. 350 a S/. 400

Jorge Luis: Un precio de S/. 400

Milagros: Un pago de S/. 350 a S/. 400 
Karina: Entre S/. 300 a S/. 400

Saúl: S/. 350

Oscar: Pagos de S/. 350 a S/. 400

23. ¿Cuál considera debería ser la forma de pago deseada?

Lizet: A través del banco con un solo pago con la finalidad del descuento.

Jorge Luis: Pago por cuenta y anual si hay un descuento por el pago tota mejor.

Milagros: Si uno puede realizar el pago desde la comunidad de su casa es mejor se evitas muchas cosas porque el problema de muchos es el tiempo.

Karina: Un servicio virtual donde se pueda pagar.

Saúl:

Oscar: Hoy en día es mas cómodo manejarlo por cuentas bancaria.

24. ¿Cuál sería el factor determinante para matricular a su hijo en este colegio?

Lizet: Para mí la infraestructura y la metodología para trabajar con nuestros niños. Jorge Luis: Infraestructura y metodología.

Milagros: Me hubiera gustado mucho que se detalle el plan de trabajo del colegio para tener una mejor idea.

Karina:

Saúl:

Oscar: La comodidad de los ambientes que existen, la infraestructura.

25. ¿Qué característica presentada no le gusta de este colegio?

Lizet:

Jorge Luis: No existen los procedimientos de cómo se va aplicar la enseñanza. 
Milagros: No sabemos la clase de personal que tiene.

Karina:

Saúl:

Oscar: No se observa la enseñanza al niño, a través del video.

26. ¿Qué diferencia considera que existe entre este colegio y el colegio que usted había considerado para matricular a su hijo? ¿Qué diferencia a este colegio inicial de los que usted ya conoce?

Lizet: Yo que yo busco es un espacio abierto donde mi niño pueda jugar.

Jorge Luis: Existen muchas diferencias como la infraestructura y demás cosas.

Milagros: Es un colegio con una buena propuesta la que ofrecen.

Karina:

Saúl:

Oscar: Muchos colegios carecen de infraestructura.

27. ¿Conoce algún colegio de características similares en la ciudad de Chiclayo o en otra ciudad? ¿Cuál?

Morador omitió pregunta.

28. ¿Tienen alguna sugerencia o propuesta de mejora al proyecto presentado?

Lizet: Detallar la metodología.

Jorge Luis: Mejorar aún más la infraestructura.

Milagros: Proponer un personal idóneo para la enseñanza.

Karina:

Saúl: No se habla de la metodología con la que trabajará el colegio

Oscar: 
29. ¿Qué medio de comunicación prefiere para recibir información sobre este colegio de educación inicial?

Lizet: Virtual

Jorge Luis: Virtual, pero las reuniones tienen que ser presenciales.

Milagros: Virtual

Karina: Virtual

Saúl: Virtual

Oscar: Virtual, cabe resaltar que la información de desempeño también tiene que ser presencial porque se conversa con el docente.

30. En su momento, ¿Le gustaría recibir algún tipo de promoción o publicidad de este colegio de educación inicial?

Lizet: Claro, necesitamos más opciones.

Jorge Luis: Si, porque estamos hablando de calidad.

Milagros: Si.

Karina: Claro

Saúl: Si.

Oscar: Si porque me gustaría visitarlo. 


\section{Anexo 13}

\section{Cuestionario}

\section{Presentación}

Estimados padres de familia, somos un grupo de alumnos del Programa de Maestría de la Universidad San Ignacio de Loyola. Como parte del proceso de graduación estamos elaborando un proyecto de investigación que tiene como objetivo analizar los elementos a tener en cuenta para crear un colegio de educación inicial para niños entre tres a cinco años. En ese sentido, nos gustaría conocer su opinión sobre el nivel de servicio que Uds. buscan en un colegio de educación inicial. La información que nos proporcionen en esta encuesta será usada de manera confidencial y anónima para la presentación del proyecto

1. ¿Tiene Ud. un hijo(s) que iniciará estudios o estará estudiando en un colegio de educación inicial privado el próximo año?

Si (continuar)

No (finalizar la encuesta)

2. ¿Ha visitado algún colegio inicial para matricular a su hijo?

Si, ¿Cuáles?

No.

3. ¿Qué colegio ha seleccionada o le gusta más para matricular a su hijo? ¿Cuál?

4. ¿Qué característica valora Ud. del colegio inicial que ha seleccionado o del colegio que más le ha gustado? Califique la respuesta en una escala de 1 a 10, donde 1 es lo de menos valor y 10 es la de más valor.

\begin{tabular}{|l|l|}
\hline & Calificación \\
\hline a. Horario de clases & \\
\hline
\end{tabular}




\begin{tabular}{|l|l|}
\hline b. Servicio al padre de familia & \\
\hline c. Calidad de la enseñanza & \\
\hline d. Infraestructura & \\
\hline e. Número de alumnos por salón & \\
\hline f. Vínculo con colegio de educación primaria & \\
\hline g. Monto de pensión mensual & \\
\hline h. Otra ¿Cuál? & \\
\hline
\end{tabular}

5. ¿De los siguientes colegios iniciales cuál considera Ud. el mejor en la ciudad de Chiclayo?

a. Boniffati.

b. Caritas Felices.

c. Kinder Smile.

d. Ceibos.

e. San Agustín.

f. Maria Reina.

g. Otro ¿Cuál?

6. ¿Cuál es la característica que más valora del colegio que considera como el mejor? Califique la respuesta en una escala de 1 a 10, donde 1 es lo de menos valor y 10 es la de más valor.

\begin{tabular}{|l|l|}
\hline & \\
\hline a. Horario de clases & \\
\hline b. Servicio al padre de familia & \\
\hline c. Calidad de la enseñanza & \\
\hline d. Infraestructura & \\
\hline e. Número de alumnos por salón & \\
\hline f. Vínculo con colegio de educación primaria & \\
\hline g. Monto de pensión mensual & \\
\hline h. Otra ¿Cuál? & \\
\hline
\end{tabular}

7. ¿Por qué medio se enteró del colegio que ha seleccionado para su hijo?

a. Recomendación de amigo o familiar

b. Búsqueda en Internet 
c. Periódico, ¿Cuál?

d. Revista, ¿Cuál?

e. Brochure del colegio

f. Otro, ¿Cuál?

8. ¿Cuál es la mensualidad que estaría pagando en el colegio que ha seleccionado para matricular a su hijo o cuánto está pagando actualmente?

¿Cuánto?

9. ¿Cuál es el monto de matrícula y derecho de admisión que estaría pagando en el colegio que ha seleccionado o cuánto está pagando actualmente?

¿Cuánto?

10. En su hogar, ¿Quién decide en que colegio se matriculará su hijo?

a. Padre.

b. Madre.

c. Ambos.

d. Los abuelos.

e. Otro

\section{Nuevo Colegio de Educación Inicial}

Si existiera en la ciudad de Chiclayo un colegio de educación inicial, que contará con un ambiente e infraestructura diseñada para la educación de los niños entre tres a cinco años, que imparta clases de inglés, que haga uso de la tecnología para la enseñanza y que brinde el servicio de educación con profesores certificados y modelo pedagógico por competencias. 
11. ¿Escogería Ud. este nuevo colegio inicial para su hijo?
a. Definitivamente sí.
b. Probablemente sí.
c. Indiferente.
d. Probablemente no.
e. Definitivamente no.

12. ¿Dónde considera Ud. que debería estar ubicado este nuevo colegio en la Ciudad de Chiclayo?
a. Santa Victoria.
b. Los Parques.
c. Carretera a Pimentel.
d. Patazca.
e. Otro ¿Cuál?

13. ¿Qué medio considera se debería usar para entregar el reporte sobre el comportamiento y desempeño de su hijo en este nuevo colegio?
a. Personalmente en el colegio.
b. En su correo electrónico.
c. En una carta a su domicilio.
d. En una carta a recoger en el colegio.
e. Por teléfono.
f. No le gustaría recibirlo.

14. ¿Considera que el nuevo colegio debería tener?

\begin{tabular}{|l|l|l|l|}
\hline & Si & No & Indiferente \\
\hline $\begin{array}{l}\text { Conexión para video vía Internet a fin de } \\
\text { observar a su hijo realizando algunas } \\
\text { actividades en el salón de clase }\end{array}$ & & & \\
\hline
\end{tabular}




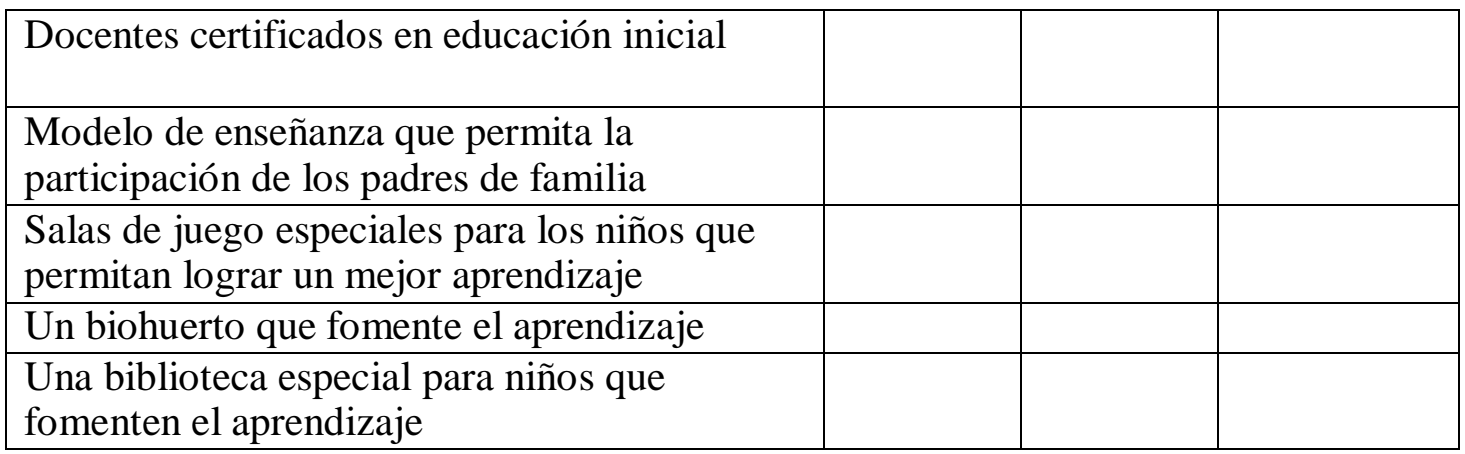

15. ¿Cómo considera que debe ser el nivel de las clases de inglés a enseñar en este nuevo colegio?
a. Integral, todas las clases en inglés
b. Parcial, enseñar inglés como un curso
c. No, solamente en español
d. Me es indiferente

16. Si tiene Ud. un hijo en otro colegio inicial, ¿estaría dispuesto a trasladar a su hijo a este nuevo colegio?
a. Definitivamente sí.
b. Probablemente sí.
c. Indiferente.
d. Probablemente no.
e. Definitivamente no.

17. ¿Cuánto estaría dispuesto a pagar de mensualidad en este nuevo colegio? ¿Cuánto?

18. Cuál es el monto de matrícula y derecho de admisión que estaría dispuesta a pagar en este nuevo colegio?

¿Cuánto? 
19. ¿Qué medio de pago le gustaría que se le ofrezca para el pago de la mensualidad por el servicio que le ofrece este nuevo colegio?
a. En el mismo colegio
b. Deposito en el Banco
c. Por internet con tarjeta de crédito
d. Otro

20. ¿Estaría Ud. dispuesto a recomendar este nuevo colegio a un familiar o un amigo que se encuentre buscando un colegio inicial para su(s) hijo(s)?

$\mathrm{Si}$

No

21. ¿Por qué medios le gustaría recibir información sobre este nuevo colegio?
a. Correo electrónico.
b. Facebook.
c. Twitter.
d. Entrega de brochure del colegio en el trabajo.
e. Entrega de brochure del colegio en casa.
f. Otro, ¿Cuál?

22. ¿Cuál le parece un nombre apropiado para este colegio?
a. Happy Land.
b. Happy Kids.
c. Niños Felices.
d. La casa del Niño. 
23. ¿Tiene Ud. alguna sugerencia sobre el servicio educativo en este nuevo colegio?

\section{DATOS DE CONTROL}

a. Indique en qué distrito y urbanización de la ciudad de Chiclayo reside Ud.

b. Indique su rango de edad:
a. Menos de 26 años
b. Entre 26 y 30 años
c. Entre 31 y 35 años
d. Entre 36 y 45 años
e. Más de 45 años

c. Indique su nivel de ingreso familiar:
a. Menos de 3,000 soles,
b. Entre 3001 y 5000 soles
c. Entre 5001 y 7500 soles
d. Entre 7501 y 10000 soles
e. Más de 10,000 soles

d. Indicar su nivel de educación
a. Colegio secundario incompleto
b. Colegio secundario completo
c. Universitario inconcluso
d. Universitario completo
e. Posgrado

Gracias 


\section{ANEXO 14}

\section{Análisis FODA}

\begin{tabular}{|c|c|c|}
\hline & Fortalezas & Debilidades \\
\hline & Conocimiento del mercado & $\begin{array}{l}\text { No cuentan con experiencia en } \\
\text { el negocio }\end{array}$ \\
\hline & Contactos en la UGEL & $\begin{array}{l}\text { Los recursos financieros son } \\
\text { limitados }\end{array}$ \\
\hline \multicolumn{3}{|l|}{ Oportunidades } \\
\hline $\begin{array}{l}\text { Crecimiento de la economía } \\
\text { del país }\end{array}$ & $\begin{array}{l}\text { Desarrollar el nuevo colegio } \\
\text { para educación básica para } \\
\text { padres de familia que trabajan: } \\
\text { desarrollo de mercado }\end{array}$ & $\begin{array}{l}\text { La inversión se puede llevar a } \\
\text { cabo optimizando los recursos: } \\
\text { Liderazgo en costos }\end{array}$ \\
\hline \multicolumn{3}{|l|}{$\begin{array}{l}\text { Clima favorable para la } \\
\text { inversión }\end{array}$} \\
\hline $\begin{array}{l}\text { Nuevas tecnologías para la } \\
\text { educación }\end{array}$ & $\begin{array}{l}\text { Utilizar nuevas tecnologías en } \\
\text { el colegio y aprobarlas en la } \\
\text { UGEL: desarrollo de producto }\end{array}$ & $\begin{array}{l}\text { Uso de la tecnología para } \\
\text { reducir costos: Liderazgo en } \\
\text { costos }\end{array}$ \\
\hline $\begin{array}{l}\text { Nuevo gobierno impulsa } \\
\text { programas para mejorar la } \\
\text { educación }\end{array}$ & $\begin{array}{l}\text { Formar colegio con nuevo } \\
\text { modelo que permita ofrecer } \\
\text { una educación distinta: } \\
\text { Diferenciación }\end{array}$ & \\
\hline $\begin{array}{l}\text { Costo de los equipos y } \\
\text { mobiliario tendrán un ligera } \\
\text { variación en el precio }\end{array}$ & & $\begin{array}{l}\text { Los nuevos equipos se deben } \\
\text { comprar de manera gradual }\end{array}$ \\
\hline \multicolumn{3}{|l|}{ Amenazas } \\
\hline Inseguridad ciudadana & $\begin{array}{l}\text { Colegio debe tener un sistema } \\
\text { de seguridad para los niños: } \\
\text { desarrollo de producto }\end{array}$ & \\
\hline $\begin{array}{l}\text { Incertidumbre sobre la nueva } \\
\text { política en educación }\end{array}$ & & $\begin{array}{l}\text { Colegio debe reducir sus } \\
\text { gastos hasta lograr su punto de } \\
\text { equilibrio: Liderazgo Costos }\end{array}$ \\
\hline \multicolumn{3}{|l|}{$\begin{array}{l}\text { Falta definir e implementar } \\
\text { nuevas políticas económicas }\end{array}$} \\
\hline $\begin{array}{l}\text { Integración vertical hacia atrás } \\
\text { de las instituciones educativas }\end{array}$ & $\begin{array}{l}\text { Colegio debe tener elementos } \\
\text { diferenciadores claros que } \\
\text { sirvan de barrera de entrada: } \\
\text { Diferenciación }\end{array}$ & \\
\hline $\begin{array}{l}\text { Colegios de otras regiones se } \\
\text { instalen en Chiclayo }\end{array}$ & & $\begin{array}{l}\text { Colegio debe iniciar su } \\
\text { implementación de manera } \\
\text { gradual }\end{array}$ \\
\hline
\end{tabular}


ANEXO 15

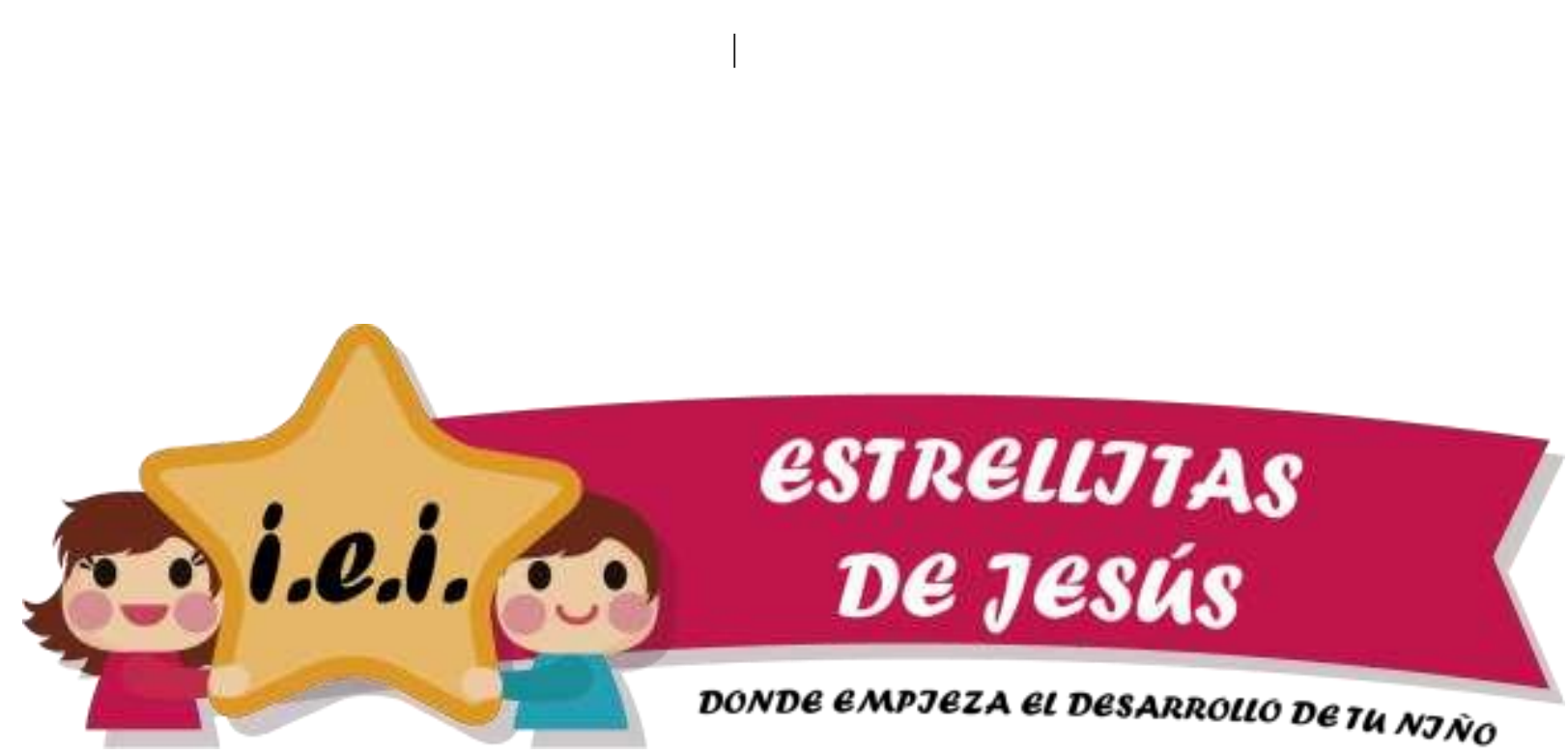

REGLAMENTO INTERNO

2018 


\section{PRESENTACIÓN}

El presente Reglamento Interno, es un documento de gestión que establece las normas académicas y administrativas que rigen la estructura, organización y relaciones de la Institución Educativa Inicial "Estrellitas de Jesús”, para el logro de sus fines y objetivos. A lo prescrito en este documento están sujetos todos los miembros de la Comunidad Educativa sin excepción alguna.

El conocimiento de los alcances del reglamento, permitirá a los miembros de la comunidad educativa conocer y cumplir a cabalidad sus funciones respetando las normas establecidas por la institución de acuerdo a las directivas por MINEDU tomando decisiones dentro de un marco de respeto a los derechos de los servidores. Este documento, será obligatoriamente difundido y conocido, para lograr los fines Institucionales anteponiendo a todo el trato humano que caracteriza a nuestra institución en salvaguarda de la Dignidad de la Persona Humana.

La Dirección General. 


\section{CAPITULO I}

\section{DEL REGLAMENTO Y LAS DISPOSICIONES GENERALES}

\section{GENERALIDADES}

Art. 01. El presente Reglamento Interno (RI) es un documento de gestión que establece las normas académicas y administrativas que rigen la estructura, organización y relaciones de la Institución Educativa Inicial "Estrellitas de Jesús ”, para el logro de sus fines y objetivos.

Art. 02. Es un instrumento legal al cual está sometida, toda la comunidad educativa (directivos, docentes, administrativos, personal de apoyo, padres de familia (APAFA) y estudiantes) en sus artículos y normas, siendo de observancia obligatoria.

Art. 03. La IEI "Estrellitas de Jesús" es una Institución Educativa Inicial que se encuentra ubicada en la provincia de Chiclayo, y brinda su servicio educativo formativo a la población escolar en el nivel de educación Inicial según los lineamientos y objetivos de la Ley General de Educación y su Proyecto Educativo.

\section{FINALIDAD}

Art. 04. El presente Reglamento tiene como finalidad normar: Los asuntos técnico-pedagógicos de la Institución.

- La estructura organizacional y funciones de los diferentes órganos y miembros que la integran.

- La organización del trabajo administrativo. 
- Las relaciones entre todos los estamentos internos y externos y demás disposiciones inherentes al proceso de enseñanza aprendizaje.

\section{BASE LEGAL}

Art. 05. El presente Reglamento Interno tiene sus bases legales en:

1. Constitución Política del Perú.

2. Ley $\mathrm{N}^{\circ} 28044$, Ley General de Educación

3. Ley $N^{\circ} 29944$, Ley de Reforma Magisterial

4. Ley $\mathrm{N}^{\circ}$ 28628, Ley que regula la participación de las Asociaciones de Padres de Familia en las Instituciones Educativas Públicas y privadas.

5. Ley $\mathrm{N}^{\circ} 28988$, Ley que declara a la Educación Básica Regular como servicio público esencial.

6. Ley $\mathrm{N}^{\circ} 26549$ de los Centros Educativos Privados

7. Ley $\mathrm{N}^{\circ} 29719$, Ley que promueve la convivencia sin violencia en las instituciones educativas.

8. Ley $N^{\circ} 29973$, Ley General de la Persona con Discapacidad

9. Ley $\mathrm{N}^{\circ}$ 28740, Ley del Sistema Nacional de Evaluación, Acreditación y Certificación de la Calidad Educativa.

10. Decreto Ley $\mathrm{N}^{\circ}$ 25762, Ley Orgánica del Ministerio de Educación, modificada por la Ley $\mathrm{N}^{\circ} 26510$

11. Resolución Ministerial $\mathrm{N}^{\circ}$ 0234-2005-ED que aprueba la Directiva $\mathrm{N}^{\circ}$ 004VMGP2005, sobre evaluación de los aprendizajes de los estudiantes de la Educación Básica Regular. 
12. Decreto Supremo $\mathrm{N}^{\circ}$ 017-2007-ED, que aprueba el Reglamento de la Ley $\mathrm{N}^{\circ}$ 28988, Ley que declara la Educación Básica Regular como Servicio Público Esencial.

13. Resolución Ministerial $\mathrm{N}^{\circ}$ 0201-2009-ED, que aprueba la Directiva "Procedimientos para la prevención y sanción del hostigamiento sexual en el sector Educación.

14. Decreto Supremo $N^{\circ}$ 006-2012-ED, que aprueba el Reglamento de Organización y Funciones (ROF) y el Cuadro para Asignación de Personal (CAP) del Ministerio de Educación.

15. D.S. $N^{\circ}$ 001-96-ED. Reglamento de los Centros Educativos Privados 17.

Decreto Supremo $\mathrm{N}^{\circ}$ 011-2012-ED, que aprueba el Reglamento de la Ley $\mathrm{N}^{\circ}$ 28044 Ley General de Educación.

18. Reglamento para Educación Primaria D.S. 03-83-ED

19. Ley de Protección de la Inversión privada en el sector Educación D.L. N ${ }^{\circ} 882$

20. Decreto Supremo $\mathrm{N}^{\circ}$ 004-2013-ED, que aprueba el Reglamento de la Ley $\mathrm{N}^{\circ}$ 29944, Ley de Reforma Magisterial.

21. Resolución Ministerial $\mathrm{N}^{\circ}$ 0369-2012-ED, que aprueba prioridades de la Política Educativa Nacional 2012 - 2016

22. Resolución Ministerial $\mathrm{N}^{\circ}$ 0518-2012-ED, que aprueba el Plan Estratégico Sectorial Multianual de Educación (PESEM) 2012-2016

23. Resolución Ministerial Nº519-2012-ED, que aprueba la Directiva Nº 0192012 MINEDU/VMGI-OET, Lineamientos para la prevención y protección de las y los estudiantes contra la violencia ejercida por personal de las instituciones educativas. 


\section{ALCANCES}

Art. 06. El presente Reglamento normativo de orden interno tiene los siguientes alcances:

- Contextualizar la realidad educativa del momento actual en concordancia con los actos del proceso de enseñanza-aprendizaje.

- Involucrar a todo el personal que labora en la Institución Educativa: Director, Docentes, Administrativos, Personal de Apoyo, padres de Familia, de la jurisdicción correspondiente

\section{MODIFICACIÓN Y APROBACIÓN}

Art. 07. El presente Reglamento interno está sujeto a revisión y actualización en razón de su funcionalidad, desarrollo institucional y principios que enmarcan el accionar del centro educativo.

Art. 08. El Reglamento Interno debe ser aprobado por Resolución Directoral emitida por el Director General.

\section{CAPÍtULO II}

\section{DE LA INSTITUCIÓN PROMOTORA - PROPIETARIO}

Art. 09. El promotor y propietario de la Institución Educativa es con personería jurídica, que en la sociedad promueve la acción educativo-formativa de la niñez y la juventud.

9.1. el Director General de la Institución quien se encarga de la organización y funcionamiento de la Institución de acuerdo a la filosofía de la educación 
personalizada, los principios y valores establecidos en la Constitución Política del Perú, las leyes y normas vigentes de la Educación Peruana y del presente Reglamento.

9.2. El Promotor en coordinación con el Director aprueban la implementación, mejoramiento y ampliación de la infraestructura y equipamiento educativo.

9.3. Vela por el cumplimiento de los aspectos: académicos, formativo pastorales, disciplinarios y administrativos establecidos en la Institución de acuerdo a la normativa vigente y el presente reglamento.

9.4 El Director de la IEI "Estrellitas de Jesús" ejerce sus funciones bajo contrato establecido.

\section{FINES Y OBJETIVOS}

Art. 10. La Institución "Estrellitas de Jesús”, es una Institución Educativa Inicial, cuya finalidad es impulsar la formación humanista integral de los estudiantes a través de un enfoque curricular centrado en la persona, inclusivo por competencias, para alcanzar los objetivos de la escolaridad en el Perú, de acuerdo a las directivas del Ministerio de Educación, en el presente Reglamento. 10.1. Ser líderes en la formación humanista integral de calidad que equilibre los requerimientos académicos con la formación personal y cristiana, respete y oriente las diferencias individuales, incorpore tecnologías y medios actualizados y sea conducida por profesionales de la educación en permanente formación y actualización.

10.2. Potenciar el liderazgo participativo dentro de una comunidad educativa en pleno aprendizaje, que viva la cultura evaluativa como parte de su identidad, donde todas las personas sean corresponsables de las metas educativas, las 
familias encuentren acogida y formación, que haga posible la práctica de nuestros valores institucionales en bien de la solidaridad y la responsabilidad social.

10.3. Educar para formar personas íntegras que sean capaces de discernir que toda cultura que pretenda ser tal ha de tener sus bases en la búsqueda de la verdad a través de:

- Conocimientos y meta-conocimientos sistemáticos, adecuadamente estructurados y dispuestos en orden al carácter trascendente del ser humano.

- Aptitudes y destrezas que le permitan realizar las operaciones básicas del pensar y del obrar, tanto en orden a su vida personal como a la profesional.

- Virtudes y valores mediante los cuales sean capaces de actuar y tomar decisiones libres y responsables, con respeto a sí mismo, a los demás y a su entorno.

10.4. Ayudar a los Padres de Familia a formarse en la verdadera paternidad responsable con la conciencia clara que ellos constituyen uno de los bienes más preciados de la humanidad, un don insustituible para sus hijos.

\section{FUNCIONES GENERALES}

Art. 11. La IEI "Estrellitas de Jesús" tiene como actividad principal la prestación de los servicios educativos del nivel Inicial de menores en el turno diurno. Brinda educación personalizada y sistemática conforme a sus propios planes y programas curriculares, sin apartarse de los lineamientos del Ministerio de Educación. En consecuencia es su responsabilidad: 
11.1. Organizar la labor educativa de acuerdo a las características y exigencias propias del nivel que se ofrece en la Institución.

11.2. Brindar un servicio de administración educativa, documentación de matrícula, traslados, implementación, certificaciones y otros.

11.3. Planificar y desarrollar actividades culturales, sociales, religiosas, artísticas y deportivas que contribuyan a la formación integral del educando y de los demás miembros de Comunidad Educativa.

11.4. Promover y asesorar organizaciones a favor de la educación y formación integral de los estudiantes.

\section{CAPÍTULO III}

\section{DE LA ORGANIZACIÓN DEL TRABAJO EDUCATIVO}

Art. 12. Del Plan Anual de Trabajo (PAT):

12.1. El Plan Anual de Trabajo (PAT) es el documento que concreta los objetivos anuales del Plan Estratégico Institucional y derivado del Proyecto Educativo Institucional (PEI).

12.2. El Plan Anual de Trabajo (PAT) es elaborado de acuerdo a los lineamientos de las leyes educativas vigentes y al Proyecto Educativo Institucional (PEI), ejecutado y evaluado por el Personal Directivo, Docente, Administrativo y es aprobado mediante Resolución Directoral antes del inicio del año lectivo.

Art. 13. De la Matrícula:

13:1 La matrícula tiene lugar antes del inicio de cada año lectivo en los meses de enero y febrero, según rol establecido. Su incumplimiento exime a la Institución Educativa de la obligación de recibir al alumno. 
13.2. La Institución Educativa brinda a los padres o apoderados, antes de la matrícula, la información señalada en el Art. $14^{\circ}$ de la Ley de Centros Educativos Privados.

13.3. La matrícula se realiza según el plan y cronograma establecidos por la Dirección General de la Institución, comunicado a los Padres de Familia al finalizar el año escolar anterior a través de la página web, dípticos, cartas o comunicados por escrito.

13.4. La matrícula de los alumnos ingresantes en los diferentes niveles educativos es única y se realiza a partir de la primera semana de enero. 13.5. No se aceptan alumnos repitentes para ningún grado de estudios. Si algún alumno de la Institución Educativa desaprobara el año, no podrá seguir en la Institución.

13.6. Los niños que cumplan 6 años al 31 de marzo son promovidos de manera automática a la Educación Primaria.

13.7. La ficha de matrícula emitida por el SIAGIE, constituye un documento de referencia del estudiante, indispensable para sus datos y evaluación académica.

13.8. Previo informe del órgano respectivo, la nómina de matrícula es aprobada por Decreto Directoral, dentro de los primeros 45 días posteriores al inicio del año escolar. Las nóminas son firmadas por el Director General.

13.9. El traslado de matrícula procede previa presentación de la constancia de vacante del Institución de destino y se puede dar hasta antes de iniciar el tercer trimestre. 
13.10. El Personal Directivo, Docente y Administrativo de la Institución realiza el planeamiento y organización de las actividades para el año lectivo durante el mes de febrero.

13.11. La Dirección de la Institución está obligada a entregar a los estudiantes que soliciten traslados la ficha de matrícula, la partida de nacimiento, los certificados de estudios del grado concluido y una constancia de los resultados de la evaluación del estudiante hasta la fecha en que se produce el traslado, previa constancia de no adeudo.

13.12. La Dirección de la Institución se reserva el derecho de cancelar o condicionar la matrícula por problemas de comportamiento de los estudiantes o actitudes negativas de los padres de familia o porque han faltado a su compromiso de apoyar la labor educativa - formativa, a la cual se comprometieron en la matrícula.

\section{Art. 14. Del Régimen Académico}

14.1. El año lectivo tiene una duración mínima de 42 semanas divididas en Cuatro períodos, se inicia la primera semana de marzo y concluye la Segunda semana de diciembre. Después de cada período lectivo, los alumnos gozarán de una semana de vacaciones.

14.2. El horario laboral durante el año académico es el siguiente:

Nivel Inicial: 08:00 h a 12:55 h

14.3. La Programación Curricular se realiza en el mes de febrero y las unidades de trabajo o de experiencia y proyectos se elaboran periódicamente de acuerdo a la realidad a cada nivel y a las necesidades e intereses de los educandos. 
14.4. La metodología usada por el personal docente debe estar en coherencia con los objetivos que se pretenden alcanzar y estará sujeta a supervisión constante por parte de la Dirección General.

14.5. El proceso de enseñanza - aprendizaje considera métodos activos que ponen en funcionamiento e integran las diferentes funciones mentales en el proceso de aprehensión y afianzamiento de habilidades. 14.6. La Institución Educativa elabora y lleva con carácter oficial los siguientes registros:

- De ingreso y seguimiento de expedientes.

- De: Matrícula y ratificación.

Padres de familia $y$ apoderados.

- De asistencia de personal.

- De evaluación del aprendizaje y del comportamiento.

14.7. Los procedimientos de gestión usualmente utilizados por la Institución Educativa y que se especifican en el correspondiente manual, son:

- Adelanto o postergación de evaluación.

- Evaluación de recuperación.

- Autorización de evaluación extemporánea por causa justificada.

- Evaluación de subsanación de asignatura.

- Exoneración de la parte práctica de la asignatura de Educación Física.

- Autorización de traslados de matrícula. 
- Expedición de certificados de estudio.

- Rectificación de nombres y apellidos.

- Expedición de constancia de vacantes de matrícula.

- Autorización de excursiones y visitas de estudio.

- Otorgamiento de licencias.

- Selección de personal.

14.8 El Personal Directivo, Docente y Auxiliares de educación ponen en práctica medidas de seguridad para los estudiantes durante su permanencia en la Institución Educativa. En caso de emergencia se dispone su evacuación a los centros de salud.

Art. 15. De la Evaluación

15.1. La evaluación del educando se basa en indicadores que tiene en cuenta los criterios, competencias, capacidades y actividades del programa de estudio y las características de las asignaturas / áreas asegurando la objetividad, validez y confiabilidad. Se realiza conforme a la Guía de Evaluación del Estudiante

15.2. La evaluación es integral, permanente y diversificada en todos los grados y niveles.

15.3. La evaluación es diferenciada para los casos de estudiantes con necesidades educativas especiales cuando el caso así lo amerite.

15.4. La evaluación del comportamiento se realiza teniendo en cuenta el Reglamento de Convivencia Estudiantil. 
15.5. La evaluación del comportamiento no se consideran para los efectos de promoción o repotencia, pero sí para la separación temporal o definitiva del estudiante de la Institución.

15.6. El proceso de evaluación continua en la Institución Educativa es responsabilidad de la Dirección General y órganos académico formativo y está orientada a optimizar el desarrollo de las acciones educativas principalmente del proceso enseñanza-aprendizaje y la evaluación de los estudiantes.

15.7. La evaluación del rendimiento académico se expresará según las normas legales establecidas por el Ministerio de Educación.

15.8. El Director General en coordinación con los Tutores y formación Pastoral, elabora en el mes de diciembre el cronograma de los exámenes de aplazados y de subsanación, que son rendidos entre los meses de diciembre a febrero.

15.9. La información a los padres de familia acerca de los resultados de la evaluación del aprendizaje, y otros aspectos de la tarea educativa se realiza mediante despachos con el tutor, o docente del área conforme el avance de la Unidad programada.

15.10. La información de los resultados trimestrales se da a los padres dentro de un plazo de 15 días de finalizado el período correspondiente. 15.11. Los certificados de estudios se otorgan en conformidad a las normas establecidas en la Ley General de Educación. 


\section{CAPÍtULO IV}

\section{DE LA ESTRUCTURA FUNCIONAL}

Art. 16. La IEI "Estrellitas de Jesús" tiene la siguiente estructura funcional:

\begin{tabular}{|l|l|}
\hline De Dirección & Promotor \\
\hline Del Personal Docente y de & Dirección General \\
\hline Formación & Personal docente \\
\hline Personal especializado & Auxiliares de Educación. \\
\hline De Administración y servicios & Biblioteca, Biblioteca Virtual. \\
\hline De los Órganos de Participación & Tópico \\
\hline & Perrotorios \\
\hline & Personal Guardiania \\
\hline
\end{tabular}




\section{CAPÍTULO V}

\section{DE LA DIRECCION, PERSONAL DOCENTE, TUTOR, AUXILIAR DE EDUCACION}

\section{DE LA DIRECCIÓN}

Art. 17. El Director General es designado por el Promotor en cargo de confianza.

\section{Funciones principales de la Dirección General}

17.1. Seleccionar, contratar, elegir, designar y desvincular, al personal docente y los diversos miembros que integran la comunidad educativa de la institución.

17.2. Promover y presidir el Consejo Directivo.

17.3. Conducir la elaboración, ejecución y evaluación del Proyecto Educativo Institucional, Plan Anual de Trabajo y Reglamento Interno, de manera participativa.

17.4. Emitir Resoluciones Directorales de aprobación de los documentos de gestión de la Institución Educativa.

17.5. Promover y Tutelar la actividad educativa como misión.

17.6. Presenta $\mathrm{r}$ el presupuesto anual de la Institución Educativa, al Promotor para la aprobación correspondiente.

17.7. Supervisar y evaluar las actividades administrativas, pedagógicas, formativas y pastorales en coordinación con el Promotor y el Consejo de Dirección de la Institución Educativa.

17.8. Promover la actualización, perfeccionamiento, especialización y estudios de post grado de los docentes y demás personal de la Institución. 
17.9. Supervisar el estricto cumplimiento de los dispositivos específicos que norman la matrícula, pago de pensiones y concesión de beneficios económicos y becas a los estudiantes.

17.10. Visar los Certificados de Estudios, constancias de servicios prestados a la Institución Educativa, así como las constancias de pago del personal a su cargo.

17.11. Redactar la correspondencia oficial, y disponer la publicación de directivas y demás documentos informativos del plantel.

17.12. Supervisar que la Secretaría remita oportunamente la documentación oficial de la Institución Educativa a los órganos competentes, de conformidad con lo establecido en las leyes y reglamentos vigentes.

17.13. Aprobar los cuadros de distribución de horas de clase y la calendarización y periodificación del año escolar.

17.14. Mantener el principio de autoridad y velar por la responsabilidad y funcionalidad de los diferentes órganos del plantel.

17.15. Convocar a sesiones del Consejo Directivo para recibir información sobre el avance curricular, logros significativos, deficiencias, omisiones y problemas de conducta de los estudiantes para determinar las alternativas de solución.

17.16. Otorga permiso al personal a su cargo, hasta por tres días al año en casos debidamente justificados.

17.17. Incentivar y reconocer el esfuerzo y mérito individual y colectivo del trabajador y en caso de incurrir en falta emitir las sanciones correspondientes según la normativa vigente e institucional. 
17.18. Promover innovaciones científicas y tecnológicas; así como la investigación educativa, estimulando la participación de los estudiantes, de los docentes, personal administrativo y de apoyo.

17.19. Promover la cooperación de instituciones locales y regionales para mejorar los servicios educativos que brinda la Institución.

17.20. Asesorar al Comité de Apoyo de Padres de Familia y cautelar su movimiento económico.

17.21. Promover el liderazgo participativo de la comunidad educativa y el buen clima institucional.

17.22. Delegar alguna o todas estas facultades a quién corresponda jerárquicamente, cuando tenga deba ausentar del trabajo por motivos justificados.

\section{DEL PERSONAL DOCENTE}

Art. 18. El docente, elemento clave del proceso educativo y formativo, es elegido cuidadosamente por la Dirección del Institución, teniendo como base la evaluación de: su currículo profesional, perfil, evaluación psicológica, académica y entrevistas personales que le permitan captar su vivencia moral cristiana, su capacidad profesional y su apertura a la Axiología y Proyecto Educativo de la Institución.

Sus funciones principales son:

18.1. Planear de acuerdo con la Dirección General, el trabajo docente en las materias específicas a su cargo y participar en la elaboración, ejecución y evaluación del Plan Anual de Trabajo.

18.2. Ser parte del equipo educador y colaborar con el Tutor respectivo para que éste cumpla plenamente sus funciones. 
18.3. Desarrollar sus actividades, conforme a lo exigido por la Institución, lo normado por las directivas de educación.

18.4. Presentar, dentro de los plazos y términos fijados, a la

Dirección General los documentos siguientes:

- La Diversificación Curricular de Área

- $\quad$ La Programación de Unidad

- Guía del Estudiante

- Sesiones de clase

- Adaptaciones curriculares

- Guía de Trabajo o Aprendizaje Autónomo

- Fichas de Trabajo y material complementario

- Las pruebas escritas para revisión

- Las evaluaciones diferenciadas para revisión, cuando se requiera.

- Los registros auxiliar de evaluación

- Los informes solicitados, según requerimiento de la Dirección General,

18.5. Planear estrategias para el trabajo con el eje, temas transversales y núcleos temáticos.

18.6. Planificar adaptaciones curriculares integrales para la atención a los estudiantes con habilidades diferentes.

18.7. Planificar la evaluación diferenciada como medio de ayuda para desarrollar o monitorear procesos de mejora en los estudiantes.

18.8. Admitir la supervisión de su labor que los órganos responsables ejecuten; $\mathrm{y}$, realizar las acciones sugeridas para solucionar las deficiencias, omisiones o carencias detectadas. 
18.9. Velar por el desarrollo de actitudes, hábitos y actitudes positivas de los alumnos y orientarlos para la realización eficaz de su trabajo.

18.10. Vivir el ideario y la filosofía educativa de la institución y hacer que los estudiantes la vivan.

18.11. Asumir la cultura evaluativa de la institución como medio de mejora continua.

18.12. Ofrecer a los estudiantes un trato digno e imparcial, a través del ejemplo.

18.13. Esmerarse en la formación de hábitos de trabajo, orden, mutuo respeto y sinceridad.

18.14. Participar en las diversas actividades pastorales que promueva la Institución.

18.15. Asistir puntualmente a las clases en la Institución y excusarse por anticipado a la Dirección General en caso de darse alguna imposibilidad de asistencia.

18.16. Estudiar los resultados de las evaluaciones, del rendimiento escolar de sus alumnos y conocer la situación de cada uno para estimular o aplicar la acción correctiva pronto.

18.17. Preparar con el tutor las entrevistas que le soliciten los Padres de Familia, las cuales se referirán siempre a temas pedagógicos.

18.18. Asistir a las reuniones periódicas a las que sea convocado.

18.19. Cumplir con los encargos que se le hagan por parte de los Directivos de la Institución.

18.20. Cuidar celosamente el orden y la disciplina durante el desarrollo de las clases empleando los recursos que aconseja la pedagogía. 
18.21. Planificar, programar, desarrollar y evaluar las actividades curriculares que le corresponda, así como, las de tutoría, y de pastoral, de acuerdo, a los objetivos de las asignaturas o grados a su cargo, del Proyecto Educativo y la axiología de la Institución.

18.22. Participar en acciones programadas de investigación y experimentación de nuevos métodos y técnicas de trabajo educativo.

18.23. Orientar a los estudiantes y velar por su seguridad durante el tiempo que permanecen en la institución, en especial en las horas de ingreso, salida, juego y recreación.

18.24. Realizar acciones de recuperación pedagógica y detección de problemas que afectan el desarrollo del estudiante y su aprendizaje, siempre en coordinación con los tutores.

18.25. Cooperar en las acciones de mantenimiento y conservación de los bienes institucionales.

18.26. Participar y colaborar en actividades extra-curriculares, según los fines y objetivos institucionales.

18.27. Participar activamente en la Comunidad Docente y con ella en los distintos encuentros de:

\section{AUXILIARES DE EDUCACIÓN.}

Son funciones del auxiliar de educación:

a) Orientar el comportamiento de los alumnos en concordancia con las normas establecidas y Tutores de Aula de las estudiantes. 
b) Orientar y apoyar en la disciplina de las estudiantes, en la formación y actividades programadas por la IE.

c) Colaborar en las acciones de tutoría y orientación de educando programadas en la IE.

d) Informar al tutor de aula, oportunamente, sobre el comportamiento de las estudiantes a su cargo, en especial de aquellas que presenten dificultades en el área personal.

e) Controlar en caso de ausencia del docente, la realización de tareas escolares en las aulas o uso de la Biblioteca.

f) Ejecutar visitas periódicas en los diferentes ambientes de la IE. para velar por el cumplimiento de las normas disciplinarias.

g) Verificar al final de cada jornada de trabajo, la buena conservación del mobiliario escolar.

h) Mantener actualizado el registro de asistencias e inasistencias de los alumnos por grados.

i) Controlar el ingreso y salida de los alumnos a la IE. Velando por el orden, así como verificar las aulas al concluir la jornada de clases

j) Informar a la dirección respectiva sobre la inasistencia y tardanzas del docente, permanecer en el aula en caso de ausencia del profesor.

k) Cumplir con su horario establecido de ingreso de acuerdo a las normas vigentes, 25 minutos antes y después de ingreso y salida de las estudiantes respectivamente.

I) Propiciar un clima de cooperación, amistad y respeto entre los agentes de la comunidad educativa. 
m) Orientar a los alumnos en la adecuada presentación personal; así como la conservación de la infraestructura, el material educativo y el mobiliario escolar.

n) Presentar un informe Bimestral sobre el desarrollo de las actividades, indicando los logros obtenidos, las dificultades y sugerencias necesarias para el mejoramiento del servicio educativo.

o) El trabajo a realizar será siempre coordinado y aprobado por el Tutor, del cual depende.

\section{CAPÍTULO VI}

\section{DEL RÉGIMEN LABORAL}

Art. 22. El personal y los trabajadores en general, que están bajo relación de dependencia laboral se rigen exclusivamente por las normas del régimen laboral de la actividad privada y por las relaciones laborales que se norman en nuestro Reglamento Interno de Trabajo (RIT), con el propósito de garantizar la eficiencia del quehacer educativo.

\section{DE LOS ESTÍMULOS, FALTAS GRAVES O PROHIBICIONES Y SANCIONES ESTÍMULOS}

Art. 23. Es característica de la Institución Educativa estimular al personal por actos sobresalientes tales como:

- $\quad$ Identificación, compromiso y desempeño profesional destacado.

- Desarrollar actividades extracurriculares que deriven en prestigio y mejoramiento de la imagen institucional. 
- $\quad$ Ejecutar en la institución tareas de investigación educativa que constituyan aportes significativos al desarrollo institucional y comunal.

23.1. Constituyen estímulos a la labor extraordinaria:

a) Felicitación escrita.

b) Resolución de reconocimiento

c) Premio al concluir el año lectivo.

\section{FALTAS GRAVES Y PROHIBICIONES}

Art. 24. Se considera falta grave y está totalmente prohibida toda aquella acción que altere o impida el orden, la disciplina, la buena marcha de la actividad institucional o un sano crecimiento moral, personal y colectivo.

24.1. Está prohibido:

a) Atentar contra la moral y buenos principios, y la línea axiológica de la institución.

b) Disminuir intencionalmente el ritmo de trabajo.

c) Faltar al trabajo sin causa debidamente justificada.

d) Dejar de marcar su registro de asistencia y salida de la institución.

e) Ausentarse de su puesto de trabajo sin la debida autorización de la Dirección General.

f) El abandono de la clase o de la institución antes de la hora.

g) Introducir o distribuir volantes, propagandas políticas dentro de la institución.

h) Dormir durante la jornada de trabajo o presentarse en sus horas de labores en estado de embriaguez o bajo los efectos de sustancias tóxicas. 
i) Murmurar, injuriar; faltar de palabra u obra a los estudiantes, a los compañeros de trabajo o al personal de vigilancia.

j) Fumar en los lugares que por seguridad faltan a la ley de prohibición de fumar.

k) El dictado de clases particulares remuneradas a los estudiantes.

I) La venta de objetos, libros y otros artículos a la Comunidad Educativa sin autorización de la Dirección General.

m)La utilización de las instalaciones e implementos de la Institución para fines particulares sin permiso de la Dirección General.

n) La solicitud de dinero, de especies para mejorar los resultados de la evaluación, o adulterar cualquier otra información.

o) Portar armas en la Institución, con excepción del personal de vigilancia debidamente autorizado.

p) Llegar tarde al dictado de clases.

q) Hacer mal uso de laptop o celulares en horas de clase.

r) Utilizar horas de la jornada laboral y materiales de la institución en actividades personales que no corresponden a la Institución.

24.2. El despido del trabajador por falta grave se sujeta estrictamente a lo dispuesto en las normas legales en vigencia y lo establecido por el Reglamento Interno de la Institución. 


\section{SANCIONES}

Art. 25. Las faltas, omisiones e infracciones básicas del trabajador a lo dispuesto en el Manual de Organización y Funciones (MOF), Reglamento (RI) y demás normas de la Institución, y órdenes dictadas por sus representantes, dan origen a la aplicación de medidas disciplinarias o sanciones.

25.1. La Institución Educativa, aplica las sanciones señaladas teniendo en cuenta y evaluando la gravedad de la falta cometida, la repercusión que esta pueda tener en el desenvolvimiento de la actividad institucional y las normas legales vigentes sobre la materia. Estas son:

a) Amonestación verbal o escrita.

b) Descuento de sus remuneraciones por las horas o días no laborados.

c) Suspensión temporal en sus funciones

d) Despido por falta grave

25.2. La amonestación verbal, se aplica en privado y por el Jefe superior inmediato, u otro jefe superior de la misma área de actividad.

25.3. La amonestación escrita, se archiva al file del trabajador sancionado, con copia a la autoridad administrativa de trabajo si se trata de personal que labore bajo la modalidad de servicios personales o sea con estabilidad. Serán objeto de amonestación por escrito los trabajadores que incurran en las siguientes faltas:

a) Llegar tarde al trabajo.

b) Salir o ausentarse del trabajo antes de la hora señalada sin la debida justificación.

c) No marcar su asistencia al trabajo en la forma correspondiente. 
d) Incurrir en actos reñidos con la disciplina y moral en el trabajo, inclusive jugar, agruparse interrumpiendo sus labores.

e) Negligencia o falta de voluntad en el trabajo.

f) Proferir palabras soeces o injuriosas dentro de la institución.

g) Hacer mal uso de laptop o celulares en horas de clase.

h) Utilizar horas de la jornada laboral y materiales de la institución en actividades personales que no corresponden a las del Institución

25.4. Dos amonestaciones dan lugar a que la Institución aplique una suspensión al trabajador.

25.5. Son motivo de suspensión los siguientes casos y sus similares:

a) Indisciplina.

b) Embriaguez en el trabajo.

c) Dormir en el trabajo.

d) Daño por descuido o negligencia en propiedades de la institución.

e) Ausencia sistemática al trabajo.

f) Dedicarse a realizar trabajos particulares o hacer negocios en horas de trabajo.

g) Reincidencia en los casos específicos anteriormente señalados.

25.6. Es causal de despido por falta grave, las faltas contempladas en la ley de Fomento y Estabilidad en el trabajo y su reglamento para los trabajadores comprometidos en el D.L. 728 (Arts. 20 al 28) y el Reglamento Interno de la Institución.

25.7. Para aplicar las sanciones se tiene en cuenta los siguientes criterios: 
a) Deben ser adecuadas, idóneas, justas y con fin correctivo, sin ningún criterio de discriminación.

b) Deben estar en relación con la gravedad de la falta y en las circunstancias que se produjeran los hechos y otros factores que contribuyen a crear la situación anómala.

c) Los antecedentes del trabajador según su record personal, así como su posición dentro de la institución y el grado de responsabilidad dentro de la institución.

25.8. Los trabajadores quedan obligados a recepcionar y firmar los documentos que le remite la Dirección de la institución, haciéndole saber la falta cometida y las medidas disciplinarias que se le apliquen, en caso de negativa se le hace llegar por conducto notarial, considerando la misma como agravante.

25.9. Es propósito de la institución, que todo trabajador tenga la oportunidad de corregir su conducta y las faltas en que incurra en el cumplimiento de sus obligaciones de trabajo, antes de recurrir a la rescisión del respectivo contrato de trabajo, salvo en los casos de falta grave o infracciones en las disposiciones legales vigentes y las normas establecidas en este Reglamento que por su gravedad justifiquen el despido inmediato.

\section{CAPÍTULO VII}

\section{DEL PERSONAL ESPECIALIZADO}

\section{DE LA BIBLIOTECARIA (O)}

Art. 26. Tiene como funciones principales: 
26.1. Atiende la Biblioteca y sirve de soporte al aula de investigación.

26.2. Fomenta la lectura, la investigación y contribuye al desarrollo del proceso educativo - formativo, la Misión, Visión y metas de la Institución, así como, cumple con las directivas y normas internas que la Dirección General dicte sobre la materia.

26.3. Recepciona, clasifica las obras bibliográficas, y recursos audiovisuales y elaborar el respectivo fichero y catálogo por autores y materias en el sistema automatizado.

26.4. Mantiene actualizado el inventario de la Biblioteca.

26.5. Vela por la conservación de los bienes y enseres a su cargo.

26.6. Orienta a los usuarios en la selección y cuidado de los textos y controla préstamos y devoluciones de los mismos.

38.7. Realiza otras funciones inherentes al cargo establecidas en el MOF y demás normas institucionales.

\section{DE LOS RESPONSABLES DE LABORATORIOS/TALLERES.}

Art. 27. Los responsables de los laboratorios están encargados de brindar apoyo a las labores académicas con los recursos y herramientas a su cargo. Tanto en el Laboratorio de Ciencia, Tecnología y Ambiente como en los Laboratorios de Cómputo. Tienen como funciones principales:

27.1. Atiende a los estudiantes según horario establecido.

27.2. Organiza y coordina, con las áreas respectivas el uso del laboratorio, previa autorización de la jefatura pertinente. 
27.3. Mantiene un registro de la salida, baja o préstamo de los equipos y materiales del laboratorio, previa autorización de las autoridades responsables empleando los formatos oficiales de control.

27.4. Mantiene actualizado el inventario de los equipos y materiales de los respectivos laboratorios.

27.5. Se responsabiliza de la seguridad de los estudiantes mientras permanezcan en las instalaciones de los laboratorios.

27.6. Vela por la conservación de las instalaciones, bienes, enseres y materiales a su cargo.

27.7. Realiza otras funciones inherentes al cargo establecidas en el MOF y demás normas o reglamentos.

\section{DEL TÓPICO}

Art. 28. Es un servicio permanente de primeros auxilios al estudiante y al personal de la institución, está a cargo de una enfermera.

28.1. Sus funciones se detallan en el Manual Organización y Funciones.

\section{CAPITULO VIII}

\section{DE LA ORGANIZACIÓN DEL TRABAJO ADMINISTRATIVO DE LA SECRETARÍA/RECAUDACION.}

Art. 31. Tiene como funciones principales:

31.1. Organiza, coordina y ejecuta las labores propias de la cargo.

31.2. Elabora, clasifica y distribuye la documentación de la Secretaría a su cargo. 31.3. Vela por la seguridad de los bienes y documentos de la Secretaría a su cargo. 
31.4. Realiza otras funciones inherentes al cargo y de acuerdo a su competencia establecida en el MOF y demás normas o reglamentos de la Institución Educativa.

\section{Art. 33.- Personal de Servicio:}

Las Funciones del Personal de Servicio son:

1. Realizar el mantenimiento, conservación y limpieza de los bienes del Colegio (pisos, servicios higiénicos, paredes, ventanas, etc

2. Vigilar el adecuado uso del fluido eléctrico así como que las luces no queden encendidas en las aulas.

3. Apoyar en el desarrollo de las diversas actividades de la IE.

4. Cuidar y ser responsable de los bienes que están dentro de su área de trabajo.

5. Realizar labores de seguridad, vigilancia y portería de la IE.

6. Controlar y orientar el ingreso y salida del público en general.

7. Controlar que los muebles y enseres que salen del plantel, cuenten con la respectiva autorización de la Dirección

8. Elaborar los informes de acciones y hechos ocurridos durante su jornada.

9. Apoyar en las tareas de distribución de documentos dentro y fuera del plantel.

10. Realizar traslados de muebles, equipos y otros enseres.

\section{Art. 34. -Del Guardián.}

Son funciones del responsable de guardianía:

1. Cumplir actividades de vigilancia y seguridad en horario nocturno y en días no laborables.

2. Controlar el ingreso de materiales diversos dentro de su jornada de trabajo, dando cuenta en el día, al Promotor y la Dirección.

3. Velar por la seguridad y conservación de los bienes de la IE. 
4. Realizar rondas permanentes por todos los ambientes de la IE., verificando por todo este sin novedad, en caso contrario tomará las acciones más convenientes revisar cada uno de los ambientes de la IE. verificando que no existen aulas, luces y/o artefactos encendidos.

5. Informar oportunamente y bajo responsabilidad al Promotor y la Dirección de la IE sobre irregularidades suscitadas en el plantel.

6. Hacer limpieza general de la frontera de la IE., incluyendo sábados y domingos (dos veces al día); así como de las plataformas deportivas y áreas no construidas.

7. Controlar que la basura sea retirada por el carro recolector de la municipalidad.

\section{CAPÍTULO IX}

\section{DE LOS ESTUDIANTES.}

Art. 35. Se considera estudiante a todo niño, niña que hace uso de nuestro servicio educativo por estar regularmente matriculado en los grados correspondientes al nivel de Inicial. Son la razón de ser de nuestro quehacer educativo. Sus deberes son:

35.1. Conocer y aceptar la Filosofía institucional.

35.2. Crecer en pertenencia e identidad de nuestra institución.

35.3. Participar activamente en la ejecución del Proyecto Educativo Institucional.

35.4. Crear un ambiente de amable convivencia, solidaridad y alegría entre sus compañeros(as) y demás estamentos de la Comunidad educativa.

35.5. Participar con responsabilidad y creatividad y según sus aptitudes en las diversas asociaciones estudiantiles, celebraciones y actividades extracurriculares. 
35.6. Conocer, respetar y cumplir los Deberes contemplados en el Reglamento Interno que se refieren a su quehacer formativo, a su conducta y participación.

35.7. Conocer, ejercer y respetar los Derechos de los estudiantes establecidos en el Reglamento Interno.

35.8. Participar activamente en el proceso enseñanza-aprendizaje, colaborando en todo lo que esté a su alcance para que sus compañeros aprovechen al máximo el aprendizaje y las prácticas propuestas por los docentes

\section{Son sus derechos:}

35.9. Recibir formación integral dentro de un ambiente que le brinde seguridad moral y física, de acuerdo con los postulados de la Constitución Política Peruana, la Ley General de Educación y el ideario de la institución, que los ayude a crecer en todos los aspectos de su personalidad y los estimule a asumir su formación como empeño insustituible, responsable y creativo de toda la vida. 35.10. Ser acogidos y escuchados en un clima de respeto y cordialidad que afiance sus sentimientos de seguridad.

35.11. Ser tratado con dignidad, sin discriminación y ser informado de las disposiciones que le concierne como estudiante.

35.12. Participar en las actividades extra programáticas organizadas por la institución

35.13. Recibir estímulos en mérito al cumplimiento de acciones que prestigien la institución.

35.14. Presentar verbalmente o por escrito, las quejas o reclamos al estamento correspondiente. 
35.15. Participar de los grupos pastorales de la institución y de las elecciones para el consejo estudiantil.

\section{DE LOS ESTIMULOS, CONDUCTAS QUE ALTERAN LA CONVIVENCIA ESCOLAR Y ACCIONES CORRECTIVAS}

\section{ESTIMULOS}

Art. 36. Son estímulos, las acciones que se realizan para reconocer, reforzar y motivar el esfuerzo, la mejora personal y las conductas positivas propuestas en el perfil del estudiante (algunas de ellas se reflejan en la calificación de la conducta del estudiante), así como su participación y desempeño destacado en el deporte y actividades en la Institución o fuera de él:

- Reconocimiento público en ceremonia cívica

- Felicitación verbal

- Felicitación escrita

- Diploma de reconocimiento

- Medalla de plata

36.1. Se otorga reconocimiento público verbal a los estudiantes que se esfuerzan por lograr las metas de cada trimestre, evidenciándose en sus calificaciones.

36.2. Reciben del Director felicitación verbal, los estudiantes que tuvieran alguna acción destacada que demuestra esfuerzo y responsabilidad en su mejora académica, actitudinal o en su identificación con el Institución. 
36.3. Reciben del Director felicitación escrita, los estudiantes que demuestran esfuerzo, perseverancia, responsabilidad y constante identificación con su institución educativa.

36.4. Se otorga Diploma por reconocimiento a su desempeño académico a los tres primeros estudiantes de cada grado y sección que en los diferentes niveles obtengan los puntajes más altos y observen buen comportamiento o sobresaliente reflejado en la calificación de la conducta del estudiante y a aquellos cinco primeros estudiantes que durante toda su secundaria han obtenido los más altos puntajes.

36.5. Se otorga premio al esfuerzo a los cinco primeros alumnos de cada aula que durante el año escolar se han esforzado por hacer vida nuestro lema institucional en pro de su desarrollo integral.

\section{CONDUCTAS QUE ALTERAN LA CONVIVENCIA ESCOLAR}

Art. 37. Son todas aquellas que alteran el orden, el respeto, la responsabilidad, generosidad, y honestidad, la disciplina y la buena marcha de la actividad o un sano crecimiento moral, personal y / o colectivo.

\section{ACCIONES CORRECTIVAS}

Art. 38. La medida correctiva debe ser proporcional a la falta incurrida, considerando el carácter formativo de la misma y en su conjunto.

38.1. Un estudiante puede perder el derecho a la ratificación de su matrícula cuando:

1. Repite el año por negligencia personal.

2. Por incurrir en el $30 \%$ de faltas injustificadas a las actividades curriculares programadas. 
3. Cuando incurre en una falta grave o demuestra poca voluntad de corregir su comportamiento, a pesar de las motivaciones y acciones correctivas que recibe.

38.2. Un estudiante puede ser separado definitivamente de la Institución cuando:

1. Demuestra actitudes contrarias a la axiología institucional.

2. Incurre en falta grave que van en contra del honor y seguridad de sus compañeros o docentes, dentro o fuera de la institución.

3. Su comportamiento, léxico o actitudes son un abierto desafío a la autoridad que ejerce cada personal de la institución.

38.3. La separación definitiva de un estudiante se hace efectiva previo informe de la Coordinación de Formación Pastoral y dictamen del Consejo de Dirección.

\section{CAPÍTULO X}

DE LAS RELACIONES Y COORDINACIONES DEL INSTITUCIÓN CON LOS ÓRGANOS EXTERNOS DE COLABORACIÓN

\section{DE LAS ORGANIZACIONES ESTUDIANTILES}

Art. 39. Ofrecen a los estudiantes, la posibilidad de desarrollar la capacidad de liderazgo y un justo ejercicio de participación democrática. 
Art. 40. Los padres son los principales educadores de sus hijos, responsabilidad de la que nadie los puede eximir y que tampoco puede delegar. Por ello la Institución Educativa colabora con la acción educativa familiar pero no la sustituye.

40.01 En este contexto la acción educativa del Institución es subsidiaria y se ejerce en nombre de los padres y por encargo suyo. Razón de ser para que haya una estrecha relación, comunión y coordinación entre el Institución, los Padres y los Educadores.

40.02 Al matricular a sus hijos en la Institución Educativa, los Padres de familia eligen asumir la Axiología y el Proyecto Educativo del mismo y se comprometen a colaborar directa y personalmente en la educación de sus hijos. 40.03 Esta relación se establece a través de los siguientes canales:

- Relación directa con el tutor según sea el caso y con el equipo educador de su hijo(a).

40.04 Es deber de la Institución Educativa hacia los Padres de Familia:

- Dar a conocer el contenido de la Axiología y del Proyecto Educativo.

- Informar periódicamente sobre los distintos aspectos de la formación de sus hijos y la calidad o avance de su desempeño académico, como sobre las dificultades que se observan en ellos.

- Brindar espacios de formación y sensibilización a los padres de familia mediante:

Asesoramiento educativo familiar

Despachos y entrevistas.

Escuela de padres.

Jornadas para padres 
40.05 Es deber de todo Padre de Familia:

- Asumir su protagonismo como responsable de la formación integral de sus hijos e hijas.

- Cumplir y hacer cumplir las normas del presente reglamento, en especial lo que se refiere a sus hijos e hijas.

- Concurrir a las entrevistas personales, reuniones de aula y escuelas de padre, participando activa y responsablemente.

- Firmar los documentos que así lo exijan: reporte de notas, comunicaciones, entrevistas, cartas de compromiso, etc.

- Cumplir con el pago de las cuotas de enseñanza señalados por la Institución Educativa y las de la COPAFA.

- Participar cuando es requerida su presencia en las actividades programadas por la Institución Educativa.

40.06 El incumplimiento reiterado de estas normas será sancionado, según el caso por la Dirección de la Institución.

\section{DEL COMITÉ DE PADRES DE FAMILIA}

Art. 41. El comité de padres de familia o COPAFA, trabaja en coordinación con la Dirección General. Sus funciones principales son:

41.1. Propiciar la participación de los padres de familia en el mejoramiento continuo de los servicios que ofrece la Institución.

41.2. Coordinar, colaborar y apoyar en forma permanente a la Dirección.

\section{CAPÍTULO XI}




\section{DEL RÉGIMEN ECONÓMICO, DEL PAGO DE PENSIONES Y DEL OTORGAMIENTO DE BECAS DEL RÉGIMEN ECONÓMICO}

Art. 43. El Patrimonio del Institución pertenece a loa socios.

43.1. Es responsabilidad del Promotor con el apoyo del Administrador, el óptimo manejo de los recursos financieros de la Institución Educativa.

43.2. Son recursos financieros de la Institución:

a) Derecho por carpeta de postulante.

b) Cuota de ingreso (Estudiante nuevo)

c) Ingreso por Matrícula

d) Ingresos por pensiones de enseñanza

e) Las donaciones

f) Los ingresos propios por:

- Derecho de expedición de certificados.

43.3. Los ingresos y egresos se registran en los correspondientes libros de contabilidad.

\section{DEL PAGO DE PENSIONES}

Art. 44. La pensión de enseñanza es anual y se divide en diez (10) cuotas mensuales (marzo - diciembre)

44.1. Las pensiones de enseñanza se abonan en la entidad financiera que la Institución indique, o en oficina de Secretaria/Recaudación de la Institución Educativa y se harán efectivas el último día de cada mes. 
44.2. La Institución Educativa retiene documentos de escolaridad de los estudiantes; cuyos padres, que al término del año lectivo adeuden derechos de pensiones, hasta su total cancelación de acuerdo a ley.

\section{CAPÍTULO XII}

\section{DISPOSICIÓN FINAL}

Art. 47. Forma parte constitutiva del presente Reglamento: El Organigrama Estructural, el Manual de la Organización y Funciones (MOF), el Reglamento del COPAFA, y otros que se implementen en la Institución Educativa para su correcto funcionamiento.

\section{EVALUACIÓN ACADÉMICA EN INICIAL}

- $\quad$ Es referida a CRITERIO, pues valora el grado de aprendizaje en cada alumno de aspectos previamente establecidos como capacidades a desarrollar. A diferencia de la evaluación referida a la norma, deja de considerar la ubicación de cada individuo en el grupo, evitando la comparación para fomentar las bases de la propia estima en base al desarrollo de las propias potencias personales.

- $\quad$ Es FORMATIVA: observa el proceso de enseñanza y aprendizaje para intervenir oportunamente en él, valorando todos los elementos que intervienen. Cada alumno posee un ritmo y estilo personal de aprendizaje que es necesario atender durante el desarrollo del proceso y la evaluación permanente del mismo, lo que determina posibilidades diferenciadas de desarrollo personal. 
- Siendo la educación el perfeccionamiento intencionado de las propias potencialidades, la adquisición de un aprendizaje depende tanto de las disposiciones individuales como del esfuerzo personal realizado por parte de cada alumno.

\section{Sobre la base de dichos principios, se considera:}

1. El nivel de logro y el nivel de esfuerzo se obtienen mediante la consideración de los criterios e indicadores que evidencian los aprendizajes.

2. Para la Apreciación Trimestral del Rendimiento, se correlaciona el nivel de logro y el nivel de esfuerzo, del cual se obtiene el Progreso trimestral logrado en cada área:

- AD: Logro sobresaliente en el aprendizaje del objetivo referido - A: Logro satisfactorio en el aprendizaje del objetivo referido.

- B: En proceso de aprendizaje del objetivo referido.

- C: En inicio del proceso de aprendizaje del objetivo referido

\section{EVALUACION DEL COMPORTAMIENTO}

El comportamiento del alumno está referido, para una mejor orientación, en la educación de virtudes humanas a la luz de los valores institucionales Justicia, Fortaleza, Prudencia y Templanza y los valores operativos: Respeto, responsabilidad, generosidad y honestidad, además de todos aquellos que subyacen en el desarrollo de los mismos como: la amistad, audacia, comprensión, flexibilidad, fortaleza, generosidad, humildad, justicia, laboriosidad, lealtad, obediencia, optimismo, orden, paciencia, patriotismo, 
perseverancia, prudencia, respeto, pudor, responsabilidad, sencillez, sinceridad, sobriedad y sociabilidad.

Estas virtudes se programarán según la edad, el grado de estudios y de acuerdo al período sensitivo que le corresponde (momento propicio para adquirir dicha virtud con mayor facilidad), las cuales se detallan en el Programa de Valores. Ejemplo:

Inicial 4 años, le corresponderá trabajar las virtudes del programa Vamos creciendo orientadas a fomentar la práctica de los valores operativos.

\section{RECONOCIMIENTO AL FINALIZAR EL AÑO ESCOLAR:}

En Inicial: Se reconocerá a cada uno de los alumnos de 5 años por culminar sus estudios en el nivel. 
Anexo 16

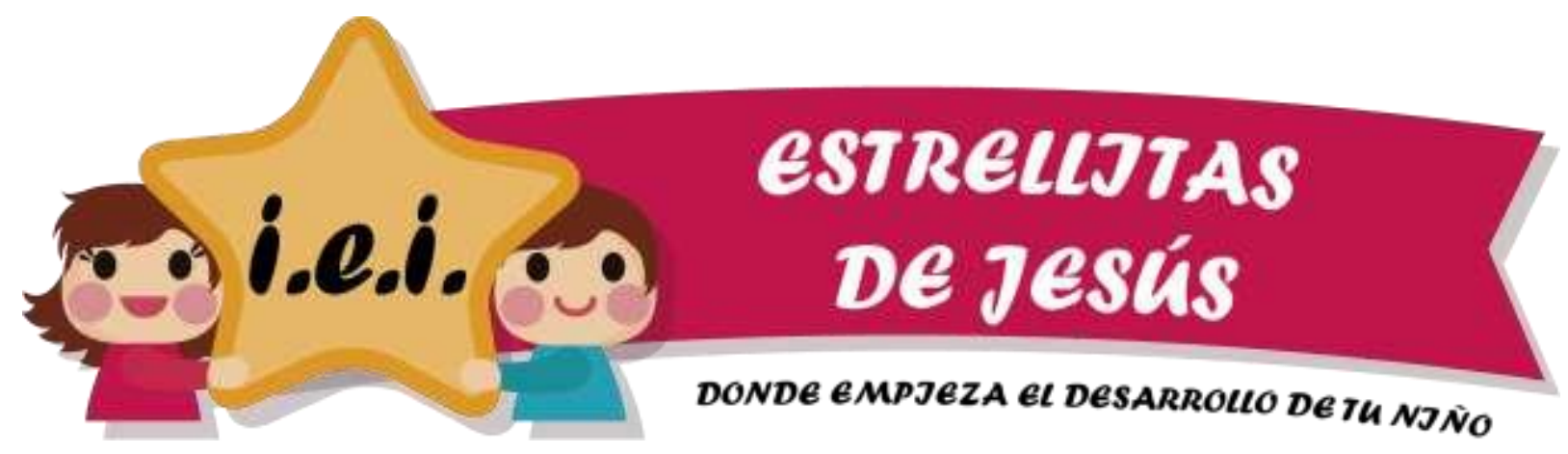

REGLAMENTO INTERNO

2018

PRESENTACIÓN 
El presente Reglamento Interno, es un documento de gestión que establece las normas académicas y administrativas que rigen la estructura, organización y relaciones de la Institución Educativa Inicial "Estrellitas de Jesús”, para el logro de sus fines y objetivos. A lo prescrito en este documento están sujetos todos los miembros de la Comunidad Educativa sin excepción alguna.

El conocimiento de los alcances del reglamento, permitirá a los miembros de la comunidad educativa conocer y cumplir a cabalidad sus funciones respetando las normas establecidas por la institución de acuerdo a las directivas por MINEDU tomando decisiones dentro de un marco de respeto a los derechos de los servidores. Este documento, será obligatoriamente difundido y conocido, para lograr los fines Institucionales anteponiendo a todo el trato humano que caracteriza a nuestra institución en salvaguarda de la Dignidad de la Persona Humana. 


\section{CAPITULO I}

\section{DEL REGLAMENTO Y LAS DISPOSICIONES GENERALES}

\section{GENERALIDADES}

Art. 01. El presente Reglamento Interno (RI) es un documento de gestión que establece las normas académicas y administrativas que rigen la estructura, organización y relaciones de la Institución Educativa Inicial "Estrellitas de Jesús ”, para el logro de sus fines y objetivos.

Art. 02. Es un instrumento legal al cual está sometida, toda la comunidad educativa (directivos, docentes, administrativos, personal de apoyo, padres de familia (APAFA) y estudiantes) en sus artículos y normas, siendo de observancia obligatoria.

Art. 03. La IEI "Estrellitas de Jesús" es una Institución Educativa Inicial que se encuentra ubicada en la provincia de Chiclayo, y brinda su servicio educativo formativo a la población escolar en el nivel de educación Inicial según los lineamientos y objetivos de la Ley General de Educación y su Proyecto Educativo.

\section{FINALIDAD}

Art. 04. El presente Reglamento tiene como finalidad normar: Los asuntos técnico-pedagógicos de la Institución.

- La estructura organizacional y funciones de los diferentes órganos y miembros que la integran.

- La organización del trabajo administrativo. 
- Las relaciones entre todos los estamentos internos y externos y demás disposiciones inherentes al proceso de enseñanza aprendizaje.

\section{BASE LEGAL}

Art. 05. El presente Reglamento Interno tiene sus bases legales en:

16. Constitución Política del Perú.

17. Ley $\mathrm{N}^{\circ}$ 28044, Ley General de Educación

18. Ley $\mathrm{N}^{\circ} 29944$, Ley de Reforma Magisterial

19. Ley $\mathrm{N}^{\circ} 28628$, Ley que regula la participación de las Asociaciones de Padres de Familia en las Instituciones Educativas Públicas y privadas.

20. Ley $\mathrm{N}^{\circ} 28988$, Ley que declara a la Educación Básica Regular como servicio público esencial.

21. Ley $\mathrm{N}^{\circ} 26549$ de los Centros Educativos Privados

22. Ley $\mathrm{N}^{\circ} 29719$, Ley que promueve la convivencia sin violencia en las instituciones educativas.

23. Ley $\mathrm{N}^{\circ}$ 29973, Ley General de la Persona con Discapacidad

24. Ley $\mathrm{N}^{\circ}$ 28740, Ley del Sistema Nacional de Evaluación, Acreditación y Certificación de la Calidad Educativa.

25. Decreto Ley $\mathrm{N}^{\circ}$ 25762, Ley Orgánica del Ministerio de Educación, modificada por la Ley $\mathrm{N}^{\circ} 26510$

26. Resolución Ministerial $N^{\circ}$ 0234-2005-ED que aprueba la Directiva $\mathrm{N}^{\circ}$ 004VMGP2005, sobre evaluación de los aprendizajes de los estudiantes de la Educación Básica Regular. 
27. Decreto Supremo $\mathrm{N}^{\circ}$ 017-2007-ED, que aprueba el Reglamento de la Ley $\mathrm{N}^{\circ}$ 28988, Ley que declara la Educación Básica Regular como Servicio Público Esencial.

28. Resolución Ministerial $\mathrm{N}^{\circ}$ 0201-2009-ED, que aprueba la Directiva "Procedimientos para la prevención y sanción del hostigamiento sexual en el sector Educación.

29. Decreto Supremo $N^{\circ}$ 006-2012-ED, que aprueba el Reglamento de Organización y Funciones (ROF) y el Cuadro para Asignación de Personal (CAP) del Ministerio de Educación.

30. D.S. N 001-96-ED. Reglamento de los Centros Educativos Privados 17.

Decreto Supremo $N^{\circ}$ 011-2012-ED, que aprueba el Reglamento de la Ley $\mathrm{N}^{\circ}$ 28044 Ley General de Educación.

24. Reglamento para Educación Primaria D.S. 03-83-ED

25. Ley de Protección de la Inversión privada en el sector Educación D.L. N ${ }^{\circ} 882$

26. Decreto Supremo $\mathrm{N}^{\circ}$ 004-2013-ED, que aprueba el Reglamento de la Ley $\mathrm{N}^{\circ}$ 29944, Ley de Reforma Magisterial.

27. Resolución Ministerial $\mathrm{N}^{\circ}$ 0369-2012-ED, que aprueba prioridades de la Política Educativa Nacional 2012 - 2016

28. Resolución Ministerial $\mathrm{N}^{\circ}$ 0518-2012-ED, que aprueba el Plan Estratégico Sectorial Multianual de Educación (PESEM) 2012-2016

29. Resolución Ministerial Nº519-2012-ED, que aprueba la Directiva Nº 0192012 MINEDU/VMGI-OET, Lineamientos para la prevención y protección de las y los estudiantes contra la violencia ejercida por personal de las instituciones educativas. 


\section{ALCANCES}

Art. 06. El presente Reglamento normativo de orden interno tiene los siguientes alcances:

- Contextualizar la realidad educativa del momento actual en concordancia con los actos del proceso de enseñanza-aprendizaje.

- Involucrar a todo el personal que labora en la Institución Educativa: Director, Docentes, Administrativos, Personal de Apoyo, padres de Familia, de la jurisdicción correspondiente

\section{MODIFICACIÓN Y APROBACIÓN}

Art. 07. El presente Reglamento interno está sujeto a revisión y actualización en razón de su funcionalidad, desarrollo institucional y principios que enmarcan el accionar del centro educativo.

Art. 08. El Reglamento Interno debe ser aprobado por Resolución Directoral emitida por el Director General.

\section{CAPÍTULO II}

DE LA INSTITUCIÓN PROMOTORA - PROPIETARIO

Art. 09. El promotor y propietario de la Institución Educativa es con personería jurídica, que en la sociedad promueve la acción educativo-formativa de la niñez y la juventud. 
9.1. el Director General de la Institución quien se encarga de la organización y funcionamiento de la Institución de acuerdo a la filosofía de la educación personalizada, los principios y valores establecidos en la Constitución Política del Perú, las leyes y normas vigentes de la Educación Peruana y del presente Reglamento.

9.2. El Promotor en coordinación con el Director aprueban la implementación, mejoramiento y ampliación de la infraestructura y equipamiento educativo.

9.3. Vela por el cumplimiento de los aspectos: académicos, formativo pastorales, disciplinarios y administrativos establecidos en la Institución de acuerdo a la normativa vigente y el presente reglamento.

9.4 El Director de la IEI "Estrellitas de Jesús" ejerce sus funciones bajo contrato establecido.

\section{FINES Y OBJETIVOS}

Art. 10. La Institución "Estrellitas de Jesús", es una Institución Educativa Inicial, cuya finalidad es impulsar la formación humanista integral de los estudiantes a través de un enfoque curricular centrado en la persona, inclusivo por competencias, para alcanzar los objetivos de la escolaridad en el Perú, de acuerdo a las directivas del Ministerio de Educación, en el presente Reglamento. 10.1. Ser líderes en la formación humanista integral de calidad que equilibre los requerimientos académicos con la formación personal y cristiana, respete y oriente las diferencias individuales, incorpore tecnologías y medios actualizados y sea conducida por profesionales de la educación en permanente formación y actualización. 
10.2. Potenciar el liderazgo participativo dentro de una comunidad educativa en pleno aprendizaje, que viva la cultura evaluativa como parte de su identidad, donde todas las personas sean corresponsables de las metas educativas, las familias encuentren acogida y formación, que haga posible la práctica de nuestros valores institucionales en bien de la solidaridad y la responsabilidad social.

10.3. Educar para formar personas íntegras que sean capaces de discernir que toda cultura que pretenda ser tal ha de tener sus bases en la búsqueda de la verdad a través de:

- Conocimientos y meta-conocimientos sistemáticos, adecuadamente estructurados y dispuestos en orden al carácter trascendente del ser humano.

- Aptitudes y destrezas que le permitan realizar las operaciones básicas del pensar y del obrar, tanto en orden a su vida personal como a la profesional.

- Virtudes y valores mediante los cuales sean capaces de actuar y tomar decisiones libres y responsables, con respeto a sí mismo, a los demás y a su entorno.

10.5. Ayudar a los Padres de Familia a formarse en la verdadera paternidad responsable con la conciencia clara que ellos constituyen uno de los bienes más preciados de la humanidad, un don insustituible para sus hijos.

\section{FUNCIONES GENERALES}

Art. 11. La IEI “Estrellitas de Jesús" tiene como actividad principal la prestación de los servicios educativos del nivel Inicial de menores en el turno diurno. Brinda educación personalizada y sistemática conforme a sus propios 
planes y programas curriculares, sin apartarse de los lineamientos del Ministerio de Educación. En consecuencia es su responsabilidad:

11.1. Organizar la labor educativa de acuerdo a las características y exigencias propias del nivel que se ofrece en la Institución.

11.2. Brindar un servicio de administración educativa, documentación de matrícula, traslados, implementación, certificaciones y otros.

11.3. Planificar y desarrollar actividades culturales, sociales, religiosas, artísticas y deportivas que contribuyan a la formación integral del educando y de los demás miembros de Comunidad Educativa.

11.4. Promover y asesorar organizaciones a favor de la educación y formación integral de los estudiantes.

\section{CAPÍTULO III}

\section{DE LA ORGANIZACIÓN DEL TRABAJO EDUCATIVO}

Art. 12. Del Plan Anual de Trabajo (PAT):

12.1. El Plan Anual de Trabajo (PAT) es el documento que concreta los objetivos anuales del Plan Estratégico Institucional y derivado del Proyecto Educativo Institucional (PEI).

12.2. El Plan Anual de Trabajo (PAT) es elaborado de acuerdo a los lineamientos de las leyes educativas vigentes y al Proyecto Educativo Institucional (PEI), ejecutado y evaluado por el Personal Directivo, Docente, Administrativo y es aprobado mediante Resolución Directoral antes del inicio del año lectivo.

Art. 13. De la Matrícula: 
13:1 La matrícula tiene lugar antes del inicio de cada año lectivo en los meses de enero y febrero, según rol establecido. Su incumplimiento exime a la Institución Educativa de la obligación de recibir al alumno. 13.2. La Institución Educativa brinda a los padres o apoderados, antes de la matrícula, la información señalada en el Art. $14^{\circ}$ de la Ley de Centros Educativos Privados.

13.3. La matrícula se realiza según el plan y cronograma establecidos por la Dirección General de la Institución, comunicado a los Padres de Familia al finalizar el año escolar anterior a través de la página web, dípticos, cartas o comunicados por escrito.

13.4. La matrícula de los alumnos ingresantes en los diferentes niveles educativos es única y se realiza a partir de la primera semana de enero. 13.5. No se aceptan alumnos repitentes para ningún grado de estudios. Si algún alumno de la Institución Educativa desaprobara el año, no podrá seguir en la Institución.

13.6. Los niños que cumplan 6 años al 31 de marzo son promovidos de manera automática a la Educación Primaria.

13.7. La ficha de matrícula emitida por el SIAGIE, constituye un documento de referencia del estudiante, indispensable para sus datos y evaluación académica.

13.8. Previo informe del órgano respectivo, la nómina de matrícula es aprobada por Decreto Directoral, dentro de los primeros 45 días posteriores al inicio del año escolar. Las nóminas son firmadas por el Director General. 
13.9. El traslado de matrícula procede previa presentación de la constancia de vacante del Institución de destino y se puede dar hasta antes de iniciar el tercer trimestre.

13.10. El Personal Directivo, Docente y Administrativo de la Institución realiza el planeamiento y organización de las actividades para el año lectivo durante el mes de febrero.

13.11. La Dirección de la Institución está obligada a entregar a los estudiantes que soliciten traslados la ficha de matrícula, la partida de nacimiento, los certificados de estudios del grado concluido y una constancia de los resultados de la evaluación del estudiante hasta la fecha en que se produce el traslado, previa constancia de no adeudo.

13.12. La Dirección de la Institución se reserva el derecho de cancelar o condicionar la matrícula por problemas de comportamiento de los estudiantes o actitudes negativas de los padres de familia o porque han faltado a su compromiso de apoyar la labor educativa - formativa, a la cual se comprometieron en la matrícula.

\section{Art. 14. Del Régimen Académico}

14.1. El año lectivo tiene una duración mínima de 42 semanas divididas en Cuatro períodos, se inicia la primera semana de marzo y concluye la Segunda semana de diciembre. Después de cada período lectivo, los alumnos gozarán de una semana de vacaciones.

14.2. El horario laboral durante el año académico es el siguiente:

Nivel Inicial: 08:00 h a 12:55 h 
14.3. La Programación Curricular se realiza en el mes de febrero y las unidades de trabajo o de experiencia y proyectos se elaboran periódicamente de acuerdo a la realidad a cada nivel y a las necesidades e intereses de los educandos.

14.4. La metodología usada por el personal docente debe estar en coherencia con los objetivos que se pretenden alcanzar y estará sujeta a supervisión constante por parte de la Dirección General.

14.5. El proceso de enseñanza - aprendizaje considera métodos activos que ponen en funcionamiento e integran las diferentes funciones mentales en el proceso de aprehensión y afianzamiento de habilidades. 14.6. La Institución Educativa elabora y lleva con carácter oficial los siguientes registros:

- De ingreso y seguimiento de expedientes.

- De: Matrícula y ratificación.

Padres de familia $y$ apoderados.

- De asistencia de personal.

- De evaluación del aprendizaje y del comportamiento.

14.7. Los procedimientos de gestión usualmente utilizados por la Institución Educativa y que se especifican en el correspondiente manual, son:

- Adelanto o postergación de evaluación.

- Evaluación de recuperación. 
- Autorización de evaluación extemporánea por causa justificada.

- Evaluación de subsanación de asignatura.

- Exoneración de la parte práctica de la asignatura de Educación Física.

- Autorización de traslados de matrícula.

- Expedición de certificados de estudio.

- Rectificación de nombres y apellidos.

- Expedición de constancia de vacantes de matrícula.

- Autorización de excursiones y visitas de estudio.

- Otorgamiento de licencias.

- Selección de personal.

14.8 El Personal Directivo, Docente y Auxiliares de educación ponen en práctica medidas de seguridad para los estudiantes durante su permanencia en la Institución Educativa. En caso de emergencia se dispone su evacuación a los centros de salud.

Art. 15. De la Evaluación

15.12. La evaluación del educando se basa en indicadores que tiene en cuenta los criterios, competencias, capacidades y actividades del programa de estudio y las características de las asignaturas / áreas asegurando la objetividad, validez y confiabilidad. Se realiza conforme a la Guía de Evaluación del Estudiante

15.13. La evaluación es integral, permanente y diversificada en todos los grados y niveles.

15.14. La evaluación es diferenciada para los casos de estudiantes con necesidades educativas especiales cuando el caso así lo amerite. 
15.15. La evaluación del comportamiento se realiza teniendo en cuenta el Reglamento de Convivencia Estudiantil.

15.16. La evaluación del comportamiento no se consideran para los efectos de promoción o repotencia, pero sí para la separación temporal o definitiva del estudiante de la Institución.

15.17. El proceso de evaluación continua en la Institución Educativa es responsabilidad de la Dirección General y órganos académico formativo y está orientada a optimizar el desarrollo de las acciones educativas principalmente del proceso enseñanza-aprendizaje y la evaluación de los estudiantes.

15.18. La evaluación del rendimiento académico se expresará según las normas legales establecidas por el Ministerio de Educación.

15.19. El Director General en coordinación con los Tutores y formación Pastoral, elabora en el mes de diciembre el cronograma de los exámenes de aplazados y de subsanación, que son rendidos entre los meses de diciembre a febrero.

15.20. La información a los padres de familia acerca de los resultados de la evaluación del aprendizaje, y otros aspectos de la tarea educativa se realiza mediante despachos con el tutor, o docente del área conforme el avance de la Unidad programada.

15.21. La información de los resultados trimestrales se da a los padres dentro de un plazo de 15 días de finalizado el período correspondiente. 15.22. Los certificados de estudios se otorgan en conformidad a las normas establecidas en la Ley General de Educación. 


\section{CAPÍtULO IV}

\section{DE LA ESTRUCTURA FUNCIONAL}

Art. 16. La IEI "Estrellitas de Jesús" tiene la siguiente estructura funcional:

\begin{tabular}{|l|l|}
\hline De Dirección & Promotor \\
\hline Del Personal Docente y de & Dirección General \\
\hline Formación & Personal docente \\
\hline Personal especializado & Auxiliares de Educación. \\
\hline De Administración y servicios & Biblioteca, Biblioteca Virtual. \\
\hline De los Órganos de Participación & Tópico \\
\hline & Personal Servicio \\
\hline & Personal Guardiania \\
\hline
\end{tabular}




\section{CAPÍtULO V}

\section{DE LA DIRECCION, PERSONAL DOCENTE, TUTOR, AUXILIAR DE EDUCACION}

\section{DE LA DIRECCIÓN}

Art. 17. El Director General es designado por el Promotor en cargo de confianza.

\section{Funciones principales de la Dirección General}

17.1. Seleccionar, contratar, elegir, designar y desvincular, al personal docente y los diversos miembros que integran la comunidad educativa de la institución.

17.2. Promover y presidir el Consejo Directivo.

17.3. Conducir la elaboración, ejecución y evaluación del Proyecto Educativo Institucional, Plan Anual de Trabajo y Reglamento Interno, de manera participativa.

17.4. Emitir Resoluciones Directorales de aprobación de los documentos de gestión de la Institución Educativa.

17.5. Promover y Tutelar la actividad educativa como misión.

17.6. Presenta $\mathrm{r}$ el presupuesto anual de la Institución Educativa, al Promotor para la aprobación correspondiente.

17.7. Supervisar y evaluar las actividades administrativas, pedagógicas, formativas y pastorales en coordinación con el Promotor y el Consejo de Dirección de la Institución Educativa.

17.8. Promover la actualización, perfeccionamiento, especialización y estudios de post grado de los docentes y demás personal de la Institución. 
17.9. Supervisar el estricto cumplimiento de los dispositivos específicos que norman la matrícula, pago de pensiones y concesión de beneficios económicos y becas a los estudiantes.

17.10. Visar los Certificados de Estudios, constancias de servicios prestados a la Institución Educativa, así como las constancias de pago del personal a su cargo.

17.11. Redactar la correspondencia oficial, y disponer la publicación de directivas y demás documentos informativos del plantel.

17.12. Supervisar que la Secretaría remita oportunamente la documentación oficial de la Institución Educativa a los órganos competentes, de conformidad con lo establecido en las leyes y reglamentos vigentes.

17.13. Aprobar los cuadros de distribución de horas de clase y la calendarización y periodificación del año escolar.

17.14. Mantener el principio de autoridad y velar por la responsabilidad y funcionalidad de los diferentes órganos del plantel.

17.15. Convocar a sesiones del Consejo Directivo para recibir información sobre el avance curricular, logros significativos, deficiencias, omisiones y problemas de conducta de los estudiantes para determinar las alternativas de solución.

17.16. Otorga permiso al personal a su cargo, hasta por tres días al año en casos debidamente justificados.

17.17. Incentivar y reconocer el esfuerzo y mérito individual y colectivo del trabajador y en caso de incurrir en falta emitir las sanciones correspondientes según la normativa vigente e institucional. 
17.18. Promover innovaciones científicas y tecnológicas; así como la investigación educativa, estimulando la participación de los estudiantes, de los docentes, personal administrativo y de apoyo.

17.19. Promover la cooperación de instituciones locales y regionales para mejorar los servicios educativos que brinda la Institución.

17.20. Asesorar al Comité de Apoyo de Padres de Familia y cautelar su movimiento económico.

17.21. Promover el liderazgo participativo de la comunidad educativa y el buen clima institucional.

17.22. Delegar alguna o todas estas facultades a quién corresponda jerárquicamente, cuando tenga deba ausentar del trabajo por motivos justificados.

\section{DEL PERSONAL DOCENTE}

Art. 18. El docente, elemento clave del proceso educativo y formativo, es elegido cuidadosamente por la Dirección del Institución, teniendo como base la evaluación de: su currículo profesional, perfil, evaluación psicológica, académica y entrevistas personales que le permitan captar su vivencia moral cristiana, su capacidad profesional y su apertura a la Axiología y Proyecto Educativo de la Institución.

Sus funciones principales son:

18.1. Planear de acuerdo con la Dirección General, el trabajo docente en las materias específicas a su cargo y participar en la elaboración, ejecución y evaluación del Plan Anual de Trabajo.

18.2. Ser parte del equipo educador y colaborar con el Tutor respectivo para que éste cumpla plenamente sus funciones. 
18.3. Desarrollar sus actividades, conforme a lo exigido por la Institución, lo normado por las directivas de educación.

18.4. Presentar, dentro de los plazos y términos fijados, a la

Dirección General los documentos siguientes:

- La Diversificación Curricular de Área

- La Programación de Unidad

- Guía del Estudiante

- Sesiones de clase

- Adaptaciones curriculares

- Guía de Trabajo o Aprendizaje Autónomo

- Fichas de Trabajo y material complementario

- Las pruebas escritas para revisión

- Las evaluaciones diferenciadas para revisión, cuando se requiera.

- Los registros auxiliar de evaluación

- Los informes solicitados, según requerimiento de la Dirección General,

18.13. Planear estrategias para el trabajo con el eje, temas transversales y núcleos temáticos.

18.14. Planificar adaptaciones curriculares integrales para la atención a los estudiantes con habilidades diferentes.

18.15. Planificar la evaluación diferenciada como medio de ayuda para desarrollar o monitorear procesos de mejora en los estudiantes.

18.16. Admitir la supervisión de su labor que los órganos responsables ejecuten; $\mathrm{y}$, realizar las acciones sugeridas para solucionar las deficiencias, omisiones o carencias detectadas. 
18.17. Velar por el desarrollo de actitudes, hábitos y actitudes positivas de los alumnos y orientarlos para la realización eficaz de su trabajo.

18.18. Vivir el ideario y la filosofía educativa de la institución y hacer que los estudiantes la vivan.

18.19. Asumir la cultura evaluativa de la institución como medio de mejora continua.

18.20. Ofrecer a los estudiantes un trato digno e imparcial, a través del ejemplo.

18.13. Esmerarse en la formación de hábitos de trabajo, orden, mutuo respeto y sinceridad.

18.28. Participar en las diversas actividades pastorales que promueva la Institución.

18.29. Asistir puntualmente a las clases en la Institución y excusarse por anticipado a la Dirección General en caso de darse alguna imposibilidad de asistencia.

18.30. Estudiar los resultados de las evaluaciones, del rendimiento escolar de sus alumnos y conocer la situación de cada uno para estimular o aplicar la acción correctiva pronto.

18.31. Preparar con el tutor las entrevistas que le soliciten los Padres de Familia, las cuales se referirán siempre a temas pedagógicos.

18.32. Asistir a las reuniones periódicas a las que sea convocado.

18.33. Cumplir con los encargos que se le hagan por parte de los Directivos de la Institución.

18.34. Cuidar celosamente el orden y la disciplina durante el desarrollo de las clases empleando los recursos que aconseja la pedagogía. 
18.35. Planificar, programar, desarrollar y evaluar las actividades curriculares que le corresponda, así como, las de tutoría, y de pastoral, de acuerdo, a los objetivos de las asignaturas o grados a su cargo, del Proyecto Educativo y la axiología de la Institución.

18.36. Participar en acciones programadas de investigación y experimentación de nuevos métodos y técnicas de trabajo educativo.

18.37. Orientar a los estudiantes y velar por su seguridad durante el tiempo que permanecen en la institución, en especial en las horas de ingreso, salida, juego y recreación.

18.38. Realizar acciones de recuperación pedagógica y detección de problemas que afectan el desarrollo del estudiante y su aprendizaje, siempre en coordinación con los tutores.

18.39. Cooperar en las acciones de mantenimiento y conservación de los bienes institucionales.

18.40. Participar y colaborar en actividades extra-curriculares, según los fines y objetivos institucionales.

18.41. Participar activamente en la Comunidad Docente y con ella en los distintos encuentros de:

\section{AUXILIARES DE EDUCACIÓN.}

Son funciones del auxiliar de educación:

p) Orientar el comportamiento de los alumnos en concordancia con las normas establecidas y Tutores de Aula de las estudiantes. 
q) Orientar y apoyar en la disciplina de las estudiantes, en la formación y actividades programadas por la IE.

r)Colaborar en las acciones de tutoría y orientación de educando programadas en la IE.

s) Informar al tutor de aula, oportunamente, sobre el comportamiento de las estudiantes a su cargo, en especial de aquellas que presenten dificultades en el área personal.

t) Controlar en caso de ausencia del docente, la realización de tareas escolares en las aulas o uso de la Biblioteca.

u) Ejecutar visitas periódicas en los diferentes ambientes de la IE. para velar por el cumplimiento de las normas disciplinarias.

v) Verificar al final de cada jornada de trabajo, la buena conservación del mobiliario escolar.

w) Mantener actualizado el registro de asistencias e inasistencias de los alumnos por grados.

x) Controlar el ingreso y salida de los alumnos a la IE. Velando por el orden, así como verificar las aulas al concluir la jornada de clases

y) Informar a la dirección respectiva sobre la inasistencia y tardanzas del docente, permanecer en el aula en caso de ausencia del profesor.

z) Cumplir con su horario establecido de ingreso de acuerdo a las normas vigentes, 25 minutos antes y después de ingreso y salida de las estudiantes respectivamente.

aa) Propiciar un clima de cooperación, amistad y respeto entre los agentes de la comunidad educativa. 
bb) Orientar a los alumnos en la adecuada presentación personal; así como la conservación de la infraestructura, el material educativo y el mobiliario escolar.

cc) Presentar un informe Bimestral sobre el desarrollo de las actividades, indicando los logros obtenidos, las dificultades y sugerencias necesarias para el mejoramiento del servicio educativo.

dd) El trabajo a realizar será siempre coordinado y aprobado por el Tutor, del cual depende.

\section{CAPÍTULO VI}

\section{DEL RÉGIMEN LABORAL}

Art. 22. El personal y los trabajadores en general, que están bajo relación de dependencia laboral se rigen exclusivamente por las normas del régimen laboral de la actividad privada y por las relaciones laborales que se norman en nuestro Reglamento Interno de Trabajo (RIT), con el propósito de garantizar la eficiencia del quehacer educativo.

\section{DE LOS ESTÍMULOS, FALTAS GRAVES O PROHIBICIONES Y SANCIONES ESTÍMULOS}

Art. 23. Es característica de la Institución Educativa estimular al personal por actos sobresalientes tales como:

- Identificación, compromiso y desempeño profesional destacado.

- Desarrollar actividades extracurriculares que deriven en prestigio y mejoramiento de la imagen institucional. 
- $\quad$ Ejecutar en la institución tareas de investigación educativa que constituyan aportes significativos al desarrollo institucional y comunal.

23.1. Constituyen estímulos a la labor extraordinaria:

d) Felicitación escrita.

e) Resolución de reconocimiento

f) Premio al concluir el año lectivo.

\section{FALTAS GRAVES Y PROHIBICIONES}

Art. 24. Se considera falta grave y está totalmente prohibida toda aquella acción que altere o impida el orden, la disciplina, la buena marcha de la actividad institucional o un sano crecimiento moral, personal y colectivo.

24.1. Está prohibido:

s) Atentar contra la moral y buenos principios, y la línea axiológica de la institución.

t) Disminuir intencionalmente el ritmo de trabajo.

u) Faltar al trabajo sin causa debidamente justificada.

v) Dejar de marcar su registro de asistencia y salida de la institución.

w) Ausentarse de su puesto de trabajo sin la debida autorización de la Dirección General.

x) El abandono de la clase o de la institución antes de la hora.

y) Introducir o distribuir volantes, propagandas políticas dentro de la institución.

z) Dormir durante la jornada de trabajo o presentarse en sus horas de labores en estado de embriaguez o bajo los efectos de sustancias tóxicas. 
aa) Murmurar, injuriar; faltar de palabra u obra a los estudiantes, a los compañeros de trabajo o al personal de vigilancia.

bb) Fumar en los lugares que por seguridad faltan a la ley de prohibición de fumar.

cc) El dictado de clases particulares remuneradas a los estudiantes.

dd) La venta de objetos, libros y otros artículos a la Comunidad Educativa sin autorización de la Dirección General.

ee) La utilización de las instalaciones e implementos de la Institución para fines particulares sin permiso de la Dirección General.

ff) La solicitud de dinero, de especies para mejorar los resultados de la evaluación, o adulterar cualquier otra información.

gg) Portar armas en la Institución, con excepción del personal de vigilancia debidamente autorizado.

hh) Llegar tarde al dictado de clases.

ii) Hacer mal uso de laptop o celulares en horas de clase.

jj) Utilizar horas de la jornada laboral y materiales de la institución en actividades personales que no corresponden a la Institución.

24.2. El despido del trabajador por falta grave se sujeta estrictamente a lo dispuesto en las normas legales en vigencia y lo establecido por el Reglamento Interno de la Institución.

\section{SANCIONES}

Art. 25. Las faltas, omisiones e infracciones básicas del trabajador a lo dispuesto en el 
Manual de Organización y Funciones (MOF), Reglamento (RI) y demás normas de la Institución, y órdenes dictadas por sus representantes, dan origen a la aplicación de medidas disciplinarias o sanciones.

25.1. La Institución Educativa, aplica las sanciones señaladas teniendo en cuenta y evaluando la gravedad de la falta cometida, la repercusión que esta pueda tener en el desenvolvimiento de la actividad institucional y las normas legales vigentes sobre la materia. Estas son:

e) Amonestación verbal o escrita.

f) Descuento de sus remuneraciones por las horas o días no laborados.

g) Suspensión temporal en sus funciones

h) Despido por falta grave

25.4. La amonestación verbal, se aplica en privado y por el Jefe superior inmediato, u otro jefe superior de la misma área de actividad.

25.5. La amonestación escrita, se archiva al file del trabajador sancionado, con copia a la autoridad administrativa de trabajo si se trata de personal que labore bajo la modalidad de servicios personales o sea con estabilidad. Serán objeto de amonestación por escrito los trabajadores que incurran en las siguientes faltas:

i) Llegar tarde al trabajo.

j) Salir o ausentarse del trabajo antes de la hora señalada sin la debida justificación.

k) No marcar su asistencia al trabajo en la forma correspondiente.

I) Incurrir en actos reñidos con la disciplina y moral en el trabajo, inclusive jugar, agruparse interrumpiendo sus labores.

m) Negligencia o falta de voluntad en el trabajo. 
n) Proferir palabras soeces o injuriosas dentro de la institución.

o) Hacer mal uso de laptop o celulares en horas de clase.

p) Utilizar horas de la jornada laboral y materiales de la institución en actividades personales que no corresponden a las del Institución

25.6. Dos amonestaciones dan lugar a que la Institución aplique una suspensión al trabajador.

25.7. Son motivo de suspensión los siguientes casos y sus similares:

h) Indisciplina.

i) Embriaguez en el trabajo.

j) Dormir en el trabajo.

k) Daño por descuido o negligencia en propiedades de la institución.

I) Ausencia sistemática al trabajo.

m)Dedicarse a realizar trabajos particulares o hacer negocios en horas de trabajo.

n) Reincidencia en los casos específicos anteriormente señalados.

25.8. Es causal de despido por falta grave, las faltas contempladas en la ley de Fomento y Estabilidad en el trabajo y su reglamento para los trabajadores comprometidos en el D.L. 728 (Arts. 20 al 28) y el Reglamento Interno de la Institución.

25.9. Para aplicar las sanciones se tiene en cuenta los siguientes criterios:

d) Deben ser adecuadas, idóneas, justas y con fin correctivo, sin ningún criterio de discriminación. 
e) Deben estar en relación con la gravedad de la falta y en las circunstancias que se produjeran los hechos y otros factores que contribuyen a crear la situación anómala.

f) Los antecedentes del trabajador según su record personal, así como su posición dentro de la institución y el grado de responsabilidad dentro de la institución.

25.10. Los trabajadores quedan obligados a recepcionar y firmar los documentos que le remite la Dirección de la institución, haciéndole saber la falta cometida y las medidas disciplinarias que se le apliquen, en caso de negativa se le hace llegar por conducto notarial, considerando la misma como agravante.

25.11. Es propósito de la institución, que todo trabajador tenga la oportunidad de corregir su conducta y las faltas en que incurra en el cumplimiento de sus obligaciones de trabajo, antes de recurrir a la rescisión del respectivo contrato de trabajo, salvo en los casos de falta grave o infracciones en las disposiciones legales vigentes y las normas establecidas en este Reglamento que por su gravedad justifiquen el despido inmediato.

\section{CAPÍTULO VII}

DEL PERSONAL ESPECIALIZADO

\section{DE LA BIBLIOTECARIA (O)}

Art. 26. Tiene como funciones principales:

26.1. Atiende la Biblioteca y sirve de soporte al aula de investigación.

26.2. Fomenta la lectura, la investigación y contribuye al desarrollo del proceso educativo - formativo, la Misión, Visión y metas de la Institución, así como, 
cumple con las directivas y normas internas que la Dirección General dicte sobre la materia.

26.3. Recepciona, clasifica las obras bibliográficas, y recursos audiovisuales y elaborar el respectivo fichero y catálogo por autores y materias en el sistema automatizado.

26.4. Mantiene actualizado el inventario de la Biblioteca.

26.5. Vela por la conservación de los bienes y enseres a su cargo.

26.6. Orienta a los usuarios en la selección y cuidado de los textos y controla préstamos y devoluciones de los mismos.

38.7. Realiza otras funciones inherentes al cargo establecidas en el MOF y demás normas institucionales.

\section{DE LOS RESPONSABLES DE LABORATORIOS/TALLERES.}

Art. 27. Los responsables de los laboratorios están encargados de brindar apoyo a las labores académicas con los recursos y herramientas a su cargo. Tanto en el Laboratorio de Ciencia, Tecnología y Ambiente como en los Laboratorios de Cómputo. Tienen como funciones principales:

27.1. Atiende a los estudiantes según horario establecido.

27.2. Organiza y coordina, con las áreas respectivas el uso del laboratorio, previa autorización de la jefatura pertinente.

27.3. Mantiene un registro de la salida, baja o préstamo de los equipos y materiales del laboratorio, previa autorización de las autoridades responsables empleando los formatos oficiales de control. 
27.4. Mantiene actualizado el inventario de los equipos y materiales de los respectivos laboratorios.

27.5. Se responsabiliza de la seguridad de los estudiantes mientras permanezcan en las instalaciones de los laboratorios.

27.6. Vela por la conservación de las instalaciones, bienes, enseres y materiales a su cargo.

27.7. Realiza otras funciones inherentes al cargo establecidas en el MOF y demás normas o reglamentos.

\section{DEL TÓPICO}

Art. 28. Es un servicio permanente de primeros auxilios al estudiante y al personal de la institución, está a cargo de una enfermera.

28.1. Sus funciones se detallan en el Manual Organización y Funciones.

\section{CAPITULO VIII}

\section{DE LA ORGANIZACIÓN DEL TRABAJO ADMINISTRATIVO DE LA SECRETARÍA/RECAUDACION.}

Art. 31. Tiene como funciones principales:

31.3. Organiza, coordina y ejecuta las labores propias de la cargo.

31.4. Elabora, clasifica y distribuye la documentación de la Secretaría a su cargo. 31.3. Vela por la seguridad de los bienes y documentos de la Secretaría a su cargo.

31.4. Realiza otras funciones inherentes al cargo y de acuerdo a su competencia establecida en el MOF y demás normas o reglamentos de la Institución Educativa. 


\section{Art. 33.- Personal de Servicio:}

Las Funciones del Personal de Servicio son:

11. Realizar el mantenimiento, conservación y limpieza de los bienes del Colegio (pisos, servicios higiénicos, paredes, ventanas, etc

12. Vigilar el adecuado uso del fluido eléctrico así como que las luces no queden encendidas en las aulas.

13. Apoyar en el desarrollo de las diversas actividades de la IE.

14. Cuidar y ser responsable de los bienes que están dentro de su área de trabajo.

15. Realizar labores de seguridad, vigilancia y portería de la IE.

16. Controlar y orientar el ingreso y salida del público en general.

17. Controlar que los muebles y enseres que salen del plantel, cuenten con la respectiva autorización de la Dirección

18. Elaborar los informes de acciones y hechos ocurridos durante su jornada.

19. Apoyar en las tareas de distribución de documentos dentro y fuera del plantel.

20. Realizar traslados de muebles, equipos y otros enseres.

\section{Art. 34. -Del Guardián.}

Son funciones del responsable de guardianía:

8. Cumplir actividades de vigilancia y seguridad en horario nocturno y en días no laborables.

9. Controlar el ingreso de materiales diversos dentro de su jornada de trabajo, dando cuenta en el día, al Promotor y la Dirección.

10. Velar por la seguridad y conservación de los bienes de la IE.

11. Realizar rondas permanentes por todos los ambientes de la IE., verificando por todo este sin novedad, en caso contrario tomará las acciones más convenientes 
revisar cada uno de los ambientes de la IE. verificando que no existen aulas, luces y/o artefactos encendidos.

12. Informar oportunamente y bajo responsabilidad al Promotor y la Dirección de la IE sobre irregularidades suscitadas en el plantel.

13. Hacer limpieza general de la frontera de la IE., incluyendo sábados y domingos (dos veces al día); así como de las plataformas deportivas y áreas no construidas.

14. Controlar que la basura sea retirada por el carro recolector de la municipalidad.

\section{CAPÍTULO IX}

\section{DE LOS ESTUDIANTES.}

Art. 35. Se considera estudiante a todo niño, niña que hace uso de nuestro servicio educativo por estar regularmente matriculado en los grados correspondientes al nivel de Inicial. Son la razón de ser de nuestro quehacer educativo. Sus deberes son:

35.1. Conocer y aceptar la Filosofía institucional.

35.2. Crecer en pertenencia e identidad de nuestra institución.

35.3. Participar activamente en la ejecución del Proyecto Educativo Institucional.

35.4. Crear un ambiente de amable convivencia, solidaridad y alegría entre sus compañeros(as) y demás estamentos de la Comunidad educativa.

35.5. Participar con responsabilidad y creatividad y según sus aptitudes en las diversas asociaciones estudiantiles, celebraciones y actividades extracurriculares. 35.6. Conocer, respetar y cumplir los Deberes contemplados en el Reglamento Interno que se refieren a su quehacer formativo, a su conducta y participación. 
35.7. Conocer, ejercer y respetar los Derechos de los estudiantes establecidos en el Reglamento Interno.

35.8. Participar activamente en el proceso enseñanza-aprendizaje, colaborando en todo lo que esté a su alcance para que sus compañeros aprovechen al máximo el aprendizaje y las prácticas propuestas por los docentes

\section{Son sus derechos:}

35.9. Recibir formación integral dentro de un ambiente que le brinde seguridad moral y física, de acuerdo con los postulados de la Constitución Política Peruana, la Ley General de Educación y el ideario de la institución, que los ayude a crecer en todos los aspectos de su personalidad y los estimule a asumir su formación como empeño insustituible, responsable y creativo de toda la vida. 35.10. Ser acogidos y escuchados en un clima de respeto y cordialidad que afiance sus sentimientos de seguridad.

35.11. Ser tratado con dignidad, sin discriminación y ser informado de las disposiciones que le concierne como estudiante.

35.12. Participar en las actividades extra programáticas organizadas por la institución

35.13. Recibir estímulos en mérito al cumplimiento de acciones que prestigien la institución.

35.14. Presentar verbalmente o por escrito, las quejas o reclamos al estamento correspondiente.

35.15. Participar de los grupos pastorales de la institución y de las elecciones para el consejo estudiantil. 


\section{DE LOS ESTIMULOS, CONDUCTAS QUE ALTERAN LA CONVIVENCIA ESCOLAR Y ACCIONES CORRECTIVAS}

\section{ESTIMULOS}

Art. 36. Son estímulos, las acciones que se realizan para reconocer, reforzar y motivar el esfuerzo, la mejora personal y las conductas positivas propuestas en el perfil del estudiante (algunas de ellas se reflejan en la calificación de la conducta del estudiante), así como su participación y desempeño destacado en el deporte y actividades en la Institución o fuera de él:

- Reconocimiento público en ceremonia cívica

- Felicitación verbal

- Felicitación escrita

- Diploma de reconocimiento

- Medalla de plata

36.6. Se otorga reconocimiento público verbal a los estudiantes que se esfuerzan por lograr las metas de cada trimestre, evidenciándose en sus calificaciones.

36.7. Reciben del Director felicitación verbal, los estudiantes que tuvieran alguna acción destacada que demuestra esfuerzo y responsabilidad en su mejora académica, actitudinal o en su identificación con el Institución.

36.8. Reciben del Director felicitación escrita, los estudiantes que demuestran esfuerzo, perseverancia, responsabilidad y constante identificación con su institución educativa. 
36.9. Se otorga Diploma por reconocimiento a su desempeño académico a los tres primeros estudiantes de cada grado y sección que en los diferentes niveles obtengan los puntajes más altos y observen buen comportamiento o sobresaliente reflejado en la calificación de la conducta del estudiante y a aquellos cinco primeros estudiantes que durante toda su secundaria han obtenido los más altos puntajes.

36.10. Se otorga premio al esfuerzo a los cinco primeros alumnos de cada aula que durante el año escolar se han esforzado por hacer vida nuestro lema institucional en pro de su desarrollo integral.

\section{CONDUCTAS QUE ALTERAN LA CONVIVENCIA ESCOLAR}

Art. 37. Son todas aquellas que alteran el orden, el respeto, la responsabilidad, generosidad, y honestidad, la disciplina y la buena marcha de la actividad o un sano crecimiento moral, personal y / o colectivo.

\section{ACCIONES CORRECTIVAS}

Art. 38. La medida correctiva debe ser proporcional a la falta incurrida, considerando el carácter formativo de la misma y en su conjunto.

38.1. Un estudiante puede perder el derecho a la ratificación de su matrícula cuando:

4. Repite el año por negligencia personal.

5. Por incurrir en el $30 \%$ de faltas injustificadas a las actividades curriculares programadas. 
6. Cuando incurre en una falta grave o demuestra poca voluntad de corregir su comportamiento, a pesar de las motivaciones y acciones correctivas que recibe.

38.2. Un estudiante puede ser separado definitivamente de la Institución cuando:

4. Demuestra actitudes contrarias a la axiología institucional.

5. Incurre en falta grave que van en contra del honor y seguridad de sus compañeros o docentes, dentro o fuera de la institución.

6. Su comportamiento, léxico o actitudes son un abierto desafío a la autoridad que ejerce cada personal de la institución.

38.3. La separación definitiva de un estudiante se hace efectiva previo informe de la Coordinación de Formación Pastoral y dictamen del Consejo de Dirección.

\title{
CAPÍTULO X
}

\section{DE LAS RELACIONES Y COORDINACIONES DEL INSTITUCIÓN CON LOS ÓRGANOS EXTERNOS DE COLABORACIÓN}

\section{DE LAS ORGANIZACIONES ESTUDIANTILES}

Art. 39. Ofrecen a los estudiantes, la posibilidad de desarrollar la capacidad de liderazgo y un justo ejercicio de participación democrática.

\author{
DE LOS PADRES DE FAMILIA
}


Art. 40. Los padres son los principales educadores de sus hijos, responsabilidad de la que nadie los puede eximir y que tampoco puede delegar. Por ello la Institución Educativa colabora con la acción educativa familiar pero no la sustituye.

40.01 En este contexto la acción educativa del Institución es subsidiaria y se ejerce en nombre de los padres y por encargo suyo. Razón de ser para que haya una estrecha relación, comunión y coordinación entre el Institución, los Padres y los Educadores.

40.02 Al matricular a sus hijos en la Institución Educativa, los Padres de familia eligen asumir la Axiología y el Proyecto Educativo del mismo y se comprometen a colaborar directa y personalmente en la educación de sus hijos. 40.03 Esta relación se establece a través de los siguientes canales:

- Relación directa con el tutor según sea el caso y con el equipo educador de su hijo(a).

40.04 Es deber de la Institución Educativa hacia los Padres de Familia:

- Dar a conocer el contenido de la Axiología y del Proyecto Educativo.

- Informar periódicamente sobre los distintos aspectos de la formación de sus hijos y la calidad o avance de su desempeño académico, como sobre las dificultades que se observan en ellos.

- Brindar espacios de formación y sensibilización a los padres de familia mediante:

Asesoramiento educativo familiar

Despachos y entrevistas.

Escuela de padres.

Jornadas para padres 
40.05 Es deber de todo Padre de Familia:

- Asumir su protagonismo como responsable de la formación integral de sus hijos e hijas.

- Cumplir y hacer cumplir las normas del presente reglamento, en especial lo que se refiere a sus hijos e hijas.

- Concurrir a las entrevistas personales, reuniones de aula y escuelas de padre, participando activa y responsablemente.

- Firmar los documentos que así lo exijan: reporte de notas, comunicaciones, entrevistas, cartas de compromiso, etc.

- Cumplir con el pago de las cuotas de enseñanza señalados por la Institución Educativa y las de la COPAFA.

- Participar cuando es requerida su presencia en las actividades programadas por la Institución Educativa.

40.06 El incumplimiento reiterado de estas normas será sancionado, según el caso por la Dirección de la Institución.

\section{DEL COMITÉ DE PADRES DE FAMILIA}

Art. 41. El comité de padres de familia o COPAFA, trabaja en coordinación con la Dirección General. Sus funciones principales son:

41.1. Propiciar la participación de los padres de familia en el mejoramiento continuo de los servicios que ofrece la Institución.

41.2. Coordinar, colaborar y apoyar en forma permanente a la Dirección. 


\section{CAPÍTULO XI}

\section{DEL RÉGIMEN ECONÓMICO, DEL PAGO DE PENSIONES Y DEL OTORGAMIENTO DE BECAS}

\section{DEL RÉGIMEN ECONÓMICO}

Art. 43. El Patrimonio del Institución pertenece a loa socios.

43.1. Es responsabilidad del Promotor con el apoyo del Administrador, el óptimo manejo de los recursos financieros de la Institución Educativa.

43.2. Son recursos financieros de la Institución:

g) Derecho por carpeta de postulante.

h) Cuota de ingreso (Estudiante nuevo)

i) Ingreso por Matrícula

j) Ingresos por pensiones de enseñanza

k) Las donaciones

I) Los ingresos propios por:

- Derecho de expedición de certificados.

43.3. Los ingresos y egresos se registran en los correspondientes libros de contabilidad.

\section{DEL PAGO DE PENSIONES}

Art. 44. La pensión de enseñanza es anual y se divide en diez (10) cuotas mensuales (marzo - diciembre). 
44.1. Las pensiones de enseñanza se abonan en la entidad financiera que la Institución indique, o en oficina de Secretaria/Recaudación de la Institución Educativa y se harán efectivas el último día de cada mes.

44.2. La Institución Educativa retiene documentos de escolaridad de los estudiantes; cuyos padres, que al término del año lectivo adeuden derechos de pensiones, hasta su total cancelación de acuerdo a ley.

\section{CAPÍTULO XII}

\section{DISPOSICIÓN FINAL}

Art. 47. Forma parte constitutiva del presente Reglamento: El Organigrama Estructural, el Manual de la Organización y Funciones (MOF), el Reglamento del COPAFA, y otros que se implementen en la Institución Educativa para su correcto funcionamiento.

\section{EVALUACIÓN ACADÉMICA EN INICIAL}

- $\quad$ Es referida a CRITERIO, pues valora el grado de aprendizaje en cada alumno de aspectos previamente establecidos como capacidades a desarrollar. A diferencia de la evaluación referida a la norma, deja de considerar la ubicación de cada individuo en el grupo, evitando la comparación para fomentar las bases de la propia estima en base al desarrollo de las propias potencias personales.

- $\quad$ Es FORMATIVA: observa el proceso de enseñanza y aprendizaje para intervenir oportunamente en él, valorando todos los elementos que intervienen. Cada alumno posee un ritmo y estilo personal de aprendizaje que es necesario atender durante el desarrollo del proceso y la evaluación permanente del mismo, lo que determina posibilidades diferenciadas de desarrollo personal. 
- Siendo la educación el perfeccionamiento intencionado de las propias potencialidades, la adquisición de un aprendizaje depende tanto de las disposiciones individuales como del esfuerzo personal realizado por parte de cada alumno.

\section{Sobre la base de dichos principios, se considera:}

1. El nivel de logro y el nivel de esfuerzo se obtienen mediante la consideración de los criterios e indicadores que evidencian los aprendizajes.

2. Para la Apreciación Trimestral del Rendimiento, se correlaciona el nivel de logro y el nivel de esfuerzo, del cual se obtiene el Progreso trimestral logrado en cada área:

- AD: Logro sobresaliente en el aprendizaje del objetivo referido - A: Logro satisfactorio en el aprendizaje del objetivo referido.

- B: En proceso de aprendizaje del objetivo referido.

- C: En inicio del proceso de aprendizaje del objetivo referido

\section{EVALUACION DEL COMPORTAMIENTO}

El comportamiento del alumno está referido, para una mejor orientación, en la educación de virtudes humanas a la luz de los valores institucionales Justicia, Fortaleza, Prudencia y Templanza y los valores operativos: Respeto, responsabilidad, generosidad y honestidad, además de todos aquellos que subyacen en el desarrollo de los mismos como: la amistad, audacia, comprensión, flexibilidad, fortaleza, generosidad, humildad, justicia, laboriosidad, lealtad, obediencia, optimismo, orden, paciencia, patriotismo, 
perseverancia, prudencia, respeto, pudor, responsabilidad, sencillez, sinceridad, sobriedad y sociabilidad.

Estas virtudes se programarán según la edad, el grado de estudios y de acuerdo al período sensitivo que le corresponde (momento propicio para adquirir dicha virtud con mayor facilidad), las cuales se detallan en el Programa de Valores. Ejemplo:

Inicial 4 años, le corresponderá trabajar las virtudes del programa Vamos creciendo orientadas a fomentar la práctica de los valores operativos.

\section{RECONOCIMIENTO AL FINALIZAR EL AÑO ESCOLAR:}

En Inicial: Se reconocerá a cada uno de los alumnos de 5 años por culminar sus estudios en el nivel. 